\title{
NORTHRIDGE EARTHQUAKE RECONNAISSANCE REPORT
}

\author{
Report of the NZNSEE Reconnaissance Team on the \\ 17 January 1994 Northridge, Los Angeles Earthquake \\ J. A. Norton, A. B. King, D. K. Bull, H. E. Chapman, \\ G. H. McVerry, T. J. Larkin, K. C. Spring
}

\begin{abstract}
This report describes the observations and assessments of the team members on the effects of the earthquake on the ground, buildings and other structures, lifelines and the local community. Comment is made on the response to the earthquake and lessons are drawn for the New Zealand situation.
\end{abstract}

TABLE OF CONTENTS

1.Summary
1.1 Introduction
1.2 Response
1.3 Summary of Key Points
4. Strong Motion Records
5. Geotechnical Features
7. Non-Structural Building Component Behaviour
11. Acknowledgements

2. Background

3. Seismology

6. Buildings

8. Bridges

9. Lifelines

10. Fire

Hutt City Council, Lower Hutt

Building Technology Ltd, BRANZ, Porirua

Dept. of Civil Engineering, University of Canterbury, Christchurch

$4 \quad$ Works Consultancy Services Ltd, Wellington

5 Institute of Geological and Nuclear Sciences, Lower Hutt

6 Dept. of Civil and Resource Engineering, University of Auckland, Auckland

Connell Wagner Consultants, Wellington

\section{SUMMARY}

\subsection{Introduction}

It has been said - "there is nothing quite like visiting an earthquake to make a believer".

The following are the major impressions brought back from the reconnaissance trip to Los Angeles to view the effects of the Northridge earthquake in January this year:

- the trauma of a community subjected to the effects of a major event,

- the value of mitigation measures to reduce the damage caused, and

- the importance of preparedness and response planning to minimise the impacts on the community.

The substantial effort of earthquake engineering in New Zealand over the past 30 years has centred on mitigation, particularly for structures and buildings through design and materials developments. It is timely to remind ourselves that earthquakes are about people and communities and to focus attention also on the organisational and engineering issues of response planning as a discipline - particularly for utility and emergency service providers.

The earthquake struck at 4:30 a.m. (local time) on the morning of Monday 17 January. It measured moment magnitude $M_{w} 6.7$ and centred on the Northridge community in the San Fernando valley $35 \mathrm{~km}$ to the north-west of downtown Los Angeles : The shaking lasted for 20 seconds, 10 seconds of which would be classed as damaging. The earthquake was peculiar in that it contained a 1 second spike with two heavy ground shaking pulses of around $1.0 \mathrm{~g}$ peak acceleration. This is in contrast to 
the 1989 Loma Prieta magnitude $\mathrm{M}_{\mathrm{w}} 6.9$ (Richter magnitude 7.1) earthquake with a maximum peak ground acceleration of $0.64 \mathrm{~g}$.

Because of this, damage was more extensive than might have been expected from this magnitude of event. Damage was largely the result of the strong ground shaking rather than the result of permanent ground deformations from liquefaction or settlement as was the case in Loma Prieta. This was due to the different ground conditions and the nature of the earthquake. Different lessons are therefore to be taken from the two earthquakes.

The most serious damage occurred at Northridge within a $10 \mathrm{~km}$ radius of the epicentre. Northridge is a largely residential community with many two and three storey apartment buildings. It has low rise commercial and institution buildings, and shopping centres, all up to six storeys. The population of the area is approximately 1 million out of the total Los Angeles City of 3.5 million and the Greater Los Angeles area of 14.5 million.

Serious damage also occurred at a number of other locations:

- in a strip along Ventura Boulevard to Sherman Oaks along the base of the Santa Monica Mountains immediately to the south of Northridge
- at Santa Monica $25 \mathrm{~km}$ south-east of Northridge - at the small township of Fillmore $35 \mathrm{~km}$ to the north-west of Northridge, and

- in the Santa Clarita Valley $25 \mathrm{~km}$ to the north and northeast.

Figure 1.1 shows the location of some of these areas.

There were 57 deaths and 8,700 injuries of which 1,600 were serious (hospitalised). Nearly 4,000 buildings were severely damaged and 11,300 more were moderately damaged and unable for a time to be occupied. In the fortnight after the earthquake, up to 22,000 people were housed in tents.

After the event, the entire City of Los Angeles and neighbouring cities comprising 2 million customers were blacked out for up to 24 hours. After 3 days all but 7,500 customers had power restored.

Approximately 100,000 customers in Northridge were without water after the earthquake. Service was restored progressively from day 3 until day 11 . On day two, 75 water tankers were brought in to supply water locally.

Highway structures at seven locations collapsed wholly or partially and others suffered significant damage, closing parts of

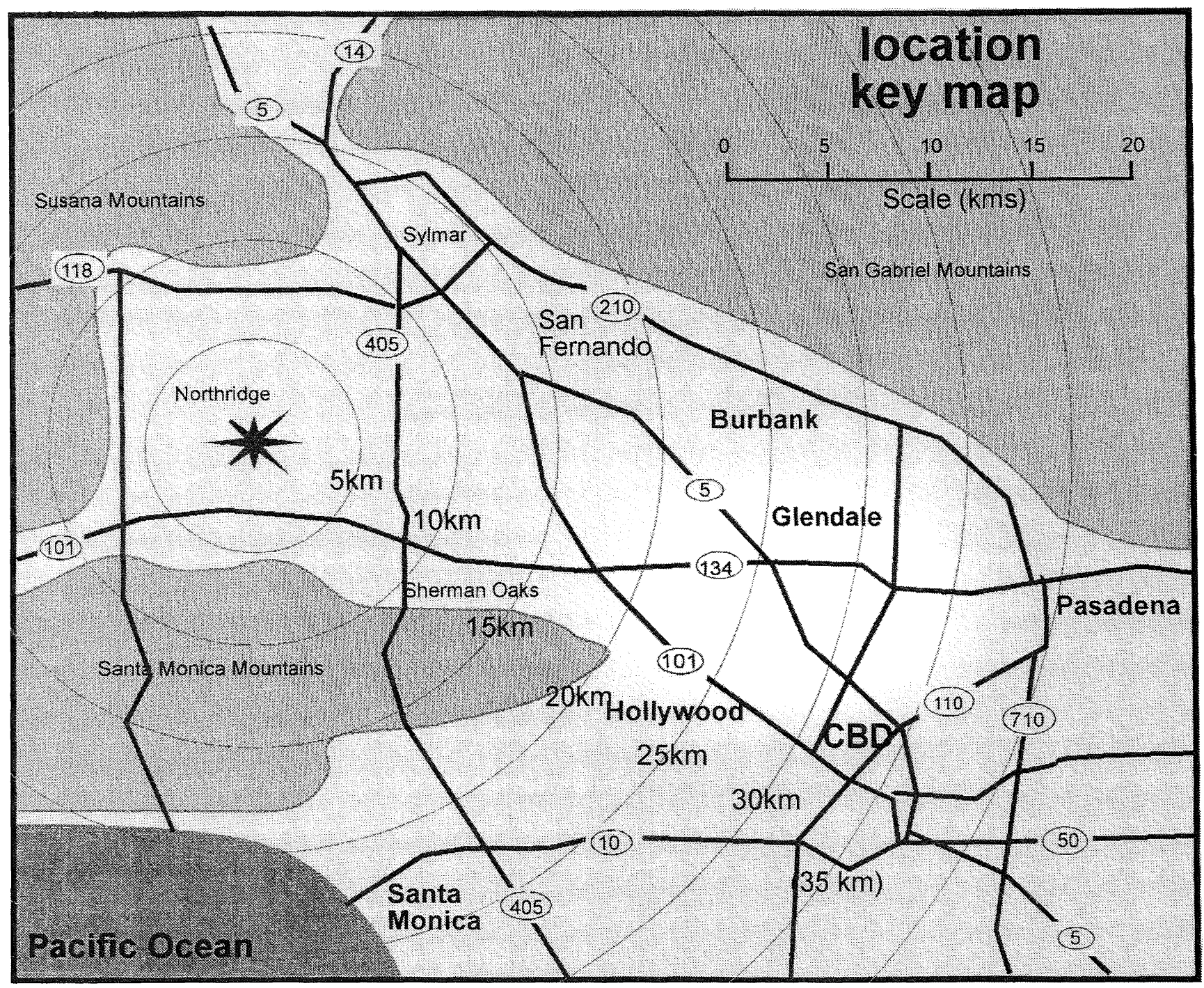

FIGURE 1.1 Northridge Location Map 
14 roads. Although this represented only a small proportion of the freeway network major delays were caused on routes entering Downtown Los Angeles from the north and west.

These are some of the impacts to put the scene into context. Damage is estimated to be US\$18-20 Billion.

Eight days after the earthquake a team of eight New Zealanders arrived in Los Angeles to observe its effects. At that stage the entire city seemed to be in a state of extreme nervousness with fresh anxieties being raised with each felt aftershock, which were a daily occurrence. The community of Northridge was still traumatised. People were willing to talk about their experience in fact they seemed relieved to do so.

Services had mostly effected a basic recovery and the huge task of assessing detailed damage was under way. Resources from mutual aid agreements with neighbouring cities and organisations were in evidence in the affected areas and the coordinated response was impressive. People were removing belongings from collapsed homes and property owners were securing sites with netting fences. By the time we left 10 days later access to damaged sites was becoming difficult.

The team covered a range of disciplines with six people supported by the NZNSEE with sponsorship from the Earthquake Commission and BRANZ, one person supported by HERA and one from the NZ Fire Service.

The team comprised John Norton, leader and covering lifelines, Andrew King, buildings and non-structural components, Des Bull, structures and concrete, Howard Chapman, bridges, Graeme McVerry, seismology and ground motion records, Tam Larkin, geomechanics, Kevin Spring, for HERA - structures and steel and Bruce Jones for the NZ Fire Service. In addition, Lam Pham of the Australian CSIRO joined the group and participated with the team.

Material from Bruce Jones has been included in the report.

The Report is structured to highlight the key points from each area in a self contained Summary in Section 1. Included in this Section is comment on the local organisation response to the earthquake as the team observed it and some broad general conclusions. Section 2 briefly outlines background material and subsequent Sections provide detailed comment on each area

The Report presents the observations and assessments of the team members of the things they saw and discussed during the 10 day visit commencing 8 days after the earthquake. It was not the intention to undertake detailed analysis of any particular aspects and therefore some of the observations may be overtaken as more detailed technical evaluations are published from California.

The purpose of the visit was to learn for the New Zealand situation and the report should reflect that. Finally one is left with the realisation that earthquakes are a percentage game. Our own vulnerabilities are unique but we can learn a lot about reducing them by observing the impacts on others.

\subsection{Response}

Los Angeles has been subjected to a number of major disasters or emergencies over the past decade and the issue of preparedness and response has a particular emphasis as a result not only with the Police and Fire Departments but also with the utility companies and the city and state emergency management organisations.

It was apparent most organisations had prepared detailed response plans and had undertaken preparedness measures and training exercises. Many had undertaken quite major programmes of mitigation to strengthen buildings, brace racks and anchor bases over recent years. There was a feeling amongst the operators that finally, after some previous embarrassments Los Angeles had got its emergency response right. Indeed it was clear that the response had been impressive and huge resources had been mobilised to manage the effects of the earthquake.

Some examples of this are :

- LA City mobilised 1,000 inspectors to check on buildings safety. Within 17 days of the earthquake more than 52,000 buildings had been inspected. Standard inspection forms were used and buildings were tagged as green for "safe for occupancy", yellow as "damaged and unable to be occupied but accessible for removal of contents" and red as "unsafe for entry"

- The Gas Company had 3,400 people in the field - 1,200 for leak detection using flame ionisation detectors and the remainder answering calls $(130,000$ in four days) and doing meter checks and restoring valves. In two weeks $3,700 \mathrm{~km}$ of gas main and 150,000 service meters were checked.

- Within eight days the debris from a number of major freeway structures which had collapsed had been cleared away and preparations for temporary on - ramps were being put in place.

- There were over 1,000 welfare people in the field attending to peoples needs. Within two days around 22,000 people were being housed in tents within locations in their communities.

While the overall response was impressive there were details which did not work and which caused major problems. In several instances emergency generators for key installations either failed to start or failed after some time in operation. In one case a generator stopped after an hour and it was found the main fuel tank was not connected to the emergency circuits and the generator stopped once the auxiliary tank emptied.

In another instance the loss of power to the computer system of the City Police Department communication centre caused the 911 response for the Police and Fire Departments to go into manual mode from 6.00 am on the morning of the earthquake for 6 hours. At the time 3,000 calls per hour were being handled and the loss of speed in logging and tracking calls led to 16 minute delays in answering 911 calls and up to 2 hours in responding to them.

The problem was caused by a bearing failure on one of the two emergency generators running the control $\mathrm{CAD}$ computer systems. This overloaded the second generator which burst a coolant line, overheated and set off the sprinkler system which damaged the CAD system on the floor below. The generator was restored in an hour but it took another 5 hours to get the CAD system back in operation! 
Although most organisations were satisfied with their response, all who were asked acknowledged that their resources were stretched to the limit. All agreed that in a bigger event their ability to respond would have been diminished. All stressed the importance of response planning and the value of preparedness measures. One area which was often commented on was that insufficient field support was available for staff who were working long hours to effect a recovery. Questions like provision of food and water in the field and provision of accommodation and payroll had been raised.

Another issue to be recognised for this earthquake in relation to the response is that the timing in the early morning on the day of a public holiday meant that freeways were relatively empty and a number of buildings which collapsed were empty or had fewer people than normal. An earthquake five hours later would have had a substantially greater number of casualties. In addition the winter season meant power demand was much lower than for the summer (when demand for air conditioning doubles power demand) and the recovery of the power system was easier and quicker than it could have been.

Finally it is important to observe that at major collapse sites visited, the rescue operations effected by the Fire Department would be beyond the capability of anything other than a professionally organised unit in terms of skills, equipment and resources and the ability to manage the trauma of such rescues.

\subsection{Summary of Key Points}

\subsubsection{Seismology}

- The Northridge earthquake of 17 January 1994 was of medium size, with a moment magnitude, $\mathrm{M}_{\mathrm{w}}$, of 6.7 .

- It was a "blind-thrust" earthquake, i.e. a reverse mechanism event with the fault rupture not extending to the ground surface, rather than a strike-slip earthquake more commonly associated with California.

- Blind-thrust faults present a double danger, in that it is difficult to recognise their presence and also there is evidence that thrust earthquakes produce stronger ground shaking than strike-slip earthquakes of the same magnitude.

- The potential for blind-thrust earthquakes in the Los Angeles area has been recognised in recent years, particularly since the magnitude 5.9 Whittier earthquake of 1 October 1987. The occurrence of reverse faulting in this region and its link with compression caused by the "Big Bend" of the San Andreas fault has been known for longer.

- The fault rupture in the Northridge earthquake started at depth of $18 \mathrm{~km}$ below the epicentre in Northridge and propagated updip to a depth of about $5 \mathrm{~km}$ in the Sylmar area to the north-east of Northridge.

- Although it seems that the primary fault rupture did not extend to the ground surface, extensional cracking associated with surface upwarping occurred in several localities in the Santa Susana Mountains to the north of the San Fernando Valley.

- In plan view, the rupture surface of the 1994 Northridge earthquake was close to that of the $\mathrm{M}_{\mathrm{w}}$ 6.6 San Fernando earthquake of 1971 . The Northridge fault surface dipped to the south, with the densely populated San Fernando Valley lying above it, while the San Fernando rupture zone dipped to the north under virtually unpopulated mountains. The 1971 epicentre was about $25 \mathrm{~km}$ northeast of the epicentre of the Northridge earthquake.

- The peak ground accelerations from this earthquake are high for its magnitude particularly at sites to the north of the epicentre. It seems that systematic effects associated with the fault rupture process caused high accelerations updip from the hypocentre.

\subsubsection{Strong-motion records}

- The Northridge earthquake was very important for the number and range of strong-motion accelerograph records that it produced, both from ground sites and from structures.

- In the northern part of the San Fernando Valley, peak ground accelerations were typically about $0.5-1.0 \mathrm{~g}$, considerably exceeding code-level design motions.

- Ground motions of around code-level, with peak accelerations of $0.3 \mathrm{~g}$ to $0.5 \mathrm{~g}$, were typical in the southern San Fernando Valley and to the south of the Santa Monica Mountains.

- In central Los Angeles, ground motions were typically less than code-level, with peak accelerations in the $0.15-0.25 \mathrm{~g}$ range.

- There were some sites to the south of the Santa Monica Mountains with very strong peak ground accelerations, notably $0.93 \mathrm{~g}$ at Santa Monica City Hall, $0.66 \mathrm{~g}$ in the grounds of UCLA and $0.49 \mathrm{~g}$ at the free-field site at the USC University Hospital. However, these records with strong peak accelerations were high-frequency in character, with the $5 \%$ damped response spectra falling below code-level at periods of $0.4 \mathrm{~s}$ and greater.

- In general, the ratio of the peak vertical to peak horizontal ground accelerations in this earthquake were not unusually high, generally less than the value of $2 / 3$ typically assumed in design in California. The publicity given to the ArletaNordhoff record recovered soon after the earthquake, which had a peak vertical acceleration of $0.59 \mathrm{~g}$ associated with a peak horizontal acceleration of $0.35 \mathrm{~g}$, gave a misleading impression about typical levels of vertical acceleration in this earthquake.

- Early reports also gave the impression that peak ground accelerations of over $1.0 \mathrm{~g}$ were recorded over a wide region. Ground accelerations of this strength were recorded at two locations: on the abutment of Pacoima Dam, where a much more modest acceleration at a nearby site on the canyon floor showed that there was marked topographic amplification; and at Cedar Hill Nursery at Tarzana, where abnormally high accelerations were recorded in the Whittier earthquake and where it seems that there were very localised effects probably related to a combination of near-surface soil amplification and topographic amplification. Other records reported as exceeding $1.0 \mathrm{~g}$ were obtained in structures, and in most cases appeared to be either the result of localised responses, such as high-frequency vibrations of a parapet, or were spiky in character, indicative of impact effects.

- The thrust mechanism of the earthquake is important for interpreting the recorded ground motions, particularly for those sites updip from the focus. As well as high peak 
accelerations, records from many of the updip sites showed a strong "fault-fling" pulse associated with strong ground velocities. Structures may be badly damaged in dissipating the energy imparted to them by large ground velocities.

- There were examples of very strong ground-motion records in the Sylmar area from sites that appeared to have been affected by liquefaction at depth. These records were deficient in high-frequency content compared to records from nearby sites, and showed reduced peak accelerations, but nevertheless the peak ground accelerations reached up to about $0.6 \mathrm{~g}$, as against up to $0.98 \mathrm{~g}$ at neighbouring sites.

- The very strong response of $1.7 \mathrm{~g}$ (reported as $2.31 \mathrm{~g}$ in the "Quick Reports") at the County Hospital at Sylmar was notable in that it was associated with no structural damage. This hospital was designed for very severe motions, in that it replaced the Olive View Hospital that partially collapsed in the San Fernando earthquake.

- Given the collapse of a number of carpark structures in this earthquake, records from a six-storey carpark building in central Los Angeles will doubtless receive considerable scrutiny. The engineers in our team believe that the fundamental causes of the collapsed carparking buildings that they inspected at close quarters can be determined without resort to sophisticated analysis of recorded responses.

- An array of accelerographs recorded the ground motions and response of the Van Nuys Holiday Inn, in which shear failure occurred in the south wall columns at the 4 th floor level. The response of this building was recorded in the San Fernando earthquake, when it suffered some damage, and in other more recent earthquakes after it had been repaired.

- For the first time, the responses of base-isolated structures were recorded in strong earthquake motions. However, despite the strong peak ground accelerations, this earthquake did not provide a particularly stringent test of isolated structures in that the spectra of its ground motions at the sites of base-isolated structures were considerably weaker than code spectra in the long period range greater than about $1.0 \mathrm{~s}$ that is relevant to these structures.

- The USC University Hospital showed the expected response features of a well-designed isolated structure, including structural acceleration responses reduced significantly from the ground accelerations.

- The records from the Los Angeles County Fire Command Centre showed acceleration spikes associated with impact between the building and pavement tiles that obstructed the isolation gap. This behaviour demonstrates the need for vigilance throughout the life of an isolated structure to ensure that the integrity of the isolation gap is maintained.

\subsubsection{Geotechnical Features}

- The Northridge event was not particularly significant geotechnically.

- It is thought that extensive areas of liquefaction or strength loss occurred in the epicentral area where numerous pipe breaks occurred.

- The question of the influence of soft sites remains unresolved at present. One possibility being explored with regard to variation in ground motion is the focussing of wave energy at nodal points in a basin-like structure.

\subsubsection{Buildings}

- Buildings complying with modern design codes performed well. The performance of other buildings varied widely with the degree of damage sustained being a function of

- the magnitude of the accelerations

- the duration of significant shaking and

- the frequency content of the earthquake.

- Several buildings were observed to be in a such a degraded state that had the duration of strong motion been longer, collapse would have resulted.

- The vertical to horizontal ground acceleration ratio was generally consistent with that expected in California (i.e. $2 / 3$ ) and are likely to be repeated in future events. The effect of these vertical accelerations may have led to more rapid degradation of some elements, although they are unlikely to have been a critical cause of failure.

- Buildings which were structurally regular in both stiffness and strength performed much better than those with significant irregularity in either plan and elevation.

- Poorly detailed secondary non-structural elements often had a detrimental influence on the building response

- in-fill panels and architectural spandrels which were built without adequate separation commonly induced a 'short column effect' which led to column shear failures over the reduced effective column height.

- built-in concrete stairs and landings stiffened and changed the structural characteristics of several buildings commonly attracting unexpected shears and torsional effects.

- Ramps in car parks adversely modified structural response by breaking the continuity of the floor diaphragms, by acting as inclined diaphragms and by influencing attached columns

- Several concrete building failures were attributed to inadequate confinement of secondary structural systems (columns and short walls) which were designed solely to sustain gravity loads, but because of unexpected flexibility of primary lateral force resisting systems and structural continuity, had lateral force demands placed on them that they were unable to sustain.

- Some buildings appeared to experience significant torsional effects as a result of frames degrading and loosing stiffness at different rates thereby translating the effective centre of rigidity away from the centre of mass and significantly modifying the torsional response of an otherwise regular building.

- Several buildings were observed to be adversely affected by inadequate connections between structural elements. This was particularly noted at connections between floor (or roof) diaphragms and shear walls and was seen in several carpark and tilt-slab buildings.

- The reduced deformations experienced by well proportioned shear walls which were widely distributed about the plan area markedly reduced secondary damage to cladding, mechanical services, ceilings, partitions, furnishings and other contents. 
- Pre-1970 buildings, both apartment and multistorey framed buildings, were vulnerable to concentrated damage and collapse through the development of soft storeys.

- Hybrid structures which rely on materials of differing stiffness for support, such as tilt-slab concrete systems, were damaged because of displacement incompatibility between these elements.

- Some structural steel moment resisting framed buildings experienced weld failures at the beam/column joint. No collapses were reported, but huge costs are being incurred identifying and implementing remedial measures.

- Steel cross bracing generally performed well, although a few examples of brace buckling and tension weld failures were observed.

- Timber framed buildings generally performed well when regular in elevation stiffness, but suffered significant damage when weakened by basement or ground floor carparking, particularly when this was created by un-braced steel or timber framing. Concrete basement garages performed better.

- The widespread use of stucco cladding was detrimental to performance by imposing mass, without contributing to resistance. Many such claddings experienced widespread cracking at and around lintels and base-plates.

- Domestic chimneys and block masonry fences often experienced damage or collapse as did houses with unbraced sub-floor framing.

- Reinforced masonry buildings generally performed well, provided wall to roof diaphragm connections were adequately detailed

- Retrofitted unreinforced masonry buildings experienced damage, but no collapses were reported. The extent of the damage was such that building demolition has sometimes been required, a result which was not expected by building owners following retrofit. Owners need to be more fully informed of the expected state of such buildings following a major earthquake.

\subsubsection{Non-structural Building Component Performance}

- Non-structural component damage was wide-spread throughout the epicentral zone and was the cause of much disruption and very significant economic loss, both through the cost of repair of the item and secondary damage resulting, and also from business closures caused by this damage.

- Damage to water reticulation systems, particularly sprinklers and air conditioning supply lines, was common, and the resulting flooding from such breakages created significant secondary damage. Hospitals, with their greater number of services, appeared particularly vulnerable in this regard.

- The failure of suspended ceiling and lighting systems were common in commercial and retail outlets where, at best, nominal diagonal wire ties proved ineffective in preventing ceiling collapse. Such failures also damaged sprinkler heads with water damage resulting as above.
- Windows generally performed well with damage being less wide-spread than expected. Engineered facades and residential windows both performed well. Shop fronts and non-engineered commercial and retail facades were particularly vulnerable at corners and where they abut columns or walls. Windows in school classrooms experienced little damage even though they commonly extended to significant heights.

- Mechanical plant was generally adequately secured and, although damage to connecting pipework was not uncommon, the plant itself generally stayed in place.

\subsubsection{Bridges}

- This report presents a brief outline of the major damaging effects of the Northridge earthquake on bridge structures. The description does not include the numerous structures which suffered moderate or minor damage which required temporary shoring and/or repair. There were also many structures which showed no damage.

- It is difficult to answer the question "How did structures designed to current codes perform?" - because there were few such structures subjected to the strong ground motions. However, the several structures with columns retrofitted to current practice and which were strongly shaken performed excellently.

- Of particular interest in relation to current structural analysis and assessment methods were the results of the work reported in Priestley et al [1994]. Methods of assessing the seismic capacity and the expected mode and sequence of failure of bridge structures have been developed in California during recent years. These were applied to the designs of the failed structures described above, and the results are reported in Priestley et al [1994]. Good correlation was achieved between the predicted performance and modes of failure assessed, and those identified by inspection of the failed structures.

- The damage to the bridges described served to confirm the importance of using the capacity design approach for all members of a structure in order to achieve a desired hierarchy of behaviour, and to avoid unwanted modes of failure. Some of the failures demonstrated the now recognised detailing needs (eg the length over which closely spaced confining hoops should be provided in piers).

- The damage to the bridges illustrated the importance of attention to structure flexibility and displacements, and to the relative flexibility of members, during design. The concept of displacement-based, rather than force-based, design procedures appears to be a means of focusing attention on this aspect during the design process, if suitable design office procedures can be developed to facilitate its use in a production environment.

- The speed with which the damaged structures were demolished or shored, to allow resumption of traffic in the area, was impressive, as was the speed with which temporary bypasses were constructed. The speed with which replacement structures were designed, tendered and reconstruction was begun, was also most impressive. 


\subsubsection{Lifelines}

The following key points are an amalgam of those contained in the individual sections of Section 9. Many of the issues are similar for each lifeline:

- mitigation programmes pay off

- design standards need to be kept under review and design for realistic ground accelerations

- porcelain cantilevers don't work (still) and alternatives need to be found. There is interest in the NZ approach to base isolation and damping for power installations

- qualification testing of equipment should be demanded of manufacturers

- address the connections of conductors within power installations

- response plans need to address individuals and be site based. They need to be practical documents

- access into installations need to be addressed. Are there alternative routes and do staff know them?

- damage assessment following the earthquake is a response issue and procedures need to be defined

- provide better support for staff during the recovery process

- develop media responses

- mitigation and preparedness planning reduced damage and provided for a largely uninterrupted telecom service immediately after the earthquake

- regular full load testing of emergency generators is necessary to minimise start-up failures

- $\quad$ provision of 3 hour battery backup is insufficient for critical installations. The provision of AC tap boxes for portable generator hook up should be provided at critical sites as a final backup

- $\quad$ care needs to be taken with ancillary equipment to ensure it does not cause secondary damage or unexpected outages

- backup communications systems are vital to coordinate response efforts

- Network Management Centre technology is essential to reduce delays in dial tone delivery. Secure control lines are important for this to be effective

- exercises are felt to be the best preparation for actual emergencies

- industry Mutual Aid Agreements are vital

- coordination between utilities is critical to establishing response capability immediately after the event.

- large diameter jointed pipes perform reasonably well under severe ground shaking
- non-ductile pipes are susceptible to severe ground shaking

- structural and non-structural mitigation measures substantially cut losses

- preparedness planning is hugely beneficial

- maintenance and testing of emergency generators is important. It should be carried out by those relying on them, not by an external agency

- means of assessing pipe network damage are necessary to focus inspections on likely areas. GIS mapping of surface feature damage has been useful for this

- flexible pipe couplings at reservoirs are important

- key reservoirs should be fitted with automatic shut-off valves to avoid loss through broken reticulation.

\subsubsection{Fire}

- Although fire related incidents increased from a norm of around 40 to 466 over the 24 hours following the earthquake, there were no fire related deaths, and most fires were under control within the first 6 hours.

- Leaking gas (combined with an ignition source), was the most common cause of post-earthquake fires. The restoration of electricity supply to buildings was known to provide the ignition source in some instances. Thought should be given to identifying the condition of buildings before such services are reconnected.

- Damage to the supply line of gas fired water heaters were a common cause of domestic fires.

- The close proximity of homes within the manufactured (mobile) home estates was a contributing factor in the spread of fire between buildings within these complexes.

- Several favourable conditions prevented much greater fire damage from being inflicted following the earthquake. These factors included:

1. Little or no wind,

2. The early morning time of the event which resulted in:

little traffic, enabling reasonable access for suppression teams;

few vehicular related rescues;

Empty commercial buildings, minimised demand for urban rescue,

3. Largely undamaged surface roads and fire stations.

- An effective earthquake response plan, including mutual aid agreements between municipalities enabled the rapid deployment of considerable resources. These resources were self contained and had experience working together.

- The urban search and rescue capacity of the Fire Department needs to be replicated somewhere within New Zealand. At least one such force, fully trained and with a full compliment of both search and recovery equipment, should be available within New Zealand. Such a team needs to be totally professional and would be best suited to be within the responsibilities of either the NZ Fire Service or the NZ Army. 


\subsection{General Conclusions}

The following general conclusions are drawn for New Zealand:

- response planning is essential for managing major earthquakes

- rescue and recovery operations in major structural collapses need specialist professionals

- bridge assessment programmes should continue

- current NZ code design practices do not give cause for concern

- pre 1970 buildings may need reassessment

- the NZ seismic monitoring programme is essential and should be supported

- lifeline mitigation measures have a large payback.

\section{BACKGROUND}

The visit to the Northridge earthquake followed the practice of the NZ National Society for Earthquake Engineering to send a reconnaissance team to major events in order to learn from actual experience what level of effects and degree of damage we might expect from a similar or larger event in New Zealand.

The purposes of the visit were to :

- observe the nature of damage to buildings, facilities and infrastructure

- assess ground movements and distortions and other effects of the earthquake

- assess the sorts of things which contributed to damage such as ground conditions, structure type or other interaction

- observe the recovery response processes of authorities and utilities.

There is clearly value in such visits.

\section{SEISMOLOGICAL FEATURES}

The magnitude $M_{w} 6.7$ Northridge earthquake at 4:30 Pacific Standard Time on 17 January 1994 was, in Californian terminology, a "blind-thrust" earthquake. In a thrust or reversemechanism earthquake, a block of the earth's crust is "thrusted" up over a lower block on an inclined fault plane. In the Northridge earthquake, the primary rupture did not reach to the ground surface, leading to the descriptions of "blind" or "concealed". The Northridge earthquake was different from the more common type of damaging earthquake in California, namely shallow, surface-rupturing strike-slip events in which blocks of the crust slide past each other.

The mechanism of the Northridge earthquake has important implications in interpreting the ground motions associated with it and in assessing the seismic hazard in southern California. "Blind thrust" faults present a double hidden danger in that not only is their presence more difficult to detect than for surface faults with a well-defined trace, but also there is evidence suggesting that earthquakes on thrust faults produce stronger ground motions than earthquakes of similar magnitude on strike-slip faults [Campbell, 1981].
Earthquakes with thrust, or reverse, mechanisms are common in New Zeaiand. "Blind" faults are also common in New Zealand, where focal depths are often deeper than in California. Concerns in California about increased hazards posed by thrust earthquakes with respect to strike-slip earthquakes are thus of relevance to New Zealand.

Despite the predominance of strike-slip earthquakes in California, damaging thrust earthquakes have been prevalent there over the last decade, with examples including the 1983 Coalinga earthquake, the 1987 Whittier Narrows earthquake and the 1992 Cape Mendocino earthquake. The 1989 Loma Prieta earthquake also contained a thrust component.

The potential for thrust or reverse faulting in the Los Angeles area has been recognised for some time [e.g. Yerkes, 1985], and is easily explained. The tectonics of California are dominated by the major strike-slip San Andreas fault system. The Pacific Plate slides northwards past the North American Plate along this system. However, north of Los Angeles there is a change in direction of the strike of the San Andreas Fault, in its "Big Bend" section (Figure 3.1). In this section the fault has a greater east-west component in its trend. Consequently, the region of the Pacific Plate to the south of the Big Bend is being compressed against the North American plate, rather than sliding along it. This compression causes blocks to thrust over each other on dipping reverse faults. The magnitude $\mathrm{M}_{\mathrm{W}} 6.6$ San Fernando earthquake of 1971, located near the 1994 Northridge earthquake, was on a reverse fault that broke the earth's surface.

The damaging potential of "blind" faults in this region has been appreciated only comparatively recently [Davis, Namson and Yerkes, 1989; Jones and Hauksson, 1988; Hauksson and Jones, 1989; Stein and Yeats, 1989; Hauksson, 1990], with concern triggered in particular by the magnitude 5.9 Whittier earthquake of 1 October, 1987. The Whittier earthquake occurred on a fault at between 11 and $16 \mathrm{~km}$ depth, with no surface rupture. Analysis of source locations of small earthquakes underway at that time and continued since has revealed the presence of major buried thrust systems beneath the Los Angeles area, one of which appears to be associated with the Northridge earthquake.

Stein and Yeats [1989] discussed some of the problems of assessing the threat from the buried thrust systems in the Los Angeles region. The techniques for assessing the seismic potential of buried thrust systems are in their infancy; presumably the occurrence of the Northridge earthquake on such a system will provide impetus for their refinement. Among the surface indications of active blind thrust faults are growing folds. Determining rates of earthquake activity from folds is much more difficult than assessing displacements on active surface fault traces. Some indication is obtained by studying uplift rates of mountain ranges associated with fold systems. All of the historical earthquakes from the thrust fault systems in the Los Angeles area have been of only moderate magnitude, and far too infrequent to provide the average uplift rate shown by the Santa Monica mountains over the last 3.3 million years. Although it is possible that much of the fold growth results from gradual creep, Stein and Yeats consider that it is more likely that the required uplift is provided by earthquakes of about magnitude 7 or greater, larger than the historical earthquakes such as the 1987 Whittier event, with typical recurrence intervals of a few hundred years. Such an event could occur under the Los Angeles basin, and be far more destructive than a larger magnitude earthquake centred on the San Andreas Fault $50 \mathrm{~km}$ away. The Northridge 


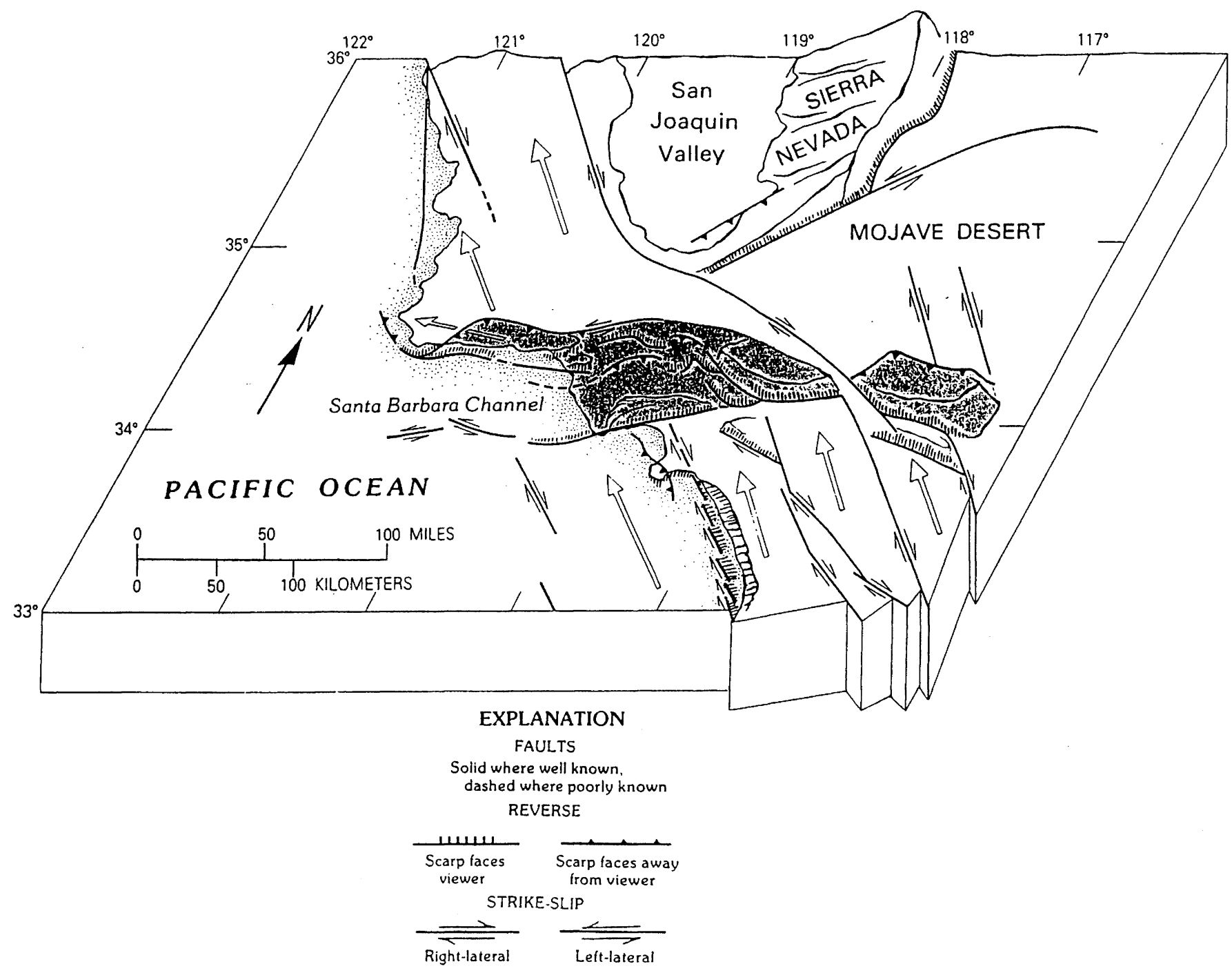

FIGURE 3.1. Relative motions of the Pacific and North American plates in the vicinity of Los Angeles. The "Big Bend" of the San Andreas fault north of Los Angeles causes the Pacific Plate to collide with the North American Plate rather than to slide past it in this region, producing compression associated with the Transverse Ranges (shaded) to the north of Los Angeles and the occurrence of reverse faulting earthquakes [from Yerkes(1985)].

earthquake, which was significantly larger than the Whittier earthquake, will no doubt lead to a reassessment of these possibilities.

One explanation of the Northridge earthquake is that it had its focus on the Elysian Park thrust, a major ramp feature sloping up to the south towards the Santa Monica Mountains from a nearly horizontal fault surface, called a "detachment", underlying the San Fernando Basin. The ramp is intersected near its top edge, at about $10 \mathrm{~km}$ depth, by the more steeply dipping Santa Monica Fault that extends to the surface. A series of relatively steeply dipping reverse faults correspond to fractures either splintering off the more major features of the ramp and detachment below or induced by the stresses set up by their movement. The detachment is thought to deform by "creeping" in that the temperature at its depth is sufficient for the crust to be ductile and able to steadily slip. On the other hand, the ramp and the other more steeply dipping faults are likely to accumulate stresses that are released spasmodically as earthquakes. It is also possible that stress fields set up by the major underlying structures could set off subsidiary rupture on some of the reverse fractures. The rupture was thought to have propagated from the ramp up one of these intersecting faults in a northerly direction towards the surface. At the time of our reconnaissance visit, there was some uncertainty as to the actual fault on which rupture occurred. My impression was that the location from the seismological records was reasonably precise, but that there were difficulties in associating it with a particular known structure. Some early reports placed the rupture on the Frew Fault (one of the steep reverse faults that break away from the Elysian Park thrust), while others discussed an extension of the Oak Ridge Fault. Others showed the rupture as occurring on a previously unknown, or at least unnamed, fault in the web of faults that underlie the San Fernando Basin.

There may have been two faults involved in that the Northridge earthquake contained at least two major sub-events, the first associated with the initial rupture and the second occurring updip from the hypocentre about 2.2 seconds later. The 


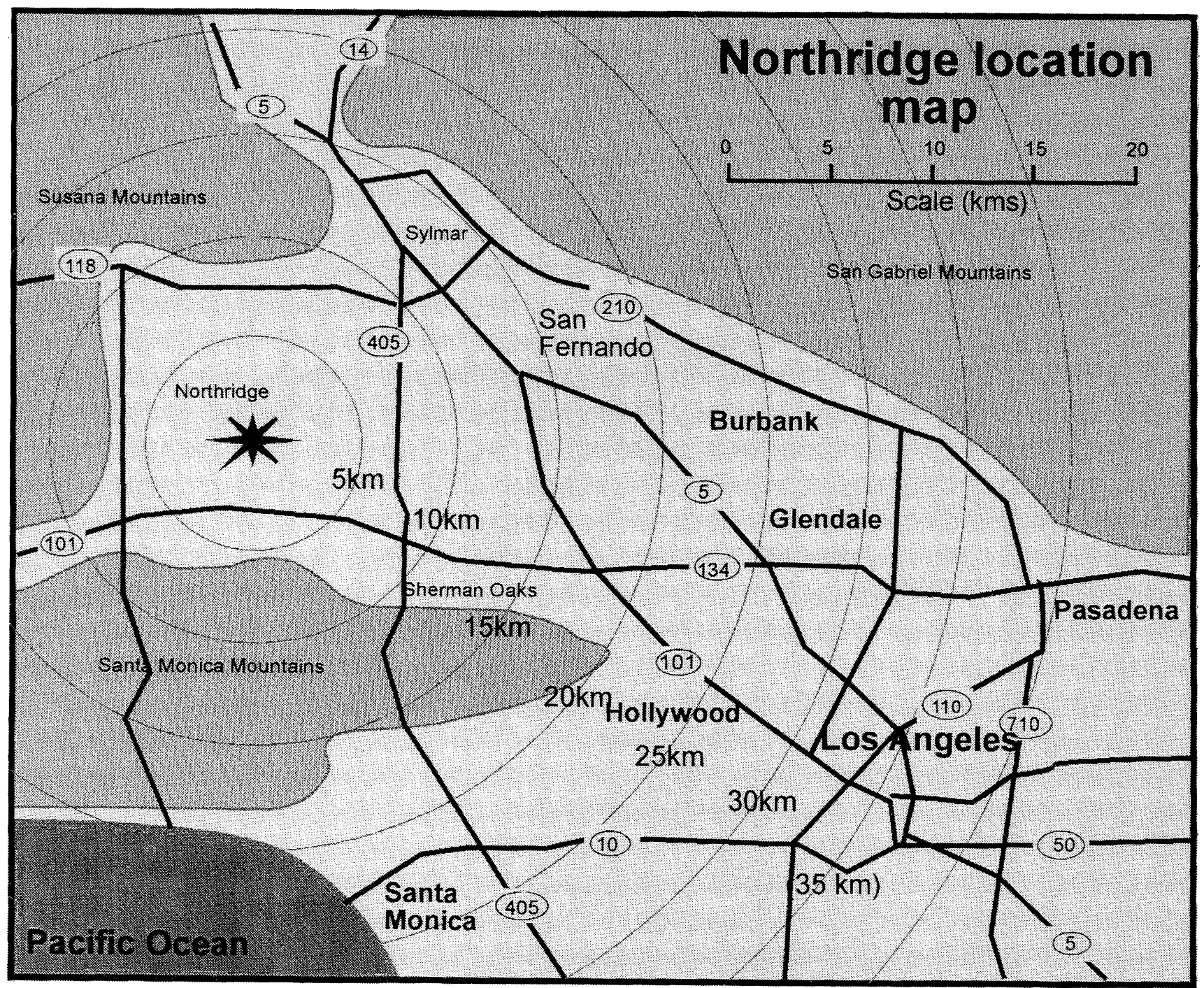

FIGURE 3.2. Map of the Los Angeles region, showing localities affected by the Northridge earthquake. The epicentre was near the boundary of Northridge and Reseda, in the centre of the San Fernando Valley which is bounded by the Santa Monica Mountains to the south, the Santa Susana Mountains to the north and the San Gabriel Mountains to the north-east. The fault rupture surface extended north-east towards Sylmar from beneath the epicentre.

subevents are prominent in many of the strong-motion records, the second sub-event appearing in the records between about 2 and 5 seconds after the initial $\mathrm{S}$-wave depending on the location of the site with respect to the foci of the two subevents. In the strong-motion records, the direction of strongest motion of this second pulse was usually quite different from that of the initial S-wave phase, apparently almost at right angles to it, indicating that the two sub-events were associated with either different sources or different mechanisms. At sites to the north of the epicentre, the first sub-event usually caused the strongest shaking, but at sites to the south the second subevent often produced the strongest ground motions. The predominant directions of shaking in both subevents varied with location.

The main shock initiated at a depth of $18 \mathrm{~km}$ at a location of $34^{\circ} 12.68^{\prime} \mathrm{N}, 118^{\circ} 32.25^{\prime} \mathrm{W}{ }^{\prime}$ beneath the Northridge and Reseda areas of the San Fernando Valley (Figure 3.2). A roughly circular fault plane extended updip from the hypocentre at this point along a strike of $\mathrm{N} 60^{\circ} \mathrm{W}$ at an angle of about $40^{\circ}$ to the horizontal, up to a depth of about $5 \mathrm{~km}^{2}$. The length of the fault rupture along the dipping plane was reported as about 15 $\mathrm{km}{ }^{3}$, about half that of the $\mathrm{M}_{\mathrm{W}} 6.9\left(\mathrm{M}_{\mathrm{S}}\right.$ 7.1) Loma Prieta earthquake in the San Francisco Bay area in 1989. The shallowest part of the ruptured fault plane was near the Santa Clarita valley, to the north of the San Fernando valley.

The distribution of aftershocks extended further north than would be indicated by a rupture length of $15 \mathrm{~km}$ up the dip of the fault. According to the Berkeley preliminary reconnaissance report [Moehle (ed.), 1994], the aftershock zone covered an area roughly $30 \mathrm{~km}$ east-west by $25 \mathrm{~km}$ north-south extending north (ie up dip) from the hypocentre. Plots published by the CUBE project showing the aftershock

Updated coordinates given by Caltech on 1 February 1994, as reported in "Los Angeles Times" of 2 February

2 Reports of Caltech-USGS Broadcast of Earthquakes (CUBE) Project

3 Caltech seismology seminar 4 February 1994 


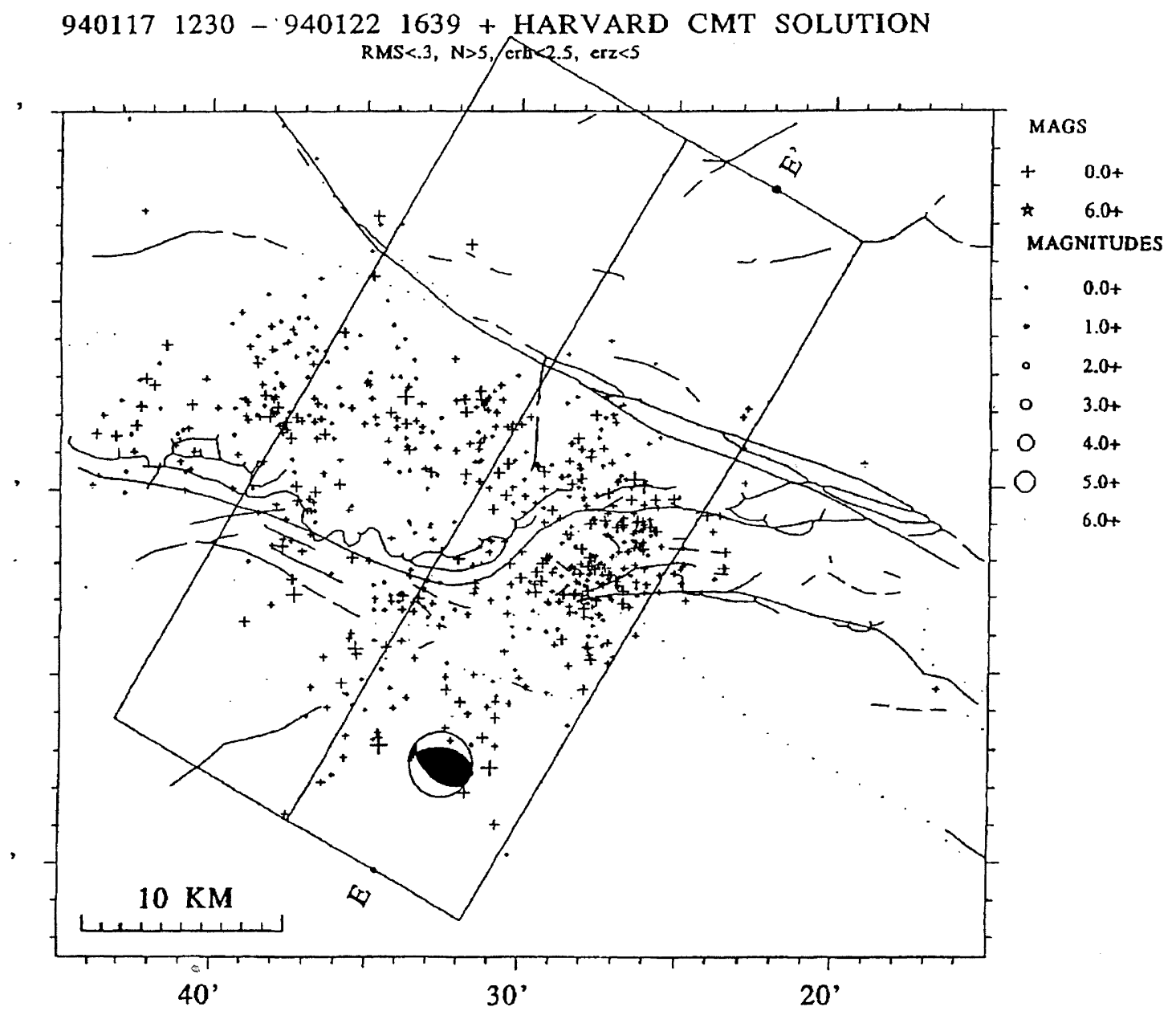

NW WINDOW

SE WINDOW

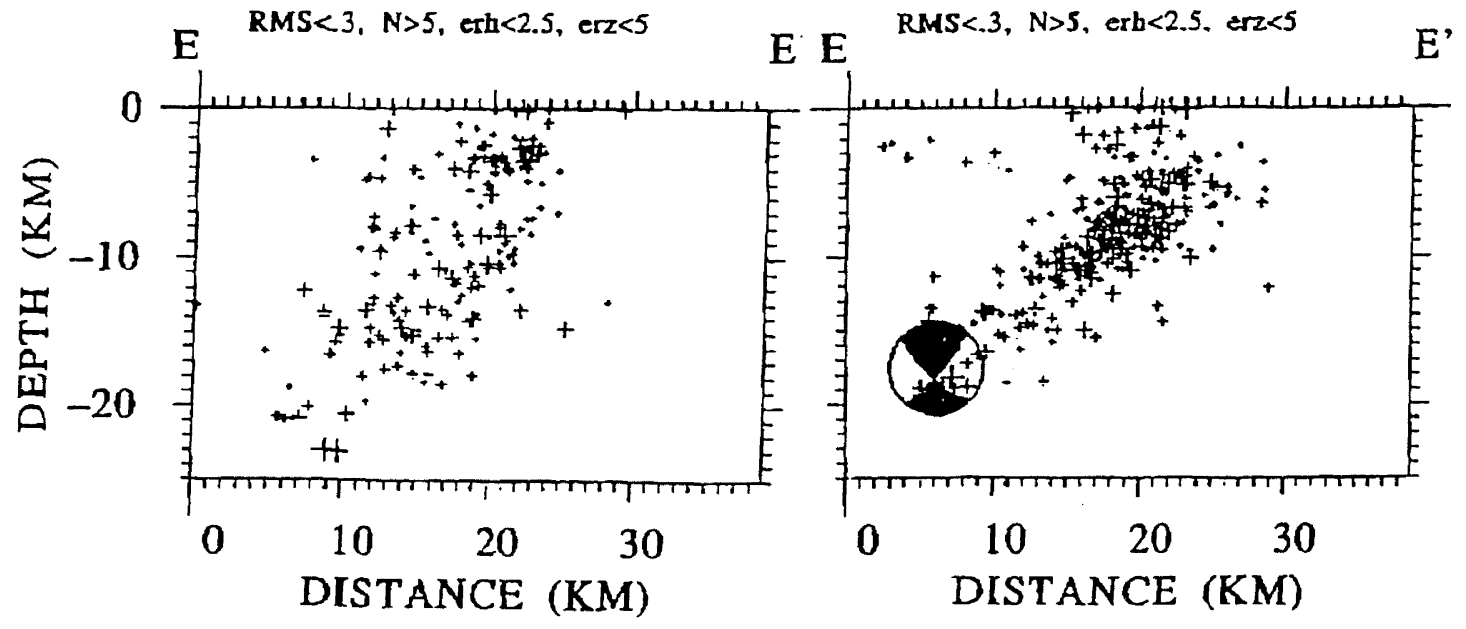

FIGURE 3.3. Locations of the Northridge mainshock and aftershocks in plan and section views. Note the concentration of aftershocks in the SE window dipping up from the mainshock focus at $18 \mathrm{~km}$ depth and terminating at about $5 \mathrm{~km}$ depth indicating the location of the rupture plane, contrasting with the more diffuse spread of locations in the NW window. (From CUBE report). 
locations on vertical windows give a reasonably well-defined fault-plane in the south-east window extending from about the mainshock focus at $18 \mathrm{~km}$ depth up to about $5 \mathrm{~km}$ depth, but a rather more diffuse distribution in the north-west window (Figure 3.3).

Various surface fracture effects occurred in the Northridge earthquake. In some media reports, these were described as fault rupture. However, it seems that the main fault rupture did not reach the ground surface, as supported by the aftershock distribution. A surface manifestation of blind thrust ruptures is upwarping, causing extensional fractures in the region where the rupture plane extrapolates to the surface. An extension of the Northridge main shock rupture plane brings it to the surface near the northern edge of the Santa Susana Mountains (Figure 3.2 ), in the region where upwarping and tension cracking occurred in several locations, for example in the NewhallPortrero Canyon area. The zone of ground extension included the area around the bridge and interchange collapses on I-5 and I-14 freeways. There was also possibly "sympathetic" rupture on subsidiary faults.

Preliminary GPS (Global Positioning Satellite) measurements showed a shortening of the San Fernando valley in an approximately north-south direction and an uplifting of the Santa Susana Mountains that form the northern boundary of the valley. A site in the Santa Susana Mountains showed a displacement of $38 \mathrm{~cm}$ up and $15 \mathrm{~cm}$ to the north. A second site north of Castaic Junction to the east of Interstate 5 moved down $9 \mathrm{~cm}$ and south $3.8 \mathrm{~cm}^{4}$.

Seismological and deformation modelling indicated that most of the slip on the fault plane occurred at depths below $8 \mathrm{~km}$, in particular from the hypocentre at about $18 \mathrm{~km}$ depth up to about $11 \mathrm{~km}$ depth. Preliminary geodetic modelling suggested

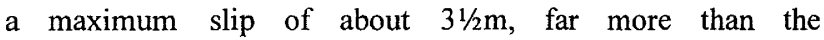
displacements at the surface.

As is usual for most earthquakes, various magnitudes have been reported for the Northridge earthquake. Initial reports gave the magnitude as $M_{L} 6.6$ (Caltech). At the time of our visit, the surface wave magnitude $M_{S}$ was also given as 6.6, but this was later updated to $\mathrm{M}_{\mathrm{S}} 6.8$ (NEIC) when world-wide data was analysed. Other updated magnitude measures quoted in the CSMIP report of strong-motion records [Shakal et al., 1994a] issued on 18 February 1994 are $M_{L} 6.4$ (Caltech) and $\mathrm{M}_{\mathrm{W}} 6.7$ (Caltech and Berkeley).

The fault plane of the 1994 Northridge earthquake was close to that of the magnitude $M_{w}$ 6.6 San Fernando earthquake of 1971. The epicentre of the San Fernando earthquake was about $25 \mathrm{~km}$ northeast of the 1994 epicentre. In plan view, the aftershock zone of the Northridge earthquake overlapped with that of the San Fernando earthquake, with the aftershock zone somewhat larger in 1994. The San Fernando earthquake also occurred on a thrust fault, but the fault dipped to the north. Most of the rupture zone of that earthquake was under the mountains to the north and east of the San Fernando Valley, although it did reach to the surface in the valley. The rupture in the 1971 San Fernando earthquake propagated towards the population centres of the San Fernando valley and Los Angeles basin to the south, while the 1994 Northridge rupture ran from under the San Fernando Valley towards the mountains to the north.

CUBE Report, 27 January 1994
The peak ground accelerations from this earthquake seem quite high for its magnitude, particularly at sites to the north of the epicentre [Moehle (ed)., 1994]. Plots published soon after the earthquake showed comparisons between recorded peak ground accelerations and values predicted by the Joyner and Boore [1988] PGA attenuation model widely used in California. A similar plot is shown as Figure 3.4. The readily available parameter of epicentral distance has been used as the measure of the horizontal distance from the source in these plots. Unfortunately, this is an inappropriate distance measure for near-source sites, particularly those located above or near a dipping fault plane. However, even when the horizontal distance is taken as zero, as appropriate for sites above the rupture plane, those records from sites in the Sylmar region unaffected by liquefaction have peak ground accelerations about a standard deviation above the mean predicted by the Boore, Joyner and Fumal [1993] attenuation model. Records from sites near the epicentre above the southern part of the rupture plane have peak accelerations near the mean value predicted at zero horizontal distance by this attenuation relation. The reconnaissance team did not obtain information allowing more appropriate source-to-site distances to be calculated; it is understood that now reliable estimates of the source location are available, comparisons of recorded and predicted peak ground accelerations have been performed in California using distance measures appropriate to near-source locations. It is also understood that the recorded accelerations are closer to the values predicted in these studies than those indicated by the initial plots using epicentral distance.

The accelerations at sites in the updip direction from the focus may have been enhanced by directivity effects, with the rupture propagation causing the amplitudes of the waves to pile up in that direction. Wedge effects from a reduction in the thickness towards the top of the up-thrown block are also likely to have contributed towards enhanced accelerations in the region above the top of the rupture, although to a lesser extent than for a reverse fault rupturing all the way to the ground surface.

\section{STRONG-MOTION RECORDS}

\subsection{Introduction}

The 1994 Northridge earthquake was very important for the number and range of strong-motion accelerograph records that it produced, both from ground sites and structures. The records include some of very strong ground motions in the northern part of the San Fernando Valley within a few kilometres of the ruptured fault surface, with peak accelerations of $0.5-1.0 \mathrm{~g}$, considerably exceeding code-level design motions. In the southern San Fernando Valley and immediately to the south of the Santa Monica Mountains, recorded motions typically had peak ground accelerations of about $0.30 \mathrm{~g}$ to $0.50 \mathrm{~g}$, around code-level for southern California. There were some cases of ground accelerations exceeding $0.5 \mathrm{~g}$ south of the Santa Monica mountains, notably $0.93 \mathrm{~g}$ at Santa Monica City Hall and $0.66 \mathrm{~g}$ in the grounds of UCLA. In downtown Los Angeles, the ground motions were typically less than code-level, in the 0.15 $0.25 \mathrm{~g}$ range.

The blind-thrust mechanism of the earthquake is an important feature in interpreting the recorded ground-motions in that there is some evidence suggesting that ground motions are stronger than for strike-slip earthquakes of the same magnitude [Campbell, 1981; Joyner and Boore, 1988], and also there appear to be systematic effects resulting from the locations of 


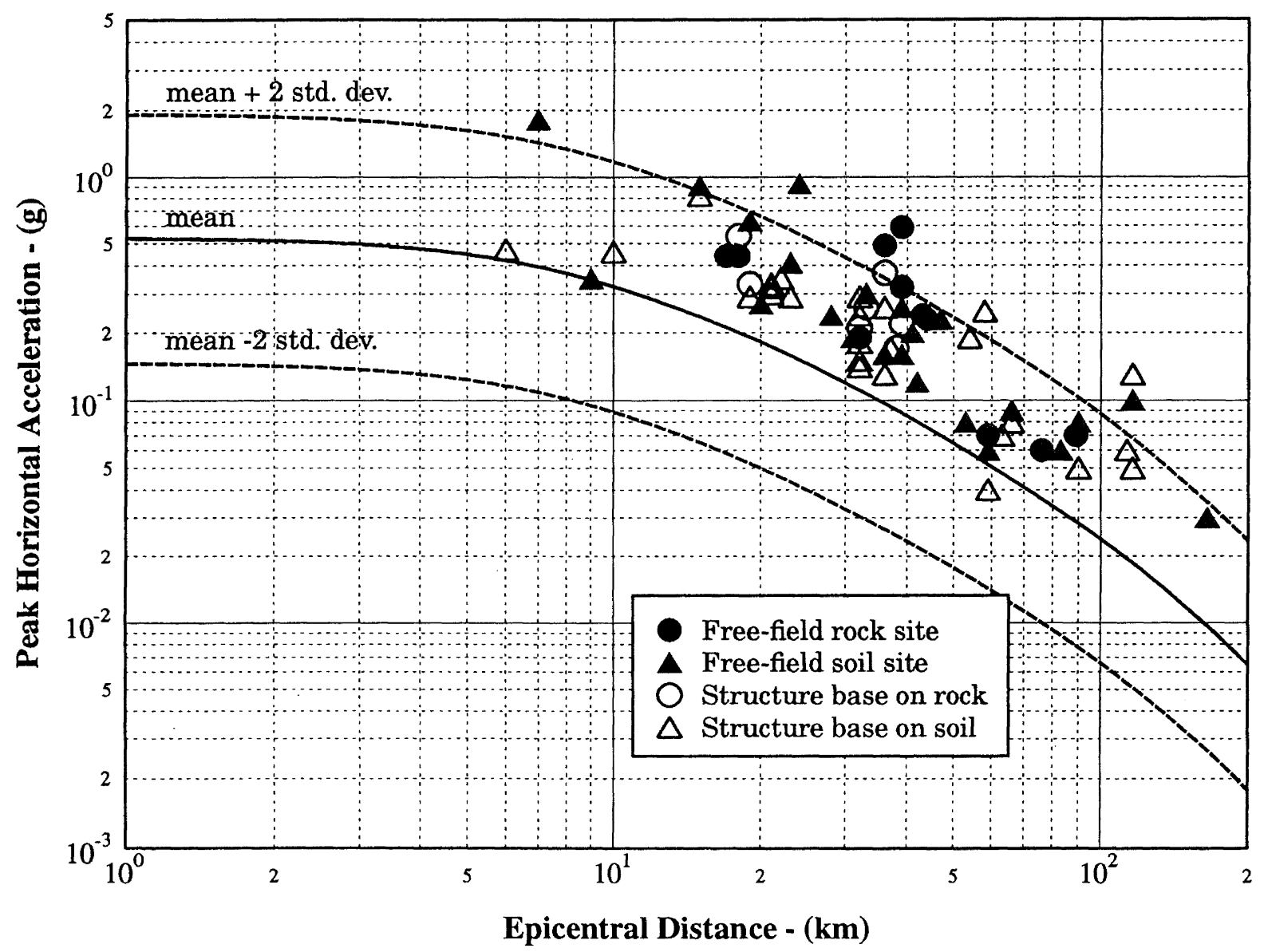

FIGURE 3.4. Peak accelerations of the stronger horizontal component of records from the Northridge earthquake plotted as a function of epicentral distance, compared with the mean and mean \pm 2 standard deviation curves predicted by the Joyner and Boore [1988] attenuation relation. Data from CSMIP Fifth Quick Report.

the recording sites with respect to the geometry of the fault rupture plane. Several records demonstrate near-source effects that are of significance for structural design, in particular strong "fault-fling" pulses associated with large velocities in the ground motions. Some of the recorded ground motions in the Sylmar area appear to have been affected by liquefaction close to the recording sites.

Structural response records included some from a seriously damaged building (Van Nuys Holiday Inn), others from the County Hospital at Sylmar showing very strong response in a structurally undamaged building, and the first records of the response of base-isolated structures to strong ground motions.

The following discussion on strong-motion records is based largely on five "Quick Reports" [CSMIP, 1994a-e] issued by the California Division of Mines and Geology (CDMG) on a selection of strong-motion data from their California StrongMotion Instrumentation Program (CSMIP), and a similar report by USGS [Porcella et al, 1994] on a selection of their records. Since the reconnaissance visit, Shakal et al [1994a] have produced a comprehensive report containing all CSMIP accelerograms from the Northridge earthquake. The processed CSMIP records have been presented in a series of reports [Darragh et al, 1994a-e; CSMIP, 1994f-i, and Shakal et al, 1994b] that give the recorded acceleration histories and the calculated velocities, displacements and spectra. Plots of contours of peak horizontal and vertical accelerations were also received from the University of Southern California (USC)
[Todorovska, Trifunac \& Ivanovic, 1994], but that report contained no records for individual sites in the USC network. Kinemetrics were also very co-operative in providing information on some of the sites that they maintain.

The discussion which follows considers sets of ground-motion and basement accelerograms from various regions: (i) along the northern edge of the San Fernando Valley and in the Santa Clarita and Castaic areas, near or beyond the north-eastern edge of the rupture plane; (ii) above or near the fault plane in the central San Fernando Valley; (iii) immediately south of the fault plane, along the southern edge of the San Fernando Valley (iv) south of the Santa Monica Mountains, in the Beverley Hills, Century City and Santa Monica areas; and (v) in downtown Los Angeles and adjacent areas. This is followed by discussion of some of the recorded structural response motions, for conventional and base-isolated structures.

Before discussing individual records, there is a need to dispel some false perceptions of the ground and structural response motions in the Northridge earthquake that have been gained by some New Zealand engineers, arising from early reports of the earthquake.

\subsection{False Perceptions of the Recorded Motions in the Northridge Earthquake}

A widespread impression among structural engineers in both 


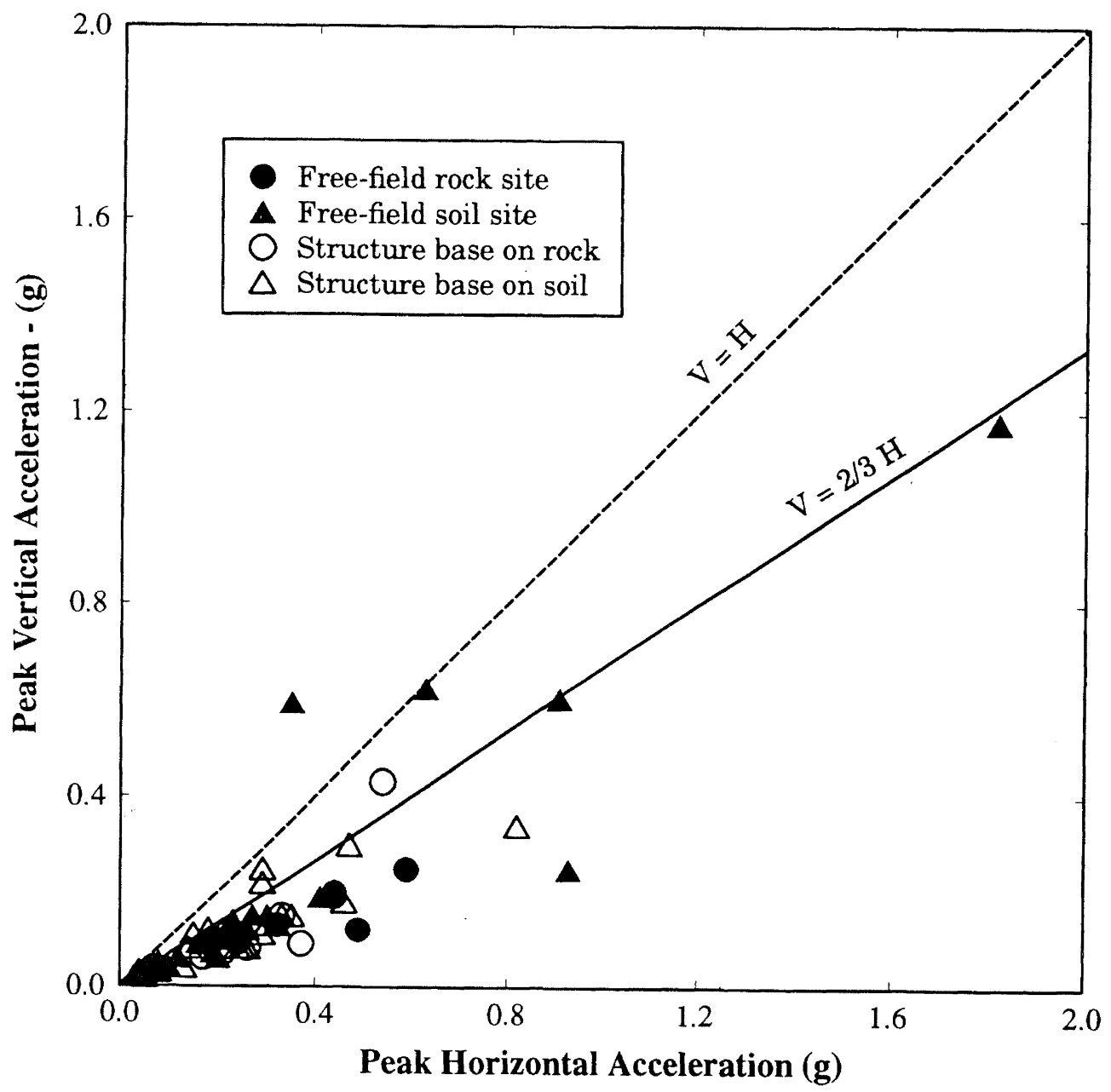

FIGURE 4.1. Plot of the peak vertical acceleration (V) versus peak horizontal acceleration (H) at 70 CSIMP strong-motion recording stations. Note that the $V=2 / 3 H$ line is an upper bound to most of the points. The obvious outlier with the vertical acceleration much stronger than the horizontal is the Arleta-Nordhoff record that gave rise to the impression of an unusually high $V / H$ ratio in this earthquake. The Tarzana Cedar Hills Nursery record had very strong horizontal and vertical accelerations, but a $V / H$ ratio of about $2 / 3$. Data from Fifth Quick Report.

California and New Zealand is that vertical accelerations were a key factor in the structural collapses in Northridge. Early reports indicated that there had been very strong vertical accelerations in the Northridge earthquake, with an unusually high ratio between the vertical and horizontal peak accelerations (sometimes greater than 1). This impression was also given in some briefings to the team and from discussions with various Californian engineers. A common explanation that we heard from engineers for some of the structural collapses in the Northridge area was along the lines 'we were caught out by the very high accelerations, particularly in the vertical'.

These generalisations about the strength of the vertical motions are inaccurate, as shown by the records published in the CDMG and USGS reports. This point was made in a preliminary report on the earthquake published during our stay by the University of California Berkeley (UCB) [Moehle (editor), 1994]. The perception of strong vertical accelerations exceeding the horizontal motions was based largely on the record from one site, Arleta. This record was one of the first to be published from sites in the San Fernando Valley. The only other site with a peak horizontal ground acceleration exceeding $0.2 \mathrm{~g}$ where the recorded peak vertical acceleration was stronger than the peak horizontal value was the Canoga Park site of the USC network. The Canoga Park record had a very strong peak vertical acceleration, $0.63 \mathrm{~g}$, that exceeded the horizontal peak of $0.46 \mathrm{~g}$. The record from Tarzana also had very strong vertical accelerations, but that record was exceptionally strong in all components. The UCB report noted that 'although at a few stations vertical accelerations recorded were nearly equal to the recorded horizontal accelerations, and at one station the peak vertical acceleration was higher than the peak horizontal acceleration, in general, peak vertical accelerations were more typically equal to approximately twothirds of the peak horizontal accelerations'. The basis for this conclusion is a plot similar to that of Figure 4.1. The ratio of two-thirds is commonly used as a rule-of-thumb in design in California.

Nevertheless, some prominent Californian engineers are continuing to explain some of the structural damage caused by the earthquake in terms of these generalisations four months after the event. In addition to the evidence about the ratio of vertical to horizontal accelerations in the recorded motions, the structural engineers on our team formed their own opinions 
(e.g. Bullocks department store, section 6.3.2.1(a), and CSUN parking building, section 6.3.5.1(a)) as to the primary causes of some of the more spectacular collapses of modern structures that some engineers in California were ascribing to strong vertical accelerations.

Another false perception of widespread ground accelerations greater than $1.0 \mathrm{~g}$ seems to have arisen from misinterpretation of a map published on Saturday 22 January by the "Los Angeles Times" newspaper. The map showed four locations with accelerations greater than $1.0 \mathrm{~g}$. The values corresponded to a list released by CDMG. While not claiming that the values shown were ground accelerations, the "Los Angeles Times" map, unlike the CDMG list, failed to differentiate between peak accelerations at ground sites and on structures. In particular, the value of $1.0 \mathrm{~g}$ shown for the I10/405 (Santa Monica-San Diego) freeway interchange near the collapsed overpass structures on the Santa Monica freeway seems to have gained wide circulation as indicative of ground motions in that area. The accelerations of $1.0 \mathrm{~g}$ horizontally and $1.83 \mathrm{~g}$ vertically were recorded on the freeway structure itself, so were not measures of the ground motion, and furthermore corresponded to spikes probably associated with impact between various components of the interchange structure. An acceleration of $1.61 \mathrm{~g}$ shown on the map for Hollywood was recorded at the top of a 14-storey building, and also had the spiky character typical of impacts. An acceleration of $1.21 \mathrm{~g}$ mapped south of downtown Los Angeles corresponded to highfrequency vibrations of a parapet on the roof of a six-storey parking building. In fact, six of the ten accelerations plotted on the map corresponded to structural response records. Of the four accelerations of $1.0 \mathrm{~g}$ or greater shown on the map, only the value of $1.82 \mathrm{~g}$ shown for Woodland Hills was for a ground motion record, at Cedar Hill Nursery in Tarzana. The strength of motion recorded at this Tarzana site seems likely to have been very localised (section 4.3.3). Some of the strongest ground accelerations, including those of between $0.8 \mathrm{~g}$ and $1.0 \mathrm{~g}$ recorded at sites in Sylmar and Santa Monica, were not shown.

\subsection{Ground and Basement Records}

It is instructive to consider the recorded ground motions and structural responses in various parts of the Los Angeles region for several reasons. The Northridge earthquake produced many very strong ground-motion records from the near-source zone. The ground motions in other parts of the Los Angeles area were more modest, less than code-level design motions. In interpreting the seismic performance of various structures, it is necessary to have an appreciation of the strength of ground motions in their vicinity because of this degree of variation of the earthquake excitation within the Los Angeles region. Also, there were some recorded motions in structures that were near or exceeded code-level design values, as well as lower amplitude records.

\subsubsection{Northern Stations}

The first set of sites to be considered is to the north of the epicentre, near or beyond the north-eastern edge of the rupture zone. These sites are located updip of the hypocentre, so their ground motions were likely to have been influenced by the various factors that produce enhanced accelerations updip in a reverse faulting earthquake, as discussed earlier (Section 3). Many of the northern stations were also in the near-source zone, less than about the length of the rupture zone from its nearest point, in which the ground motions retain the pulse characteristics of the rupture process.
Perhaps the most publicized of the records from the northern sites were those obtained by CDMG from the County Hospital at Sylmar. The hospital replaced the Olive View Hospital at a nearby site that was demolished after partially collapsing in the 1971 San Fernando earthquake. Sylmar Hospital was $15 \mathrm{~km}$ from the epicentre of the 1994 Northridge earthquake, but closer than this to the shallowest part of the rupture zone. The stronger peak horizontal acceleration of the processed, baselinecorrected "free-field" components was $0.89 \mathrm{~g}$, with $0.58 \mathrm{~g}$ vertically (Figure 4.2), recorded on site conditions described as alluvium. The ratio of the free-field vertical to horizontal peak acceleration was slightly less than $2 / 3$, the ratio commonly used in design. Even if Sylmar is directly above the rupture surface of the Northridge earthquake, so that the appropriate horizontal distance to use in applying the attenuation relation is $0 \mathrm{~km}$, the recorded peak horizontal acceleration is greater than the mean plus standard deviation values predicted by the Boore, Joyner and Fumal 1993 model. In the base of the 6-storey hospital, the peak motions were smaller, $0.80 \mathrm{~g}$ in the stronger horizontal component and $0.33 \mathrm{~g}$ vertically. The peak acceleration of the stronger horizontal component at the top of the structure was $1.70 \mathrm{~g}$ [CSMIP, 1994f]. This is considerably reduced from the value of $2.31 \mathrm{~g}$ given in the "Quick Reports" that came from a misidentification of tangled, overlapping waveforms from different channels.

The peak horizontal ground accelerations at Sylmar far exceed the code value of $0.4 \mathrm{~g}$ for the Los Angeles area. The response spectra of the recorded motions are also far stronger than the UBC values (Section 4.3.6).

All the records from the County Hospital show that the approximately north-south $\left(356^{\circ}\right)$ component of the motions were characterised by a broad pulse at the onset of the S-wave, approximately 3.0 seconds after triggering, with the peak motion following soon after. The broad pulse was less apparent in the east-west direction. As discussed below, similar characteristics in similar directions are typical of the records from other sites above the northerly part of the rupture zone, and are as expected in the region updip from a thrust fault. A second burst of strong motion was exhibited in the east-west components about $31 \frac{1}{2} \mathrm{~s}$ later. The "free-field" record shows similar characteristics. (Note that the directions of the horizontal components of the free-field record were interchanged in the "Quick Report", with the labelling corrected, without comment, in the later report OSMS 94-07 by Shakal et al.]

The strong pulse near the beginning of the S-wave in the northsouth component of the ground motion is reminiscent of similar pulses of about $0.7 \mathrm{~s}$ duration in the Pacoima Dam record of the 1971 San Fernando earthquake, and in an acceleration history derived from the seismoscope record from lower Van Norman Dam [Scott, 1973] in that earthquake. Studies of those records produced the conclusion that such long-duration acceleration pulses may be common in near-fault motions [Bertero et al, 1978], a conjecture that has been confirmed by records obtained in several more recent earthquakes such as Imperial Valley 1979 [Archuleta, 1982; Midorikawa, 1984; and Singh, 1985]. Structures may be badly damaged in dissipating the energy imparted over a short period of time by the strong ground velocities associated with such pulses. Analysis by Bertero et al. [1978] of the predicted response of the former Olive View Medical Centre to the Pacoima Dam record indicated that it was the long-duration pulses that probably produced the severe damage in that building in 1971, rather than the high-frequency accelerations exceeding $1 \mathrm{~g}$ that occurred later in the ground motion. The long-duration 


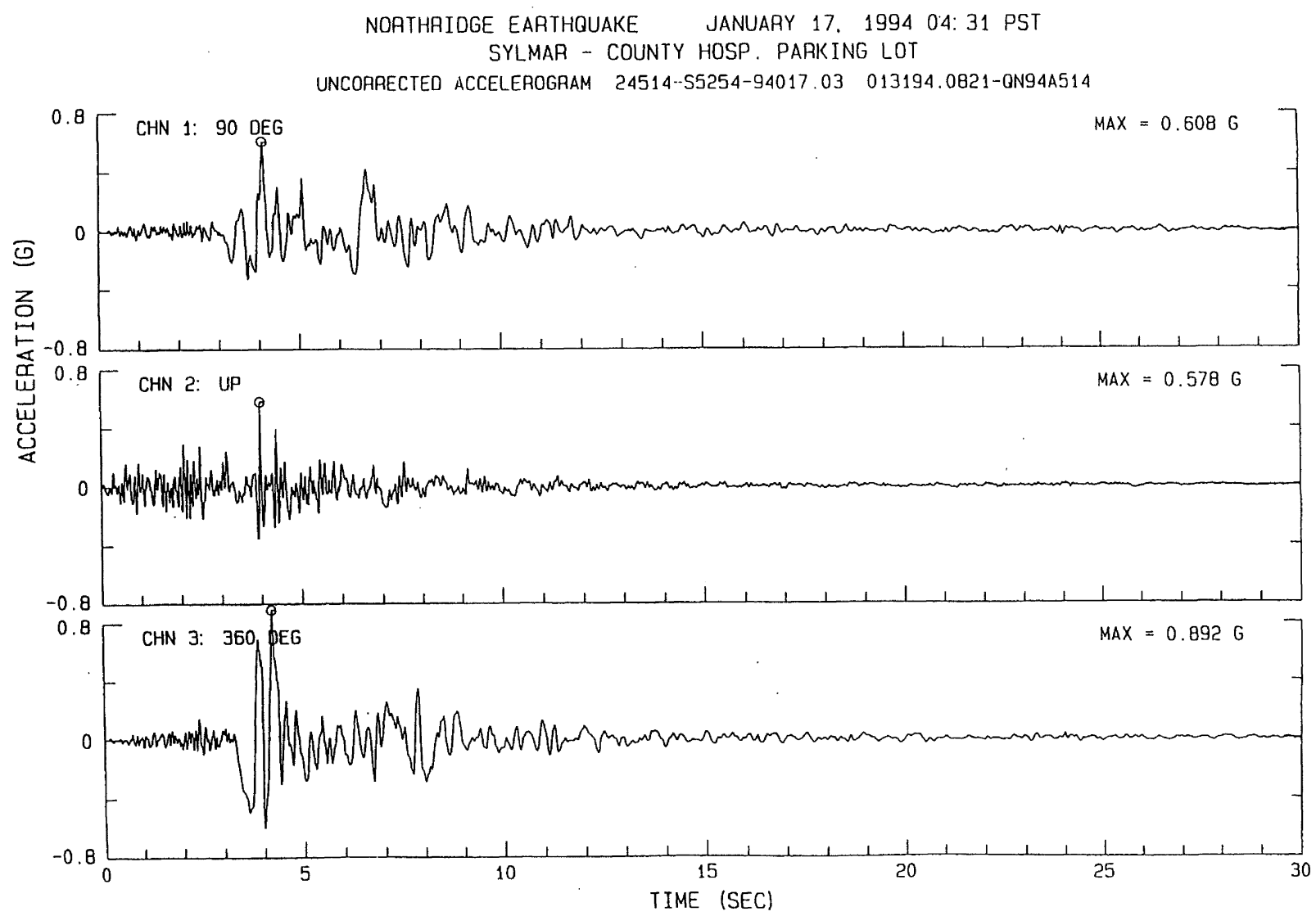

FIGURE 4.2. The three components of the CSMIP near-source acceleration record from the "free-field" Parking Lot site at the County Hospital at Sylmar. Note the strong pulse at the start of the S-wave about 3 seconds after triggering. This pulse was characteristic of the records from the near-source northern stations. [From Darragh et al., 1994aJ.

acceleration pulses in the Pacoima Dam record in 1971 integrated to a peak ground velocity of about $1.2 \mathrm{~m} / \mathrm{s}$. A similar value of $1.29 \mathrm{~m} / \mathrm{s}$ was obtained for the peak ground velocity from the 1994 north-south component of the free-field record at Sylmar County Hospital, with a peak ground displacement of $0.33 \mathrm{~m}$ (Figure 4.3).

Further sets of ground-motion records were obtained in this general vicinity at the Sylmar Converter station. Longitudinal (ie parallel to the freeway, in an approximately north-westerly direction) peak accelerations of $0.75 \mathrm{~g}$ to $0.93 \mathrm{~g}$ and transverse accelerations of $0.45 \mathrm{~g}$ to $0.60 \mathrm{~g}$ were reported [J.N.O.Coad, pers. comm.] at four locations in the station at free-field sites or at the base level of buildings. Some manifestations of liquefaction occurred on this site, adjacent to the failed tailrace channel in the LAWP site, across the valley from the Jensen plant. The peak longitudinal acceleration was only $0.54 \mathrm{~g}$ at the accelerograph closest to the liquefaction, with values for the other components unknown.

A pair of acceleration records obtained by the USGS at the Jensen Filtration Plant approximately $4 \mathrm{~km}$ west of the County Hospital differ markedly from each other in their character. The record (Figure 4.4) from a light-weight, one-storey generator shed is similar in many respects to those from the hospital. It shows very strong peak ground accelerations, $0.98 \mathrm{~g}$ in the stronger horizontal component and $0.52 \mathrm{~g}$ vertically. A long-duration pulse is apparent near the start of the S-wave, about $2.8 \mathrm{~s}$ after triggering. The second record was obtained in the basement of the Administration Building. This building appeared to be very stiff, and sat in part over a pipeline gallery containing some very large diameter water pipes. The carpark approximately $20 \mathrm{~m}$ in front of the building suffered approximately $600 \mathrm{~mm}$ of settlement, with permanent ground deformation extending under at least part of the basement of the Administration Building. The horizontal components of the Administration Building basement record (Figure 4.4) were remarkable for their lack of high-frequency content compared to those from the Generator Building about $200 \mathrm{~m}$ away on firmer ground, where there was no obvious permanent ground deformation from the earthquake. The lack of high frequencies led to considerably reduced peak accelerations in the basement of the Administration Building: $0.40 \mathrm{~g}$ in the $22^{\circ}$ component, $0.62 \mathrm{~g}$ in the $292^{\circ}$ component and $0.40 \mathrm{~g}$ in the vertical. At first glance, the Administration Building records appear to retain the long-period components of the Generator Building site, but careful study shows that the long-period cycles are in fact of longer period.

Two explanations seem possible: (i) the massive, stiff basement of the Administration building filtered out the high-frequency components from the underlying ground-motion, so that soilstructure interaction effects had considerably modified the basement records; (ii) the basement records were produced by earthquake waves that had been substantially modified by passing through a region of liquefaction at depth, with resultant filtering of the high-frequency components. 
Northridge Earthquake 17 January 1994

Sylmar - County Hospital Parking Lot CHN 3: 360 Deg
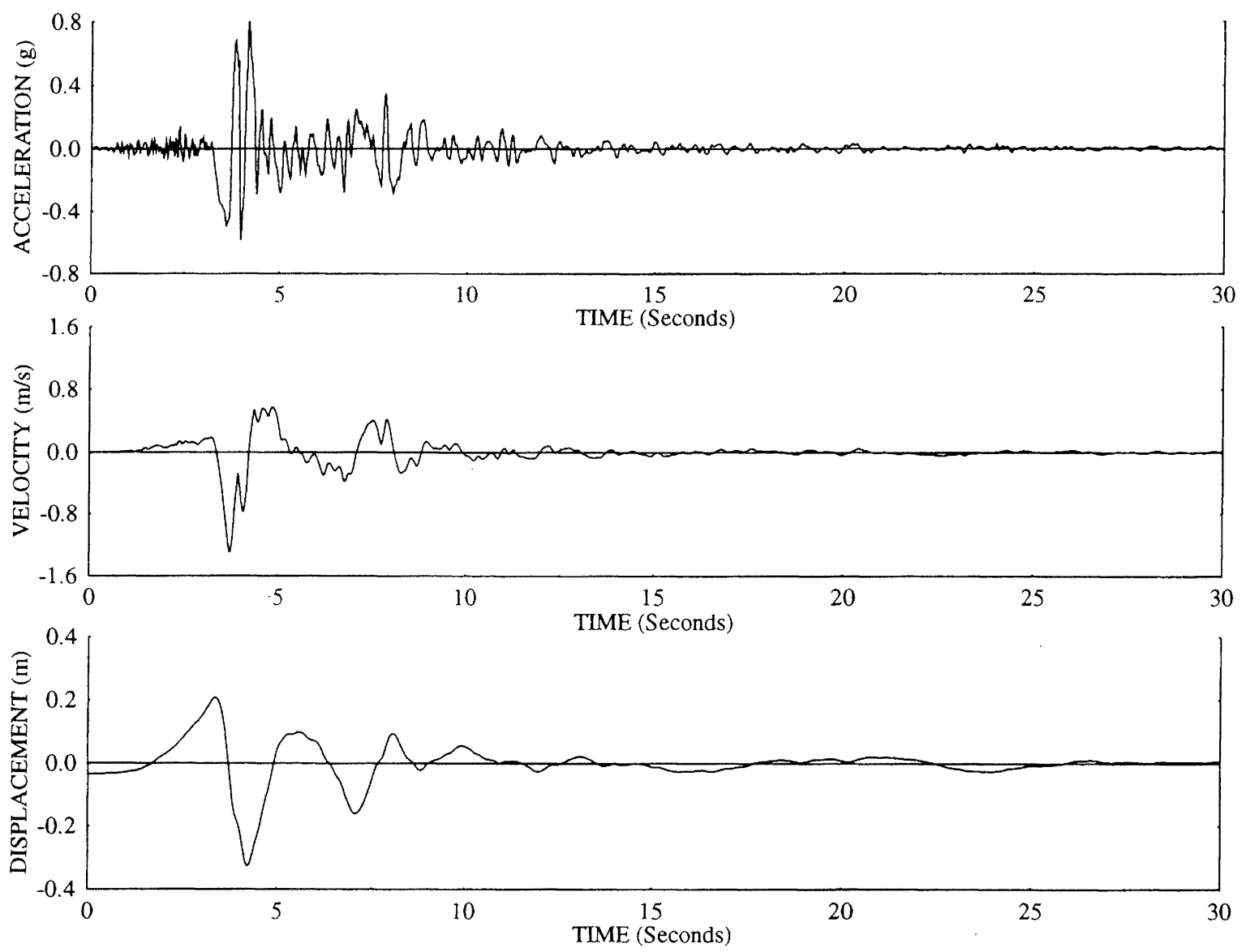

FIGURE 4.3. North-south component of the acceleration, velocity and displacement histories calculated from the accelerogram recorded at the free-field site in the Parking Lot of the County Hospital at Sylmar. Note the strong ground velocity of $1.29 \mathrm{~m} / \mathrm{s}$ corresponding to the pulse in the acceleration at the beginning of the $S$ wave. (Plotted from CSMIP data).

The second explanation seems preferable, although soilstructure interaction undoubtedly had an influence as well. The vertical motions appear much less modified in the basement of the Administration building than the horizontal components, suggesting that there was relatively little modification to the Pwave motions. The low-frequency character of the basement motions is apparent right from the initial large pulse in the Swave motions.

Liquefaction had occurred in the canyon below the Jensen site, in the LAWP Van Norman property, where sand boils and lateral spreading were widespread. In the part of the Van Norman property adjacent to the Jensen plant, a small waterretaining structure and the tailrace from an old power station had been seriously damaged in the earthquake, and rebuilt in the two weeks after. The liquefaction and lateral spreading extended at least partly into the Metropolitan Water District Jensen property, and was probably associated with the ground deformation that occurred around the Adminstration Building. Liquefaction had occurred at depth under this site in the 1971 San Fernando earthquake [Marachi, 1973]. No direct evidence of liquefaction, such as sand boils, was obvious adjacent to the building after the Northridge earthquake.
The Newhall fire station, $19 \mathrm{~km}$ north of the epicentre but only about $12 \mathrm{~km}$ from the closest part of the fault rupture surface, experienced strong horizontal and vertical accelerations, $0.63 \mathrm{~g}$ in the stronger horizontal component and $0.62 \mathrm{~g}$ vertically. Newhall was closer to the fault rupture surface than some of the accelerograph sites near the epicentre in Northridge where the fault plane was at a depth of about $18 \mathrm{~km}$. The north-south component in particular of the Newhall record showed the strong initial S-wave pulse that was present in most of the other recorded motions to the north of the epicentre. The strongest accelerations in all three components of this record occurred about 1.5-2.0s after the initial S-wave arrival. The north-south component also showed several cycles of strong accelerations $8-91 / 2$ seconds after triggering. The spectra of this record exceeded the UBC spectrum by a considerable margin for most periods, as discussed in Section 4.3.6.

The freeway interchange collapse at the I-5/I-14 junction and the overpass collapses at Gavin Canyon on I-5 occurred at locations between the Newhall site and the Jensen Filtration Plant. The hilly terrain near Newhall Pass may have affected the ground motion to some extent, but on the basis of these two records it appears that these bridge collapses occurred in response to ground motions with peak horizontal accelerations of $0.6 \mathrm{~g}$ to $1.0 \mathrm{~g}$, and vertical motions peaking at around $0.5 \mathrm{~g}$ to 
Jensen Filter Plant - Admin Bldg, Basement (MWD)

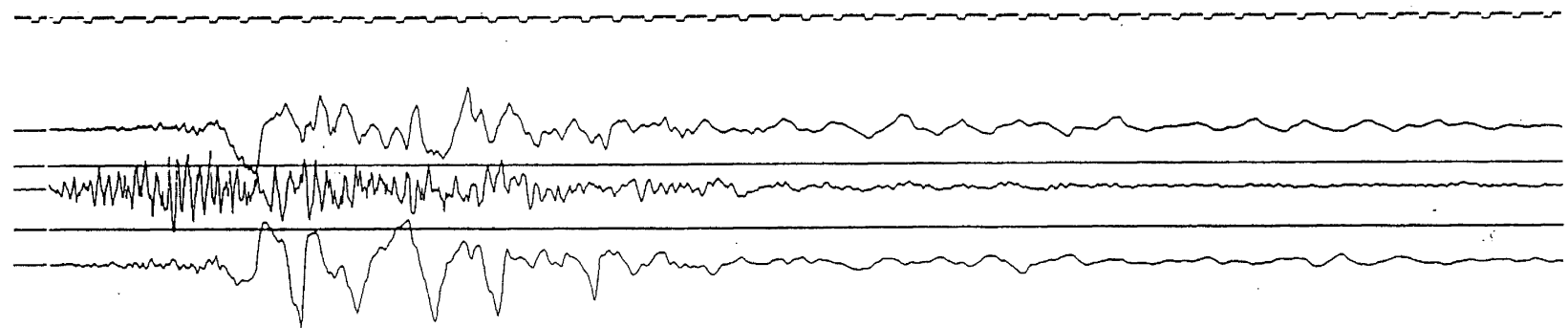

Jensen Filter Plant - Generator Bldg, Ground level (MWD)

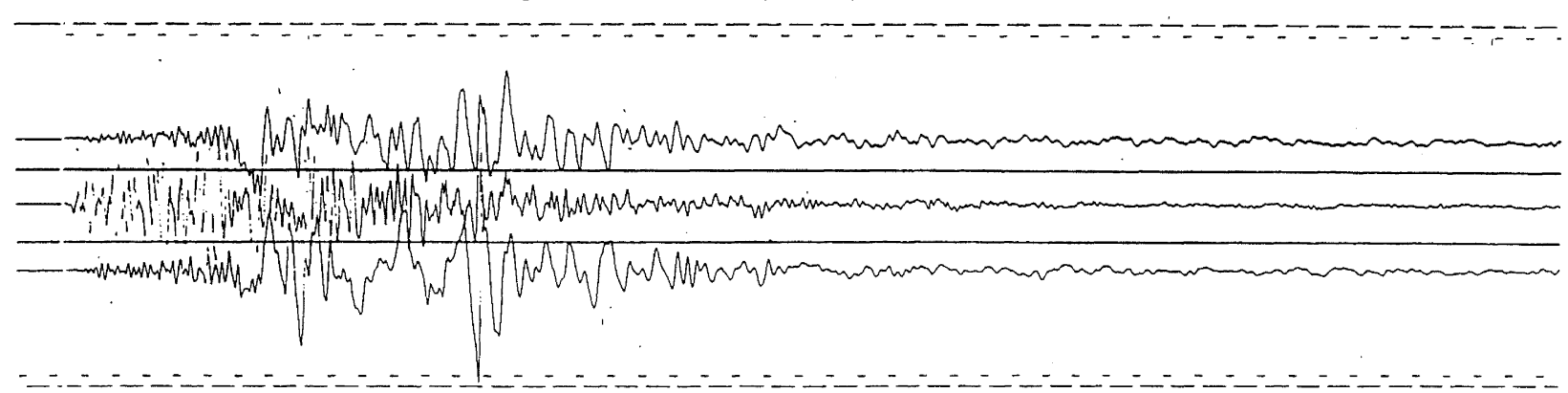

FIGURE 4.4. Ground-level records from the Jensen filter plant, for the $22^{\circ}$, vertical and $292^{\circ}$ components. Both records exhibit a strong pulse at the start of the $S$-wave. The Administration Building was sited over or near to an area apparently affected by liquefaction at depth, manifested by surface settlement that extended under the building. The attenuation of the high-frequencies in this record seems likely to have resulted from a combination of the effects of underlying liquefaction and soil-structure effects in the basement of the stiff building. The light-weight single-storey generator shed about 200 metres away did not experience these effects. [From USGS records, Porcella et al., 1994]. (Published with permission of USGS, with acknowledgement to instrument owners Metropolitan Water District of Southern California).

$0.6 \mathrm{~g}$. There is likely to have been a strong pulse in the northsouth direction at the initiation of the S-wave, associated with a peak ground velocity of about $1 \mathrm{~m} / \mathrm{s}$, followed $2-4 \mathrm{~s}$ later by strong accelerations in the east-west direction and possibly in the other components as well.

Very strong accelerations were also recorded at the Castaic Old Ridge Route site, north of Newhall at $39 \mathrm{~km}$ epicentral distance. The peak accelerations recorded at this site were $0.59 \mathrm{~g}$ in the east-west component, $0.54 \mathrm{~g}$ in the north-south component and $0.25 \mathrm{~g}$ in the vertical. The initial S-wave pulse and the strong higher-frequency later pulse are less noticeable in the record from this site than in those from the sites closer to the source.

Much lower peak horizontal and vertical accelerations of $0.16 \mathrm{~g}$ and $0.09 \mathrm{~g}$ respectively were reported from Vasquez Rocks Park, north of the Antelope Valley Freeway 14 towards Palmdale. At $36 \mathrm{~km} \mathrm{NE}$ of the epicentre, this site was closer than Castaic to the epicentre, but at a somewhat different direction from the source.

A series of records were obtained on and adjacent to Pacoima Dam, located on rock, described as metamorphic diorite gneiss [Shakal et al, 1994a], at a distance of $19 \mathrm{~km}$ from the epicentre. A free-field site on the canyon floor downstream of the dam experienced a peak horizontal acceleration of $0.44 \mathrm{~g}$, with a vertical acceleration of $0.20 \mathrm{~g}$. These values are considerably less than those at the County Hospital at Sylmar and at the Jensen Filtration Plant, despite Pacoima Dam being only $3 \mathrm{~km}$ further from the epicentre than the Hospital.
Possible reasons for the differences may be the bearing of the Pacoima site from the fault plane, and topographic effects in the canyon. The strong initial S-wave pulse was present in the motions at this site, but there was no higher-frequency pulse following later corresponding to the subevent.

Much stronger motions were recorded at the upper left abutment site where the well-known 1971 records were obtained. The stronger horizontal component exceeded $1.22 \mathrm{~g}$, with $1.39 \mathrm{~g}$ vertically. The peak accelerations of the horizontal components were similar to the $1.25 \mathrm{~g}$ recorded in 1971 , but the vertical peak was double the value of $0.70 \mathrm{~g}$ recorded in 1971 . Comparison of these values and the acceleration traces with those from the downstream site demonstrate the major effects and strong amplifications caused by the topography around Pacoima Dam (Figure 4.5). The effect of topography on the earthquake motions around Pacoima Dam was a major issue after the San Fernando earthquake, for which there was no valley floor record.

There was an array of accelerometers on the dam structure itself. Peak component accelerations ranged from $0.49 \mathrm{~g}$ in the upstream-downstream direction and $0.43 \mathrm{~g}$ vertically at the base of the downstream face to over $2.3 \mathrm{~g}$ horizontally and over $1.5 \mathrm{~g}$ vertically on the crest.

The final record to be considered in this set is that from Kagel Canyon Fire Station, which is sited on sandstone $18 \mathrm{~km}$ from the epicentre. This site is on the north-eastern side of San Fernando Valley, further east and somewhat south of the other sites considered in this group. The peak ground accelerations 


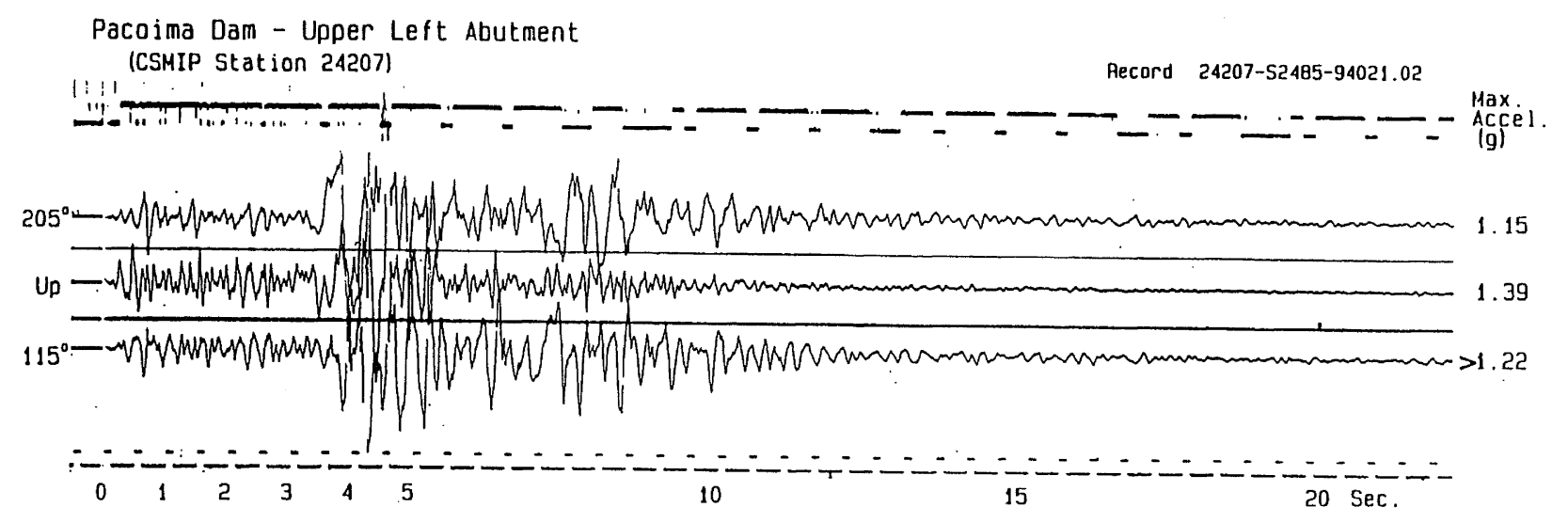

Pacoima Dam - Downstream

(CSMIP Station 24207) $\quad$ Fecord 24207-51672-94021.02

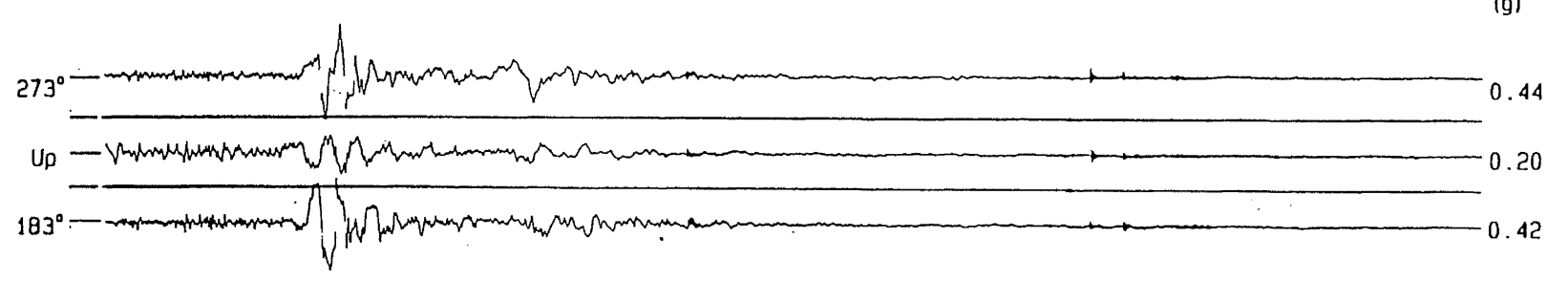

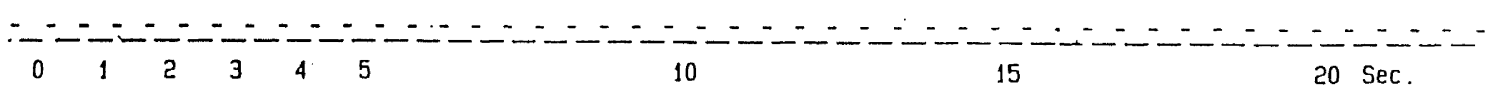

FIGURE 4.5. Ground-motion records from rock sites adjacent to Pacoima Dam. The upper left abutment record was from the site where the 1971 Pacoima Dam record was obtained, and shows the same characteristics of a strong broad pulse near the start of the $S$-wave, followed by very high accelerations. The record from the canyon floor downstream of the dam shows the initial pulse, but has much reduced peak accelerations and shorter duration. This pair of records suggests that the abutment accelerations are strongly enhanced by topographic effects, as suspected in 1971. [From CSMIP Fifth Quick Report].

were similar to those in the Pacoima downstream record, $0.44 \mathrm{~g}$ north-south, $0.30 \mathrm{~g}$ east-west and $0.19 \mathrm{~g}$ vertically. The initial $\mathrm{S}$-wave pulse was present in the traces, although to a less pronounced extent than in some other records in this group, but the later sub-event was not obvious.

Other examples of strong accelerations in the northern part of the San Fernando Valley were reported from the USC network [Todorovska et al, 1994]. The strongest horizontal acceleration reported in their Preliminary Report of January 25 was $0.94 \mathrm{~g}$, recorded at Knolls Elementary School in Santa Susana, $13 \mathrm{~km}$ WNW of the epicentre. The strongest vertical acceleration reported from the USC sites occurred in the central rather than the northern part of the San Fernando Valley, with $0.63 \mathrm{~g}$ at a location $5.9 \mathrm{~km}$ to the west of the epicentre.

In summary, many of the records from sites near or beyond the north-eastern end of the fault rupture plane showed strong horizontal accelerations, peaking at values typically between $0.6 \mathrm{~g}$ and $1.0 \mathrm{~g}$ soon after the arrival of the S-wave. The Swave arrival was often marked by a strong pulse of about $0.7 \mathrm{~s}$ duration, corresponding to a peak velocity of about $1.3 \mathrm{~m} / \mathrm{s}$ in the case of the County Hospital free-field record from Sylmar. This pulse produced similar velocities to the famous Pacoima S15W component from the 1971 San Fernando earthquake. Such large velocity pulses rather than merely strong peak accelerations are sometimes associated with major structural damage. The County Hospital performed extremely well despite the strength of the ground motions and the extremely large recorded response of $1.7 \mathrm{~g}$ at the top of the building. Records from the vicinity of Pacoima Dam showed the effects of strong topographic amplification. It is possible that motions recorded in the base of the Administration Building and in the Generator Shed at the Jensen Filtration Plant demonstrated the effects of liquefaction in the soil underlying the Administration Building.

\subsubsection{Central San Fernando Valley Stations}

The second group of records to be discussed is from the central San Fernando Valley, at sites above or adjacent to the deepest part of the rupture zone. Although many of these sites were at shorter epicentral distances than the northern San Fernando Valley sites, the rupture plane was at $18 \mathrm{~km}$ depth at the focus, so that the distance from these sites to the closest part of the rupture was greater than for some of the more northerly sites. Sites considered in this group are Arleta-Nordhoff Fire Station, Sepulveda VA Hospital, Van Nuys Holiday Inn and Northridge Plaza. The area covered by this group of records contains some of the highly publicised building failures, including the Northridge Fashion Centre Mall, the North Meadows apartments and the California State University at Northridge (CSUN) parking building collapse. The Kaiser Permanente building on Rinaldi Street in Mission Hills that partially collapsed was located about midway between these strongmotion stations and the more northerly stations discussed above. 
The Arleta-Nordhoff Avenue Fire Station was the first CDMG site close to the epicentre for which records were published. The record from this site published in the Second Quick Report gave a peak horizontal acceleration of $0.35 \mathrm{~g}$, with a stronger peak vertical acceleration of $0.59 \mathrm{~g}$, at a distance of $9 \mathrm{~km}$ east of the epicentre. The unusually high ratio of peak vertical to peak horizontal acceleration, together with the value of the vertical acceleration, gave the impression that a dominant feature of the near-source motions in this earthquake was a strong vertical component. As discussed earlier, vertical peak accelerations generally did not exceed the peak horizontal ground acceleration in this earthquake, even for near-source sites. The Arleta record produced a point lying outside the usual range of the data in the vertical versus horizontal peak acceleration plot (Figure 4.1).

The peak vertical motion at Arleta occurred at or just before the onset of the S-wave, preceding the strong velocity pulse near the beginning of the S-wave phase of the east-west motion. Some of the near-source records of the 1979 Imperial Valley earthquake, a strike-slip rather than reverse faulting event, showed similar features of strong vertical accelerations occurring between the arrival of the direct $P$ wave and the first direct S wave from the hypocentre. Archuleta [1982] suggested that the large vertical accelerations in the Imperial Valley motions resulted from a phase generated when the rupture broke into the sediments overlying the base rock. No conjecture appears to have been put forward about the cause of the strong vertical motions at Arleta. There were also some strong vertical peaks present in the S-wave phase of the motion at Arleta, but with amplitudes of only about half the maximum vertical acceleration. The vertical motions were higher frequency in character than the horizontal motions. With the attention given to the strong vertical motion shown on this record, it is worth noting that the peak vertical acceleration at this site in the 1987 Whittier earthquake equalled the peak horizontal acceleration.

The initial S-wave pulse characteristic of the north-south components of the northern group of records appears in the east-west component of this record. A second pulse associated with the later sub-event is not obvious in the Arleta record.

The Van Nuys Holiday Inn at 8244 Orion Avenue, identified on the CDMG listings as Van Nuys 7-storey hotel, is $6 \mathrm{~km}$ east of the epicentre. Peak accelerations of $0.47 \mathrm{~g}$ horizontally and $0.30 \mathrm{~g}$ vertically were recorded at the base of the building. As at Arleta, the initial S-wave pulse was most apparent in the east-west component. The vertical ground motion at this site was unexceptional.

The records from this building are important in that it suffered shear failure of the columns along the south wall at the fourth floor level. Later sections discuss the recorded response of this hotel, discuss its structural features and describe the damage (Section 6.3.2(c)).

A ground level record from the Sepulveda Veteran's Administration Hospital is included in the USGS report. This record showed horizontal accelerations of $0.94 \mathrm{~g}$ in the northsouth direction and $0.74 \mathrm{~g}$ in the east-west direction, with a peak vertical acceleration of $0.48 \mathrm{~g}$ (Figure 4.6). The USGS report gives an epicentral distance of $8 \mathrm{~km}$ for the Sepulveda VA Hospital. The Sepulveda VA Hospital record is similar in some of its features to those from the northern group of sites. Like those near-source records, there is a strong pulse at the start of the S-wave. Unlike those for the northern sites but similar to that for the Holiday Inn record, this pulse is stronger in what is assumed to be the east-west component (the USGS records do not have their components marked). A strong pulse in the other horizontal component occurs 4.2 seconds later in the record, presumably corresponding to the sub-event.

The fourth record from above the rupture plane is that supplied by Kinemetrics from the Northridge Plaza. This site is within about $3 \mathrm{~km}$ of the epicentre, and less than $1 \mathrm{~km}$ from the collapsed buildings of the Northridge Fashion Centre Mall. The Northridge Plaza records show a peak acceleration of $0.41 \mathrm{~g}$ on the stronger horizontal component, and $0.34 \mathrm{~g}$ vertically. The initial S-wave pulse is less pronounced than in some other records but produces a maximum ground velocity of $0.62 \mathrm{~m} / \mathrm{s}$ on one component, about half that at the County Hospital at Sylmar, and a maximum displacement of $0.25 \mathrm{~m}$.

A record from an instrument operated by USC in Canoga Park about. $6 \mathrm{~km}$ west of the epicentre had a peak vertical acceleration of $0.63 \mathrm{~g}$, stronger than the vertical acceleration at Arleta. The peak horizontal acceleration at this site was $0.46 \mathrm{~g}$, making it one of the few sites like Arleta where the peak vertical acceleration exceeded the peak horizontal acceleration.

The records from the Central San Fernando Valley from above the rupture zone are rather variable in their peak ground accelerations. The peak horizontal values range from $0.35 \mathrm{~g}$ to $0.91 \mathrm{~g}$, with vertical values from $0.30 \mathrm{~g}$ to $0.63 \mathrm{~g}$. The horizontal components of the records from closest to the epicentre, at

Sepulveda V.A. Hospital - Bldg 40 , Ground level (VA)
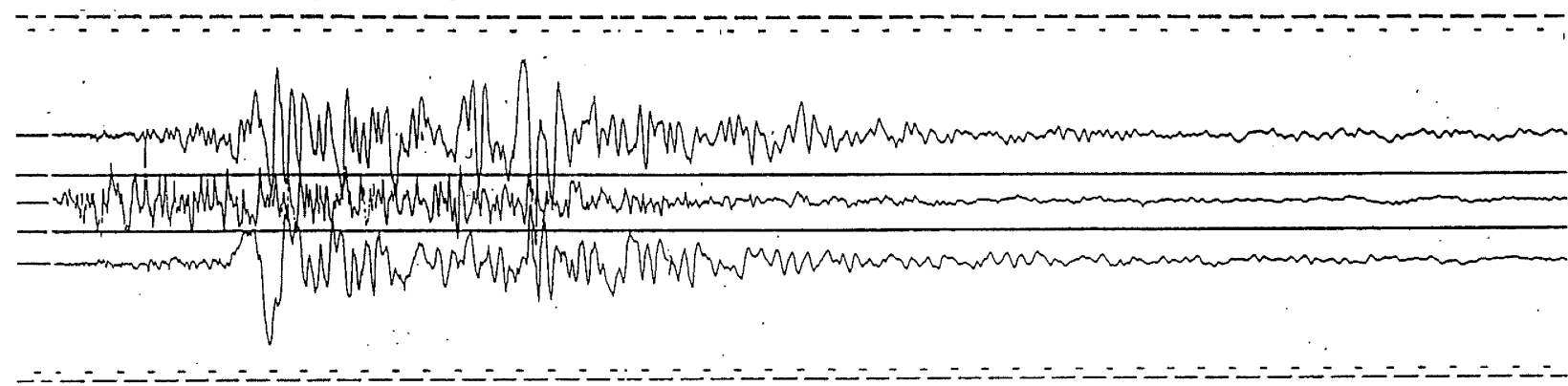

FIGURE 4.6. The Sepulveda V.A. Hospital record from above the rupture plane, showing a strong broad pulse at the start of the $S$-wave, followed by very strong peak accelerations of about $0.9 \mathrm{~g}$ [from USGS, Porcella et al., 1994]. (Published with permission of USGS, with acknowledgement to instrument owners U.S. Department of Veterans Affairs). 


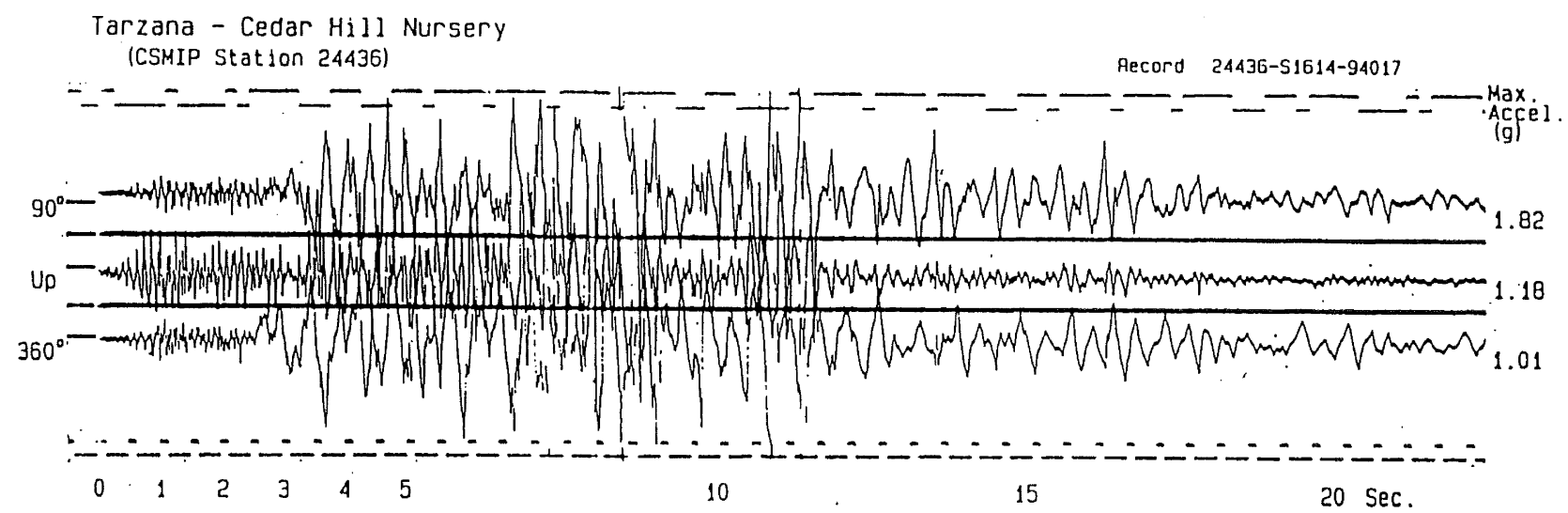

FIGURE 4.7. The exceptionally strong accelerations recorded at the Tarzana Cedar Hill nursery, exceeding 19 for many cycles in all 3 components. An apparent lack of major damage in the surrounding area, together with high accelerations at this site in the 1987 Whittier earthquake, suggest a highly localised site effect. It is understood that CDMG and USGS were to conduct extensive site investigations following the Northridge earthquake. [From CSMIP Third Quick Report, as reproduced by Moehle (ed.), 1994].

Arleta and the USC Canoga Park site, were generally weaker than those from sites near the northern end of the rupture zone, at Sylmar and Newhall, but had similar strengths of vertical motion, about $0.6 \mathrm{~g}$.

\subsubsection{Stations in the southern San Fernando Valley}

Records from sites in the southern San Fernando Valley, to the south of the rupture zone, included in the early strong-motion reports were from: Topanga Fire Station, Tarzana Cedar Hills Nursery, Sepulveda Canyon Control Facility, Pacific Manor 609 N. Glenoaks (Burbank 10-storey residential building), California Federal Savings 323 N. Glenoaks (Burbank 6-storey commercial building), Sheraton-Universal Hotel (North Hollywood 20-storey hotel), Griffith Park, Union Bank 15233 Ventura Blvd (Sherman Oaks 13-storey commercial building), and $3601 \mathrm{~W}$. Olive Avenue, Burbank.

Apart from the Tarzana Cedar Hills Nursery site, the peak horizontal accelerations on these records ranged from $0.29 \mathrm{~g}$ to $0.46 \mathrm{~g}$, with vertical accelerations of $0.13 \mathrm{~g}$ to $0.19 \mathrm{~g}$. The horizontal accelerations were similar to or somewhat greater than those for code-level design, with the vertical accelerations at levels that should cause no structural failure problems for seismically-designed modern structures in the Los Angeles region.

The initial strong "fault-fling" pulse in the S-wave that was characteristic of records from sites to the north of the rupture was not apparent in the records from these sites south of the epicentre. This is consistent with the fault rupture not propagating past them. Most records showed a pulse several seconds after the onset of the S-wave, perhaps associated with the sub-event.

The Tarzana record from Cedar Hill Nursery showed exceptionally strong peak ground accelerations, $1.82 \mathrm{~g}$ in the stronger horizontal component and $1.18 \mathrm{~g}$ vertically. Strong accelerations exceeding $1 \mathrm{~g}$ occurred repeatedly for 7-8 seconds (Figure 4.7). Records from this site in the 1987 Whittier Narrows earthquake were also notable for their strong accelerations, $0.62 \mathrm{~g}$ in the stronger horizontal component despite the epicentral distance of $45 \mathrm{~km}$. This value was comparable with or exceeded peak accelerations of $0.20 \mathrm{~g}$ to
$0.63 \mathrm{~g}$ recorded within $10 \mathrm{~km}$ of the epicentre of the Whittier earthquake. The records from the largest Whittier aftershock and several other events were unexceptional.

There have been a number of descriptions of the site conditions at Cedar Hill Nursery. Observations from a visit to the site support the description of Shakal et al [1988, p80], "the site is located in a region of low rolling hills between the alluvial San Fernando Valley and the Santa Monica Mountains.." rather than that of Campbell [1988, p135], "at the mouth of a canyon..". The site is located on the flat top of a minor ridge that runs in an approximately east-west direction. There is a fairly steep drop (perhaps with a slope of $35^{\circ}$ ) on the northerly side towards the San Fernando Valley, with around a $20 \mathrm{~m}$ drop to Tarzana Drive at its foot. The ridge rolls away gently to the south.

The strong site response presumably arises from a combination of topographic effects with a soil layer on top, although from our observations there was no reason to expect unusually strong motions at this site. It is possible that there is some feature in the basement structure under this site that causes focussing in some earthquakes. Stephenson [1994] has speculated about the cause of the strong accelerations at this site in the 1987 Whittier earthquake, and shown that the records in that earthquake are consistent with the superposition of two modes of a ridge response that have closely-spaced frequencies. The area around the site was scheduled to be studied with a dense array of aftershock recorders the week after our visit, and presumably geotechnical and geophysical studies will be performed as well. Hopefully these studies will provide some explanation for the very strong motions recorded at this site, and give some indication of how localised the motions were likely to have been. At this stage, the Tarzana Cedar Hills record should be considered as an oddity, rather than indicative of the strength of motion that occurred in the Tarzana region as a whole. Records from a number of codeinstrumented buildings in Tarzana should give an indication of the distribution of peak ground accelerations in the Tarzana area when they become available.

There were two mobile homes alongside the driveway approaching the site from the nursery sheds. A worker at the site reported that one of these homes had been knocked off its 
support blocks, while the other hadn't. Neither mobile home appeared well secured. The owner's house further up the driveway was reported as being heavily damaged; many of the roof tiles were missing at the time of our visit, but we were unable to inspect the house to assess the damage at close quarters. There were also some repairs being carried out at the Country Club building to the south of the site, but it was difficult to assess the extent of the damage from the distance of 100-200 metres.

Apart from the Tarzana Cedar Hills Nursery record, the records from this region indicate levels of motion similar to code-level design motions in terms of peak accelerations. Any further information on recorded motions and structural performance that becomes available from this area could be very valuable for the assessment of code design. There are many codeinstrumented structures in this area, so it is possible that such information will appear. Documentation of the extent of nonstructural damage in this region would be an extremely valuable contribution to the assessment of structural performance in a region experiencing near code-level motions.

\subsubsection{Stations south of the Santa Monica Mountains, in the Beverley Hills, Century City and Santa Monica areas}

A number of strong-motion records were obtained from this area, between $19 \mathrm{~km}$ and $28 \mathrm{~km}$ south to south-east of the epicentre. Sites and their peak horizontal $(H)$, vertical $(V)$ and structural (S) motions included: UCLA Math-Science Building $(0.29 \mathrm{~g} \mathrm{H}, 0.25 \mathrm{~g} \mathrm{~V}, 0.77 \mathrm{~g} \mathrm{~S})$, LA Country Club in Century City $(0.27 \mathrm{~g} \mathrm{H}, 0.15 \mathrm{~g} \mathrm{~V})$, Bullocks in Century City (3-storey commercial building) (0.33g H, 0.15g V, 0.97g HS, 0.26g VS), I10/405 Freeway Interchange Bridge $(1.00 \mathrm{~g}$ HS, $1.83 \mathrm{~g} \mathrm{VS})$, Santa Monica City Hall grounds $(0.93 \mathrm{~g} \mathrm{H}, 0.25 \mathrm{~g} \mathrm{~V})$, Baldwin Hills $(0.24 \mathrm{~g} \mathrm{H}, 0.10 \mathrm{~g} \mathrm{~V}), 19551 / 2$ Purdue Avenue $(0.44 \mathrm{~g} \mathrm{H}$, $0.16 \mathrm{~g} \mathrm{~V}, 0.63 \mathrm{~g} \mathrm{HS}, 0.46 \mathrm{~g}$ VS), and $444 \mathrm{~S}$. San Vicente $(0.64 \mathrm{~g}$ HS, $0.31 \mathrm{~g}$ VS).

Apart from the Santa Monica City Hall record, the peak horizontal ground accelerations in these records ranged from $0.24 \mathrm{~g}$ to $0.44 \mathrm{~g}$, very similar to the range of $0.26 \mathrm{~g}$ to $0.49 \mathrm{~g}$ at the southern San Fernando sites to the north across the Santa Monica mountains that were generally somewhat closer to the epicentre. A ground site record from UCLA that didn't appear in the "Quick Reports" had an uncorrected peak horizontal acceleration of $0.66 \mathrm{~g}$. This peak was spiky in character, and was reduced to $0.47 \mathrm{~g}$ in the processed record.
The Santa Monica City Hall record had a peak acceleration of $0.93 \mathrm{~g}$ in the east-west direction and only $0.42 \mathrm{~g}$ in the northsouth component. The maximum acceleration occurred about 5 seconds after the initial S-wave motion, and was extraordinary in character in that it corresponded to a motion of one and a half cycles duration lasting about $0.3 \mathrm{~s}$ superimposed on many cycles with fairly uniform amplitudes of about $0.3 \mathrm{~g}$ (Figure 4.8). The timing of this peak and its orientation correspond to the sub-event revealed on a number of other records in this group.

Much more damage occurred in Santa Monica than at places further east at a similar distance from the epicentre. Travelling in a westerly direction on Santa Monica Blvd, from central Los Angeles towards the coast, this damage became very noticeable around 20th Street, in the vicinity of St John's Hospital, and to the west. The City Hall was at about the southern limit of the heavily damaged area.

There did not appear to be any obvious explanation in terms of ground conditions for the greater concentration of damage in this region. Apparently, less damage occurred on the most recent sediments, along the coast to the south of the City Hall. The section of the Santa Monica Freeway that collapsed near Venice and La Cienaga Blvds was reported in the news media as being sited on old swamp deposits. "La Cienaga" is Spanish for swamp or marsh. This region was once also the course of the Los Angeles River, forming a flood overflow channel as recently as last century. Some other buildings also collapsed in the same locality.

Another suggestion was that the damage reflected a less rigorous policy for strengthening unreinforced masonry buildings in Santa Monica than in Los Angeles City. This may have been a factor, but other types of structures were damaged also, and the difference in the extent of damage was such that it seems likely that the ground motions were considerably stronger in parts of Santa Monica than in nearby areas, in line with the indications from the record at City Hall.

The general level of accelerations in this area, as for the southern San Fernando Valley sites, suggest that the motions experienced were generally close to code-level. The peak ground acceleration recorded in Santa Monica was considerably stronger, but was associated with a short duration pulse. The effect of this pulse on structural performance remains to be evaluated, but it may have been a contributory factor to the

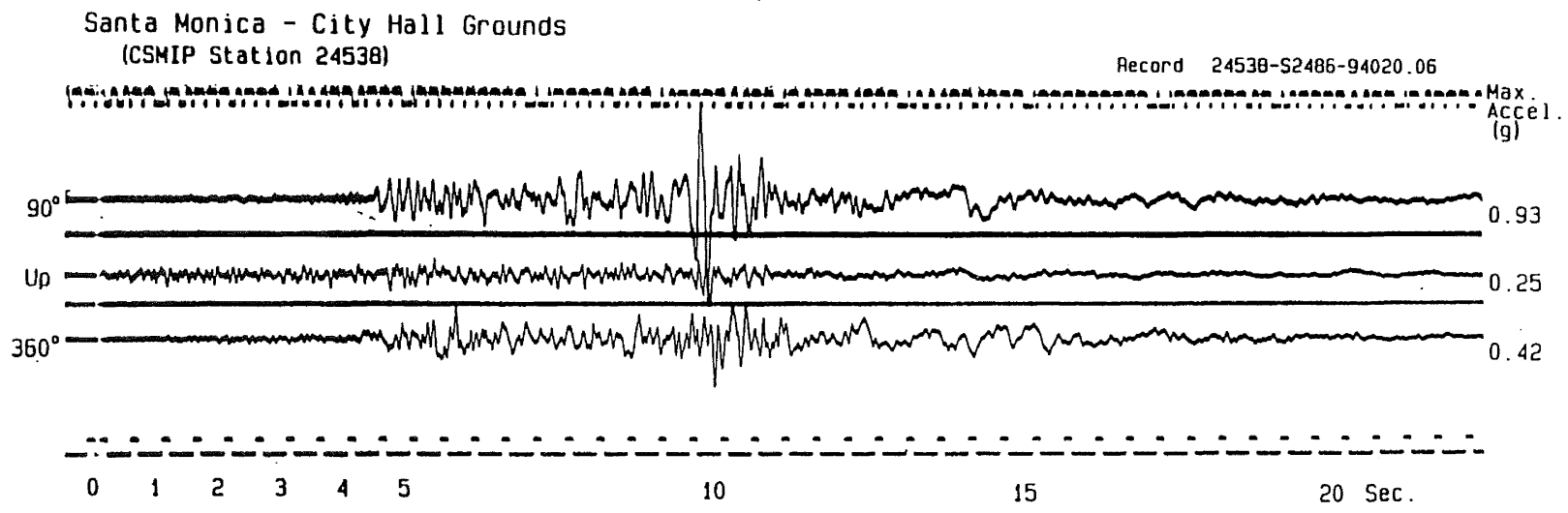

FIGURE 4.8. The CSMIP record from the grounds of the Santa Monica City Hall. Note the strong short-duration pulse in the $90^{\circ}$ component associated with the $0.93 \mathrm{~g}$ PGA, superimposed on many cycles of motion with amplitudes of about 0.3g. (From CSMIP Fourth Quick Report). 


\section{Northridge 5\% Damped Acceleration Response Spectra - Stronger Component}

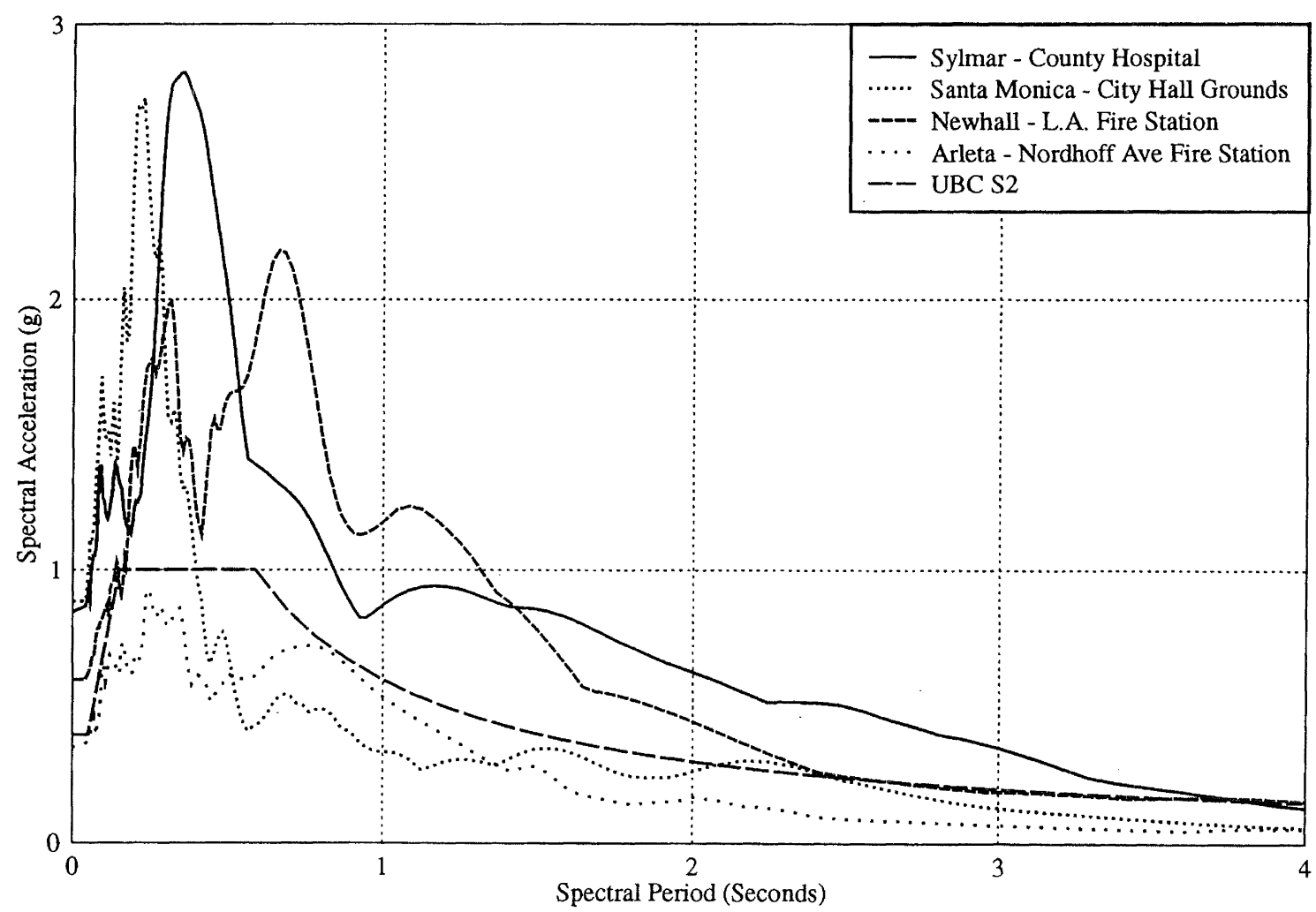

FIGURE 4.9. The four spectra presented by Krawinkler [1994] for some of the more notable strong-motion records from the Northridge earthquake. All spectra are for the stronger horizontal component, which except at Arleta was considerably stronger than the other component shown in Figure 4.10. The Sylmar and Newhall spectra exceed the UBC S2 spectrum at all periods, but the Santa Monica spectrum generally exceeds the code curve only at short periods (less than 0.4s), and the Arleta spectrum falls below the code spectrum at all periods. (Plotted from CSMIP data).

greater levels of damage in parts of Santa Monica than at other places nearby. Spectra from some sites in this area are discussed in Section 4.3.6.

\subsubsection{Central Los Angeles records}

The central Los Angeles strong-motion sites can be classified into two groups exhibiting different levels of peak ground accelerations.

The first group of sites in the vicinity of the Harbour (110) Freeway, from Sunset Boulevard south to the Convention Centre at epicentral distances of about $32 \mathrm{~km}$, had peak horizontal component ground accelerations of $0.13 \mathrm{~g}$ to $0.19 \mathrm{~g}$, significantly less than code-level design motions. The area includes most of the downtown Los Angeles business district, with high-rise buildings to over 50 stories, so it is important to realise that the buildings in this area were not tested by codelevel design motions in this earthquake. The peak accelerations at these sites were also considerably less than those in most of the San Fernando Valley and in the Beverley Hills, Century City and Santa Monica areas.

The second group of sites further to the south or east, at epicentral distances of 32 to $39 \mathrm{~km}$, had stronger peak ground accelerations, from $0.24 \mathrm{~g}$ to $0.49 \mathrm{~g}$. This range of peak ground accelerations brackets code design levels. The strongest peak acceleration of these records came from a siltstone site at the base-isolated USC Hospital, $36 \mathrm{~km}$ from the epicentre.

\subsubsection{Acceleration response spectra}

Although not available at the time of our visit, response spectra have now been calculated for many of the records obtained from the CSMIP network [Darragh et al, 1994a-e; CSMIP, 1994f-i]. Acceleration response spectra for four sites were given by Krawinkler [1994] in the EERI reconnaissance report, and compared with a code elastic spectrum defining design ground motions for S2 (stiff soil) site conditions in Los Angeles. The elastic spectrum specifies the strength of ground motions corresponding to code-level design, but the actual code design strengths may be considerably lower than indicated by the elastic spectrum because of reductions for ductility. Yielding will generally initiate in ground motions much less than those corresponding to the elastic design spectrum. Thus structures may suffer considerable inelastic response even in ground motions with spectra considerably less than the code elastic spectrum.

The 5\% damped spectra for the stronger horizontal components at the four sites considered by Krawinkler, namely Santa Monica City Hall, Sylmar County Hospital free-field, Newhall and Arleta, are shown in Figure 4.9, calculated from the corrected acceleration histories distributed by CDMG. This plot corresponds to Figure 4.2 of Krawinkler. For three of these sites, the spectrum plotted by Krawinkler was considerably stronger than that of the other horizontal component for most periods. The spectra of the weaker components of the same records are shown in Figure 4.10. 


\section{Northridge 5\% Damped Acceleration Response Spectra - Weaker Component}

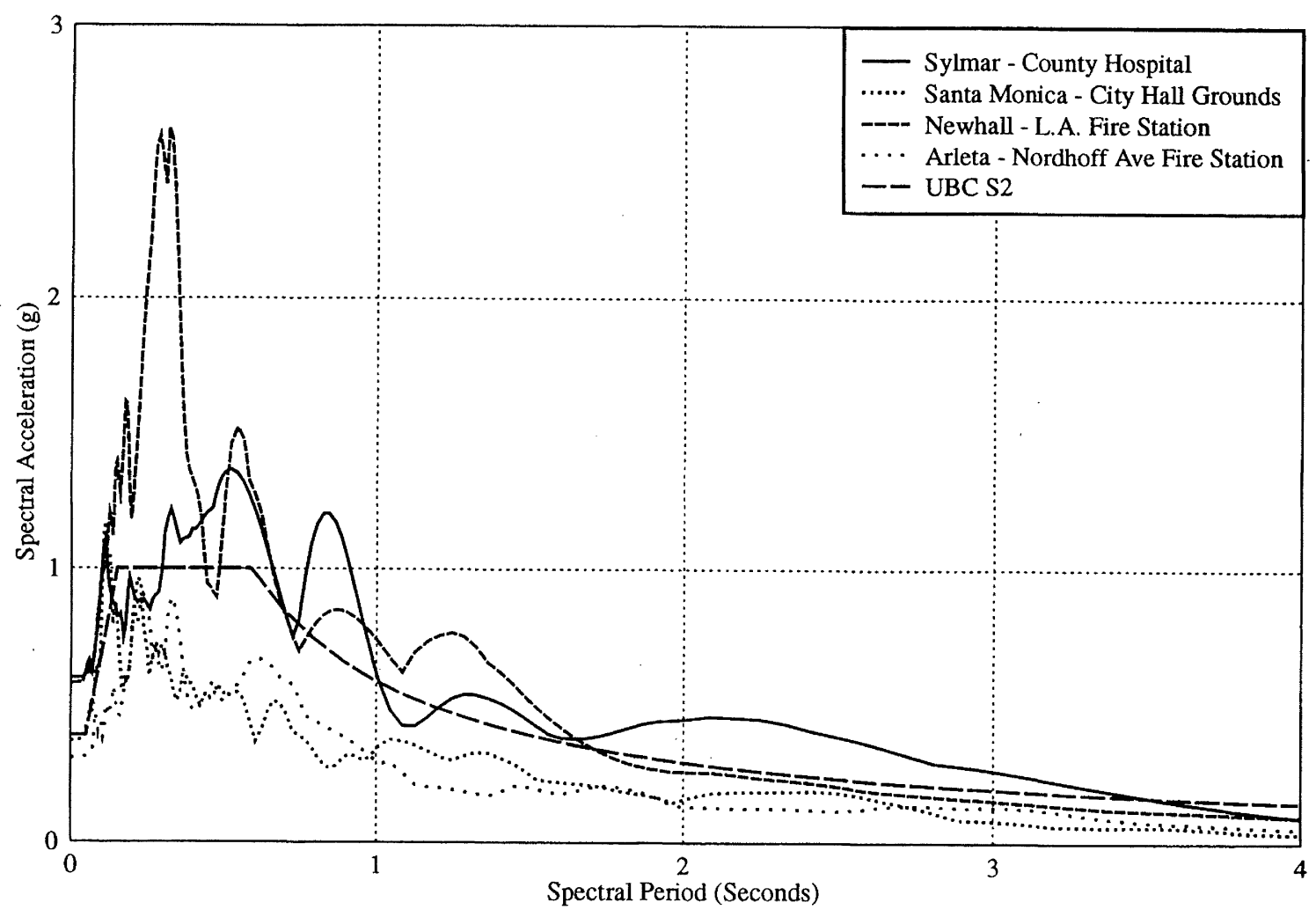

FIGURE 4.10. The spectra for the weaker horizontal component of the records shown in Figure 4.9. The spectra of the weaker Santa Monica and Arleta components generally lie below the code $\mathbf{2}$ curve, and the weaker component grossly exceeds the code curve only for Newhall, and then only at short periods. (Plotted from CSMIP data).

For each of these sites, the ground motions were notable either for their strength, generally among the strongest recorded in the earthquake, or for special features. Sylmar and Newhall were near the northern end of the rupture zone, with both peak horizontal and vertical accelerations in the range of about $0.6 \mathrm{~g}$ to $0.9 \mathrm{~g}$. Their records showed strong horizontal acceleration pulses, near the start of the S-wave phase of the motion, that produced large ground velocities. Arleta was $10 \mathrm{~km}$ from the epicentre, in the Central San Fernando Valley. Its ground motions were exceptional in that the peak vertical ground acceleration of $0.59 \mathrm{~g}$ considerably exceeded the peak of $0.35 \mathrm{~g}$ in the stronger horizontal component. The Santa Monica record was unusual because of the $0.93 \mathrm{~g}$ pulse in the east-west component superimposed on many cycles of about $0.3 \mathrm{~g}$ amplitude.

The 5\% damped acceleration response spectrum for the northsouth component of the free-field record at the County Hospital at Sylmar peaked at $2.8 \mathrm{~g}$ at $0.35 \mathrm{~s}$ period, with a peak ground acceleration of $0.89 \mathrm{~g}$. The UBC-S2 code elastic spectrum for firm soil sites in the Los Angeles area has a peak at $1.0 \mathrm{~g}$ over the period range $0.2 \mathrm{~s}$ to $0.6 \mathrm{~s}$, with a peak ground acceleration of $0.4 \mathrm{~g}$, so the free-field motions recorded at Sylmar far exceed code values. The spectrum for the east-west component of the recorded free-field motion is much weaker than for the northsouth component. It reaches a maximum of $1.3-1.4 \mathrm{~g}$ at about $0.55 \mathrm{~s}$, with a peak ground acceleration of $0.60 \mathrm{~g}$ for this component. Unlike the spectrum for the north-south component which exceeds the UBC-S2 spectrum at all periods, the east-west spectrum falls below the UBC curve at some periods.
The spectrum for the north-south component of the Newhall record, which is generally stronger than that for the east-west component, has its strongest peak at a longer period than that for the Sylmar free-field record. The strongest peak is $2.2 \mathrm{~g}$ at about $0.65 \mathrm{~s}$. There is a second peak, $1.95 \mathrm{~g}$ at $0.3 \mathrm{~s}$, and also a less pronounced third peak, of $1.25 \mathrm{~g}$ at $1.1 \mathrm{~s}$. The Newhall north-south spectrum exceeds the Sylmar spectrum over the range of about $0.55 \mathrm{~s}$ to $1.4 \mathrm{~s}$, and exceeds the UBC-S2 spectrum for all periods up to $2.6 \mathrm{~s}$. For the remaining period range up to $4.0 \mathrm{~s}$, it virtually coincides with the UBC-S2 $0.4 \mathrm{~g}$ code spectrum. The spectrum for the east-west component is generally weaker than that for the north-south component, but has a higher acceleration of $2.6 \mathrm{~g}$ at its peak at about $0.3 \mathrm{~s}$. The east-west spectrum is generally stronger than the UBC-S2 spectrum for periods up to $1.7 \mathrm{~s}$, but falls slightly below it for the remainder of the period range up to $4.0 \mathrm{~s}$.

The horizontal motion at Arleta was much weaker than those at the Sylmar and Newhall sites. The 5\% damped spectra for both its horizontal components lie below the $0.4 \mathrm{~g}$ ATC3-S2 spectrum at all periods, peaking at about $0.9 \mathrm{~g}$ at about $0.2-$ $0.25 \mathrm{~s}$ for both components. It is important to appreciate that the horizontal accelerations at this site were less than codelevel motions when assessing the performance of structures in the San Fernando Valley as a whole. While some parts of the valley experienced very strong motions far exceeding code levels, others experienced much more modest motions not reaching code-level, even at sites such as Arleta within a few kilometres of the epicentre. 


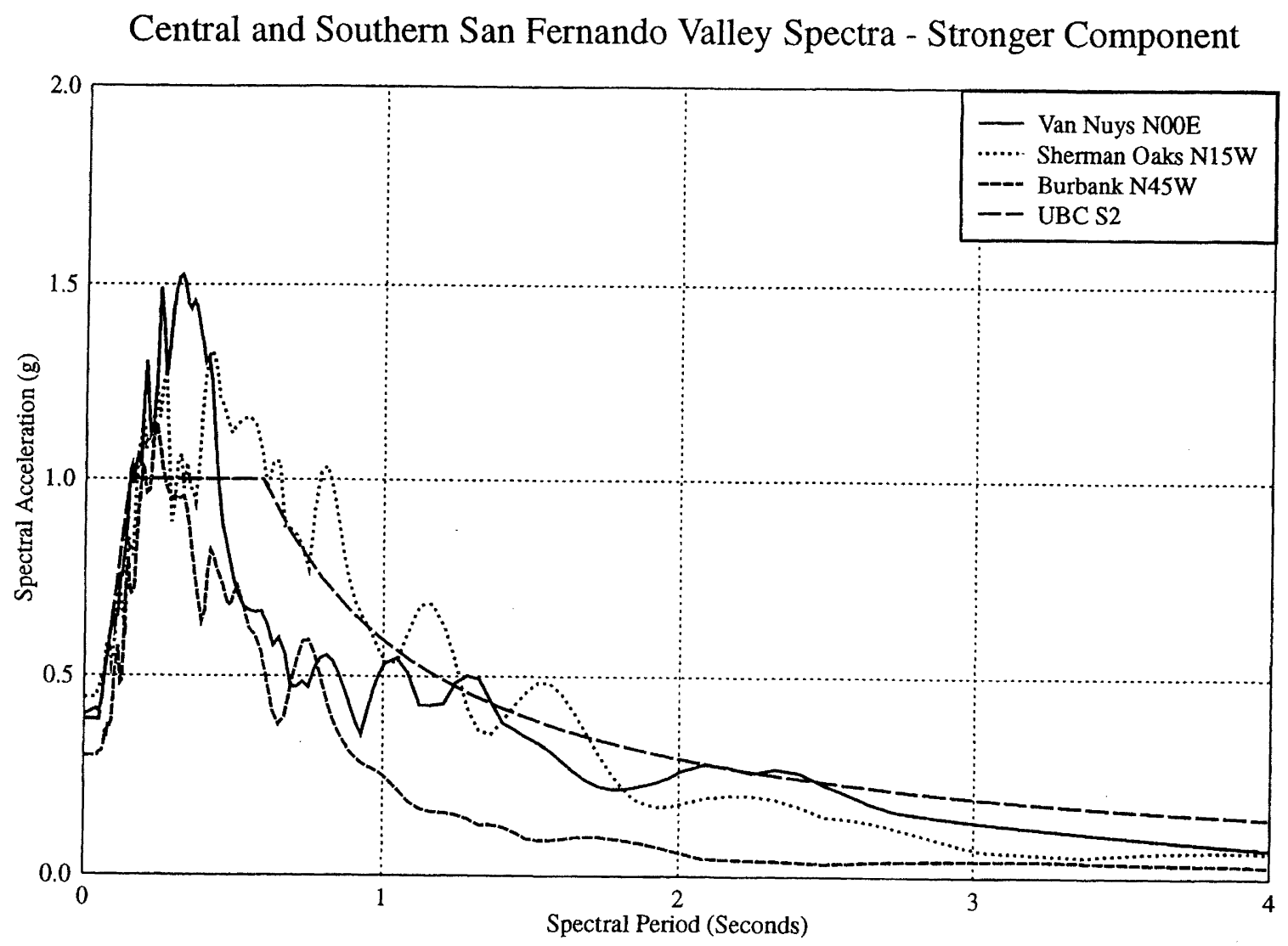

FIGURE 4.11. Spectra of the stronger components of typical records from the central and southern regions of San Fernando Valley, showing that they generally lie below the UBC S2 code curve. The Sherman Oaks spectrum provides a close envelope of the code spectrum for periods up to about 1.5s. (Plotted from CSMIP data).

The remaining spectrum considered by Krawinkler was for the record from the Santa Monica City Hall grounds. This record was notable for the remarkable $0.93 \mathrm{~g}$ peak ground acceleration in the east-west component, obtained at a distance of $23 \mathrm{~km}$ south of the epicentre. The spectrum has a very sharp peak of $2.7 \mathrm{~g}$ at $0.2 \mathrm{~s}$, dropping to $1 \mathrm{~g}$ at $0.4 \mathrm{~s}$ and generally lying below the UBC-S2 spectrum for periods longer than this. Apart from a spike of about $1.15 \mathrm{~g}$ at a period of about $0.1 \mathrm{~s}$, the spectrum for the north-south component of the Santa Monica record lies below the UBC-S2 spectrum for all periods. Thus the ground motions recorded at Santa Monica City Hall were less than code-level except for short-period structures.

To give a more balanced impression of the strength of earthquake motions experienced in the San Fernando Valley and Los Angeles Basin, spectra for other sites are shown in Figures 4.11 and 4.12 .

Figure 4.11 shows spectra typical of much of the central and southern part of the San Fernando Valley. The spectra shown are for the stronger horizontal component at each site, with the other component usually considerably weaker. All are for alluvium sites.

The Van Nuys spectrum is from the Holiday Inn on Orion Avenue, identified by CDMG as "Van Nuys 7-story hotel", station number 24386 . This structure, which was repaired after minor structural damage in the 1971 San Fernando earthquake, suffered shear failure in a line of columns (Section 6.3.2(b)). The site was $7 \mathrm{~km}$ from the epicentre, the second shortest epicentral distance of the CDMG sites. Apart from the period range of about $0.1 \mathrm{~s}$ to $0.45 \mathrm{~s}$, the spectrum generally lies below the UBC-S2 spectrum. It marginally exceeds the UBC-S2 spectrum in the period ranges $1.2-1.3 \mathrm{~s}$ and $2.1-2.5 \mathrm{~s}$.

The Sherman Oaks spectrum was from the basement of the Union Bank at 15233 Ventura Boulevard, identified as a "13story commercial building", station number 24322, by CDMG. This site was $9 \mathrm{~km}$ from the epicentre. This spectrum generally envelopes the UBC-S2 spectrum up to about $1.7 \mathrm{~s}$ period, and appears a reasonable representation of code-level motions, or slightly higher, over this period range. The spectrum falls below the code spectrum at longer periods.

The Burbank spectrum is for station number 24370 , "6-story commercial building". This site was $22 \mathrm{~km}$ from the epicentre. The greater distance is reflected in a weaker spectrum, reaching to just above the code spectrum at about $0.25 \mathrm{~s}$ but generally about half or less of the code spectrum.

Spectra of generally similar strength to the Burbank spectrum were obtained at the selection of sites south of the Santa Monica mountains shown as representative of the Los Angeles Basin in Figure 4.12. The processed, corrected records from UCLA grounds, Hollywood Storage Building grounds and Obregon Park all had peak accelerations of $0.4-0.5 \mathrm{~g}$, some of the stronger values recorded in the Los Angeles basin. All spectra fall below the code curve for periods greater than $0.4 \mathrm{~s}$.

In summary, the $5 \%$ damped response spectra for some of the ground motions recorded in the Northridge earthquake, particularly for sites near the shallower parts of the rupture 


\section{Los Angeles Basin Spectra - Stronger Component}

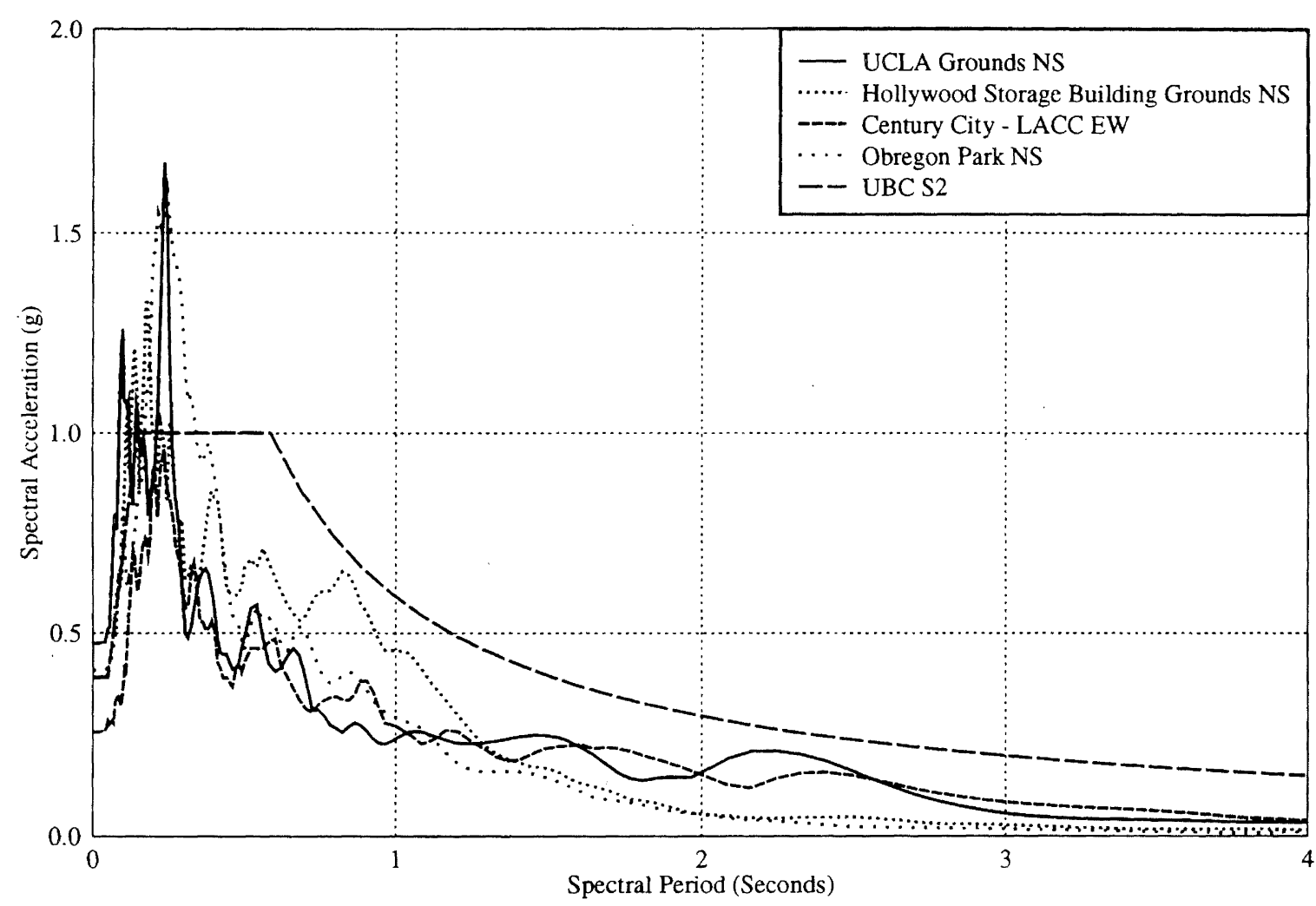

FIGURE 4.12. Spectra of the stronger components of records from the Los Angeles Basin, south of the Santa Monica Mountains. Note that they are peaked at short period, and lie below the code curve for periods greater than about 0.4s. The Northridge earthquake generally produced less than code-level motions south of the Santa Monica Mountains. (Plotted from CSMIP data).

zone, are considerably stronger than code elastic spectra for the Los Angeles region, by a factor of 2 or more. However, many other sites in the central and southern parts of the San Fernando Valley experienced motions that were at code-level or less for most periods. South of the Santa Monica Mountains, in the Los Angeles Basin, the spectra were weaker than code-level, except perhaps in the short-period range up to about $0.4 \mathrm{~s}$ for some sites (e.g. Santa Monica and UCLA Grounds) where there were very strong peak ground accelerations. For many sites, the spectra were much more highly peaked at short period than the code spectra, a feature consistent with the moderate magnitude of the earthquake. Often strong peak ground accelerations exceeding the code value of $0.4 \mathrm{~g}$ were associated with spectra that fell considerably below code values for periods in excess of about $0.4 \mathrm{~s}$

\subsection{Response Records from Conventional Structures}

The preliminary sets of accelerograms distributed by CDMG and USGS contained several sets of structural response records [CSMIP, 1994a-d; Porcella et al, 1994]. The summary tables released with the CDMG records indicated some very strong structural responses, up to more than $1 \mathrm{~g}$ in some cases, but the values in the tables need to be treated with some caution as several of the stronger responses were for elements of structures or localised effects such as impacts, rather than indications of the overall responses of complete structures. Such records are important, however, for demonstrating that some elements of structures can be subjected to much stronger accelerations than the structure as a whole, and that these elements should be designed for amplified motions. In a number of cases, the instrumentation seems to have been installed with the intention of recording such motions. There are also a number of instrumentation layouts that appear to have been designed to study possible whiplash effects at the tops of buildings, to study the effects of embedded basements, and to monitor the responses of adjacent but supposedly seismically separated parts of structures. There are records from a building (Van Nuys Holiday Inn) that experienced major damage with column failures in this earthquake. This building also suffered minor structural damage in the 1971 San Fernando earthquake when it was also instrumented, although less extensively than in 1994. Another building (Sheraton Universal Hotel) that was also instrumented in 1971 suffered considerable non-structural damage in both earthquakes. Also, the Hollywood Storage Building that has been the subject of several studies of soil-structure interaction effects was more fully instrumented in this earthquake. The County Hospital at Sylmar experienced extremely strong ground and response accelerations without structural damage. For the first time, the responses of base-isolated buildings to strong ground motions were recorded (USC Hospital and Los Angeles County Fire Command Centre). Other instrumented structures included a carpark building and freeway interchange bridges.

Different expectations of the extent of nonstructural damage was a major item of contention between building owners and engineers at the time of the team's visit, so a compilation of 
damage costs for different levels of response would be very useful information from this earthquake in which there were many instrumented structures. Such information would be a useful first step for quantifying whether current life-safety based codes are adequate for prevention of damage and protection of contents, or whether special provision should be made for these functions in a new generation of earthquake design codes.

\subsubsection{County Hospital at Sylmar}

In the northern San Fernando Valley, the exceptionally strong response of $1.70 \mathrm{~g}$ (reported as $2.31 \mathrm{~g}$ in the "Quick Reports") at the roof of the 6-storey County Hospital building at Sylmar has already been noted. This structure contained concrete shear walls in the lower two stories, and steel shear walls at the perimeter of the upper four stories. Instruments were located at the eastern and western ends of the building at the ground, 3rd and 4th floors and at the roof level to measure the northsouth responses, and alongside the south wall at the same levels to record the east-west motions. The north-south response at the east wall was stronger than that at the west wall at all levels. The east-west motions were much weaker than the north-south motions, ranging from $0.42 \mathrm{~g}$ at the ground floor to $0.79 \mathrm{~g}$ at the roof. The strong "fault-fling" pulse at the start of the S-wave portion of the ground motion propagated up the structure, and was apparent at all levels. Some other features of the response were coherent also at all levels. The design motions for the County Hospital were much higher than usual code levels, because of the political implications of the failure of a hospital that replaced one that had failed in an earlier earthquake, and must be taken into consideration in evaluating its performance. The high design strength of this building and its strong response suggest that it responded nearly elastically, an unusual feature for this strength of excitation. The structural performance was remarkably good, with no structural damage and only very minor damage to fittings. Also, despite the strong response, there was virtually no damage from shaking to contents of the building. A burst high-pressure water pipe in the machine room on the roof of the building produced flooding and water damage through the building that required its evacuation some hours after the earthquake. Given the excellent performance of this structure, it is very important that detailed analyses of these response records are performed.

\subsubsection{Van Nuys Holiday Inn}

Analysis of the accelerogram records from the Van Nuys Holiday Inn at 8244 Orion Avenue is very important in that the building was damaged significantly, with shear failure of the south wall columns at the 4th floor level (Section 6.3.2(b)). Peak shear responses are usually not expected at this level of a building. There was no simple readily apparent explanation, such as a change in section, for the occurrence of the failure at this level.

The roof response in both horizontal components was $0.59 \mathrm{~g}$. This was much increased from the 6th floor response two levels lower, where the peak recorded accelerations were only $0.34 \mathrm{~g}$ in the north-south direction and $0.48 \mathrm{~g}$ in the east-west direction. This rapid increase in acceleration at the top of the building was consistent with our observations that all the chests of drawers and TV sets on the seventh floor had been toppled over, while this occurred in only one room on the sixth floor.

The records show a marked change in character in the eastwest response between the third floor, below the failed columns, and the sixth floor.
Analysis of these records may provide an explanation of the failure mode, which would seem to require strong contributions to the response from higher-mode effects. To understand the response mechanisms that were at play, it is important to determine whether the higher-mode effects are in response to short-period components of the excitation, or are set up by nonlinear response features. The results may have important implications for how the seismic design loadings should be distributed in the design of yielding structures.

This building suffered some structural damage in the 1971 San Fernando earthquake, in which the peak ground accelerations were about half those experienced in the 1994 Northridge earthquake. A description of the building, the nature of its damage in 1971 and a dynamic analysis of its response in that earthquake is given in the NOAA report on the San Fernando earthquake [Blume \& Associates, in Murphy (ed.), 1973]. The building was repaired after the San Fernando earthquake, and its response was subsequently recorded in the 1987 Whittier earthquake, which it survived without any apparent distress. McVerry [1979] used systems identification techniques to analyse the recorded motions in the 1971 earthquake. Papageorgiou and Lin [1991] used similar techniques to analyse its response in both the 1971 San Fernando and 1987 Whittier Narrows earthquakes.

\subsubsection{Union Bank, 15233 Ventura Blvd and other structures with embedded basements}

The structural response records from Union Bank at 15233 Ventura Blvd ("Sherman Oaks 13-storey commercial building") are important in that the peak recorded response was at ground level, above a 2-storey basement, rather than at the roof. Maximum accelerations at ground-floor level were $0.90 \mathrm{~g}$ in the north-south direction, double the value of $0.46 \mathrm{~g}$ for this component of the basement acceleration, but only $0.39 \mathrm{~g}$ in the east-west direction. The structure filtered out the higherfrequency components, producing roof accelerations of $0.65 \mathrm{~g}$ north-south and $0.26 \mathrm{~g}$ east-west, in a motion with a period of about $1.0 \mathrm{~s}$.

If maximum response at ground level rather than at basement level is a general feature of the response of buildings with embedded basements, it may have important design implications. The two basement levels have concrete shearwalls, and the ground floor is of double height, so there seems likely to be a soft storey at this level, immediately above the location of the ground-floor accelerograph. The east-west component of the response from the first floor of the Los Angeles 19-storey office building (CSMIP Station No. 24643) showed similar features, with a peak acceleration of $0.53 \mathrm{~g}$ which was stronger than that at several higher levels. Like the Union Bank, this structure had a more than double-height floor at ground level, so it appears that a marked change in stiffness contributed to the amplified response at this level. The USGS records from the 12-storey building at $900 \mathrm{~S}$. Freemont also showed the strongest recorded response at a low level in the structure, with $0.13 \mathrm{~g}$ in the basement in the north-south direction amplified to $0.60 \mathrm{~g}$ at the $2 \mathrm{nd}$ floor, and then reduced at higher levels, to $0.24 \mathrm{~g}$ at the 6 th floor and $0.11 \mathrm{~g}$ at the 12 th floor.

The Union Bank building suffered some damage in 1971, when it was uninstrumented, and again in 1994. The 1994 damage was repaired by the end of the second week after the earthquake. When we passed by the site 12 days after the earthquake we were unaware that the building was instrumented and that damage had occurred. 


\subsubsection{Burbank 10-storey residential building (Pacific Manor)}

Important information may be obtained from analysis of the records for the 10-storey Burbank residential building (CSMIP Station 24385), including the degree of linearity of the response, the extent of any changes in the effective modal periods in the course of the motion, and the damping in motions that were probably less than design-level ground motions but which may have exceeded design yield levels, given the margin between elastic and inelastic design spectra. The peak accelerations of the horizontal components of the recorded first-floor motions were $0.28 \mathrm{~g}$ and $0.35 \mathrm{~g}$. The response was amplified to $0.79 \mathrm{~g}$ at the roof.

The recorded response of this Burbank building was notable for the almost complete absence of high-frequency components at the eighth floor level in both directions, although these components were present in the records from higher and lower levels. This feature resulted from a judicious choice of instrument locations, at approximately one-third and two-thirds height near antinodes and nodes for the second mode, so that first and second mode responses are virtually separated out at different locations.

\subsubsection{Hollywood Storage Building}

A number of records have been obtained from the Hollywood Storage Building basement and parking lot (free-field) sites over the last 40 years, including from the Kern County 1952, San Fernando 1971 and Whittier 1987 earthquakes. There have been several studies of the effects of soil-structure interaction using these records [Housner, 1957; Crouse and Jennings, 1975; Papageorgiou and Lin, 1989; Fenves and Serino, 1990] Prior to the Whittier earthquake, the structure itself was instrumented to allow a more thorough study of these effects on the structural response, rather than just the modification of the motions between the free-field and basement sites. The free-field and basement accelerations of $0.41 \mathrm{~g}$ and $0.29 \mathrm{~g}$ recorded in the Northridge earthquake are about double the strongest values recorded in earlier earthquakes. Very strong accelerations of $1.61 \mathrm{~g}$ were recorded at the roof in the eastwest direction, but these appear to be associated with an impact effect, as there are 12 high-frequency spikes of remarkably consistent amplitude in this component of the record. The absence of these spikes in records from other locations in the building suggests that there was some problem with the mounting of this particular transducer, as an impact of the structure itself should have been apparent in records from throughout the building.

\subsubsection{Six-storey carpark building}

An unusual structure to be instrumented was a 6-storey parking building in Central Los Angeles. This carpark building was listed as having a peak structural response of $1.21 \mathrm{~g}$ and a peak base motion of $0.29 \mathrm{~g}$. These values were some of those that gave rise to the perception of high levels of structural response and strong structural amplification in this earthquake. In fact, the $1.21 \mathrm{~g}$ acceleration occurred in high-frequency motions of a roof parapet, with a much lower-frequency response of somewhat lower amplitude, $0.84 \mathrm{~g}$, at its support level. Nevertheless, the peak acceleration response of the shear wall at roof level in this nominally north-south direction (actual orientation $30^{\circ}$ ) was amplified by about a factor of 3 from the first floor acceleration of $0.28 \mathrm{~g}$, while the presumably stiffer east-west direction, corresponding to the direction of the central core shear walls and the ramps between floors, showed much lower motions, $0.15 \mathrm{~g}$ at the first floor amplified to $0.31 \mathrm{~g}$ at the roof. A girder at roof level showed a strong modulated vertical response of $0.52 \mathrm{~g}$. Given the collapse of a number of parking buildings in this earthquake, these records will no doubt receive considerable scrutiny. It was the opinion of the structural engineers in the team that the collapses of the parking buildings that they studied were caused by factors other than merely strong excitation and response accelerations.

\subsubsection{I10/405 Interchange}

The records (Figure 4.13) from the I10/405 Interchange between the Santa Monica (I10) and San Diego (I405) Freeways showed peak accelerations of $1.00 \mathrm{~g}$ horizontally and $1.83 \mathrm{~g}$ vertically on the structure near the west abutment. This interchange was about $6 \mathrm{~km}$ west of the section of the Santa Monica Freeway that collapsed during the earthquake. The strong accelerations recorded on this structure were being cited as evidence of strong structural responses in the earthquake. However, examination of the records shows spike-like behaviour, in particular on many occasions in the vertical component. These spiky peaks can be interpreted as the results of impact, with the true structural response motions being much lower. The response measured on channel 4 in the transverse direction at deck level at a pier location about 60 metres from the west abutment appears to be a much more faithful record of the deck response, with a peak acceleration of $0.52 \mathrm{~g}$. The peak acceleration occurred about 5.2 seconds after the initial $\mathrm{S}$ wave, corresponding to the subevent.

\subsubsection{Sheraton-Universal Hotel}

The Sheraton-Universal Hotel experienced basement accelerations of $0.32 \mathrm{~g}$ in the north-south component and $0.13 \mathrm{~g}$ in the east-west component. The accelerations were amplified to $0.66 \mathrm{~g}$ and $0.34 \mathrm{~g}$ respectively at the roof of the 20 -storey building (Figure 4.14). The strong ground acceleration in the north-south direction was associated with a pulse from the subevent that propagated, with some amplification, up the structure. A striking feature of the response records was the stronger responses of the sites near the western end of the building than those at the east wall at all levels up the structure. The peak north-south response at the roof was $0.66 \mathrm{~g}$ for the western site, but only $0.39 \mathrm{~g}$ at the east wall. Similar behaviour was observed in the Whittier Narrows earthquake, with Papageorgiou and Lin [1991] showing that it was caused by torsional response. This torsional response resulted from the centre of gravity of the floors above the second being offset from the shear centre for the first two floors, combined with the effects of heavy air-conditioning and heating equipment in the top floors of the building being offset from the centres of the floors.

The Northridge earthquake produced records from a number of other instrumented structures that showed effects indicative of torsional response. Examples include the 7-storey UCLA Math-Science Building where $0.49 \mathrm{~g}$ was recorded on the roof at the west wall and $0.77 \mathrm{~g}$ at the east wall in the north-south response. At the Bullocks Century City Building (CSMIP Station 24332, identified as Los Angeles 3-storey Commercial Building), $0.97 \mathrm{~g}$ was recorded on the roof at the south wall, with only $0.72 \mathrm{~g}$ at the north wall.

The Sheraton-Universal Hotel suffered slight nonstructural damage in 1971 . When team members visited the building two weeks after the Northridge earthquake, it was closed for 
SENSOR LOCATIONS

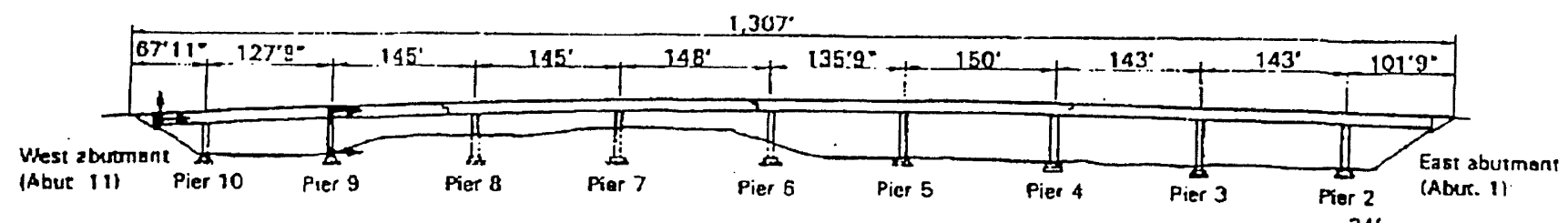

Elevation

Structure Reisrence

Orientation: $\mathrm{N}=10^{\circ}$

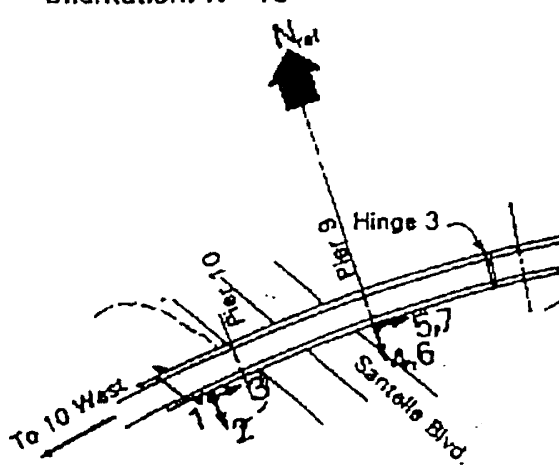

Was: aburmont

Sensors 6 \& 7 mounced on column:

Other censars mounted on dock
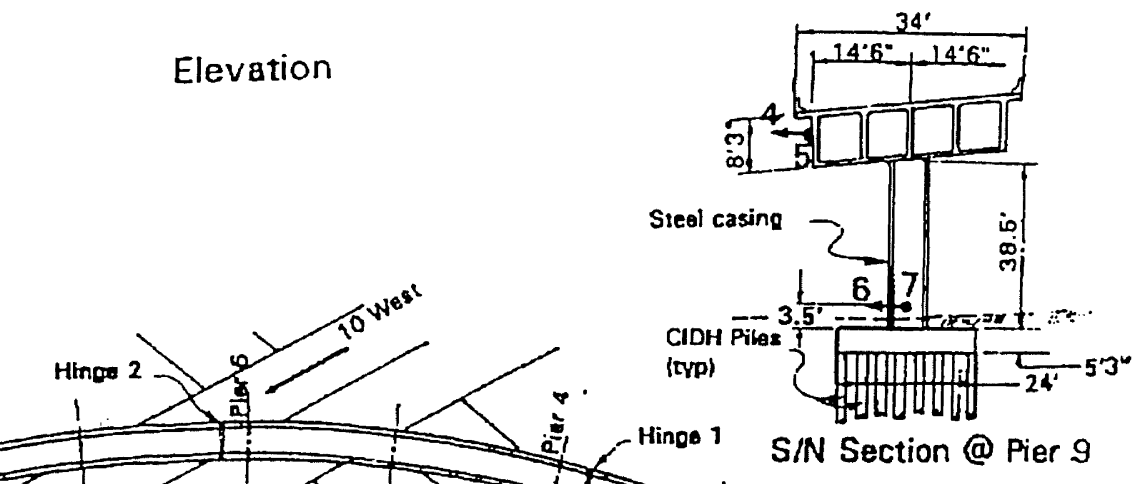

Hinos 1 S/N Section@Pier 9

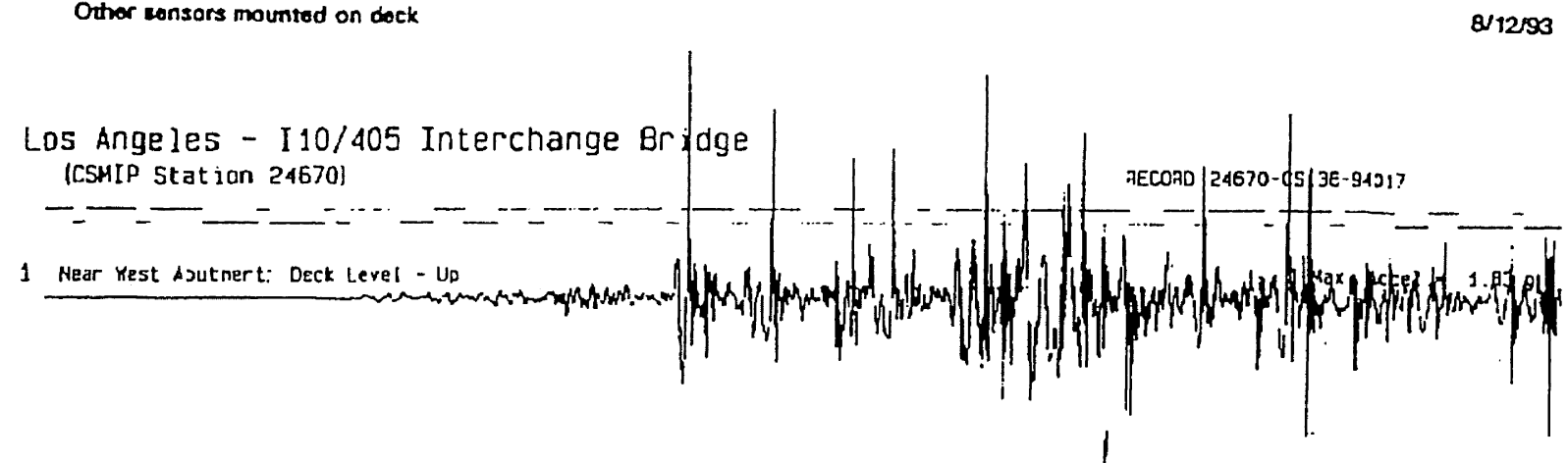

Plan
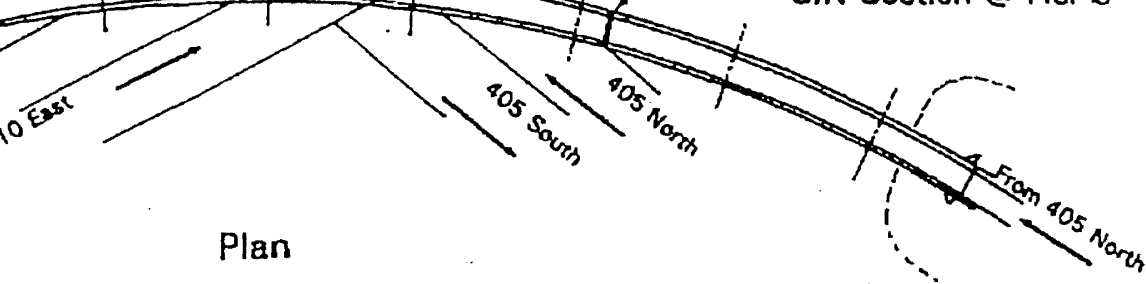

East abutmant

8/1293

3 Near Nest ndes:ment: Dezk _evel - E

2 Nerr hest etutaent: Decx Leve1 - s

4 Pler 9: Deck Lavai - 5

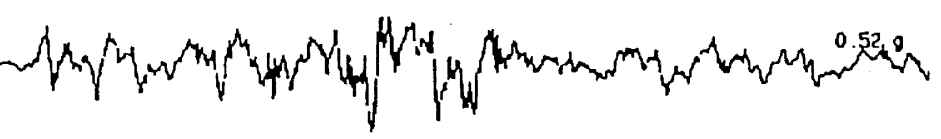

FIGURE 4.13. CSMIP records from the 110/405 Interchange Bridge, $6 \mathrm{~km}$ from the collapsed section of the 110 (Santa Monica) Freeway. The spikes giving peak accelerations of $1.83 \mathrm{~g}$ vertically and $1.0 \mathrm{~g}$ horizontally near the west abutment have the character of impacts, with the $0.52 \mathrm{~g}$ maximum horizontal acceleration at the deck level at the nearby Pier 9 appearing more representative of the Interchange response. These records contributed to the initial impressions of exceptionally strong motions in this earthquake, apparently being interpreted in some quarters as ground motions. [From CSMIP Second Quick Report]. 
North Hollywood - 20-story Hotel (CSMIP Station No. 24464)

\section{SENSOR LOCATIONS}

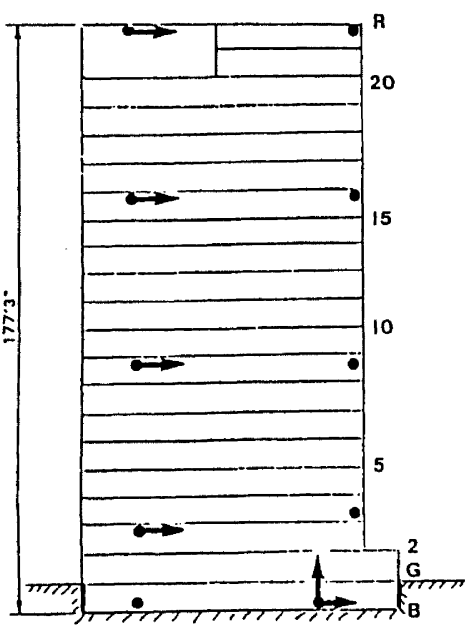

W/E Elevation

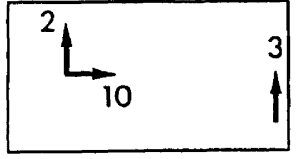

Roof Plan

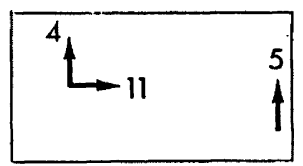

16th Floor Plan

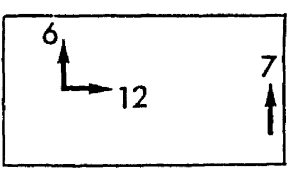

9th Floor Plan

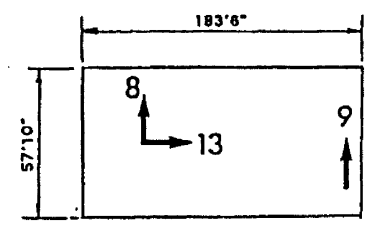

3rd Floor Plan

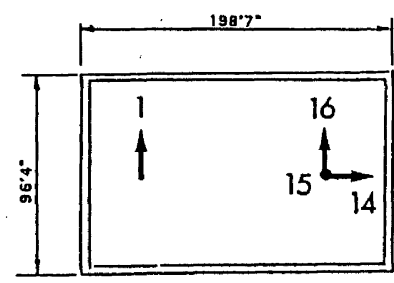

Basement Plan

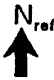

Structure Referenco Orientation: $\mathrm{N}=0^{\circ}$

(1)

13 (3) Floor: West Wall -E E

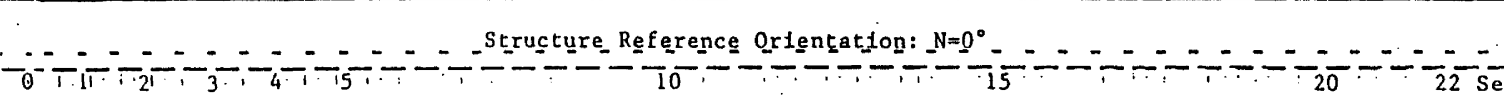

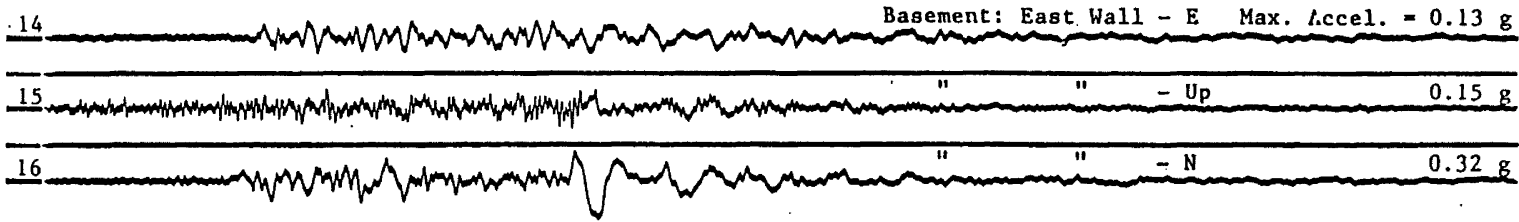

FIGURE 4.14. Basement and response records from the Sheraton-Universal Hotel (CSMIP). Note that the strong north-south pulse at 9 seconds after triggering in the basement record associated with the sub-event is propagated throughout the structure, with considerable amplification in the upper storeys. Also, the responses are stronger near the west wall than near the east wall, presumably because of torsional response. [From Shakal et al., 1994a]. 
refurbishment of the interior, required, we were told, because of earthquake damage. This building was one of many that appeared to have suffered non-structural damage that were perhaps in line with the expectations of engineers for motions that were around code-level but far in excess of the expectations of the building owners. This gulf between owner's expectations and the intentions of current life-safety based seismic codes seems likely to be an issue of lively debate over the next few years.

\subsubsection{Los Angeles 17-storey residential building}

One of the features of the response records from this building is the illustration of the contribution of higher modes to the responses of buildings with even moderately long-period response. There was a large increase in the maximum acceleration response over the top third of the building, between the 13th floor and the roof, from $0.20 \mathrm{~g}$ to $0.54 \mathrm{~g}$ in the centre of the building. However, the 13th floor location is approximately a node for the 2 nd mode in both directions, as confirmed by the appearance of the 13th floor records which are reasonably sinusoidal in appearance with a period of about $1.0 \mathrm{~s}$. On the other hand, the 7 th floor records are dominated by the second mode, at about $0.3 \mathrm{~s}$ period, with amplitudes similar to or greater than the 13th floor responses. Although the fundamental mode responses were amplified between the 13th floor and the roof, much of the difference in the peak acceleration responses at these locations appears to result from the superposition of the second mode response on the fundamental mode response at the roof, while the second mode makes little contribution at the 13th floor.

\subsubsection{Los Ängeles 52-storey and 54-storey Office Buildings}

The records from the Los Angeles 52-storey office building (CSMIP station 24602) also show the effects of higher modes in a tall building. It is difficult to pick out the building's fundamental mode periods, presumably several seconds, directly from the acceleration history plots. There were sharp increases in the peak acceleration responses between the 49th floor and the roof, from $0.13 \mathrm{~g}$ to $0.41 \mathrm{~g}$ in the north-south component and from $0.13 \mathrm{~g}$ to $0.23 \mathrm{~g}$ in the east-west component. There are considerable setbacks between these levels. The marked amplification that occurred in the top part of this structure is an illustration of the whiplash effect that often results from a reduced section at the top of a tall structure. Similar but less marked effects occurred between the 46th floor and the penthouse of the 54-storey building. Highly amplified responses near the top of tall buildings may have important implications for the seismic design of building services equipment which is often housed in this part of a building.

\subsection{Response Records - Base-Isolated Buildings}

The Northridge earthquake provided the first records of the response of base-isolated structures to strong earthquake ground accelerations. Two buildings, the USC Hospital and Los Angeles County Fire Command Centre (LACFCC), experienced strong peak ground accelerations, $0.37 \mathrm{~g}$ and $0.22 \mathrm{~g}$ respectively. Other instrumented seismically-isolated structures were subjected to lesser ground motions. These structures included the Rockwell Corporation building at Seal Beach, the San Bernadino County building at Rancho Cucamonga, and the retrofitted Santa Ana pipe bridge. In addition, records were obtained from an apartment building in the Westwood area that was understood to have been designed incorporating an isolation system.
Members of the New Zealand Reconnaissance team visited the LACFCC building. Additional information on this structure and other isolated structures in the Los Angeles area was kindly provided by Caltech graduate student Marvin Halling, including measurements of the amount of movement across the isolation systems for several of the buildings.

\subsubsection{USC Hospital}

The highly irregular eight-storey USC Hospital (Figure 4.15) is a steel-braced frame structure isolated on a combination of lead-rubber bearings, mainly around the perimeter of the base, and elastomeric bearings. A description of aspects of the seismic isolation design is given by Asher et al [1990].

The peak accelerations at the USC Hospital site occurred in the subevent that appeared in these records about 6 seconds after the initial S-wave. The peak acceleration of $0.49 \mathrm{~g}$ was reduced to $0.37 \mathrm{~g}$ on the foundation slab below the isolators, presumably because the slab was stiff enough to filter out the higher frequency components, although the basic waveform was maintained. At instrument position 9, immediately above the isolators, the accelerations were reduced dramatically as expected in a base-isolated structure, to $0.13 \mathrm{~g}$. The records from the 4th and 6th floor level show very similar motions, indicating that this part of the building moved essentially as a rigid box, with no amplification in the structure, again as expected for a well-isolated building. The roof response showed some amplification, to $0.21 \mathrm{~g}$, resulting from the change in plan area above the 6th floor level.

While this earthquake provided the strongest ground motions that have been recorded to date for base-isolated structures, the motions in this part of Los Angeles were considerably less than code-level motions except in the short-period range. Larger earthquakes are likely to produce motions for which the longperiod ( $>1-2 s$ ) components of the spectra critical for baseisolated structures are much stronger. However, the nature of the ground motions in this earthquake and the response of USC Hospital demonstrate one advantage of base-isolation. Earthquakes such as this one that are of moderate magnitude can produce strong short-period motions exceeding code-design levels, but strong long-period motions are unlikely at most sites except in large magnitude events. Base-isolation moves the effective period of the structure into a range that for moderatemagnitude earthquakes is likely to contain much less energy than the short-period range.

USC Hospital is highly irregular in both plan and elevation. This irregularity would probably lead to problems in the seismic response of a conventional ground-mounted structure. Isolation overcomes the problems associated with the irregularity in plan, although, as mentioned above, the change in vertical section had the effect of amplifying the motions in the top part of the building from those lower in the structure, although to lower amplitudes than the ground motions.

\subsubsection{Los Angeles County Fire Command Centre}

The Los Angeles County Fire Command Centre (LAFCC) is a two-storey building isolated on laminated steel and rubber bearings. The bearings contain a linked chain which controls the displacements when they exceed the design maximum. Anderson [1990] and Bachman et al. [1990] describe various aspects of the design. The building has perimeter braced steel frames to give a stiff structure above the isolators. Our team inspected this building from the outside and underneath, but did not obtain access. 
Los Angeles - 7-story University Hospital (CSMIP Station No. 24605)

SENSOR LOCATIONS

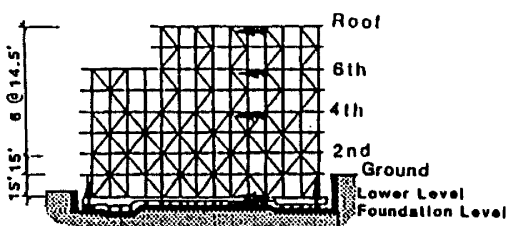

North Elevation

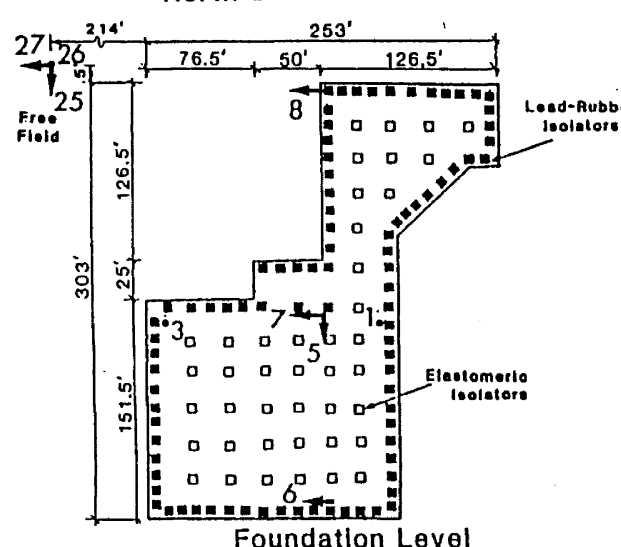

Foundation Level

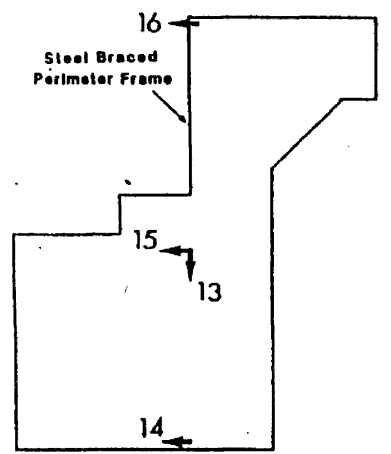

4th Floor Plan

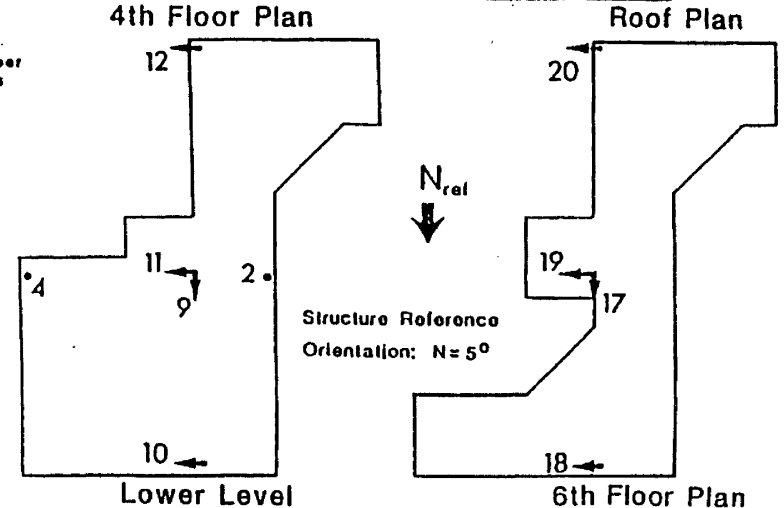

Lower Level 6th Floor Plan

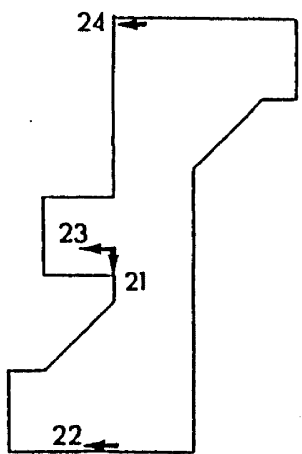

Roof Plan

Los Angeles - 7-story University Hospital (CSMIP Station 24605)

(Above Isolators)

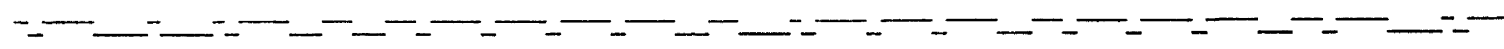

21 Roof: Center -

17 6th Floor: Center - N

13 4th Floor: Center - N

9 Lower Level: Center - N

5 Foundotion Level: Center - 1 .

25 Free fleld: - N

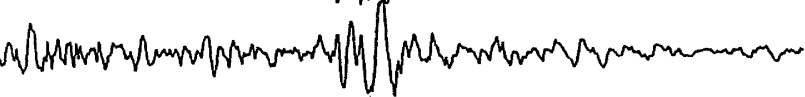

4 Lower Level: East Hall - Up

3 Foundstion Level: East Wall - Up

2 Lower Level: Hest Hall - Un

1 Foundation Level: Hest Hall - Up

26 Free fleld: - Up

Structure Reference or dentation: $N-5^{\circ}$

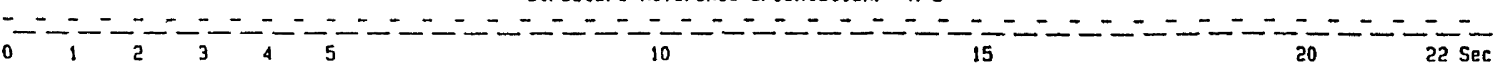

FIGURE 4.15. CSMIP records from the highly irregular base-isolated USC Hospital, showing the response to the strongest excitation recorded in a base-isolated structure. The records demonstrated that the isolation system functioned as expected, with a reduction of the basement acceleration from $0.37 \mathrm{~g}$ to $0.13 \mathrm{~g}$ across the isolator layer, with this level of response being maintained up the structure apart from amplification at the change of section in the top two levels. [From Shakal et al., 1994a]. 
The response of this building was different in character from that expected in an isolated structure. In the east-west direction, the peak recorded acceleration of $0.32 \mathrm{~g}$ at the roof exceeded the foundation level motions of $0.22 \mathrm{~g}$. The recorded east-west response from all but one location in the structure above the isolators was marked by regular high-frequency pulses (Figure 4.16). The exception was the response recorded near the south wall at the 2 nd floor, where the pulses were just discernible. The motion at this location was medium- to longperiod in character, with cycles of $1.0 \mathrm{~s}$ to $1.5 \mathrm{~s}$ in duration. The peak amplitude at this location was $0.14 \mathrm{~g}$, a reduction of the foundation accelerations. The high-frequency pulses were present in the north-south motions at the same times as they occurred in the east-west response, but were much lower in amplitude. The peak acceleration of $0.09 \mathrm{~g}$ at the roof in this direction was reduced from the peak acceleration at the foundation of $0.18 \mathrm{~g}$.

The cause of the unexpected high-frequency pulses in the records from this building was impact of the building and entrance way bridge near the north-eastern end of the building. The bridge that gave access to the building over the moat-type "rattle-space" required to accommodate the displacements across the isolation bearings was designed with a pop-out detail that was intended to allow it to slide in high amplitude motions. The pop-out detail leads to damage of some overlying tiles when it is called into play. However, following damage to the tiles in a previous earthquake, the detail had been changed to reduce tile damage, but impeding sliding of the bridge [Bachman, 1994]. The strengthened joint prevented sliding of the bridge, causing impact between the building and entrance-way that produced the regular spikes on each eastwest displacement cycle.

This problem illustrates the vigilance needed to preserve the isolation gap throughout the lifetime of an isolated structure. Minor changes to important details can prevent the isolation system functioning as intended. In these situations, it is possible that the loadings can be increased even from those with a locked isolation system, because of impact effects such as occurred in this building. With the structure above the isolators often having reduced strength and ductility capacities compared with conventional structures, these unexpected high forces could have serious consequences.

\subsubsection{Other instrumented isolated structures}

There were several other isolated structures in the Los Angeles region for which response records were obtained in the Northridge earthquake: Seal Beach 8-storey building (Rockwell building), 1955 1/2 Purdue Avenue (near UCLA) and Rancho Cucamonga Law and Justice Centre.

The Seal Beach building is an example of retrofitted isolation. Lead-rubber bearings were installed in the columns between the first and second floor, with a basement level beneath the isolators as well. Gates et al. [1990] give details of the modal properties of the building before the retrofit, while Sveinsson et al. [1990] describe some of the analysis performed for the retrofit design.

In the north-south direction, the records of the building's response in the Northridge earthquake showed the expected change in character of the response across the isolation level. There was a reduction of the higher-frequency components, but there was a doubling of the response from $0.06 \mathrm{~g}$ to $0.12 \mathrm{~g}$ between the 6 th (top) floor and the roof. The records show the acceleration response at the roof having dominant periods of $0.4 \mathrm{~s}-0.6 \mathrm{~s}$, far too short for an effective isolation system, although a period of about $1.1 \mathrm{~s}$ is also obvious at the 6th floor. The response characteristics of this building in this earthquake appear more complicated than for most base-isolated buildings, with the response certainly not being dominated by a single long-period mode. In the low-level excitation in this building, it is possible that the isolators did not yield, so that the isolators did not come into full play. It also seems possible that the placement of the isolators part way up the structure may be a factor in the complicated response characteristics. None of our team visited this building.

The response characteristics of the three-storey residence at $19551 / 2$ Purdue showed none of the features expected of an isolated structure. This structure is mounted on helical springs and dashpots. The levels above the isolators had highfrequency components in their response that were not present at the basement level. The peak horizontal accelerations were amplified from $0.44 \mathrm{~g}$ at the basement to $0.63 \mathrm{~g}$ at the $3 \mathrm{rd}$ level, and the vertical acceleration from $0.16 \mathrm{~g}$ at the base to $0.46 \mathrm{~g}$ at the first level and $0.46 \mathrm{~g}$ at the third level. Our team obtained no details of the parameters of the isolation system for this building. On the evidence of the recorded motions, the building does not appear to be isolated from the dominant frequencies of earthquake motions.

The Rancho Cucamonga Law and Justice Centre was $90 \mathrm{~km}$ from the epicentre of the Northridge earthquake. Isolation is provided by high-damping rubber bearings which have amplitude-dependent dynamic response characteristics. The peak horizontal acceleration in the basement of the building was $0.05 \mathrm{~g}$, unlikely to be sufficient for the isolation system to display its large-amplitude characteristics. The motions were amplified to a maximum roof response of $0.10 \mathrm{~g}$. Amplification of low-amplitude motions is not unexpected in a building with a nonlinear isolation system. None of our team inspected this building.

\subsection{Conclusions}

The Northridge earthquake produced a large number of ground and structural response records. There were some very strong ground motion records from near the fault rupture zone in the northern part of San Fernando Valley with peak ground accelerations of around $0.9 \mathrm{~g}$, far in excess of code levels. There seemed to be systematically higher accelerations around the shallower part of the rupture surface to the north and northeast than at the epicentre, $18 \mathrm{~km}$ above the focus. Other parts of the region experienced much less severe motions. For example, peak ground accelerations of around $0.2 \mathrm{~g}$, somewhat less than code-level motions, were typical in central Los Angeles.

Consideration of the earthquake ground motion records as a whole shows that contrary to popular belief, exceptionally strong vertical accelerations, or vertical accelerations stronger than the horizontal components, were not a general feature of the near-source zone of this earthquake. This misconception arose from this unusual feature occurring in one of the records retrieved from near the epicentre at an early stage after the earthquake.

Another misconception was that there was a geographically wide spread of recorded peak ground accelerations exceeding 1g. Very strong records were obtained at the Tarzana site and 
Los Angeles - 2-story Fire Command Control Bldg. (CSMIP Station No. 24580)

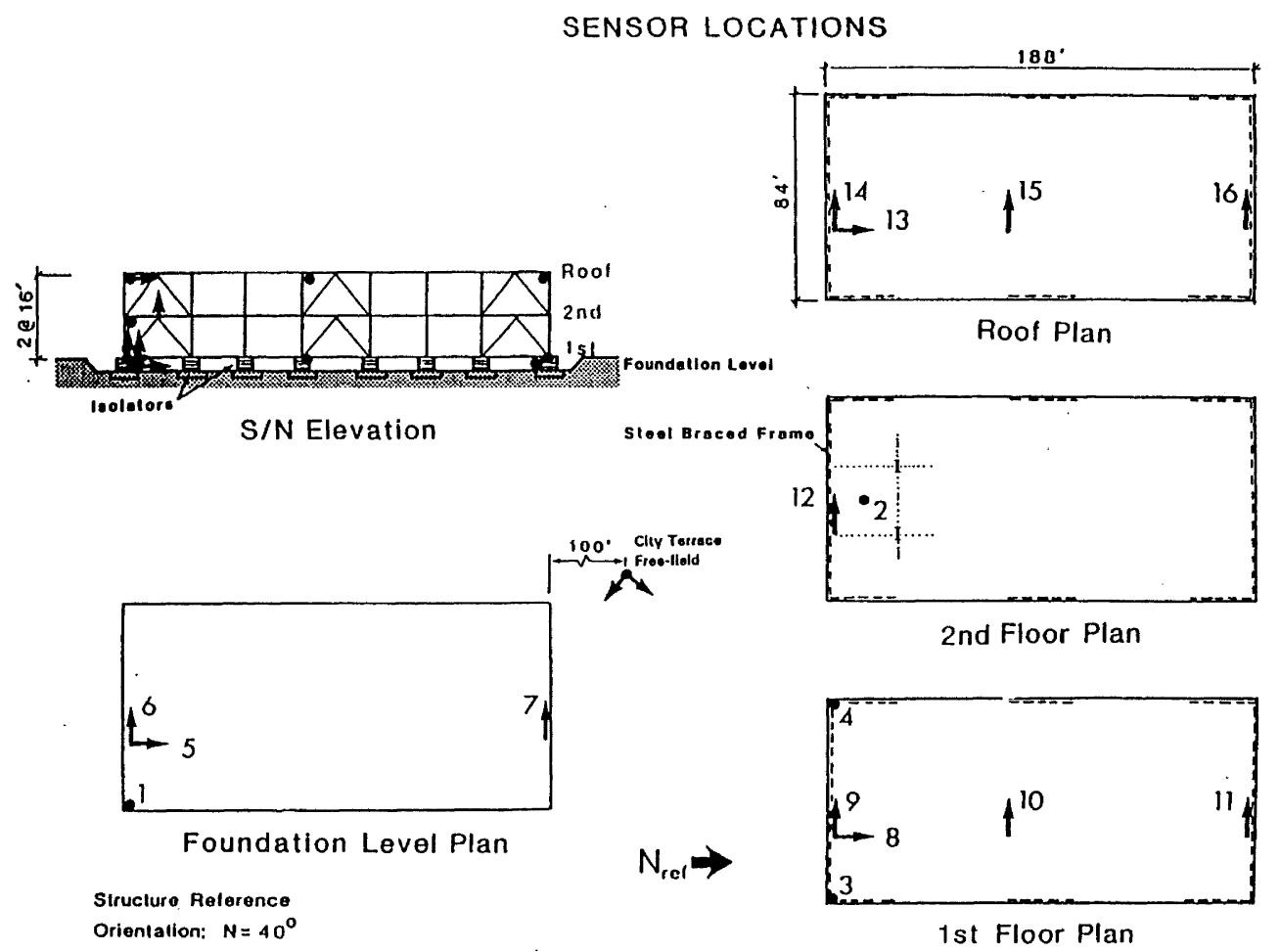

FIGURE 4.16. Recorded motions of the base-isolated Los Angeles County Fire Command Control Building (CSMIP). The reduction of the basement accelerations expected in the response of a base-isolated structure was marred in the east-west components by a minor impact problem with tiles placed across the seismic separation between the building and an entrance walkway near the NE corner of the building, producing the regular spikes on the records. [From Shakal et al., 1994a]. 
on the abutment of the Pacoima Dam, but other recorded motions exceeding $1 \mathrm{~g}$ were not ground accelerations, but rather involved impact or localised effects in structures.

There were examples of records from some sites that appeared to have been affected by liquefaction at depth. These records were lacking in high-frequency content compared with records from nearby sites, and showed reduced peak accelerations, but nevertheless reached up to $0.62 \mathrm{~g}$, compared with up to $0.98 \mathrm{~g}$ at neighbouring sites.

There was a large variation in the strengths of ground motions and levels of damage in this earthquake, but in general marked correlations with surface soil conditions were not obvious, unlike in San Francisco in the Loma Prieta earthquake. The most heavily damaged areas in the San Fernando Basin were on recent sediments rather than rock, but care needs to be taken in interpreting this observation in that there was little rock at the surface in the near-source zone. Correlations of damage with ground condition types could well be misleading, in that they may merely reflect the relative incidence of ground condition types in the near-source zone. As exceptions, it seems from the lack of extensive damage in the area that the very strong ground accelerations recorded at the Cedar Hills Nursery in Tarzana may have been localised and presumably linked to ground conditions or topographic effects, and topographic effects almost certainly contributed to the much higher accelerations on the abutment of Pacoima Dam than on the floor of the canyon a few hundred metres away.

Important sets of structural response records were also obtained in this earthquake.

There was a set of records from a building, the Van Nuys Holiday Inn, that suffered major structural damage. Such records are still very rare. The records from this building are particularly important in that records had been obtained previously in this structure from less damaging motions in the 1971 San Fernando earthquake, as well as from much weaker motions in the 1987 Whittier earthquake.

Very strong ground motions and structural responses were recorded in an essentially undamaged building, the County Hospital at Sylmar. This hospital was designed for motions much in excess of typical code levels for the Los Angeles region.

Notable records were obtained of the responses of base-isolated structures, the USC Hospital and the Los Angeles County Fire Command Centre, to earthquake motions with strong peak ground accelerations. The Hospital performed exceptionally well, as expected, with the peak recorded accelerations reduced considerably from the peak ground accelerations. The records from the Fire Command Centre showed regular high-frequency spikes superimposed on the expected low-amplitude, lowfrequency response. The spikes resulted from impact with tiles placed across an intended seismic separation joint of the entrance-way bridge. The detailing of the placement of these tiles had been changed during repair of previous tiles that had popped out, as designed, in an earlier earthquake. The response of this building was an excellent demonstration of the need for vigilance throughout the life of a seismically-isolated structure to maintain the required separations between the isolated superstructure and its surroundings.

When all records are recovered, there should be many of ground and structural motions of approximately code-design level for Southern California that could serve as a very good database for correlating with structural performance and levels of structural and non-structural damage in buildings.

\section{GEOTECHNICAL FEATURES}

\subsection{Introduction}

The epicentre of this event is located within The Los Angeles basin. The geologic structure of the area is a basin of $120 \mathrm{~km}$ by $30 \mathrm{~km}$, with a long axis running $\mathrm{NW}$, being primarily of Holocene and Pleistocene sands and silts to a very considerable depth, at some locations in excess of $8 \mathrm{~km}$. The depth to "bedrock" or a deposit of rock like material is difficult to ascertain in most locations.

Generally the geological interpretation may be explained by the Holocene deposits being found in the area of the old Los Angeles river where penetration values at depths of engineering significance are of the order of 15-20. The Pleistocene deposits yield penetration values in excess of 25 . The depth to the phreatic surface was usually unavailable and field evidence of the water table absent at most sites visited.

It became evident early in the reconnaissance that the local site conditions and geotechnical features of the basin had not played an obvious significant role in the pattern and intensity of damage to most facilities. The geotechnical role in most of the dramatic damage was small and of secondary importance to the lateral loads induced by the level of ground shaking. While this is true it is thought there was wide spread subsurface liquefaction and associated ground movements as evidenced by road, curb and buried pipeline distress. There was little direct surface evidence of liquefaction except for the areas discussed later in this report.

Landslides and rock spalling occurred as a result of ground motion at several sites in The Los Angeles area. The most dramatic of these events is the slides in the coastal bluffs of The Pacific Palisades in Santa Monica where the road was partially closed for four days.

A more detailed account follows of the sites visited where geotechnical features had a major impact.

\subsection{Description of Sites Visited}

\subsubsection{Liquefaction and Spreading at Kings Harbour}

Kings Harbour is a marina located in Santa Monica on the Pacific coast and is approximately $50 \mathrm{~km}$ from the epicentre. The liquefaction occurred in Mole B, a finger of reclaimed land extending a few hundred metres into the bay. The mole is approximately 50 metres wide, is $11 / 2 \mathrm{~m}$ above the high water mark and constructed of silty sands over a rock fill. Concrete retaining walls of $1 \frac{1}{2} \mathrm{~m}$ high enclose the mole and are reportedly founded on the rock fill.

The damage occurred in the central portion of the mole with a $2 \mathrm{~m}$ diameter sink hole appearing and subsidence of approximately $0.5 \mathrm{~m}$ occurring over a length of $100 \mathrm{~m}$ by 50 $\mathrm{m}$. The tide was nearly full at the time of the earthquake reducing the effective stresses to a minimum. All services were lost and reportedly a $200 \mathrm{~mm}$ water main ruptured with the resulting possibility of confusing liquefaction damage with the effects of the pipe break. 
Lateral spreading occurred with the retaining walls on the south side bulging outwards $5 \mathrm{~m}$ which left the manholes in the area exposed by $450 \mathrm{~mm}$. Mooring piles in the harbour adjacent to the mole rotated significantly showing that liquefaction occurred in the sea bed adjacent to the mole. These effects are shown in Figure 5.1.

Approximately $1 \mathrm{~km}$ south of Mole $\mathrm{B}$ a lagoon area with a swimming complex sustained subsidence with associated cracking of asphaltic covering and concrete paving. Sand boils of up to $2 \mathrm{~m}$ diameter were still visible ten days after the event indicating the area suffered extensive liquefaction. It appeared that the swimming area had spread down slope towards the sea.

\subsubsection{Potential Landslide at Mullholland Drive, Sherman Oaks}

This area is located on a ridge approximately $15 \mathrm{~km}$ south east of the epicentre in the Santa Monica Mountains. An area of potential instability was evident in the fractured and weathered siltstone of the mountains. The head scarp ran along the road continuously for a distance of approximately $200 \mathrm{~m}$ with cracking of the road and vertical distortion in the road of up to $400 \mathrm{~mm}$. It is possible that some of the roadway was constructed on fill although the majority was in cuttings in the side of the ridge. The geologic structure of the ridge was siltstone dipping at approximately $20^{\circ}$ to the North. The side of the ridge fell away sharply at angles of up to approximately $35^{\circ}$ for $100 \mathrm{~m}$. It was reported that similar ground cracking and distortions had taken place in the 1971 San Fernando event and it was unclear whether the distress from the latest event was further daylighting of the old pattern or whether deformation was continuing. Local residents reported ground movements down slope of up to $300 \mathrm{~mm}$. Figure 5.2 shows the cracking of the road surface.

The area of extensive cracking along the edge of the road had been covered with plastic sheeting to prevent the infiltration of rainwater. Services buried in the street had been fractured in many locations. Local geotechnical opinion was that the area was not moving significantly downslope and people were still occupying their houses although some had decided to leave their homes.

\subsubsection{The Van Norman Reservoir Complex}

This reservoir complex contains the lower and upper San Fernando dams, which no longer retain water, and the relatively new Los Angeles Dam built to replace the lower San Fernando structure which was extensively damaged and almost overtopped by the 1971 earthquake. The complex is at the northern extremity of the epicentral area approximately $15 \mathrm{~km}$ from the epicentre.

The area immediately adjacent to the lower San Fernando dam had experienced widespread liquefaction with numerous sand boils and a large sink hole (diameter $15 \mathrm{~m}$, depth $5 \mathrm{~m}$ ) appearing, as shown in Figure 5.3. Numerous cracks in the crest of the dam were evident, one appearing to run the entire length of the structure. The ground water level was difficult to ascertain but appeared to be approximately $3 \mathrm{~m}$ below the old reservoir floor.

Liquefaction had also occurred in the area of the upper reservoir which also no longer impounds water. A small land slide had occurred on the edge of the reservoir due to liquefaction of the surrounding country.
The Los Angeles dam was the only water retaining structure in the complex at the time of the earthquake. The dam itself had very little structural damage, having settled and moved downstream approximately $40 \mathrm{~mm}$. Piezometric levels within the structure were considered normal after the event and drainage through the embankment was also considered to be at normal pre earthquake rate of flow.

Cracking of the asphaltic lining of the upstream slope of the reservoir was evident, at the southern end mainly. This cracking did not appear to penetrate the embankment material. The connections between the intake structure and the accessway from the dam crest had suffered pounding damage and the walkway experienced a lateral offset of about $60 \mathrm{~mm}$ at one of the joints. After inspecting the dam the general view formed was that it had performed well and little damage was evident. The contrast with the performance of the lower San Fernando hydraulic fill dam was marked.

\subsubsection{The Port of Los Angeles}

The Port of Los Angeles lies approximately $60 \mathrm{~km}$ to the south of the epicentre. The damage to the port facilities was limited to the $150 \mathrm{~mm}$ settlement of a hydraulic fill retained by a rock fill dike, with the adjacent pile supported wharf experiencing $50 \mathrm{~mm}$ of lateral movement. The distortions were sufficient to render the crane inoperable and rapid repairs had been carried out resulting in the wharf returning into service about 10 days after the earthquake. The hydraulic fill dike is thought to have a relative density of approximately $30 \%$ and is $12 \mathrm{~m}$ in height. The ground accelerations in the area were thought to be approximately $0.2 \mathrm{~g}$.

\subsubsection{Pacific Coast Highway Landslides at Santa Monica}

These landslides occurred in the coastal bluffs of the Pacific Palisades. The bluffs, composed of weakly cemented sand, are relatively steep $\left(45^{\circ}\right)$ and of a height of approximately $50 \mathrm{~m}$. The slides appeared to be relatively shallow and of a width of about $80 \mathrm{~m}$.

The result of ground shaking was one house being carried down the slope and three others being precariously positioned hanging at the new crest of the slope with exposed piles intact. These homes were condemned. It is thought that some evidence of topographical amplification was evident resulting in the homes at the top of the slopes experiencing enhanced ground accelerations. Figure 5.4 shows the effects.

\subsubsection{Jensen Filtration Plant}

This filtration plant is situated adjacent to the Van Norman reservoir complex. The site was considered of interest since as a result of the 1971 event significant liquefaction occurred in the area adjacent to the main control building. An inspection of the site failed to reveal any sand boils, however extensive cracking of the sandy fill was evident in the parking lot with vertical offsets of $200 \mathrm{~mm}$. These cracks ran in excess of 50 metres. This parking lot is situated at the top of a $20 \mathrm{~m}$ high slope and reportedly sand boils had been observed at the base of the slope.

The area closely adjacent to the control building had settled some $100 \mathrm{~mm}$, as shown in Figure 5.5. The operators reported several pipe breaks at connections, including the main feeder line, which had forced the facility to close down. It was also reported that an underground tank had risen some $100 \mathrm{~mm}$. 


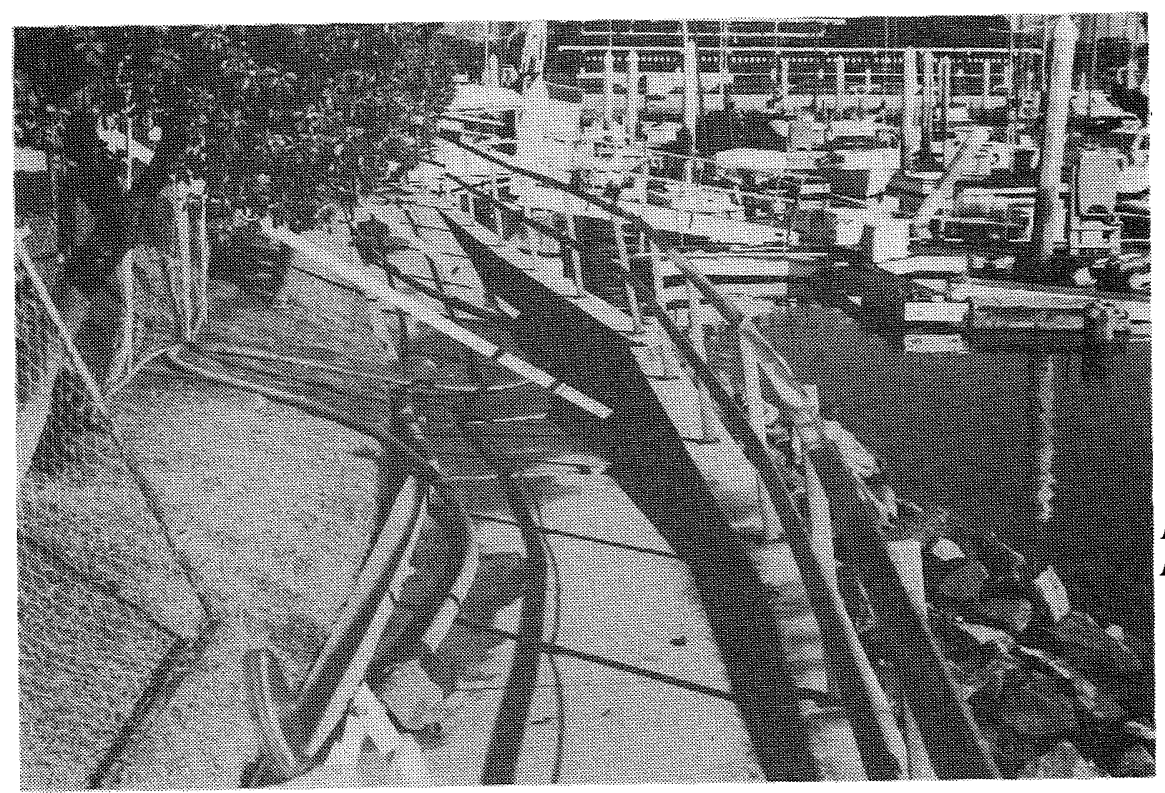

FIGURE 5.1. Lateral spreading at Kings Harbour.

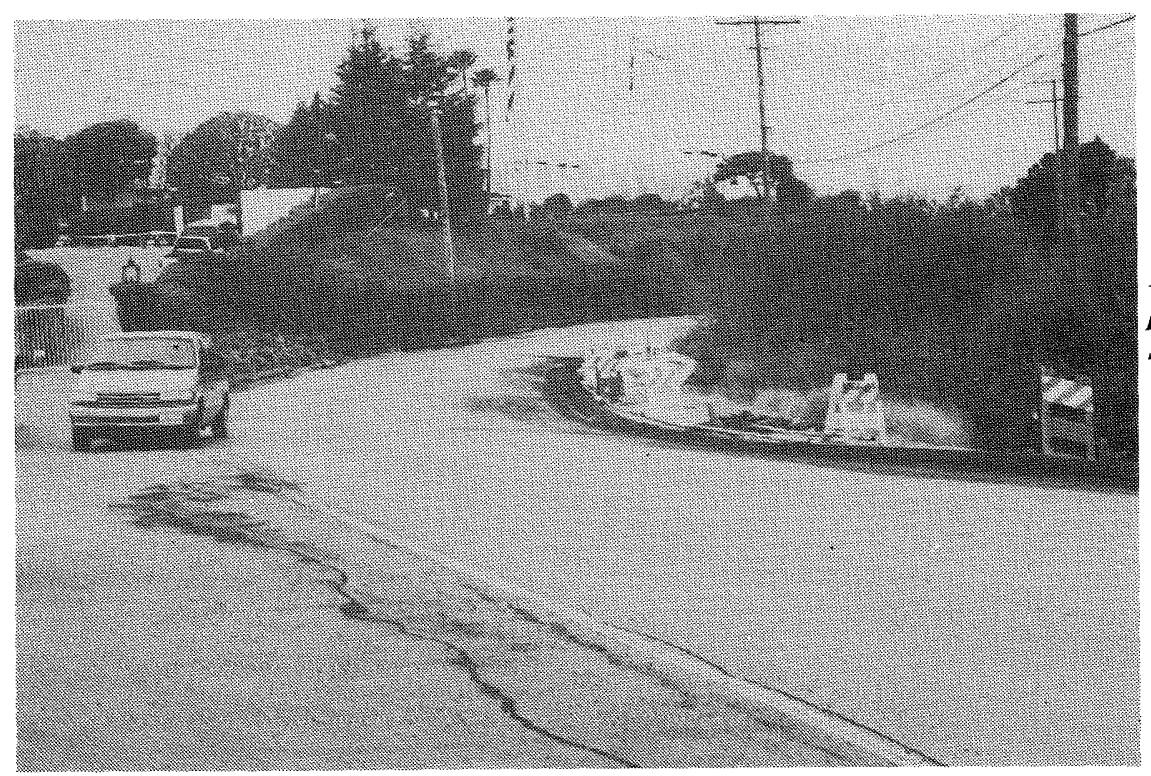

FIGURE 5.2. Road surface cracking at a potential landslide at Mulholland Drive, Sherman Oaks.

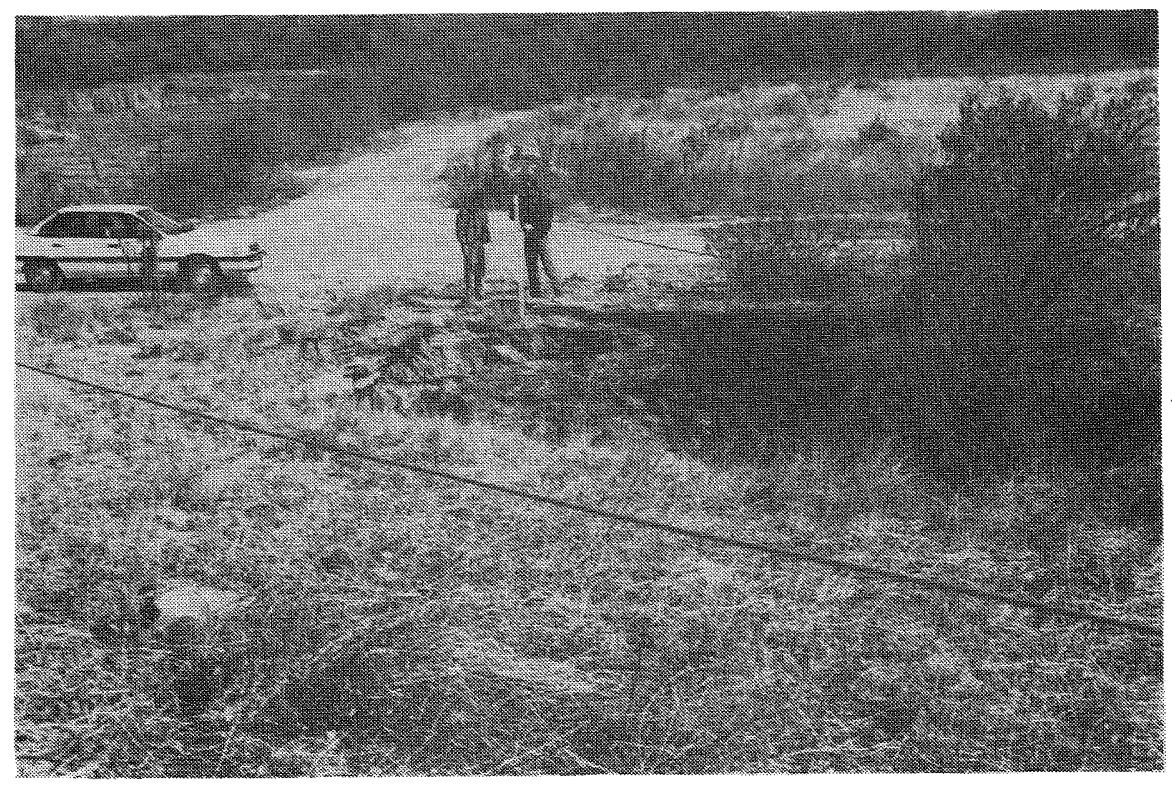

FIGURE 5.3. Large sink hole at the Van Norman Reservoir Complex. 


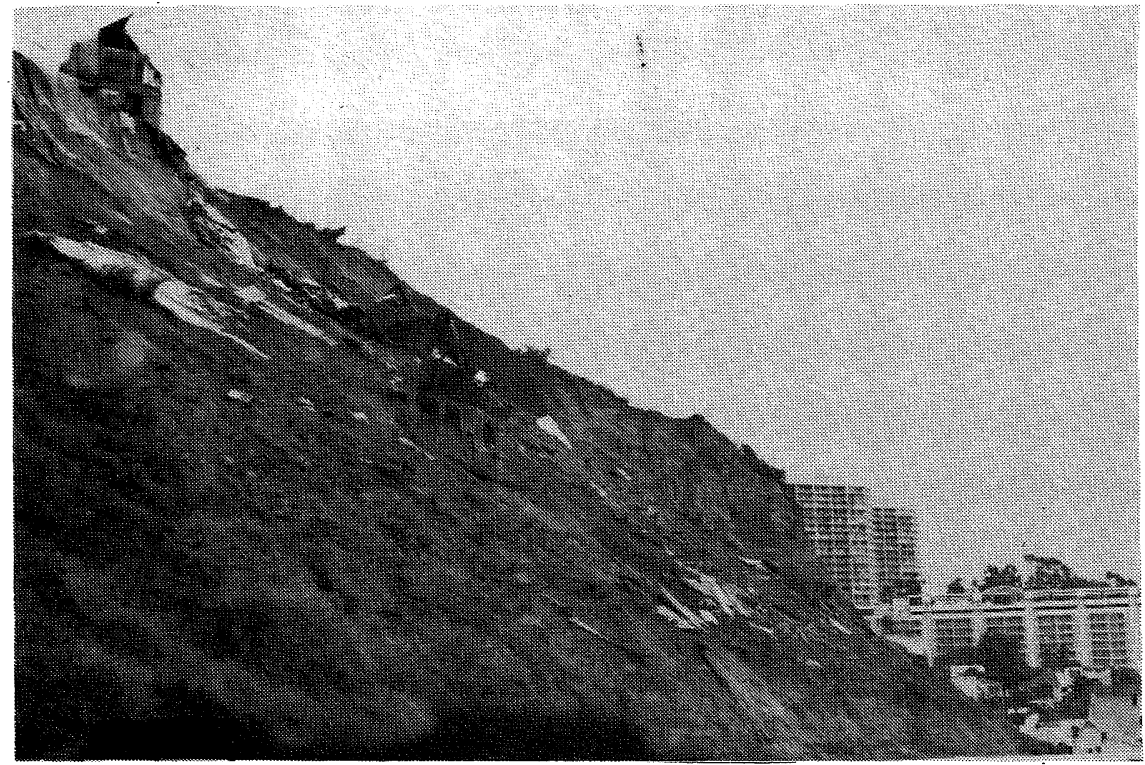

FIGURE 5.4. Landslide along the Pacific Coast Highway, Santa Monica.

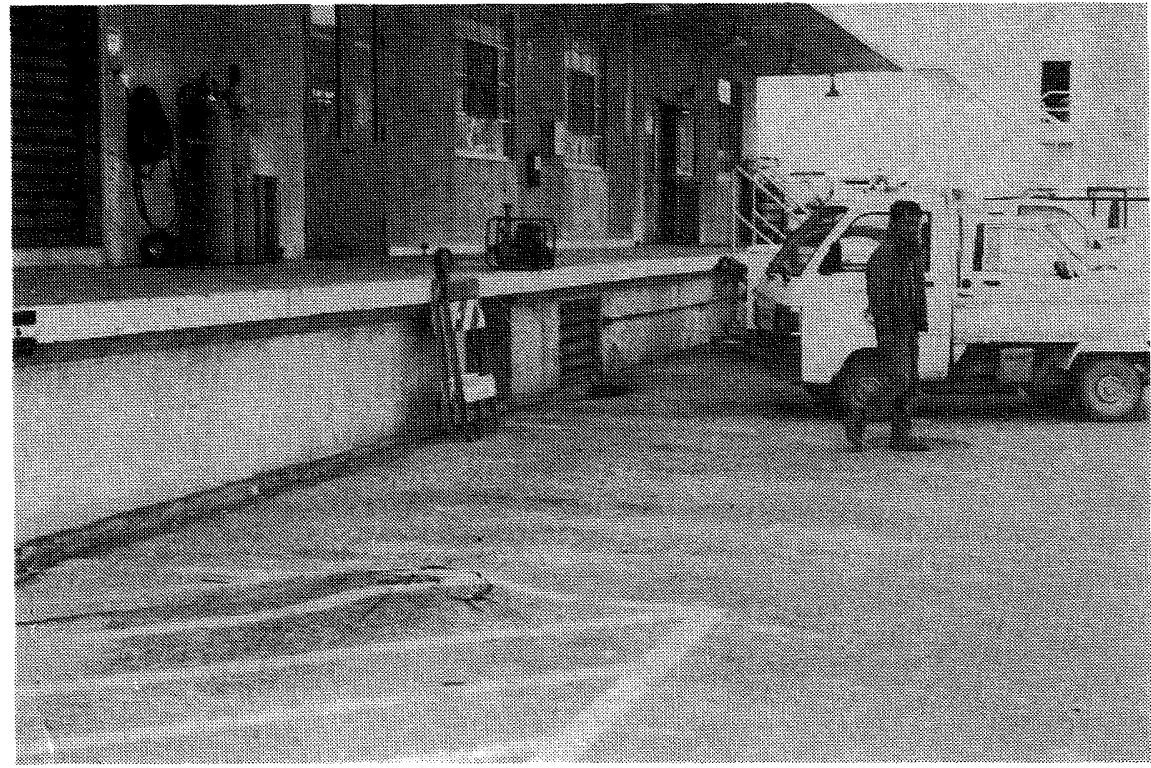

FIGURE 5.5. Settlement adjacent to the control building, Jensen Filtration plant.

More severe damage of a similar nature had occurred in the 1971 event and significant remedial works had been undertaken at the plant. Undoubtedly this work had limited the destruction experienced as a result of the Northridge event.

\subsubsection{Liquefaction in the Epicentral Area}

Evidence of probable liquefaction in the epicentral area was widespread. Features thought to be associated with this include breakage of buried pipelines, cracking of pavements and curbs and settlement of the ground surface. It seems likely that this liquefaction occurred at depth in a material that is overlaid by a more resistant material.

It was difficult to identify the position of the water table at the time of the event since pipe breaks had flooded areas of excavation. Little information could be gained at this time from civil agencies as to ground conditions.

\subsubsection{Gas Reservoir}

This facility is located in the San Gabriel Mountains to the north east of the epicentre at a distance of approximately 60 $\mathrm{kms}$. The facility stores natural gas in an underground reservoir at pressures up to $5000 \mathrm{psi}$ at elevations up to 5000 $\mathrm{ft}$ above sea level. The terrain is composed of steep ridge lines of broken weathered siltstone and sandstone and many rock slides were evident as a result of the event. At the uppermost level $(5000 \mathrm{ft})$ areas of highly broken ground were evident, as shown in the photograph below, with fissures of $300 \mathrm{~mm}$ width and vertical offsets approaching $1 / 2$ metre. Features such as this appeared to increase with elevation.

Generally the facility performed well and an inspection of the many kilometres of pipe lines showed that considerable attention had been paid to jointing details. The result was only a few points of distress caused by rock slides and loss of pipe support. 


\subsection{Conclusion}

Generally speaking the Northridge earthquake will not be remembered for its significant geotechnical damage. While extensive areas of liquefaction are thought to have occurred in the epicentral area and in the Van Norman reservoir complex, no direct structural or building damage as a result of liquefaction was evident. However numerous pipe breakages occurred which are thought to be caused or accelerated by loss of ground strength from accumulation of pore water pressure.

The most spectacular geotechnical feature was the failure of the slopes at Pacific Palisades with the resulting loss of three expensive homes. Other slope failures were relatively sparse.

While the liquefaction in the Van Norman reservoir complex is interesting it is of little engineering significance since the reservoirs are now dry. The Los Angeles dam, constructed by modern techniques, performed well with little residual displacements and no significant pore water pressures being developed.

The question of soft site effects remains unresolved at present. Local engineers were not strongly supporting the possibility of soft site effects to account for the variation in recorded surface acceleration levels. A possible explanation for this feature is the occurrence of focusing of wave energy at nodal points as a result of wave scattering in the alluvial Los Angeles basin. More work is needed to investigate this possibility.

\section{BUILDINGS}

\subsection{General}

Most of the building stock within the epicentral region was low to medium rise residential or related services buildings such as schools, hospitals, shopping centres, along with some office buildings. The building stock was relatively new, most of it having been built since 1960 .

Regular buildings which complied with modern design codes generally performed well structurally, although non-structural damage was widespread. This often resulted in buildings being rendered inoperative commonly for up to several weeks and sometimes months through the inability to effect repairs to nonstructural systems.

Some failures of reinforced concrete buildings were observed, generally in pre-1975 buildings. A lack of adequate column confinement reinforcement was noted as the most common deficiency of severely damaged concrete buildings. The inadequate separation of non-structural elements and the interference of these elements changed the assumed structural characteristics of buildings often resulting in significant structural and non-structural damage. Reinforced concrete shear wall buildings generally performed well with non-structural damage being noticeably less apparent than within more flexible framed buildings.

Ten reinforced concrete carpark buildings collapsed during the earthquake with a further 12 sustaining significant, but repairable damage. All were a combination of cast-in-situ and precast elements. Although the exact cause of collapse varied, a lack of column confinement, inadequate or poorly detailed precast connections, the dissection of deck diaphragms by inclined access ramps and the alteration of column lengths (and stiffnesses and thus lateral shear distribution) through the connection at ramps into columns and the adverse interaction that resulted, were noted as being present within badly damaged carparks.

Some structural steel moment-resisting framed buildings experienced weld failures at the beam/column joints. No collapses were reported, but huge costs are being incurred identifying and implementing remedial measures. Damage to this form of building has proven to be much more wide-spread than had been thought at the time of the team visit. The effectiveness of the remedial measure being implemented remains an open question.

Timber framed buildings with a regular structural elevation performed well. Significant damage occurred when soft storeys developed within lower floors or basements, commonly resulting from the presence of basement or ground floor carparking. Damage to stucco cladding was widespread to the extent that many buildings which used this form of cladding were rendered unsafe.

The location of some of the damaged buildings described later in this section can be found by reference to Figure 6.1 .

\subsection{Imposed Seismic Loads}

A detailed discussion of the ground motion encountered is discussed in Section 4 of this report. Although the magnitude of the Northridge earthquake is less than that expected during a major New Zealand event, it is generally considered that the short period response ( $<1$ second) in both cases will be similar. However, both the long period response and the duration of shaking are expected to be increase further with greater magnitude events. In such cases, building damage can be expected to be greater in a major New Zealand earthquake than was the case at Northridge.

\subsection{Concrete}

\subsubsection{General}

Many of the engineered structures in Los Angeles are designed and built in a similar manner to those in New Zealand. This applies to both new and older buildings. The New Zealand design standard for concrete structures [NZS 3101, 1982] has some of its origins in ACI 318 [American Concrete Institute] of the United States.

The Northridge earthquake was an opportunity to investigate the performance of structural systems that are similar in many ways to those in New Zealand.

In the epicentral region (the area of significant accelerations) concrete structures consisting of lateral load resisting frames, 'gravity'-supporting frames, structural walls (shear walls) or combinations of frames and walls, suffered the full range of damage. Damage was nominal or cosmetic in many cases, however, it extended up to near complete collapse for some structures.

In general, modern post-1970 reinforced concrete buildings performed well in terms of life safety and prevention of collapse - when designed and constructed in accordance with the modern building codes. 


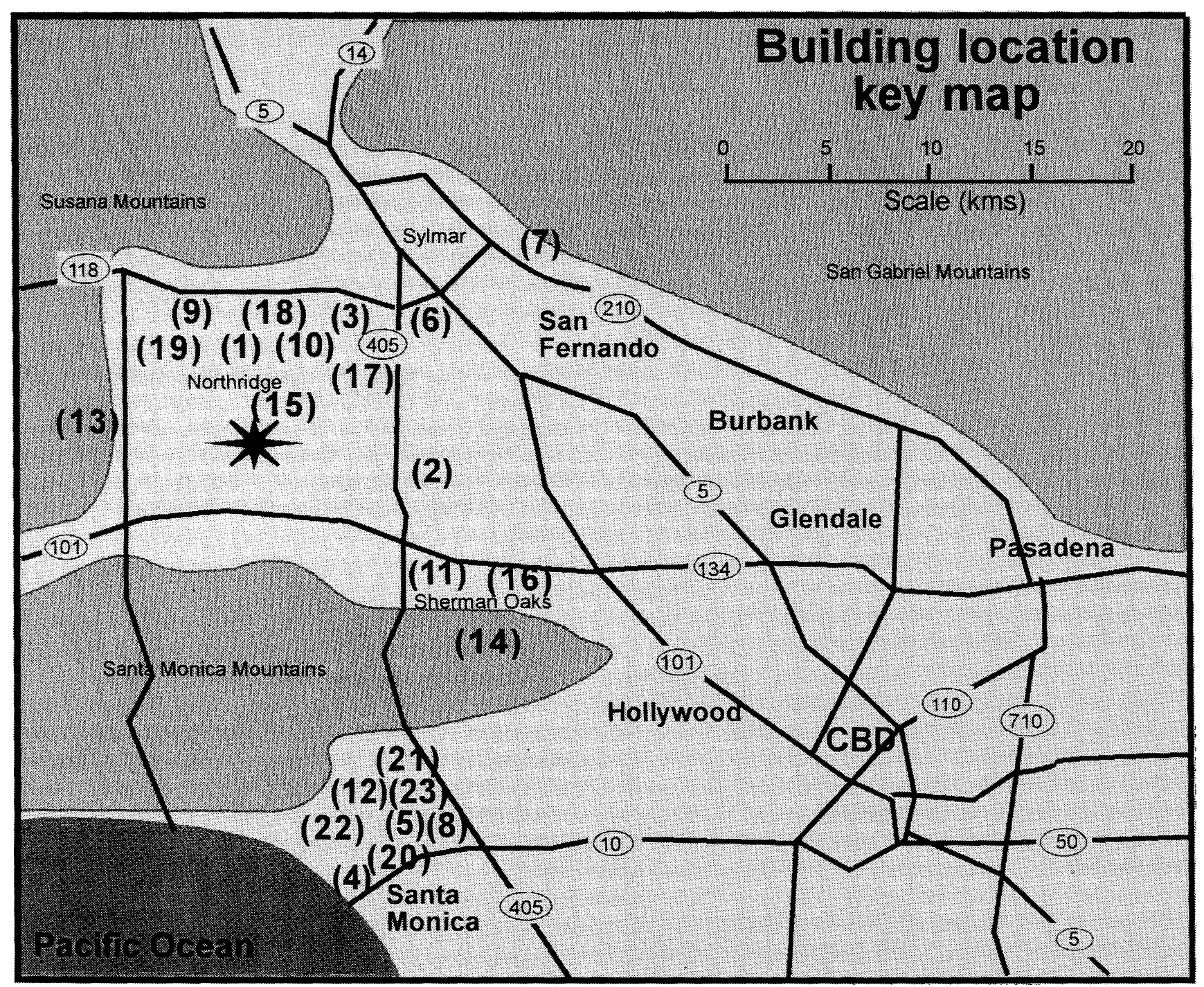

FIGURE 6.1. Key to the location of damaged structures described in the text.

Structures retrofitted to more recent seismic requirements generally performed well during the earthquake. The degree of success was varied. However it was felt that retrofitting with some of the methods seen in Los Angeles should be recommended for consideration in New Zealand.

There was a marked division in seismic performance of reinforced concrete buildings. The division appears to have been mainly established after the 1971 San Fernando earthquake. Prior to this earthquake, the structures were not detailed for any significant degree of ductility. These structures were the most severely damaged during the Northridge event. After 1971, as noted in the subsequent provisions of the United States Uniform Building Code (1973 and 1976), significant improvements were made in detailing for ductility in structural elements subjected to seismic attack. Correspondingly structures built since the San Fernando earthquake exhibited superior capabilities in this earthquake. Even so, some 'modern' structures built in the late 1980s and early 1990s suffered extensive damage. As with the older buildings (prior to 1970), in part, it was the failure to recognise load-paths that the earthquake would demand (e.g., concrete floor diaphragms disconnecting from structural walls; tilt-up wall panels failing out-of-plane because the ties to the supporting roof diaphragms were inadequate). Other critical features causing structural failure were the lack of detailing to accommodate (a) the strength demands (flexure and shear), and (b) the requirement for ductility in key elements during the earthquake (e.g., structural walls and columns that failed had a lack of transverse reinforcement to confine the concrete of the element or to prevent the longitudinal compression bars from buckling leading to failure).

\subsubsection{Framed Buildings}

The poor performance of several reinforced concrete framed buildings can be directly attributed to either to detailing which was inadequate to accommodate the strength and ductility demanded by a major earthquake, or to a lack of appreciation of sound structural design concepts, such as:

(i) Highly irregular floor plan or large variations in structural stiffness within a building. As a result torsions occurred which induced additional actions in members leading to overload. Other members that were much stiffer than had been assumed, either by accident or poor design, attracted a greater proportion of the lateral load than anticipated which again lead to overload and sometimes collapse (e.g., there were cases of columns being restrained by concrete balustrades over the lower half the columns - hence a 'short 
column effect' resulted, failing the columns in shear; a regular building appears to have shown signs of torsional effects possibly due to reduction of stiffness of one side of the building as that side went in to a significant post-elastic phase).

(ii) Several walls and columns were unable to achieve an adequate level of ductility to withstand the flexure/shear demands made of them. Such elements were not considered as primary lateral force resisting elements by the designers and they were thus only designed to carry gravity load. The greater ductility demands generally arose from the flexibility of the primary lateral force resisting system and that of the floor diaphragms which may have resulted in greater than expected interstorey drift. The resulting flexural deformations caused damage and failures within walls and columns which had not been designed to accommodate such movements. These elements were described as lacking "deformation compatibility".

A feature of some collapses was that considerable structural damage resulted from the collapse of a small number of vertical load carrying elements (e.g., columns in some of the car parks, see Section 6.3.5). Perhaps in conjunction with this primary failure mode was the lack of integrity of the rest of the structural system that allowed a domino-like, progressive collapse to occur. Such a lack of integrity seems to have arisen from insufficient detailing of connections to accommodate:

(i) reversals of moment in columns and beams or relative deflections between floors and

(ii) loss of seating/support of floors or beams was not countered by any possible 'catenary action' in the remaining structure.

The effects of vertical accelerations during the earthquake have been widely debated as to whether these played a significant role in failures, especially in reinforced concrete structures. A number of local (Los Angeles) engineers held the opinion that some structural members failed by overload in axial compression because of the local high vertical accelerations. It is generally held that the typical peak vertical accelerations were at the normal levels relative to peak horizontal accelerations (peak vertical accelerations where about two-thirds of the peak horizontal accelerations) and therefore it appears that vertical accelerations need not be regarded as the critical factor for major failures. It is felt that elements, significantly underdesigned for shear, failed in shear in the first instance or failed through insufficient detailing for the ductility demands made upon the elements.

Vertical accelerations may have contributed to the degradation of strength of elements in certain circumstances and vertical accelerations may have compounded the damage. As later reviews of structural damage have emerged there are some failures that may be explained if vertical accelerations are considered. Columns which are probably at the upper limit of axial load capacity (because of large tributary area being supported) and where there does not appear to be significant shears, have failed. Similarly vertical dynamic response may have caused the failure of concrete floor systems (see Section 6.3.5).

\subsubsection{Case Studies}

(a) Bullocks Department Store, Northridge Fashion Centre $\left(1^{1}\right)$

This building is part of a large mall complex that suffered a wide range of damage (structural failures in shops and car parks, cladding damage, ceiling failures leading to extensive asbestos contamination).

The Bullocks Department Store comprised three storeys plus a basement. Large sections of its facade collapsed, however the most dramatic failure was the multiple collapse of the concrete floor system by punching shear of the columns through the floors (Figures 6.2 and 6.3).

There was no apparent reinforcement or shear-heads extending from the columns into the floor slab. The floor appeared to be cast of a light-weight concrete.

On first impressions, there appeared to be no structural system for resisting lateral loads other than by flexural action between the columns and slabs. Closer inspection showed that structural shear walls may have been provided (if somewhat intermittently). Figure 6.2 shows that on the top floor a concrete wall exists between two columns. The lower floors have fallen away and possibly taken the lower sections of the wall with them.

If, because of wall flexibility or through failure of the walls, the walls were inadequate for keeping the lateral drifts sufficiently small, then punching shear may have been initiated by flexural action between the slabs and columns.

The store was empty at the time of the earthquake (Monday 4.31 a.m.). It was reported that this particular morning was going to be the opening of an annual sale. Stating the obvious that had the earthquake occurred during business hours, the life loss in just this one collapse would have been horrific.

(b) Holiday Inn, Van Nuys (2)

The Holiday Inn at Van Nuys is a seven storey reinforced concrete building, built in 1966 (Figure 6.4). The typical floor plan is $19 \mathrm{~m}$ by $49 \mathrm{~m}$. (Figure 6.5). Moment resisting frames on all four sides take out the lateral forces. This building was damaged during the 1971 San Fernando earthquake and subsequently repaired.

A review of studies [Blume and Associates, in Murphy (ed), 1973; EERL, 1971] of the performance of this building in 1971 indicates that the Northridge event resulted in damage in similar locations in the structure. However, this time the damage was more severe. Significant shear cracks appeared in the columns and beam-column joints at Level 4 on the south side of the building (Figures 6.6 and 6.7).

Transverse reinforcement $(6 \mathrm{~mm}$ diameter at $300 \mathrm{~mm}$ centres appear to be typical) in the beam-column joints and in the columns was not sufficient for confinement, prevention of column bars buckling in compression, or shear demands. Figure 6.8 shows the interior view of a severely damaged column with buckled longitudinal bars and steep, inclined shear cracks.

\footnotetext{
1 Refer to Figure 6.1 for the location of this building.
} 


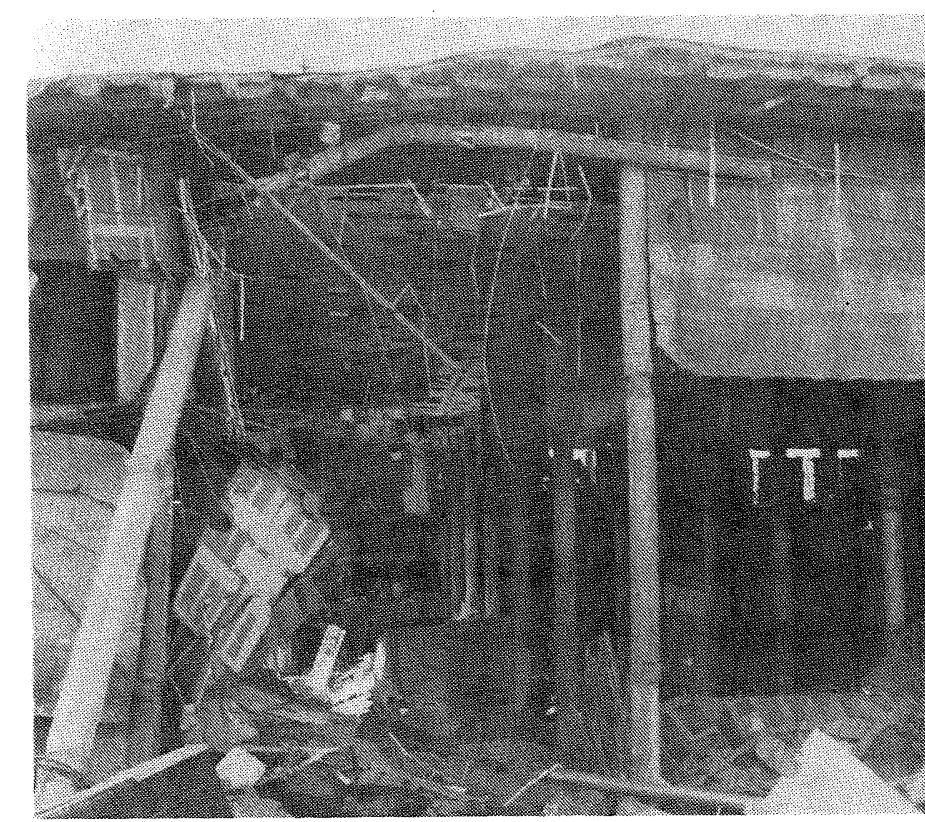

FIGURE 6.2. Bullocks Department Store, Northridge. A forest of columns remains after the punching shear failure of all the floors.

Note the waffle slab roof is still in place.

FIGURE 6.3. Bullocks Department Store, Northridge. A closer view of the floor-to-column junction. No reinforcement or shear-heads were observed extending from the column to the floor slab.

FIGURE 6.4. Holiday Inn, Van Nuys. Looking from the south-west.

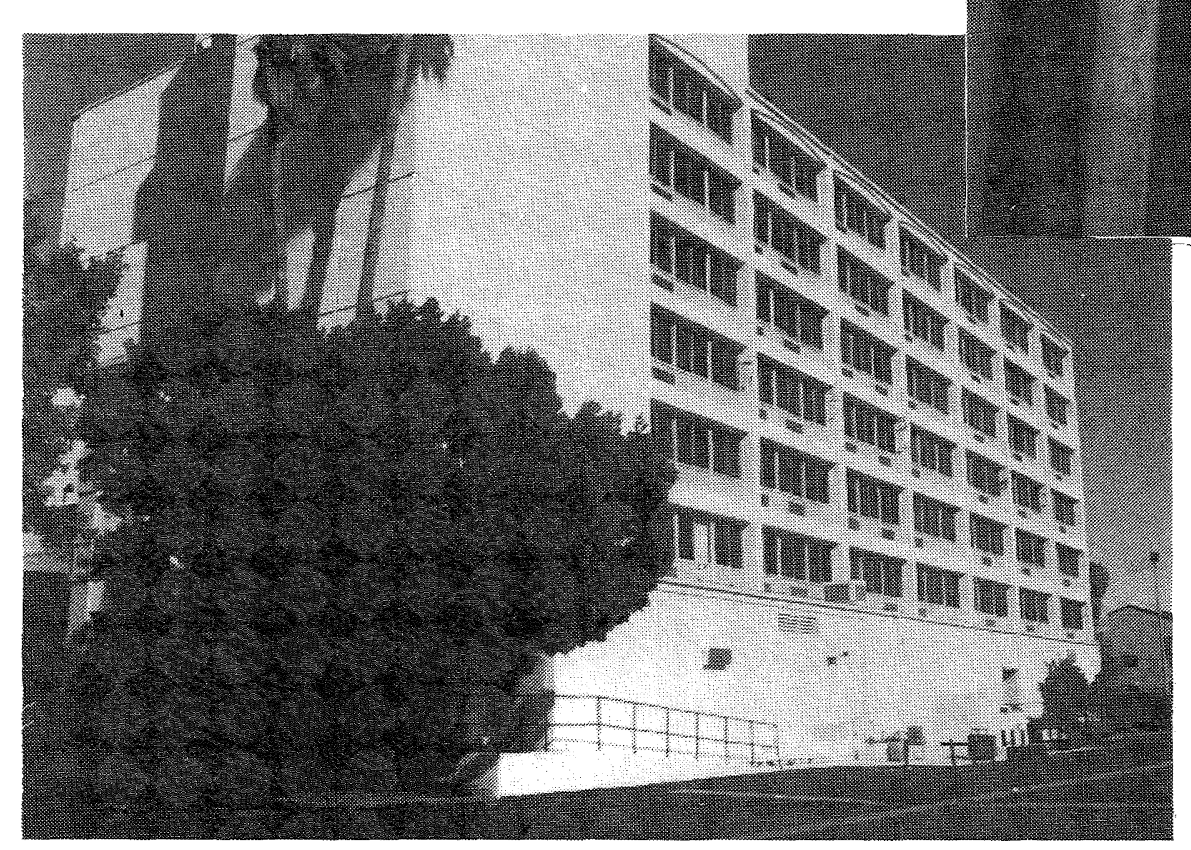




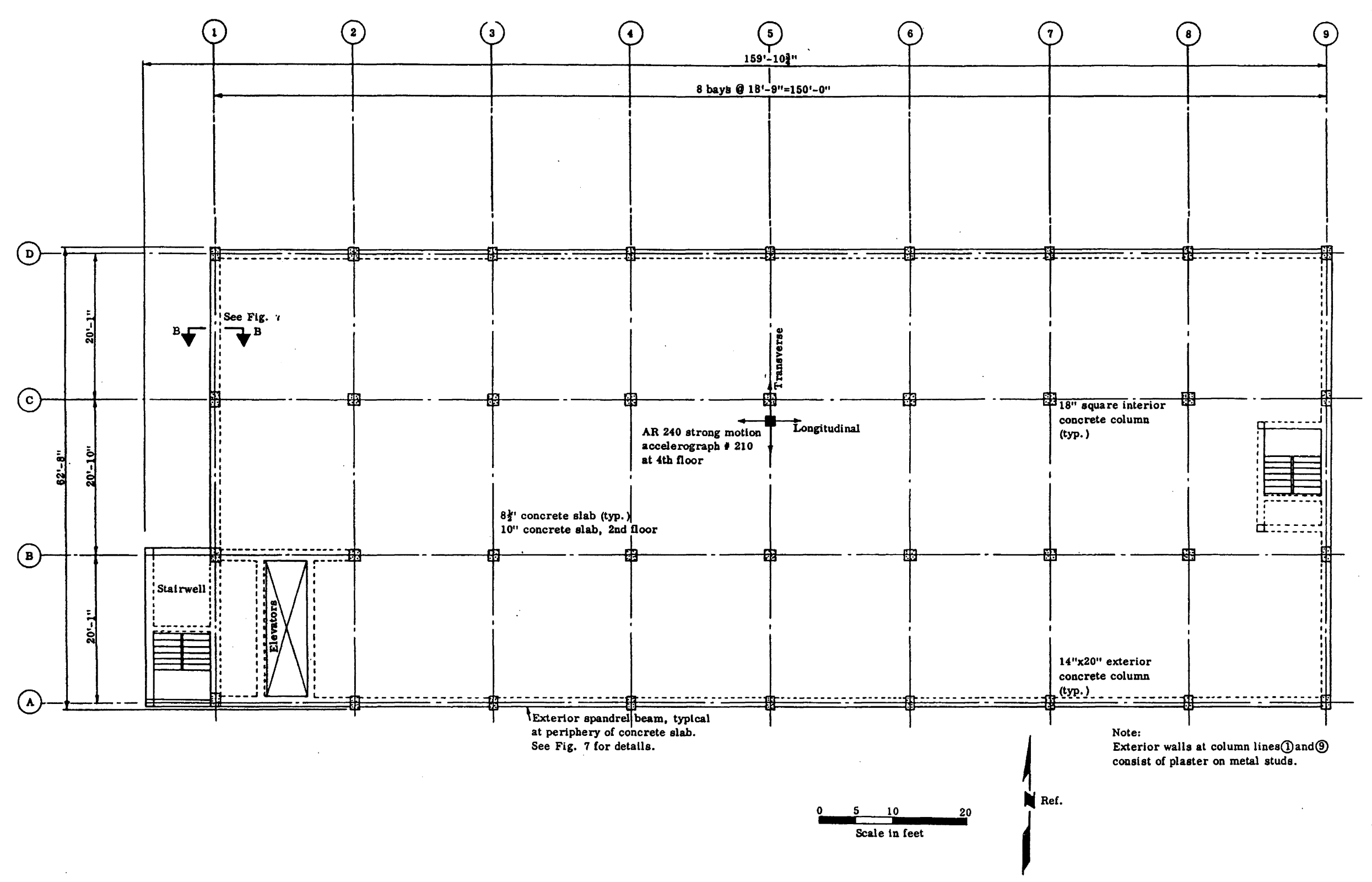

FIGURE 6.5. Holiday Inn, Van Nuys. Typical floor plan [2]. 


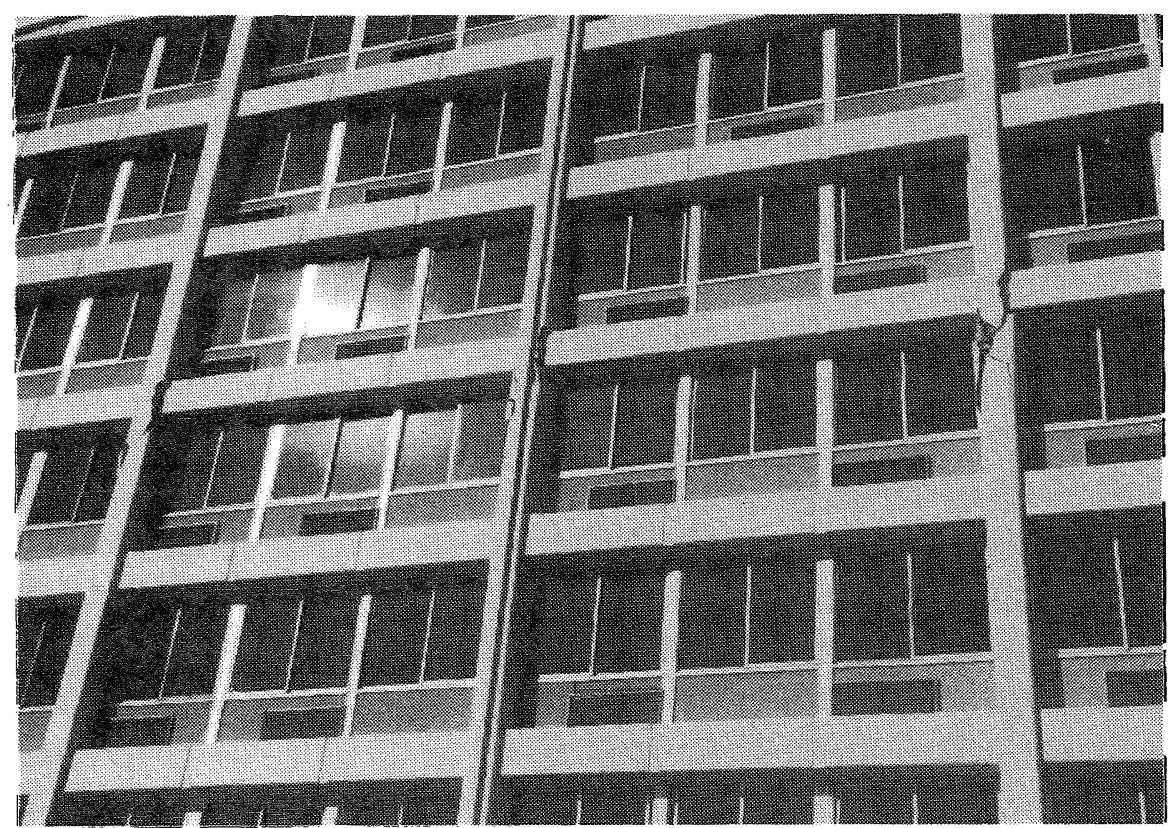

FIGURE 6.6. Holiday Inn, Van Nuys. South side, showing damage zones at Level 4.

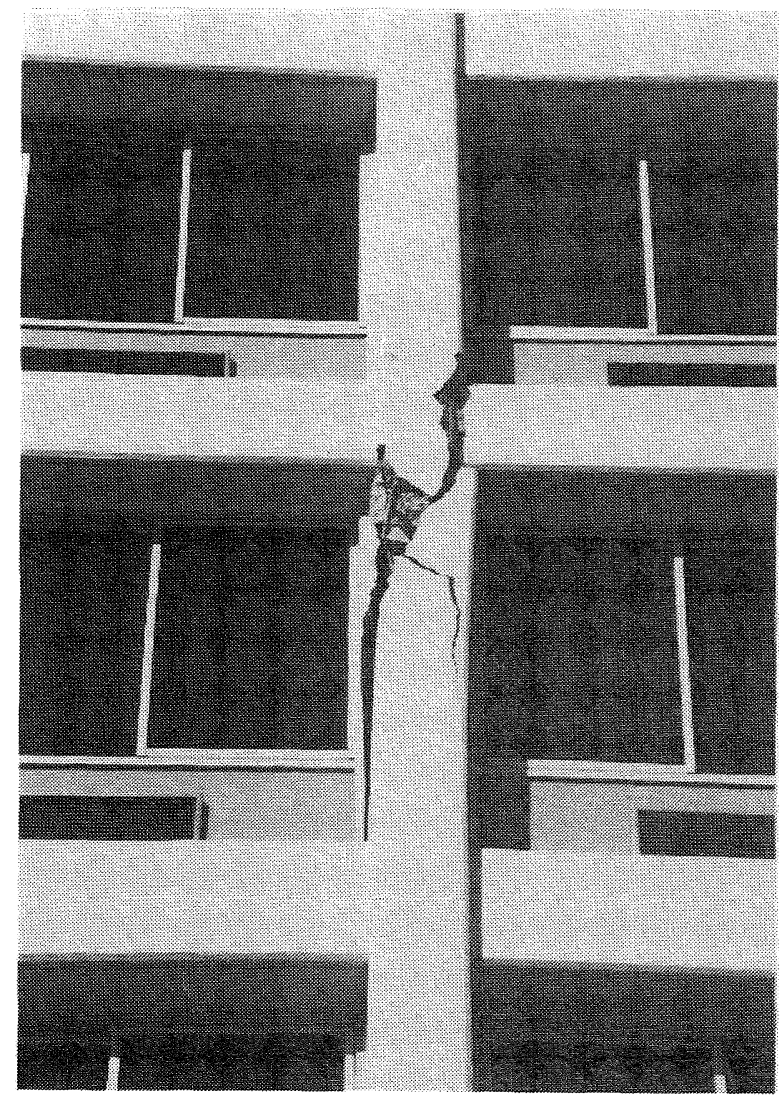

FIGURE 6.7. Holiday Inn, Van Nuys. Close-up of the damage zones at Level 4, south side.

There was some indication of early stages of yielding of reinforcement in some beams. A similar but significantly less severe damage pattern had occurred on the opposite (north) side on the building.

There is possibility that torsions may have developed during the earthquake. Definitive evidence is not presented because the

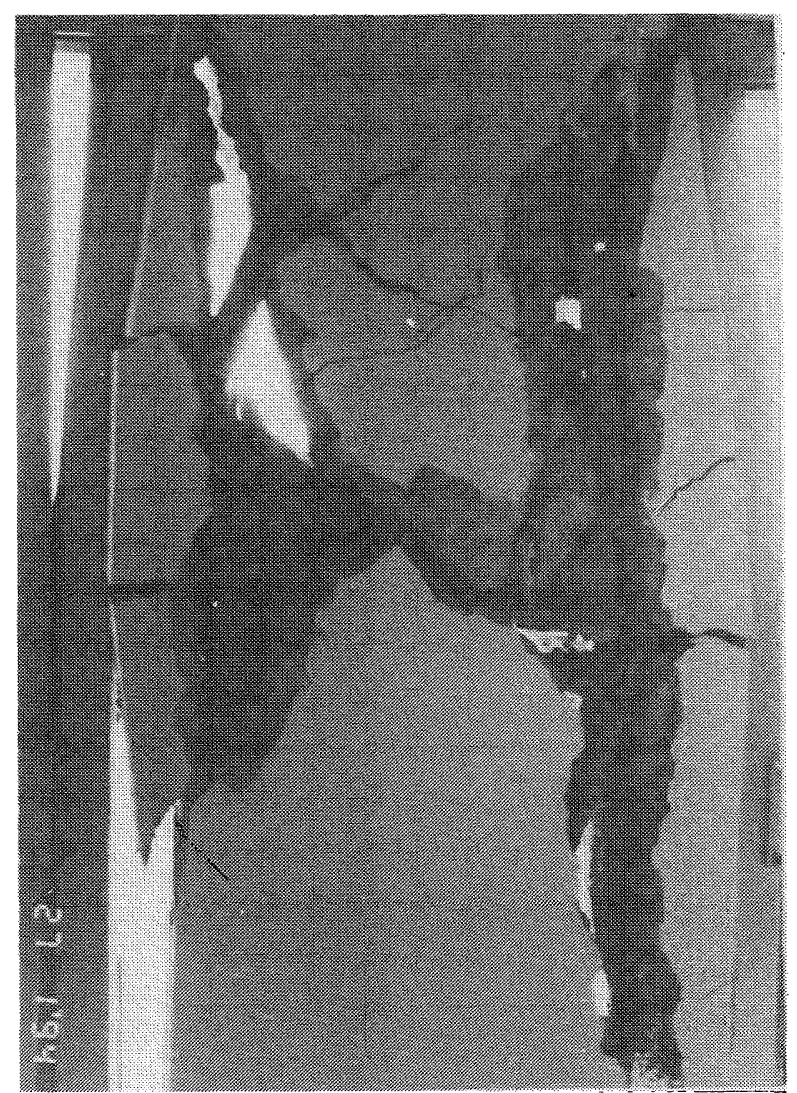

FIGURE 6.8. Holiday Inn, Van Nuys. Interior view of a damaged column as seen from Level 3.

majority of the damage to the east and west frames would have resulted from components of the earthquake that were at $90^{\circ}$ to the long axis of the building (i.e. on the base of the building: north-south peak acceleration of $0.41 \mathrm{~g}$; east-west peak ground acceleration of $0.47 \mathrm{~g}$ ). However, consider that the markedly greater damage to the south side of the building would result in a reduction of stiffness on that side and a shift of the centre-of- 


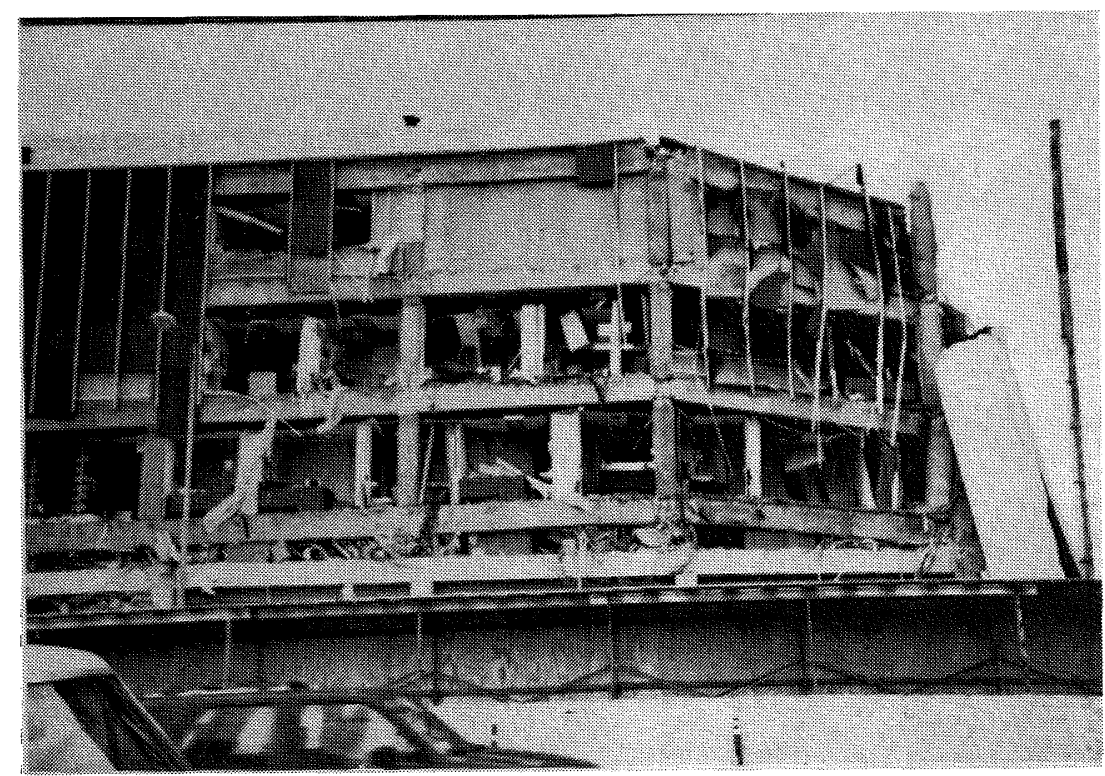

FIGURE 6.9. Kaiser Permanente, Northridge. View of long elevation of the building.

rigidity of the floors, above the primary damage zone, towards the north. The resulting eccentricity between the centre-ofrigidity and the centre-of-mass produces torsional actions.

Perhaps the behaviour of the Holiday Inn suggests that even when a building appears regular and not prone to torsional action (as this building does), torsional effects should still be considered. Consideration of the possible amplification of torsional effects because of post-elastic behaviour, as well as accidental eccentricities, is still required during the design.

The degree of damage to the east and west frames was apparently less than that of the southern frame. There is a stair well at both the east and west ends, all with built-in concrete stairs and landings. There was damaged to the stair units resulting from strutting action between floor landings. The presence of these stair structures may have offered some protection to the rest of the frames on the east and west ends.

The cladding for the majority of the east and west ends was architectural infill panels, (possibly 'stucco'-plaster, 15 to 25 $\mathrm{mm}$ thick, on wire and plywood sheet backing, supported in galvanised metal frames). These panels were damaged to varying degrees. It is unlikely that these panels had much, if any, influence on the behaviour of the building.

Inspection of the interior showed that there had been extensive damage to the non-structural components. Fit-out to the bathrooms (tiles, mirrors and plumbing) were broken up. Furniture at the top of the building was toppled.

It was reported that no injuries occurred during the earthquake and that all the people in the building were evacuated. There was evidence of doors having to be forcibly opened to allow evacuation.

\section{(c) Kaiser Permanente, Northridge (3)}

This office building (rectangular in plan) was a five storey moment resisting frame constructed in the 1960s (possibly 1968). A 'soft storey' mechanism developed in the second storey leading to complete collapse of that storey (Figures 6.9

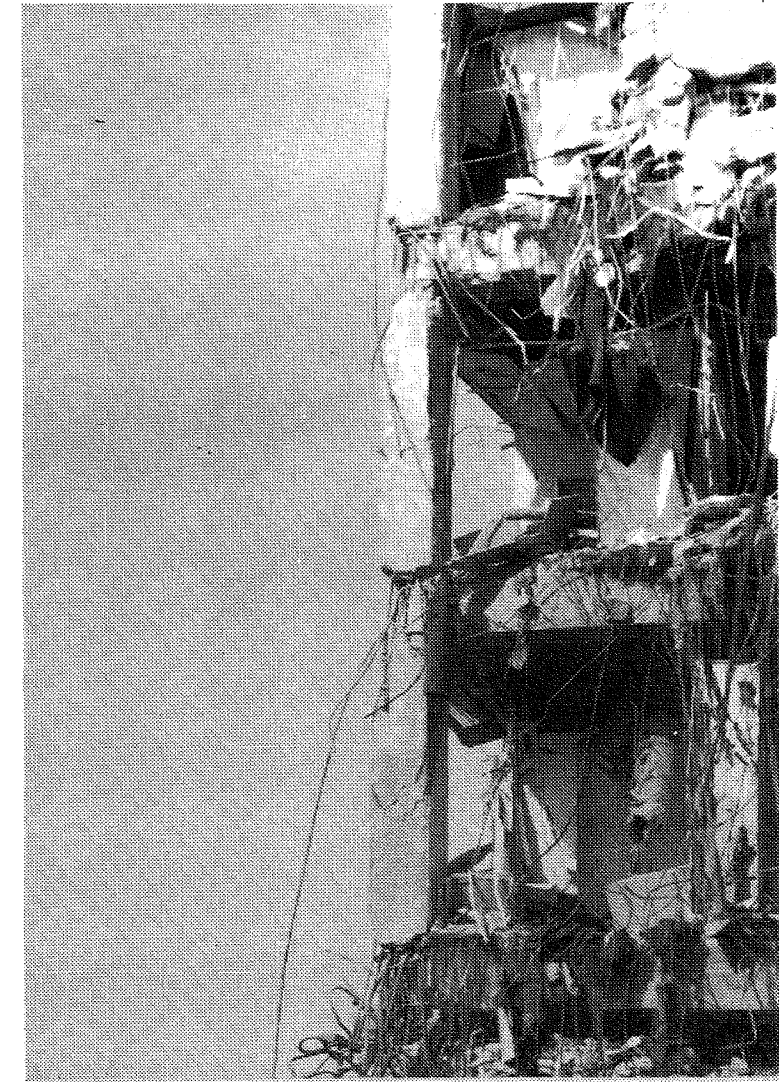

FIGURE 6.10. Kaiser Permanente, Northridge. Completely destroyed columns of Level 2 and damaged beam-column joints above. 


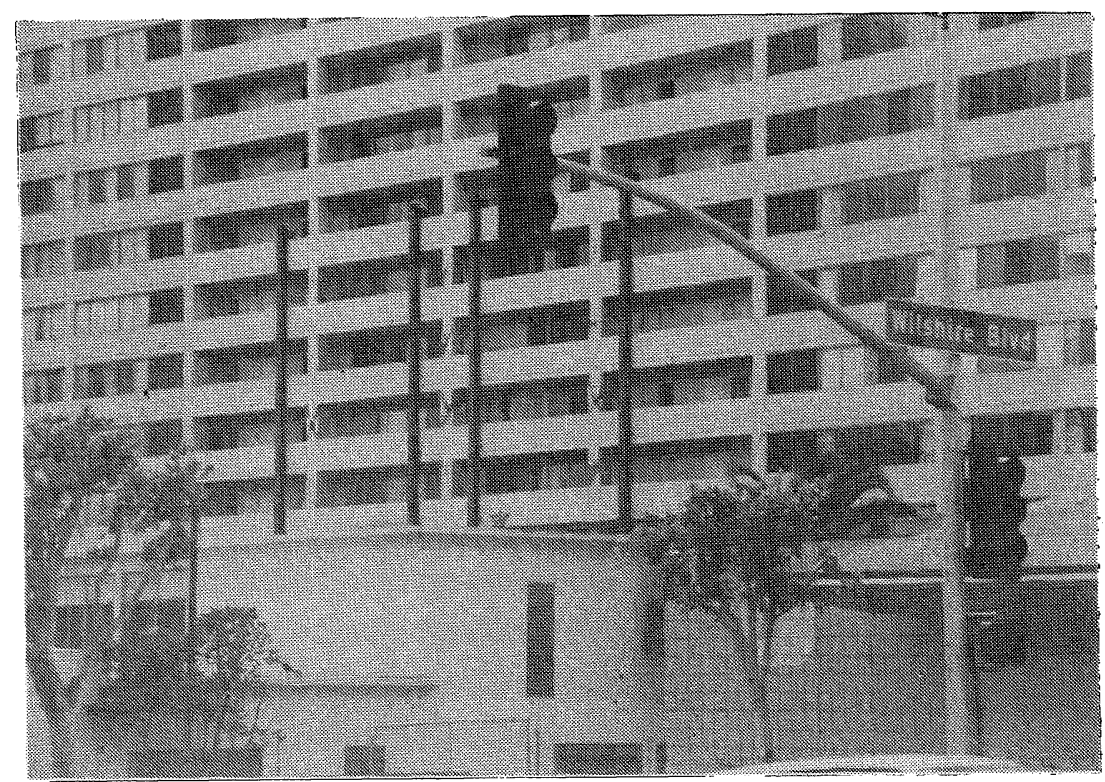

FIGURE 6.11. Champaign Tower, Santa Monica. View of east elevation of the building. Note: the extensive damage to the columns of this face.

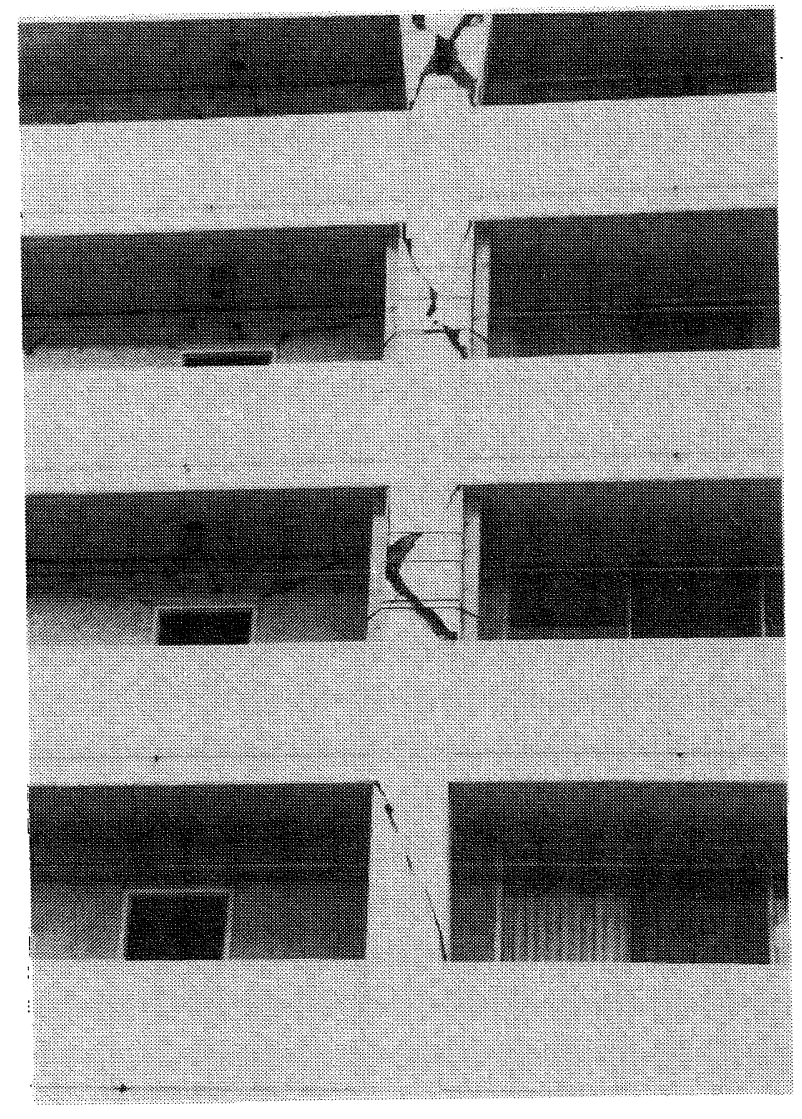

FIGURE 6.12. Champaign Tower, Santa Monica. Close view of the failed columns.

Note: the steep inclined shear cracks caused by the 'short column effect' because of the presence of the concrete balustrades. Also note the timber propping in place and the steel strapping (placed around the damaged columns in order to stop pieces of concrete falling on to people below). and 6.10). The second storey columns were typically destroyed leaving only twisted reinforcement. One column broke away from a lower beam-column joint and was left hanging in mid-air from the joint above. Note the extensive and serious damage to the beam-column joints. Typical of the era of building, there is a minimal amount of transverse reinforcement in the joints. The 'soft storey' mechanism appears to have begun as the beamcolumn joints degraded in conjunction with failing plastic hinge zones in the columns (lap splice failures and/or insufficient confinement and anti-buckling transverse reinforcement).

The end walls comprised two wythes of brick with a concrete backing (possibly shotcrete). Both end walls collapsed. These collapses are apparently associated with the collapse of the entire end bay at each end. This building was in the first stages of demolition when viewed.

\section{(d) Champaign Tower, Santa Monica (4)}

This is a 15 storey building (rectangular in plan) on the beach front in Santa Monica. The concrete building consists of moment-resisting frames on the east and west faces and twin shear walls, coupled with conventionally reinforced spandrels at the north and south ends. This building was constructed prior to 1970 .

The building exhibited a number of common failure modes (shear wall behaviour will be discussed in Section 6.3.3). The columns of the east frame over the lower half of the building, in particular, failed in shear through 'short column effects'. The concrete balustrades up against the lower parts of the columns reduced the effective length of the column, magnifying the shears to be resisted (Figures 6.11 and 6.12). This building was 'red tagged', i.e. entry was prohibited.

The same type of failure was not seen on the west side primarily because there were not the same balustrade details as on the east side.

Two car parking structures viewed displayed this 'short column' sort of failure as did Barrington Medical Centre, in West Los Angeles (Barrington was demolished before the Reconnaissance Team arrived in Los Angeles). 


\subsubsection{Shear Wall Buildings}

This section discusses the performance of a number of structures where the lateral resistance was provided by shear walls in one or both principle directions. These walls operated in conjunction with frames which contributed to lateral resistance to varying degrees.

As a general observation, buildings which incorporated well detailed walls suffered less structural damage and less nonstructural damage (to cladding, mechanical services, ceilings, partitions, furnishings and contents) particularly when these walls were well distributed about the building plan. The degree of damage appeared, in part, to be related to the magnitudes of interstorey drift. This observation applied to walls of all ages provided they were well detailed and had a low aspect ratio. Car parking structures were a class of building which was an exception to this general rule however. Such buildings are discussed in Section 6.3.5 below.

\subsubsection{Case Studies}

\section{(a) St Johns Hospital, Santa Monica (5)}

This complex was also visited, at a later date, by a second New Zealand reconnaissance team (comprising architects). The follow case study is a compilation of the observations and investigations of the two groups.

The complex covers more than one city block and comprises 10 main buildings. The hospital is licensed for 500 beds of which 300 were occupied at the time of the earthquake. No one in the hospital was physically injured during the event. The hospital continue to operate for three days after the earthquake. Eventually the degree of damage was assessed as severe and the hospital was closed with patients being transferred to other medical facilities, a notable benefit of having surplus hospital facilities available in the Los Angeles area.

Buildings ranged in age from the 1950 s to late 1980 s and, as expected, their performance was equally varied, with the pre1970 structures suffering noticeably more damage. Two buildings were so damaged that they were to be demolished. These are the North Wing (1951) of 8 storeys and the 7 storey South Wing (1966). Both buildings have reinforced concrete wall-frames with large dimensioned piers and spandrels ( similar to pierced walls). The typical structural damage was shear failure of the piers (resulting in cracks running corner to corner of the piers). The North Wing had a concentration of failures in piers at the second floor (Figures 6.13 and 6.14). The South Wing had damage spreading up the full height of the building and the shear action was apparent in the spandrels as well as the piers (Figure 6.15). Extensive internal shoring was employed in the severely damaged buildings.

The reinforced concrete Main Wing (1941) and a steel framed Mental Health Centre (1967) were damaged to lesser extents and access was restricted. The steel framed East Wing (1979) and West Wing (1978) were not structurally damaged.

Both the Main Wing and the North Wing contained clay masonry partitions (approximately $100 \mathrm{~mm}$ thick) that spanned vertically from floor to floor. These partitions suffered extensive damage. These infill walls, especially those on the second floor of the North Wing, appear to have inadvertently provided support for the upper floors as the primary structural components degraded badly during the earthquake to the extent that their axial load capacity was severely reduced. In the North, South and Main Wings the stair-well shafts (reinforced concrete) exhibited classical flexure-shear cracking.

Structural damage was primarily limited to walls and frames on the north and south faces, consistent with the primary excitation direction in this area.

Interior fit-out and contents was extensively damaged. Both reconnaissance teams gathered reports and observed damage that included: collapse of suspended ceilings, fallen light fixtures, broken water supply pipes (air conditioning and potable), electrical services were out of operation for a day ( standby power did not come on line after the earthquake), sprinkler pipe and head damage, plaster lined partitions were damaged to varying degrees. The architect team pointed out that the steel stud, wall board lined partitions in the South Wing performed well.

The architect team noted some further interesting points. As telephone systems were also knocked out the staff reverted to hand-held radios and pagers (these proving the more effective). Equipment and chattels that had been secured to the Office of State Hospital Planning and Development (OSHPD) requirements and were reported as generally surviving.

\section{(b) Indian Hills Medical Center (6)}

Indian Hills Medical Center was constructed in the late 1960s (Figure 6.16). This building is a 6 storey reinforced concrete structure. There are 8 shear walls evenly distributed around the perimeter of the building. The floors are supported in the interior by concrete frames (with column spacing ranging between 6 and 11 metres). These frames would have picked up some of the lateral forces, though probably only a small proportion relative to the walls. The walls and columns were constructed of normal weight concrete and the floors and beams were constructed of light-weight concrete. This building survived the 1971 San Fernando earthquake though there was considerable damage to main structural elements. This damaged was repaired by a number of techniques. The walls were thickened by reinforced gunite to the exterior of the existing walls [EERL, 1971].

In the Northridge earthquake the locations and types of structural damage were similar to the 1971 event:

\section{Shear walls:}

The lap splices of the longitudinal reinforcement in the end elements of the walls were damaged. The concrete spalled at the splice sites and some main bars had buckled (Figures 6.17, 6.18 and 6.19). The transverse reinforcement in these zones appears to be $6 \mathrm{~mm}$ in diameter and at 200 to $300 \mathrm{~mm}$ centres. There were numerous incidents of spalling and cracking along the horizontal construction joints in the walls (the light-weight concrete floors were cast across the top of each lower wall and were therefore included in the wall as the next lift of the wall was subsequently cast). Criss-cross shear cracking at the base of walls (parallel to the main direction of earthquake attack) was extensive, finely distributed and between $45^{\circ}$ and $60^{\circ}$ to the horizontal.

\section{Frames:}

There was spalling and possible lap failures in the main reinforcement in beams. On two floors, in a column on each, there was spalling of cover concrete and the buckling of longitudinal reinforcement (Figure 6.20). There was an 


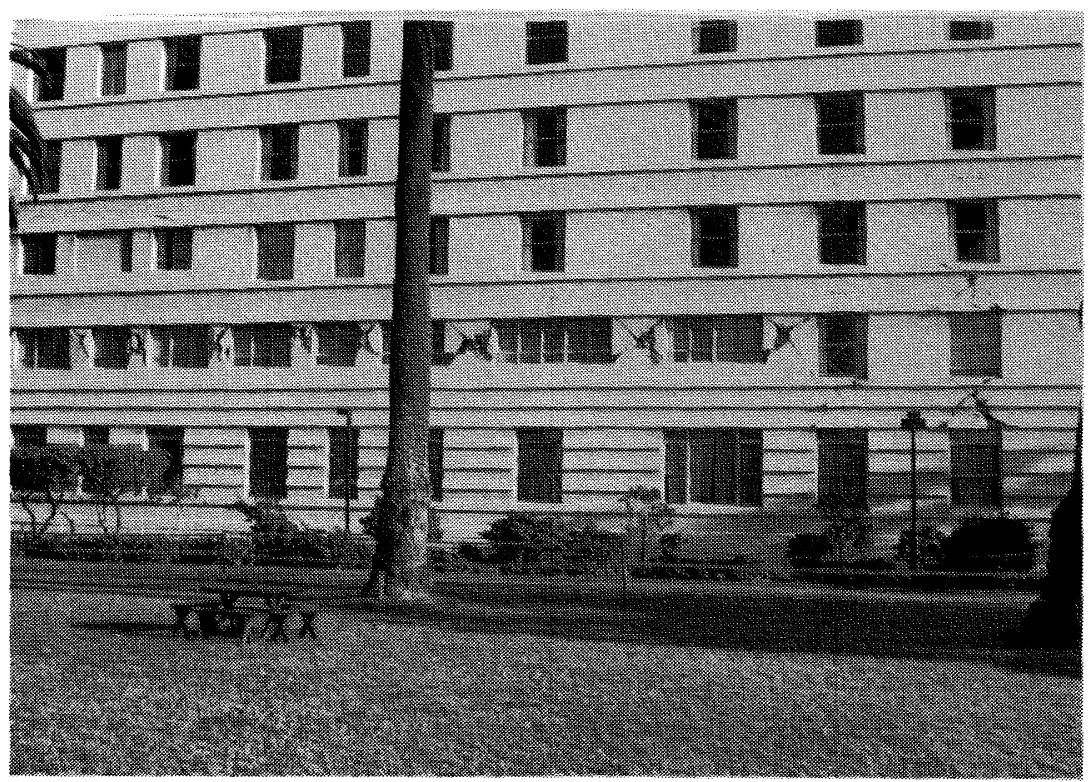

FIGURE 6.13. St Johns Hospital, Santa Monica. Elevation of the North Wing. Note: the damage to the second floor piers.
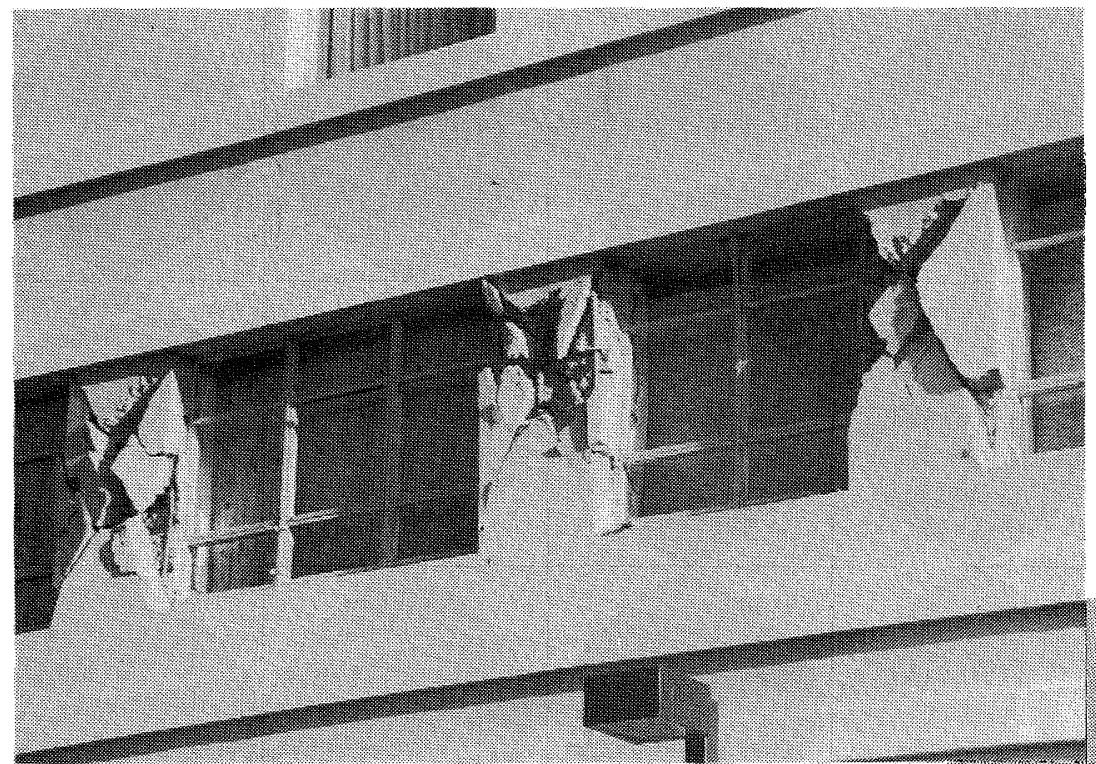

FIGURE 6.14. St Johns Hospital, Santa Monica. Close view of the failed piers (second floor, North Wing).

Note: the steep inclined shear cracks and the lack of confining transverse reinforcement.

FIGURE 6.15. St Johns Hospital, Santa Monica. Elevation of the north-east side of the South Wing.

Note the 'classic' shear cracking in the piers and to a lesser extent in the spandrels. Also there is degradation of the construction joints were the concrete of the floor slabs has been incorporated in the walls.

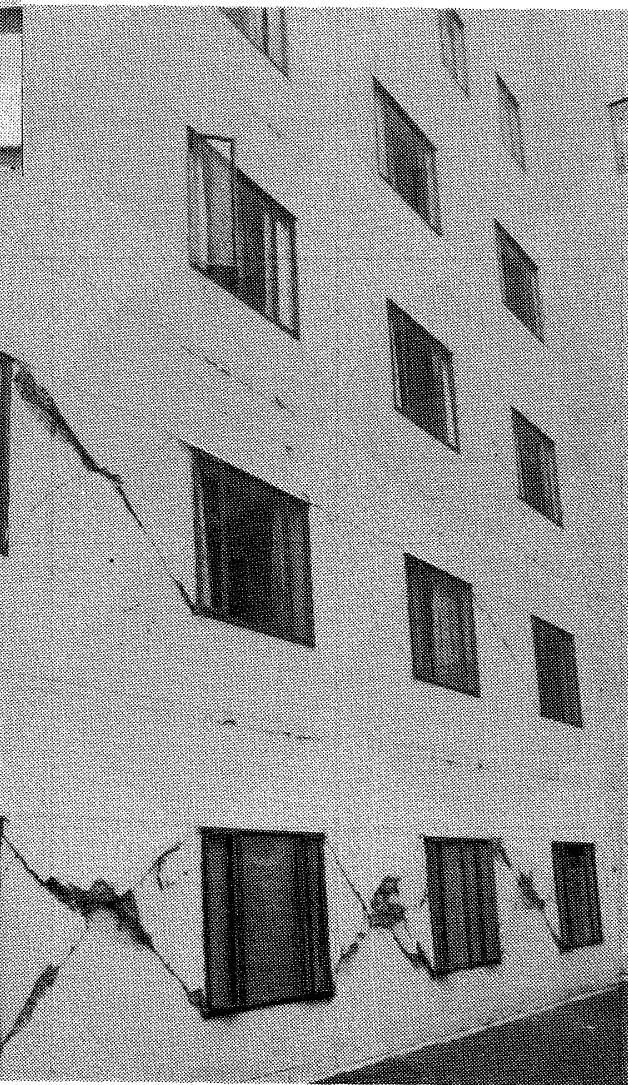


accompanying shortening of the columns. The transverse reinforcement appeared to be $6 \mathrm{~mm}$ in diameter at 250 to 300 $\mathrm{mm}$ centres. The buckled bars were part of the lap splice just above floor level. The failure of the splice zones was probably initiated by the flexure induced in the frames due to interstorey drifts (even though the drifts were expected to be small in this wall-dominated building). The failure may have been bondrelated. One proposal for the failure was overload through vertical accelerations associated with the earthquake (two free field strong motion instruments recorded maximum vertical accelerations of approximately $0.6 \mathrm{~g}$ ). Using conservative assumptions, allowing for an additional $1 \mathrm{~g}$ vertical acceleration, the likely 'axial load ratio' (axial force /concrete compressive strength /gross cross-sectional area of the column) would probably not exceed 0.6 .

The structural damage appeared to necessitate the closing of the facility. The damage to facade (architectural spandrels and windows), contents and fit-out was significantly less than other medical facilities that had been visited.

(c) Olive View Hospital (County Hospital at Sylmar) (7)

This structure (Figure 6.21) was built as a replacement for the new facility that was destroyed during the 1971 San Fernando
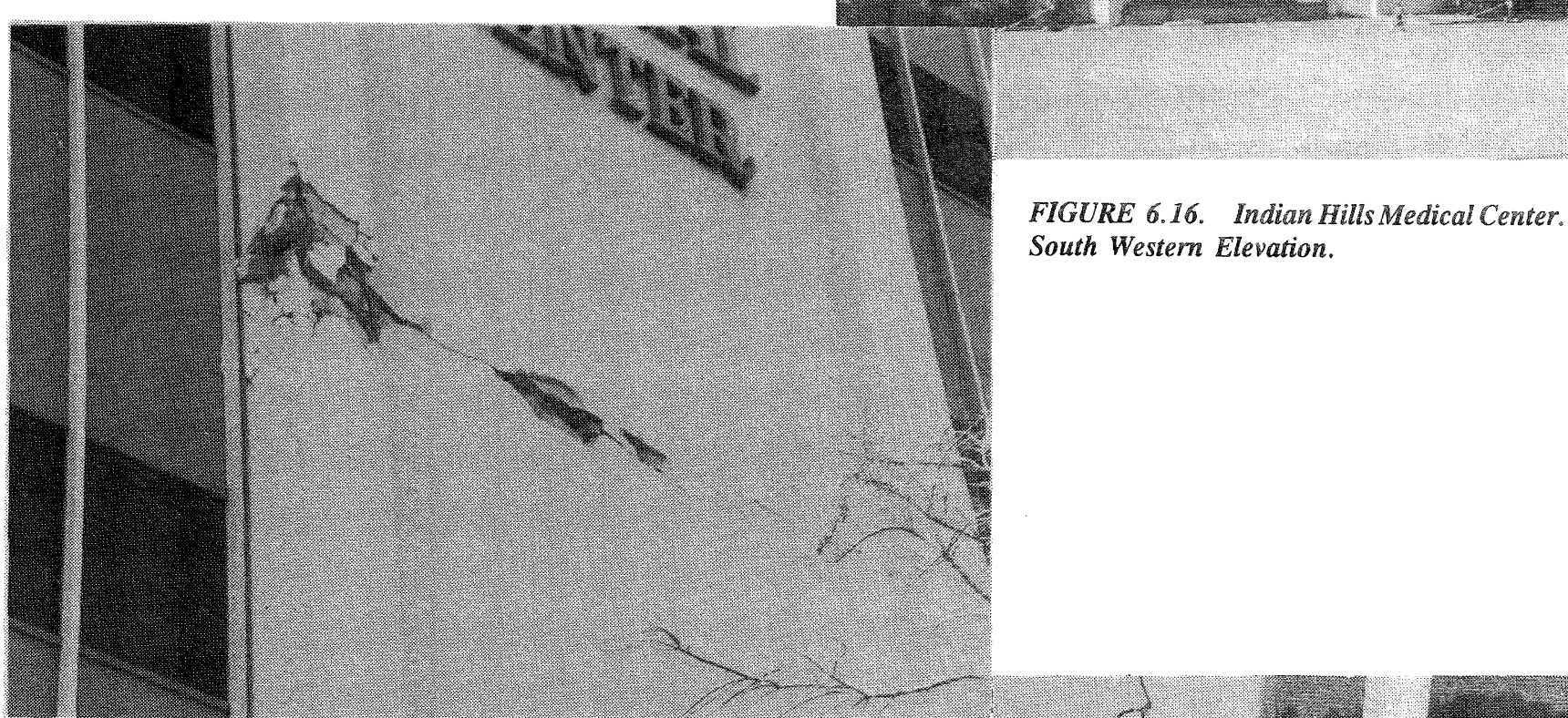

FIGURE 6.16. Indian Hills Medical Center South Western Elevation.

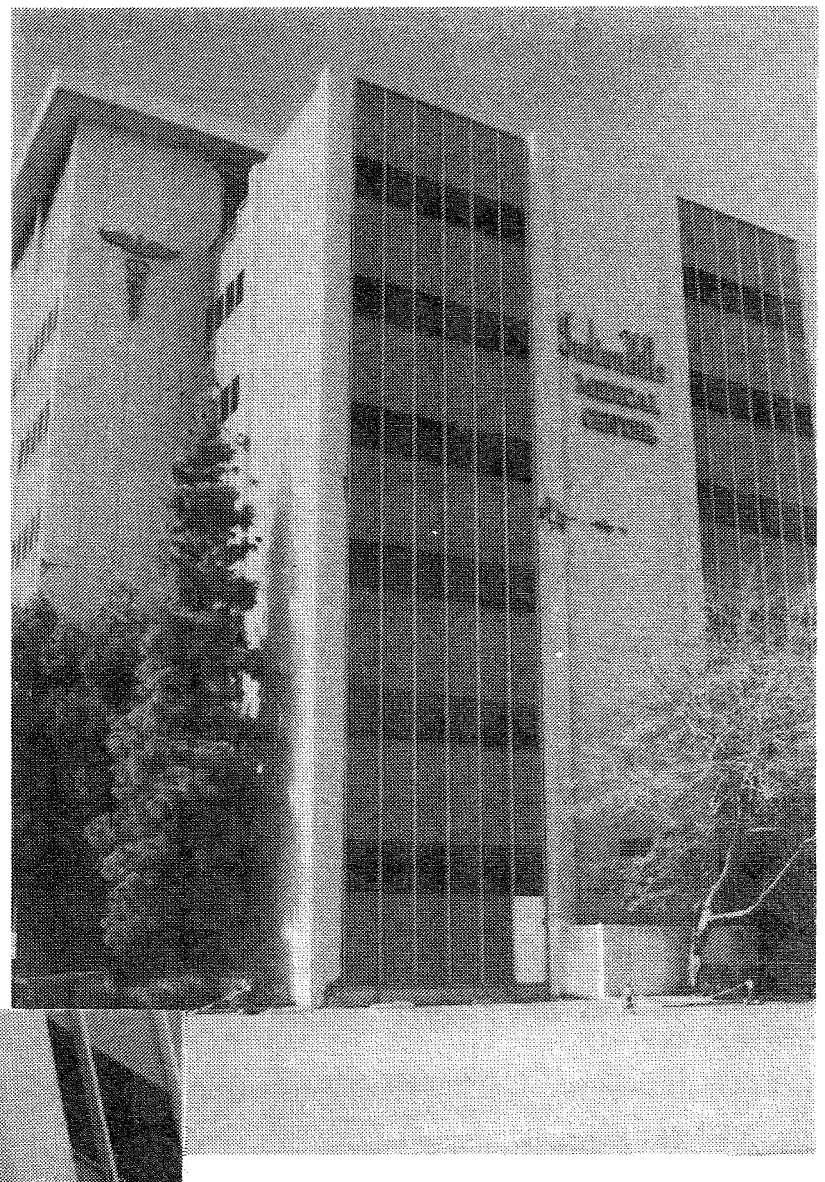

FIGURE 6.17. Indian Hills Medical Center. Failed lap splice in the end zone of the east wall and horizontal construction joint damage.

FIGURE 6.18. Indian Hills Medical Center. Close-up of failed lap splice, at the base, in the end zone of the east wall. 


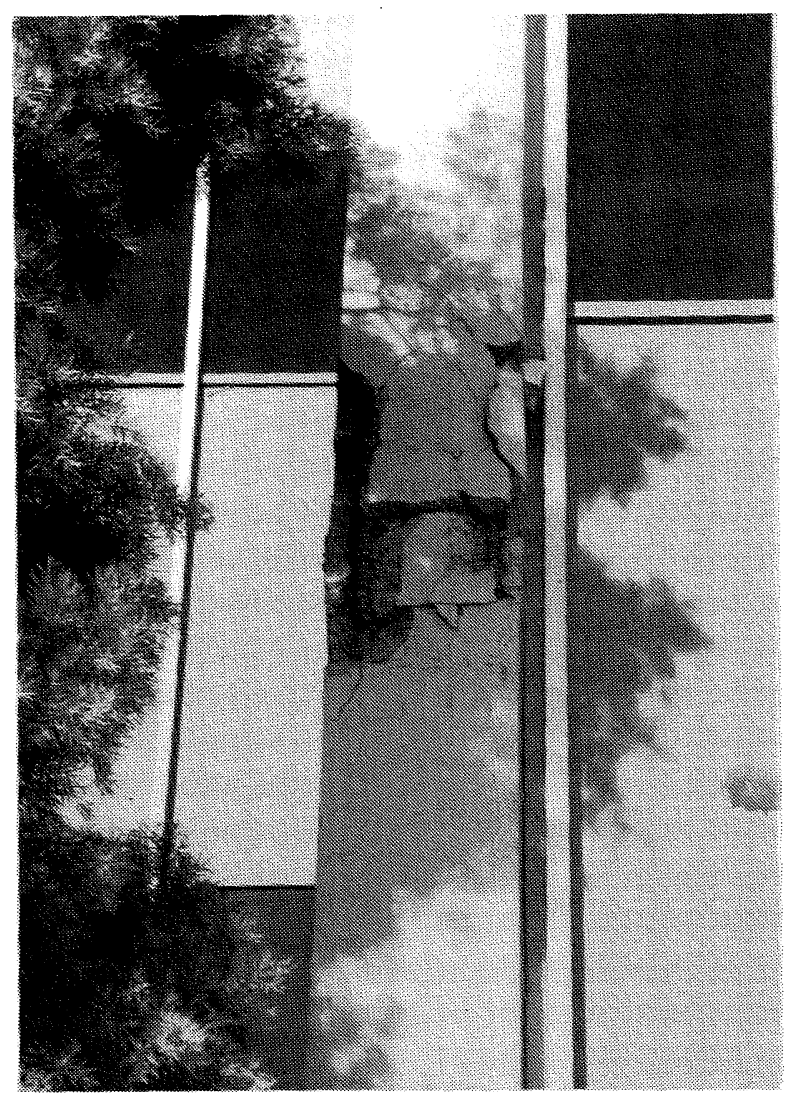

FIGURE 6.19. Indian Hills Medical Center. Failed lap splice in the end zone of south-west wall.

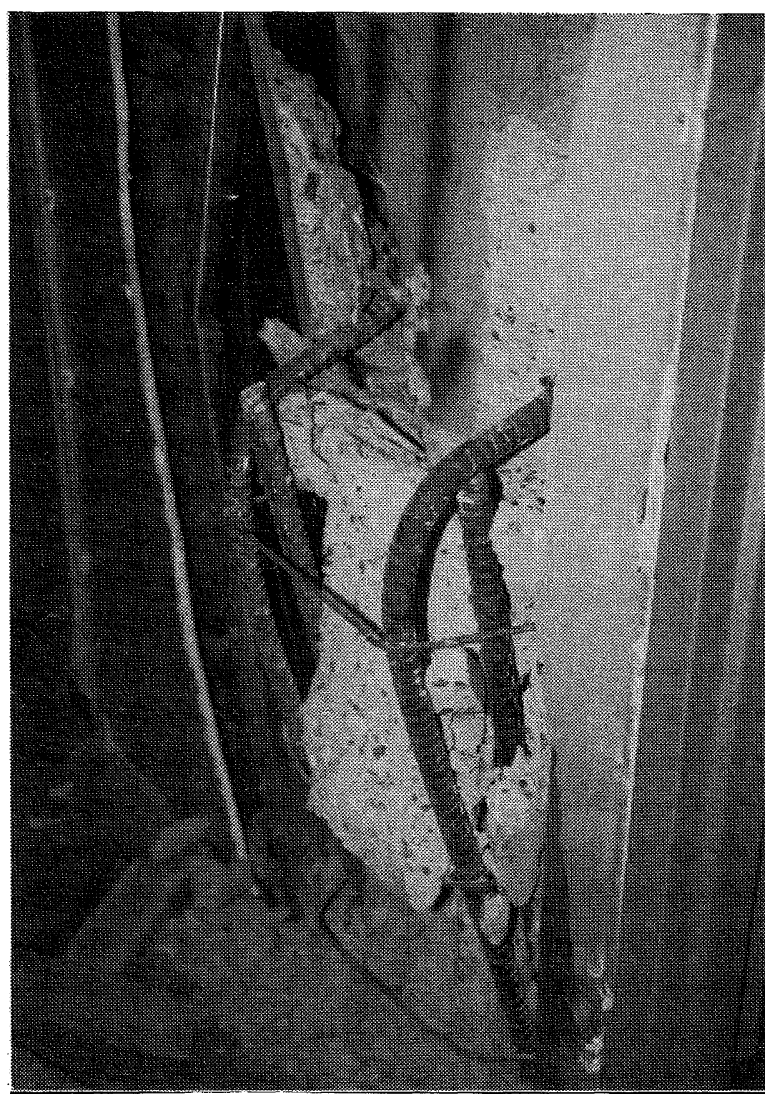

FIGURE 6.20. Indian Hills Medical Center. Failed lap splice at the base of an interior column.

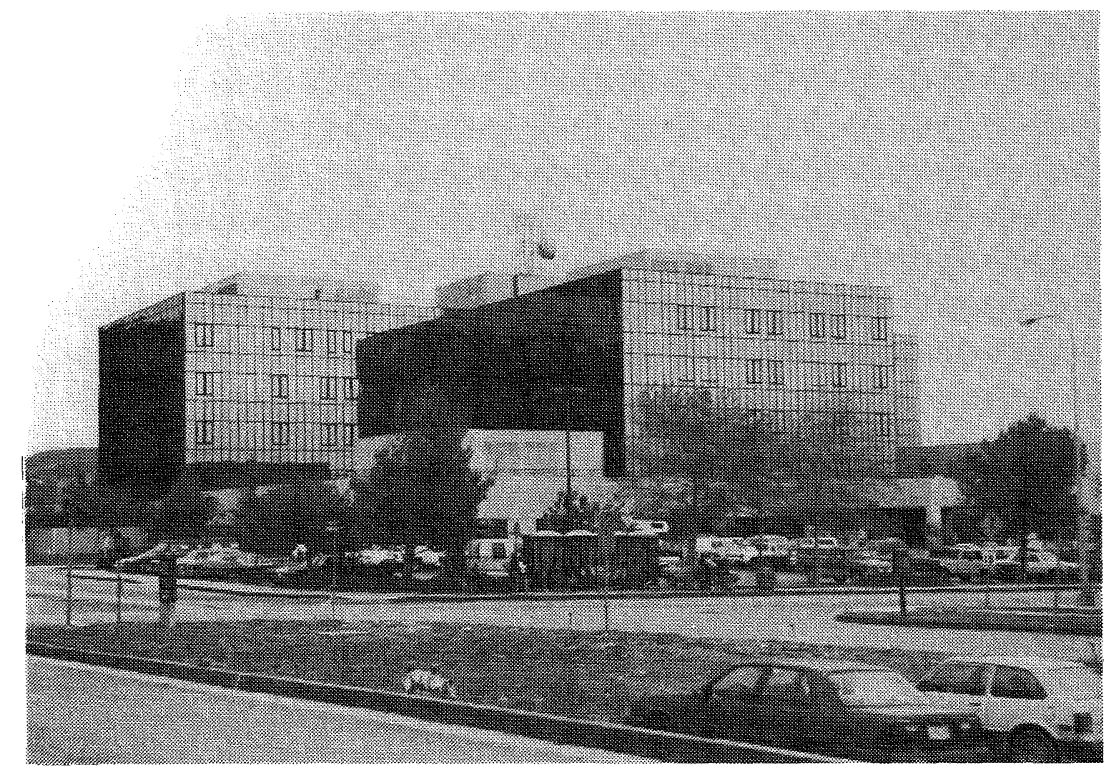

FIGURE 6.21. Olive View Hospital (i.e. County Hospital at Sylmar).

earthquake (designed in 1976). The structure is 6 storeys high, with a 2 storey podium $(93 \mathrm{~m} \times 139 \mathrm{~m})$ and the upper 4 storeys formed in a symmetrical cross (in plan, each arm of the cross, east-west, north-south, is $93 \mathrm{~m}$ long and $31 \mathrm{~m}$ wide). The reentrant vertical faces of the cross ( 8 in all, 4 in each principle direction) are shear walls (first 2 levels are concrete and the upper 4 levels are structural steel). The vertical loads were carried by the walls and a uniform grid of columns at about 8 metre centres.
The free field maximum horizontal accelerations at this site was $0.9 \mathrm{~g}$. At the roof of this structure the maximum horizontal acceleration was $1.7 \mathrm{~g}$.

The structure showed no significant structural damage, minor cracking at worst in some of the concrete structure. However the hospital was out of operation for a week, having to evacuate the patients, because of water damage when about five sprinkler heads were broken and a chiller water pipe (approx. $125 \mathrm{~mm}$ in 
diameter) fractured. The breakages occurred in the top of the building and the water permeated to the ground floor.

Damage to contents and fitout was surprisingly little. Only one window was broken in the curtain wall - a low flying seagull, not the earthquake. Note that the hospital followed a very effective scheme of securing against earthquake attack, the ceilings, mechanical services, partitions, enclosed storage racks, cupboards etc. (including computers and TVs). The level of securing appear to be significantly greater of that seen in commercial offices generally consistent with the need to maintain hospitals and other important buildings operational following earthquake attack.

\section{(d) 2020 Santa Monica Boulevard, Santa Monica (8)}

This 5 storey structure has a dual structural system of reinforced concrete moment resisting frames and concrete shear walls (along both principle axis of the building and was built in the late 1960s. It was reported that some of the shear walls were built in 1988 as a strengthening measure (Figure 6.22).

There was some damage to the columns in the form of shear cracking induced from 'short column effects'. Architectural concrete spandrels were not separated from the sides of the columns.

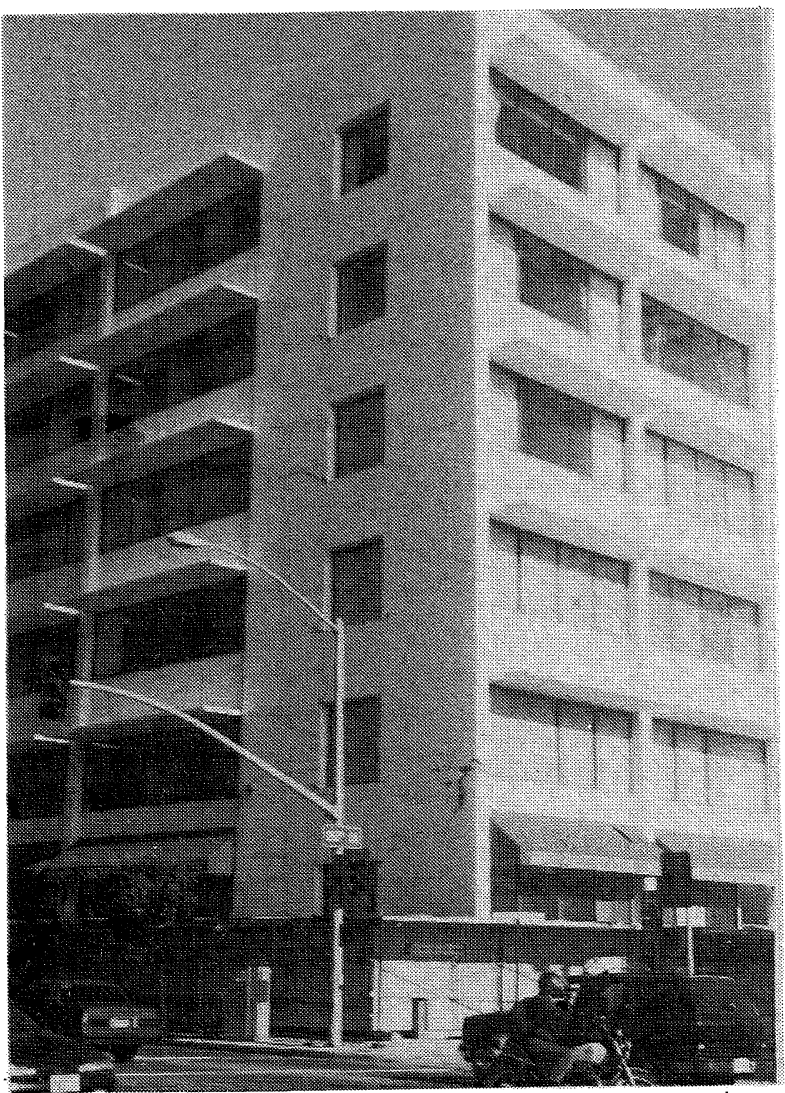

FIGURE 6.22. 2020 Santa Monica Boulevard.

Note the plywood sheets in the windows. Local frame flexibility may have over-loaded the window system.
Damage to the shear walls occurred predominantly between the first and third floors. The damage viewed in Figure 6.23 shows a splice in structural steel columns that occupied the end regions of the older walls. The concrete has spalled exposing the light reinforcement around this zone. Flexure-shear cracking in the piers of this pierced wall were typical (Figure 6.22). The older walls faired less well compared to the newer walls, as expected (possibly due to better detailing in the newer walls).

It was reported that the building was out of operation for 24 hours due in part to flooding because of sprinkler damage, an AC plant $(500 \mathrm{~kg})$ breaking its fixings, and extensive falling of ceiling tiles $(1250 \mathrm{~m}$ of ' $\mathrm{T}$ ' rails and 1000 pallets of ceiling tiles were being replaced).

(e) Champaign Tower, Santa Monica (4)

As discussed in Section 6.3.2.1, this is a 15 storey building consisting of reinforced concrete frames on the east and west faces, with coupled shear walls on the north and south faces (Figure 6.24).

It is interesting to note that the damage to the coupling beams is extensive in the lower two-thirds only of the south wall. The coupling beams are reported as having conventional reinforcement (i.e. no diagonal reinforcement as might be expected) and that these beams were penetrated by services further compromising their capacity. The bases of the walls showed only minor damage: fine shear cracking was evident

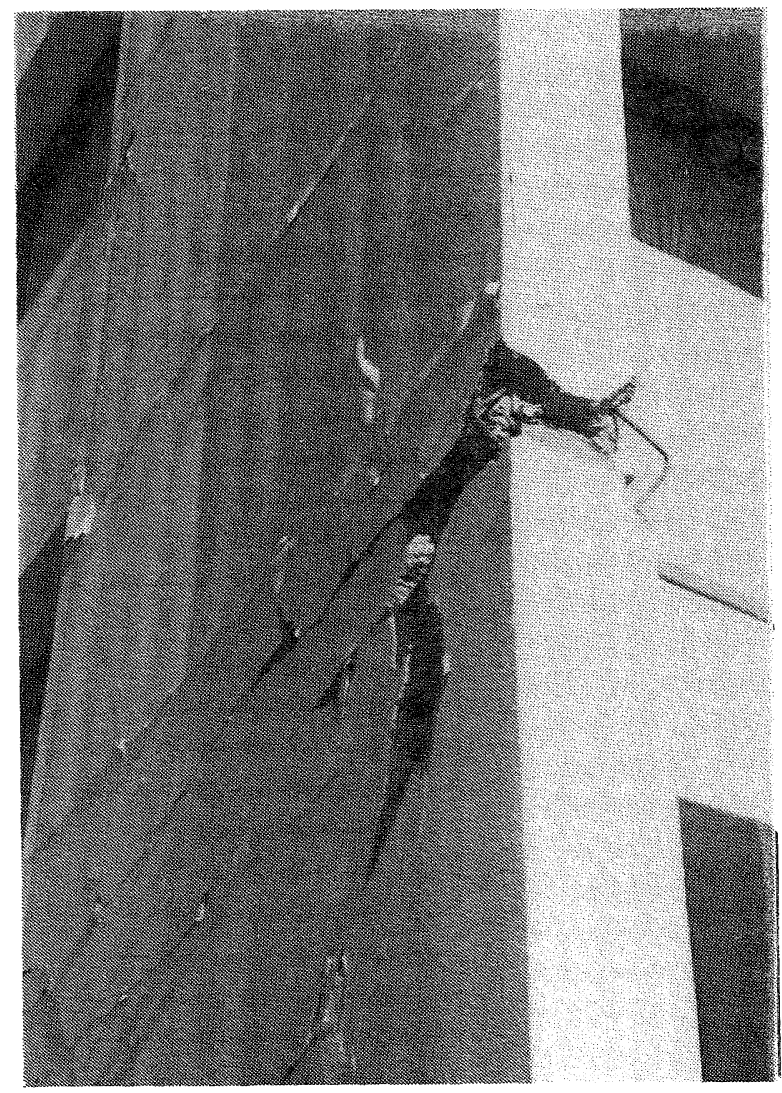

FIGURE 6.23. 2020 Santa Monica Boulevard. Close up of spalled end zone of the north west wall. 


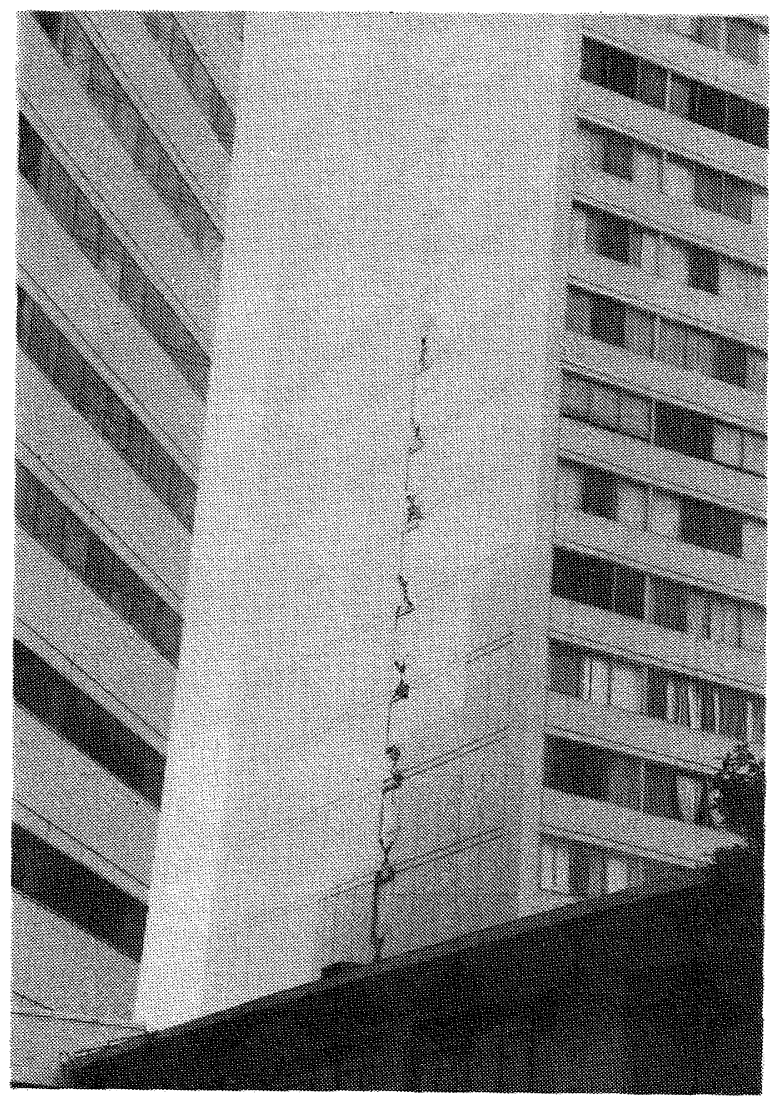

FIGURE 6.24. Champaign Tower, Santa Monica. South coupled wall.

\subsubsection{Tilt up concrete}

Many of the light industrial and low-rise retail buildings observed employed tilt-slab concrete or reinforced masonry exterior wall construction techniques for some or all of their exterior facades. These were observed to be similar in style and use to their New Zealand counterparts. They were generally single storey buildings with eaves heights of between 5 and $7 \mathrm{~m}$.
Although the majority were used for light industrial and warehouse purposes (with relatively low occupancy density) several retail shopping complexes also used this form of construction. Such buildings were commonly fitted with suspended ceilings and with some areas partitioned off with demountable office partitioning (generally to the suspended ceiling). Roof pitches were generally minimal $\left(<5^{\circ}\right)$. Roof systems were most commonly steel or although several glue laminated timber frames were observed, supported from either columns or corbels built into the perimeter walls. The roof was commonly a fabric membrane laid over a plywood substrate. Bitumen and chip-seal toppings were common.

The structural form was such that the plywood roof sheathing was required to act as a diaphragm accepting face loading from the top of the face-loaded tilt slab panels and transmitting these actions into in-plane loads on the transverse panels. The contributing seismic mass was thus the upper portions of the face-loaded walls together the self-weight of the roof system itself. Where the integrity between wall and roof diaphragm was maintained, damage was typically confined to the suspended ceiling systems with little or no structural damage. However there were several instances where the connection between the plywood diaphragm and the edge ribbon plates were inadequate. The joint became very flexible under the repeated earthquake cyclic action. This flexibility resulted in the roof systems developing a non-sympathetic dynamic response and impacting against the upper portion of the tilt-slab wall panels. The panels spread with the end-bay rafter span increasing until the rafter hanger support became ineffective whereupon first one, but sometimes both, end bays collapsed (Figures 6.25 and 6.26).

\subsubsection{Case Study}

Tilt-slab Construction, De Soto Drive (9)

A detailed study of a group of six identical buildings built in accordance with the above description revealed this form of collapse in five of the six cases. The plywood was $5 / 8$ inch thick. The plywood was attached to Douglas Fir ledger plates with a single row of $3.15 \mathrm{~mm} \times 75 \mathrm{~mm}$ long nails at approximately $150 \mathrm{~mm}$ centres around the sheet perimeter. Rafter hangers hung from the glue laminated transverse beams

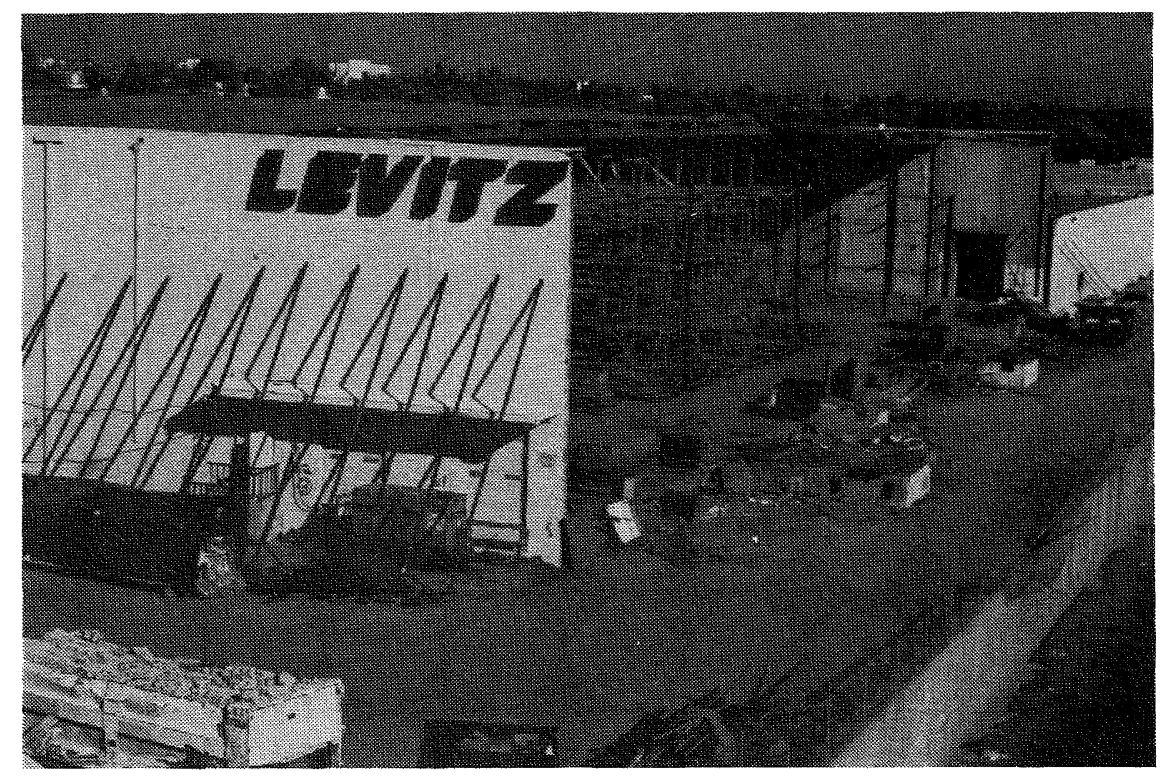

FIGURE 6.25. Levitz Store, Northridge Where both the end roof bay has collapsed and the end wall followed. 


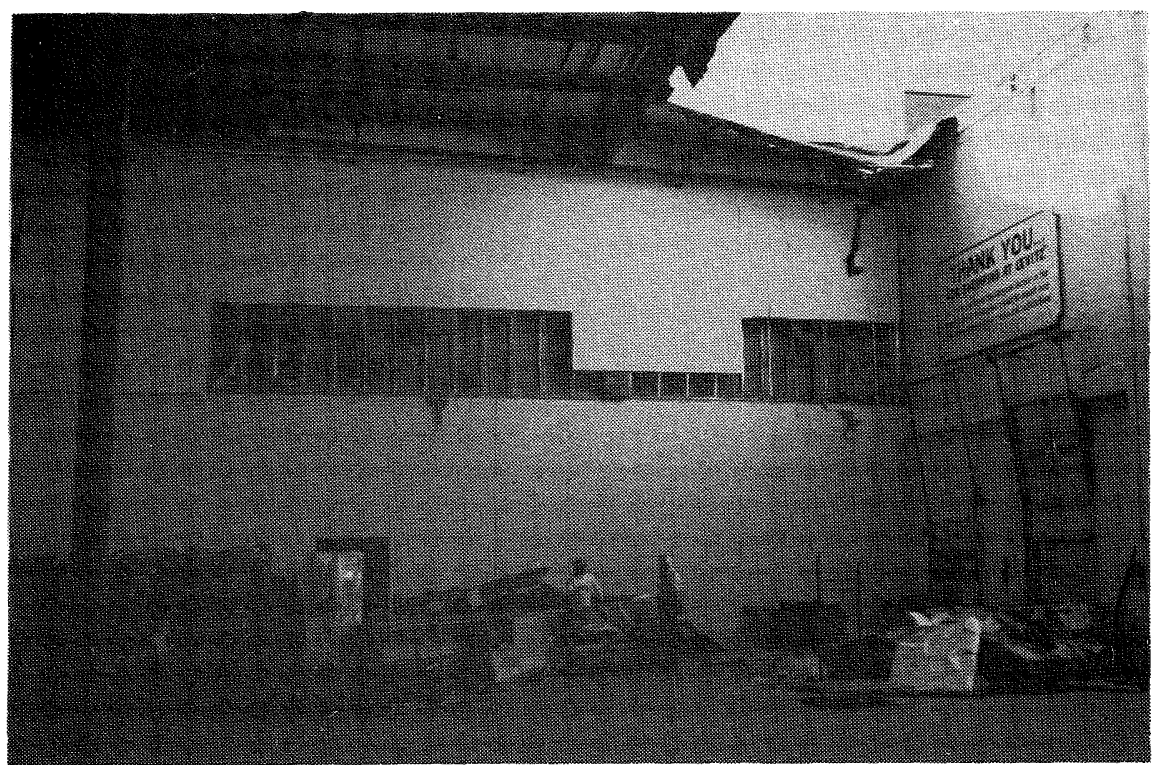

FIGURE 6.26. Levitz Store, Northridge. End bay of the roof system has spread and collapsed.

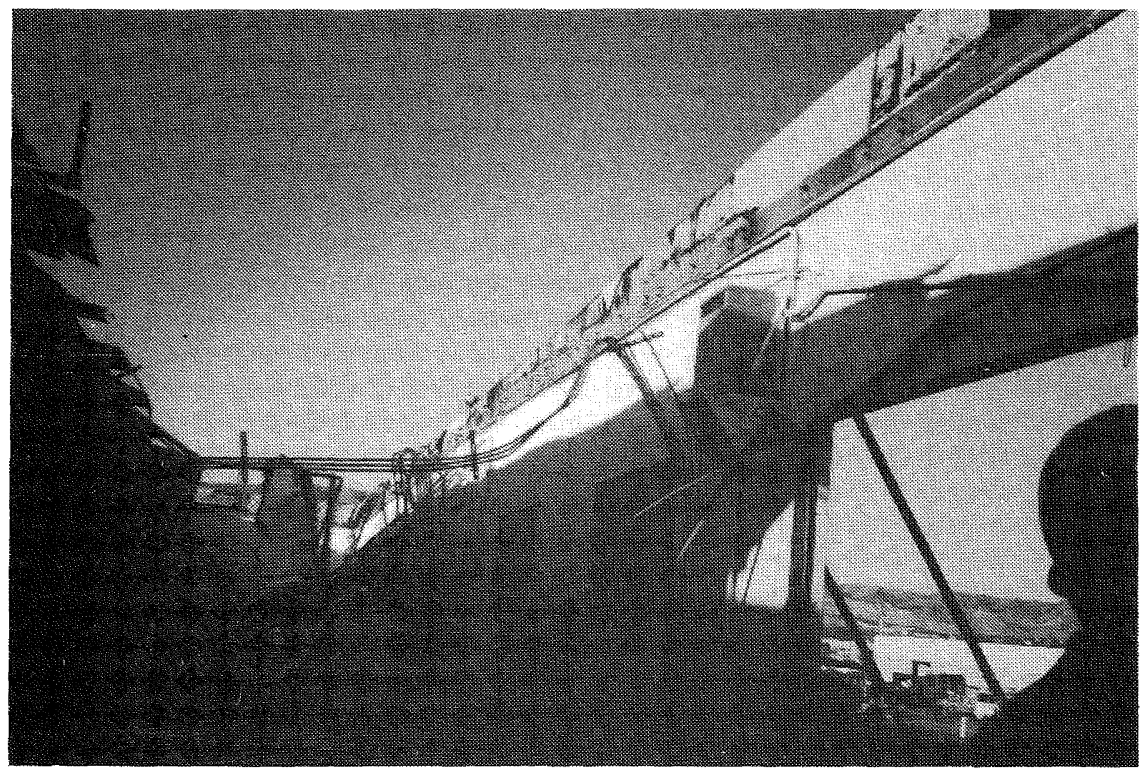

FIGURE 6.27. De Soto Drive Warehouses. The end bay has spread without positive anchorage between rafters and end wall. End bay collapse resulted.

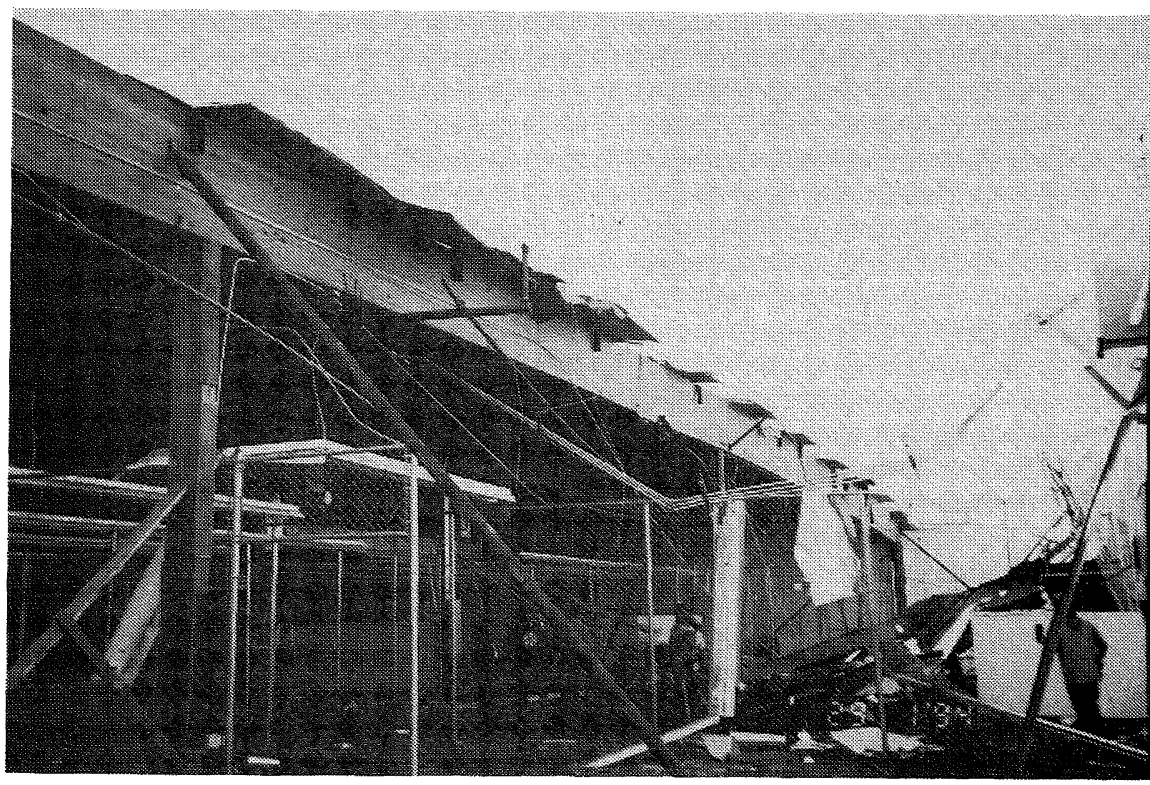

FIGURE 6.28. De Soto Drive Warehouses. Glulam portals with rafter hangers and ties prevented spread at one end only. 
at approximately $2.4 \mathrm{~m}$ centres: The rafters were connected by a light steel strap which passed over the upper face of the beam effectively tying the rafters along their length. In the end bays however, the rafters were supported on rafter hangers which were fastened to the ledger plate at their upper face. Support for the upper half of each end wall was thus limited to the plywood nails. The dynamic response of these walls and the roof systems itself were incompatible and end bay failure resulted either at one end or, in two cases at both ends. The end wall ledger plate was noted to have split perpendicular to its length (and grain) but it is not clear whether this occurred prior to or during collapse (Figures 6.27 and 6.28).

The ledger plates along the side walls, whilst continuing to provide support for the roof diaphragm, was also noted to have been working hard with the diaphragm nails showing signs of tearing the plywood. Some splitting of these transverse ledger plates was also noted. The battering action of the roof, combined with the face loading of the tilt-slab panels resulted in a permanent outwards spread of the slabs themselves. This spread was noted to be upwards of $500 \mathrm{~mm}$. Steel shoring props were required to provide stability. Damage was also noted at in the corner junctions of the tilt-slabs themselves where the linkage reinforcing present proved inadequate to maintain the integrity of the slab joint at the corner.

The sixth tilt-slab building in this particular complex had been retrofitted and performed well. Whilst it too shed its suspended ceiling, no structural damage was observed. The retrofitting program involved introducing a continuous tie around the perimeter of the building immediately below the roof diaphragm and by providing positive anchorage between the rafters and the end tilt-slab panels. Continuity of the perimeter angle $(75 \times 75$ $\mathrm{mm}$ ) was achieved at the glue laminated rafter junctions by splicing a steel bar behind the rafter and welding it onto the face of each adjacent angle. The rafter anchorage was provided by splicing a simple strap onto each side of the rafter and providing an epoxy anchor bolt into the face of the panel. (Note: the City of Los Angeles passed an ordinance that all tilt-slab panel buildings are to be retrofitted to ensure adequate connections between the panel and the supporting mechanism. This had been awaiting action for the past two years, and was passed on February 2nd along with two new ordinances which require all boundary walls greater than three feet six inches high and all domestic masonry chimneys to be subjected to specific design).

\subsubsection{Parking Buildings}

Ten car parking buildings within the epicentral suffered partial collapse during the event. The exact reasons for each collapse varied. A further twelve sustained damage that was thought to be repairable. All were concrete buildings and used a combinations of cast-in-place and precast beams, columns and slabs (both post-tensioned and conventionally reinforced). One structure, though built in concrete, had steel bracing to resist lateral forces. Some of this bracing failed during the event. Apparently within the epicentral region there are also approximately ten parking structures that suffered little to no damage. Fortunately all car parks were unoccupied at the time of the earthquake (although a street cleaner was trapped in the Northridge Fashion Centre car-park when it collapsed (Figure 6.29)). The seismic mass activated was thus solely the selfweight of the structure i.e. zero live load.

Most buildings relied heavily on the horizontal floor diaphragm to distribute the lateral forces to perimeter frames typically and/or to walls which were usually few in number and again typically located around the building perimeter (this is understood to, in part be, for ease of security within the buildings as there are fewer visual obstructions within the buildings).

The reliance on wide spanning floor diaphragms to accept, transmit and distribute seismic forces generated within the structure to these exterior frames or walls may have been misplaced, particularly when the slabs were precast and the topping thin or when the slabs were subjected to large penetrations from the ramps. Commonly, a cause of collapse was the lack of reinforcement (or connectors) between the slabs and supports. In such cases lateral forces were unable to be transmitted to the intended vertical elements. The consequent excessive horizontal deflections which resulted were required to be sustained by other vertical elements which appeared to have been designed only to carry vertical gravity loads (sometimes denoted as 'secondary frames or systems') and possessed only nominal confinement steel and were unable to accommodate the flexure and shear induced from the imposed deflections. An extreme example is shown in Figure 6.30 where the complete car park building collapsed leaving only the stair tower standing. Other examples of failure of diaphragm-to-shear wall connections are car parks at St Johns Hospital, Santa Monica and Sherman Oaks Galleria.

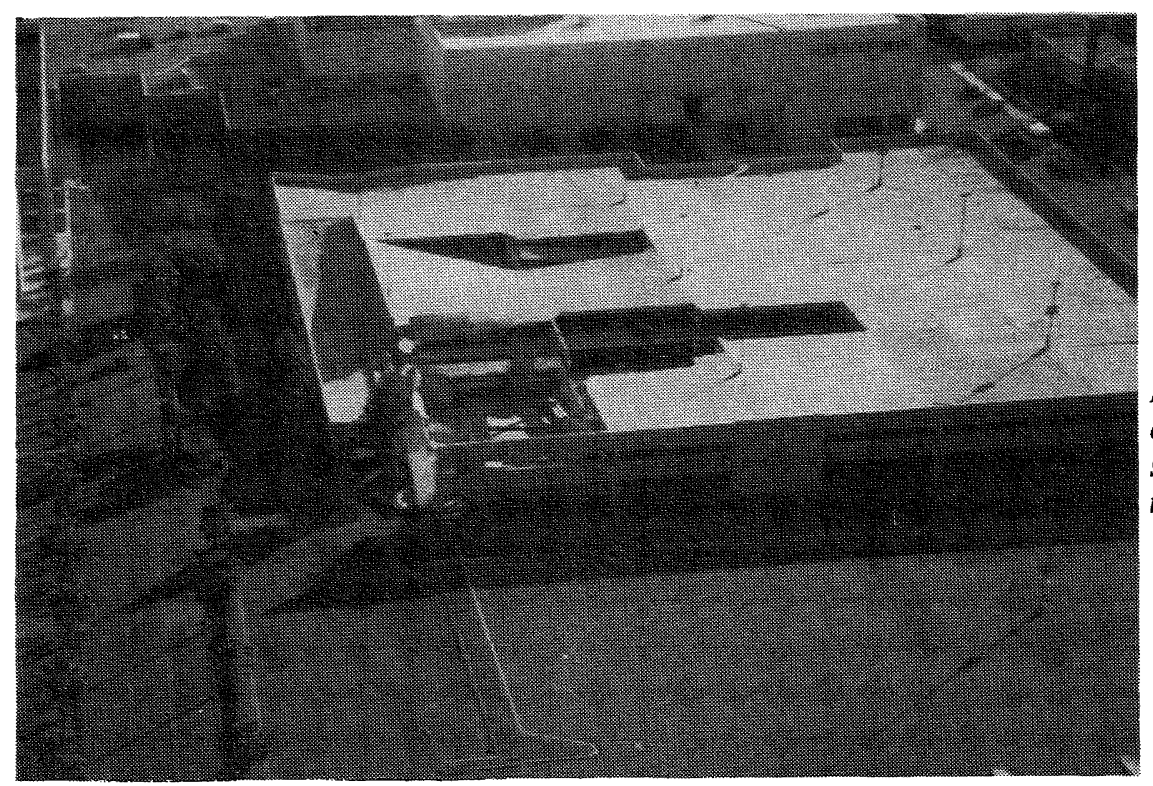

FIGURE 6.29. Sections of precast slab collapsed, in this car park, due to loss of seating because supporting columns of the interior gravity frame failed. 


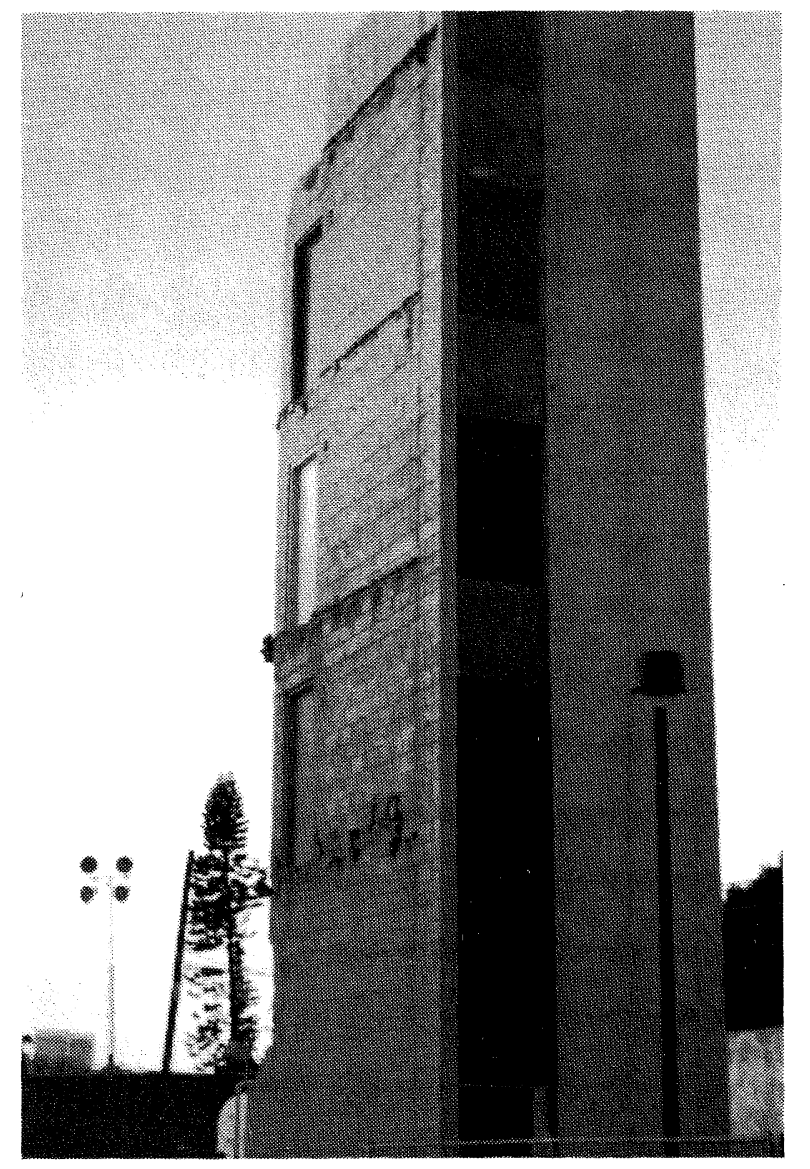

FIGURE 6.30. Car park access tower remains while the building has collapsed.

Another cause of excessive lateral deformation in secondary frames arose through the primary lateral force resisting systems (frames and/or walls) being more flexible than had been expected. Similarly, flexibility in floor and roof diaphragms (irregular shape or high degree of penetrations) would have contributed to the sidesway experienced by the secondary systems.

The influence of the ramps acting as inclined diaphragms seems to have been underestimated when considering the lateral load path. Local slab failures adjacent to the ramps were noted in some cases. Likewise the variable column heights (and thus stiffnesses) caused by their interaction with the ramps, have influenced the column shear distribution leading to overload in a number of cases.

The presence of substantial shear cracking, sometimes combined with crushed concrete (through insufficient confinement for the ductility demands experienced), followed the development of a plastic hinge zone at the column bases. Several such columns collapsed shedding the beams they supported in the process.

Whilst the empty car parks (reduced seismic mass) would have reduced the lateral forces imposed, there was some evidence that the effective damping present was also very low, a factor which may have exacerbated the vertical dynamic response of some horizontally spanning members. There were instances where the dynamic vertical effects may have induced shear failure of precast concrete 'double- $T$ ' beams and 'inverted-T' support girders. The combination of low occupancy load, low damping and significant vertical accelerations appears to have been responsible for one such failure. In this case, inclined shear cracks were seen in the support girders and in the flanges of the
'double-T' end beams, while the 'double-T' beams towards the centre of the girder support had experienced shear failure (the end support segments remaining in place together with some of the topping slab) while the beam itself collapsed.

\subsubsection{Case Studies}

(a) California State University Northridge Car Park building (10)

This 1991 car park building is located on the California State University Northridge campus. It is a four storey structure which, while capable of housing upwards of 2500 vehicles, was empty at the time of the earthquake. The overall plan dimensions are approximately $120 \mathrm{~m}(\mathrm{E} / \mathrm{W})$ by $100 \mathrm{~m}(\mathrm{~N} / \mathrm{S})$ Extensive use has been made of precast concrete with the external perimeter frame, (full height columns with integral spandrel beams extending to midspan). The internal columns were also precast concrete elements and extended the full height of the building with full restraint at their base. All columns were cast with simple seating corbels at each floor designed to accept standard precast primary beams which span approximately $15 \mathrm{~m}$ $\mathrm{N} / \mathrm{S}$. Interior columns were regularly located at approximately $5 \mathrm{~m}$ spacing with the primary beams. The exception was the first grid of interior columns was replaced with a clear spanning support beam to allow for a traffic flow around the perimeter. Two bi-directional access ramps extended between floors. Each deck was a cast-in-place concrete slab with greased prestressing tendons extending full width across the structure (in the $\mathrm{E} / \mathrm{W}$ direction). Access stairs were provided at each corner and midway along the west face. These stairs comprised two precast concrete shear panels and steel stair treads (Figure 6.31).

This building experienced substantial collapse over several bays along the full extent of the east face. Sections also collapsed about both the northern and central western stair shafts where collapse, although somewhat more localised, still extended several bays into the building. The primary collapse mechanism involved the development of plastic hinges in the base of the first interior corner columns (adjacent to the traffic assess routes where the columns were supporting both standard (N/S spanning) and primary (E/W spanning) beams.

The lateral load resisting system appears to have been designed as a perimeter frame formed from the external column and spandrel beam system which accepted lateral load from each floor diaphragm, and was expected to transmit this by frame action. The spandrels were constructed as 'half beams' springing from each column and meeting at midspan. It was reported that the only beams connected to achieve a moment capacity at midspan were located over the mid-zones of each side of the building. As a result, the beams at the corners of the building simply failed at the non-existent midspan connections. Thus the external frames reverted to cantilever columns, with the spandrel links experiencing shear dislocation at midspan (Figure 6.32). The resulting displacement of the interior precast beams from their supports saw them falling from their corbels onto the lower floors and an incremental collapse commonly resulting. Beams fell vertically directly onto their lower counterparts displaced longitudinally by the seating dimension of the corbel (Figure 6.33). The prestressing cables remained intact, but with the weight of the collapsing superstructure, pulled the east end wall into the remnant shell. Extreme curvature ductility was apparent within the intact east end panels (Figure 6.34).

The internal columns (which had not been designed to accept significant lateral loads) developed plastic hinges at their base and failed due to inadequate confinement reinforcing. In so 


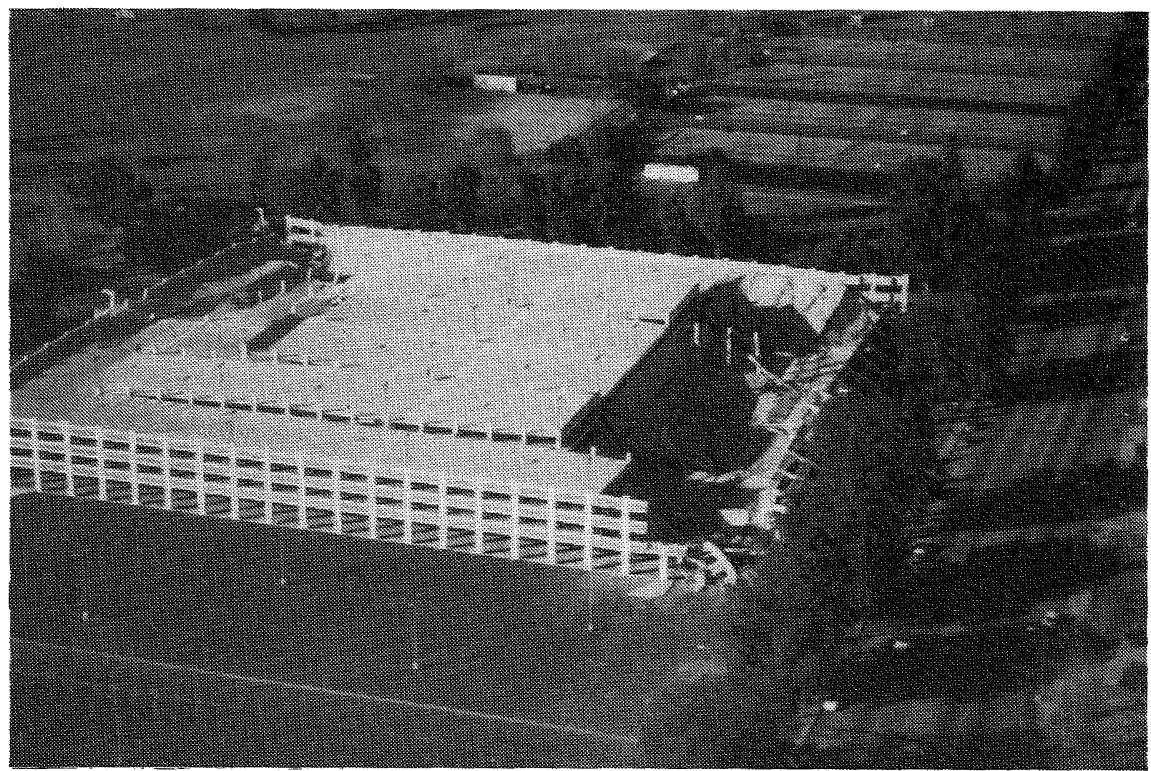

FIGURE 6.31. California State University Car Park. Aerial View showing eastern and $N / W$ corner collapse.

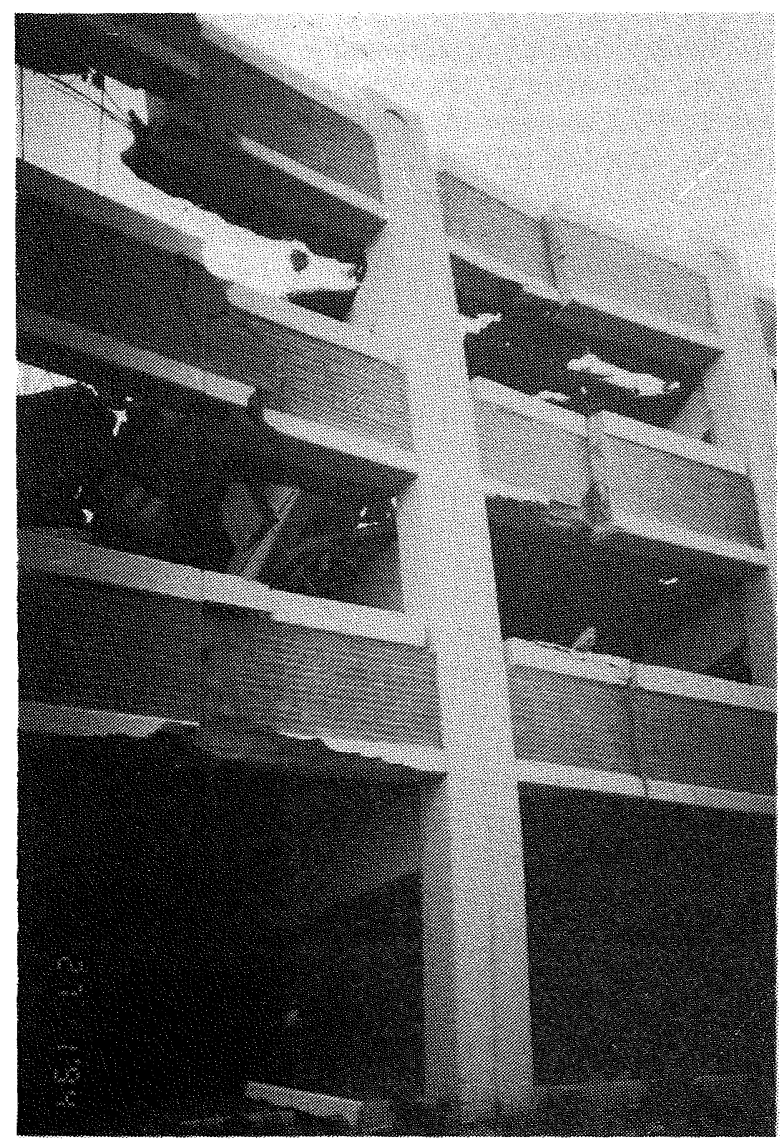

FIGURE 6.32. California State University Car Park. Exterior column/spandrel elements - note mid-span spandrel connection details.

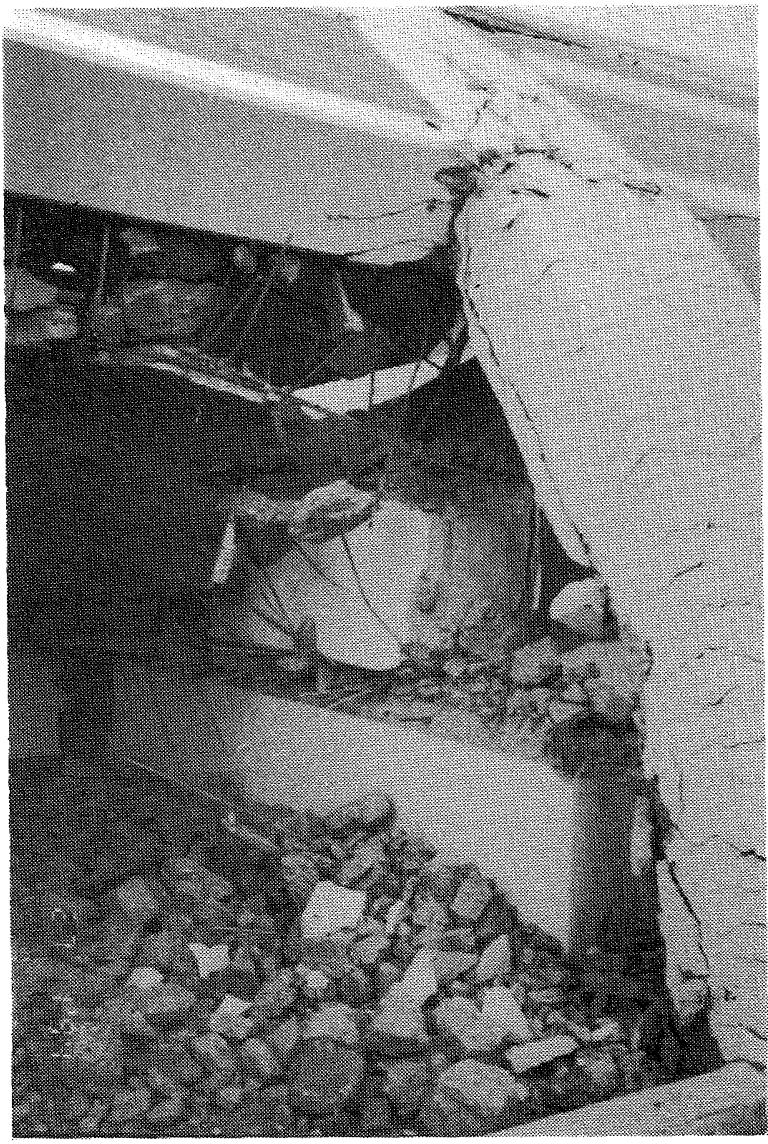

FIGURE 6.33. California State University Car Park. Upper precast beams slipped from their corbel supports and collapsed onto their lower level counterparts. 


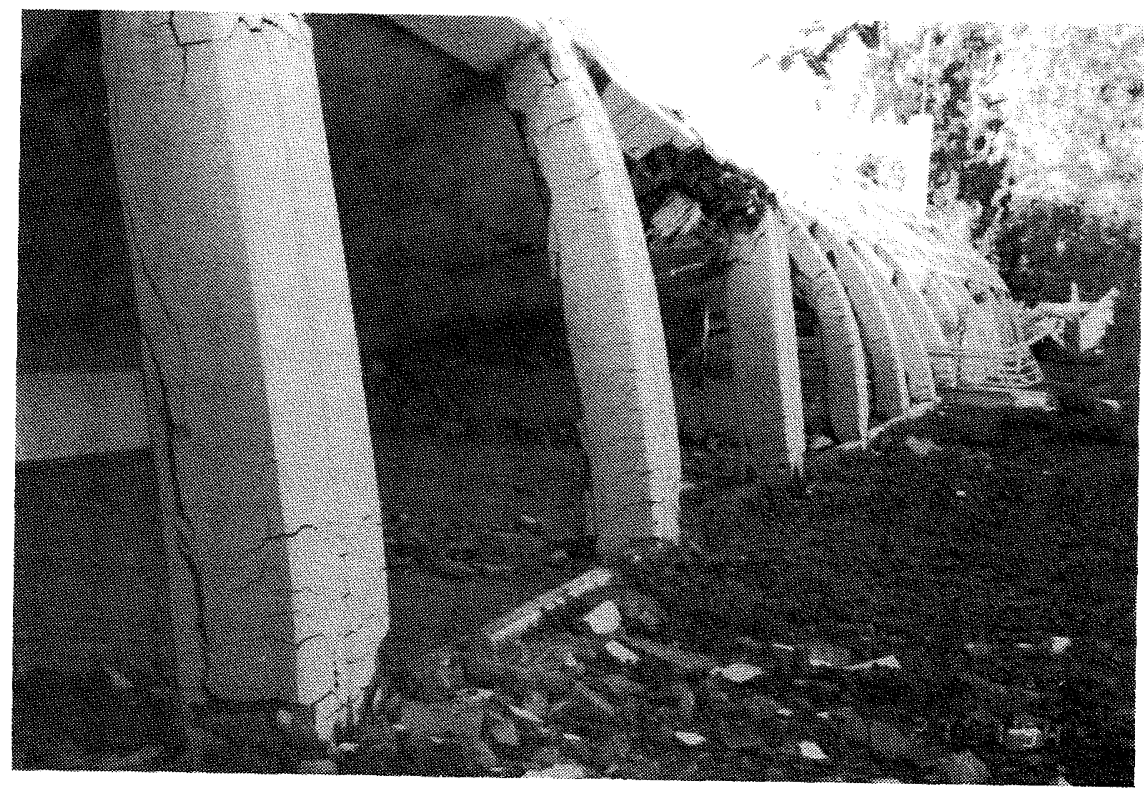

FIGURE 6.34. California State University Car Park. The prestressing tendons remained intact and pulled the East face into the building as upper beams and floor panels collapsed onto lower beams.

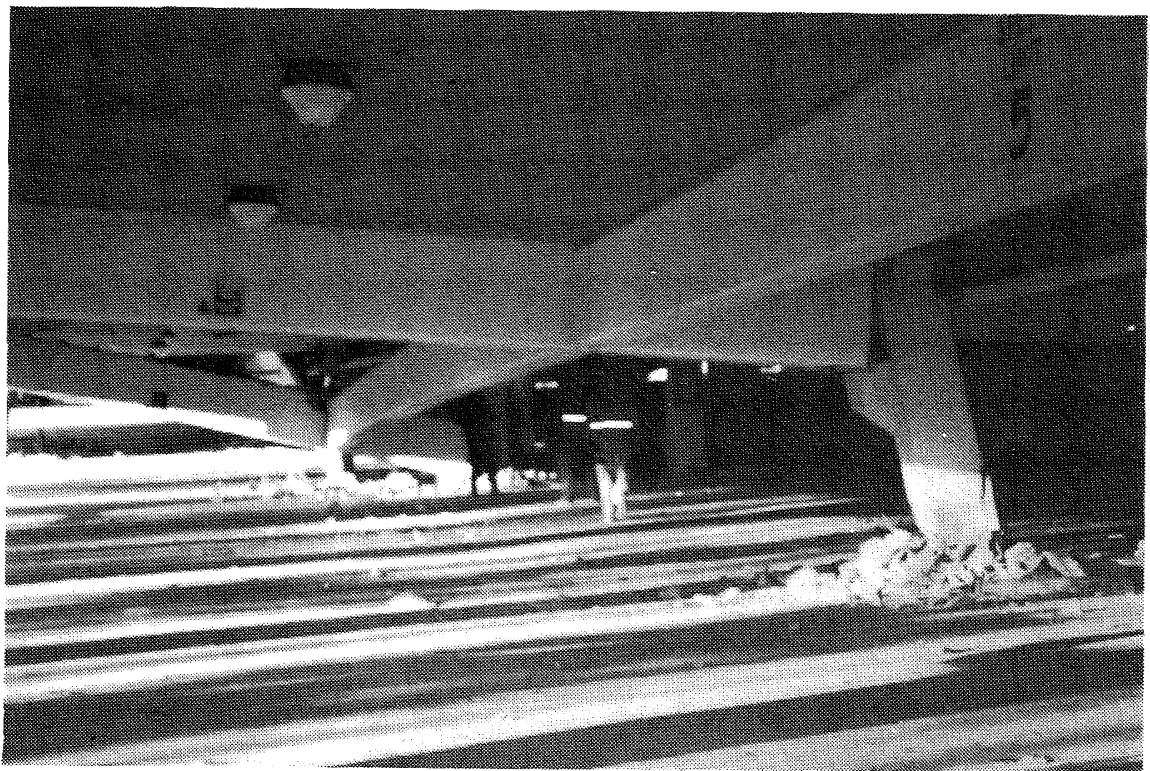

FIGURE 6.35. California State University Car Park. Internal Column Base Failures with beams slipping from their supporting corbels.

doing they displaced west by approximately $600 \mathrm{~mm}$ at their base. The precast girders fell from their supporting corbels. Collapse was sometimes localised (i.e. only affecting the beams in the immediate vicinity at one floor level) but in other cases dislodged upper level beams. The impact effect of these beams collapsing onto the greased post-tensioning cables was sufficient to displace other columns and initiate incremental failure both up the height of the column and within adjacent bays. Such beam collapses appeared not to be associated with significant lateral drifts as the $(\mathrm{E} / \mathrm{W})$ beams were neatly stacked upon each other from the upper floors (Figures 6.33 and 6.35).

\section{(b) Sherman Oaks Galleria Car Park (south) (11)}

This reinforced concrete car park consisted of two storeys, possibly of a 1980s vintage. The section viewed was part of a group of three separate structures. Access to this car park was restricted. It was reported that the lateral force resisting system included structural walls.

Figure 6.36 shows the collapsed exterior column. Note the prestressing anchorages exposed by the damage in the ends of the beam. This form of failure occurred along the entire north side of the structure. The relative displacement results from a southward movement of the upper structure with an offset of the lower columns to the north. Observations indicate that the beam-column joint contained a relatively high density of transverse reinforcement. However, there was a length of column immediately below the joint which appeared to lack any transverse reinforcement. Failure occurred within this region because there was insufficient confinement resulting in buckling of the main reinforcement and shear degradation of the column core (Figure 6.36). 


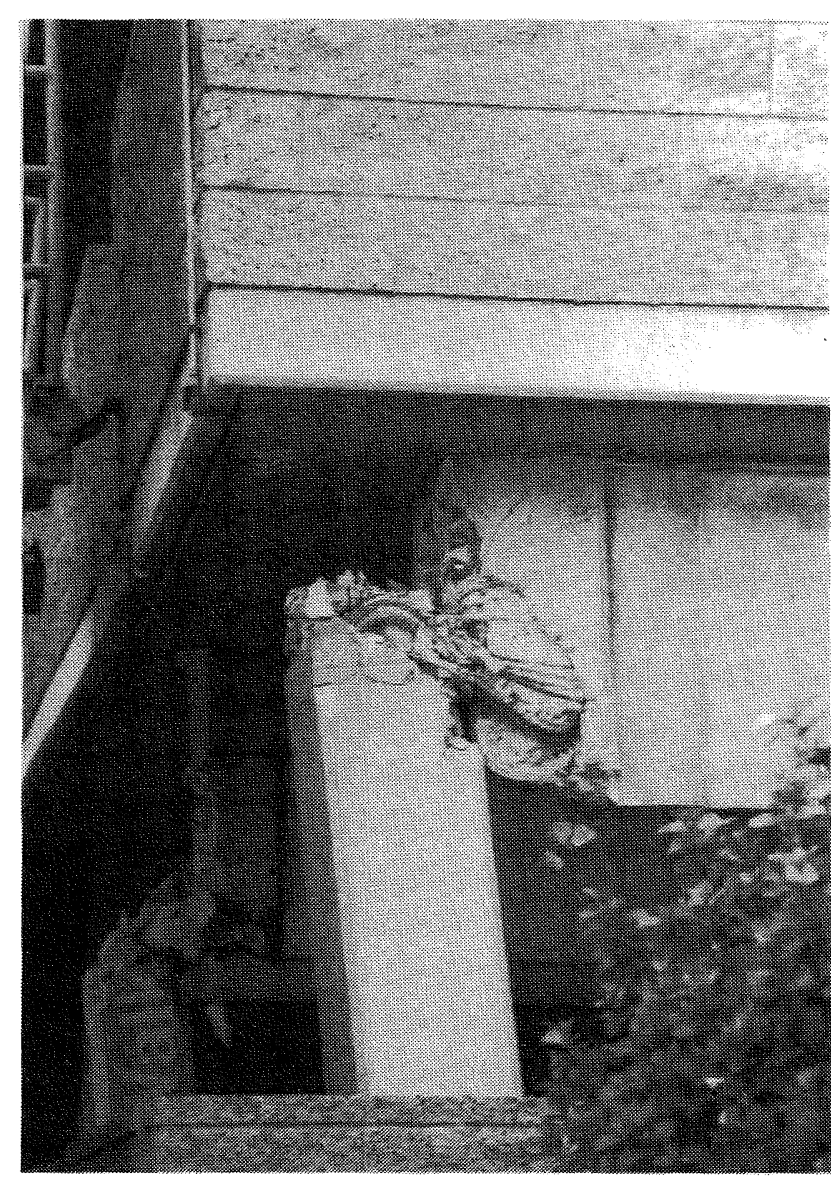

FIGURE 6.36. Sherman Oaks Galleria Car Park (south). Exterior column at ground level.

Figure 6.37 shows a collapsed column along the west perimeter. It too shows a significant length of column (under the joint) that is unreinforced in a transverse sense. There is evidence of compression bar buckling on the right side of the column (Figure 6.37). Possibly more significant is an apparent failure of the transverse reinforcement in the column, not by tension, but rather the $90^{\circ}$ hooks at the stirrup terminations appeared to unbend as cover concrete spalled during the earthquake. This straightening resulted in a loss of confinement which lead to failure. Note the ' $X$ ' shear crack pattern in the damage zone at the top of the column (Figure 6.37).

(c) St Johns Hospital, Santa Monica. Car Park (west)

The car park in Figures 6.38 and 6.39 was one of three at this hospital. In the east-west direction, the walls appeared to resist the main earthquake input. The walls were unreinforced transversely (no stirrups or ties) and had a single layer of reinforcement longitudinally.

The type of damage observed was typical of unconfined concrete. The lowest wall exhibited signs of relative movement into the building.

The building consisted of frames in the north-south direction. There were 'short column effects' in these frames because of built-in architectural infill block masonry walls. The size of these effects was not large enough to lead to column shear failure.

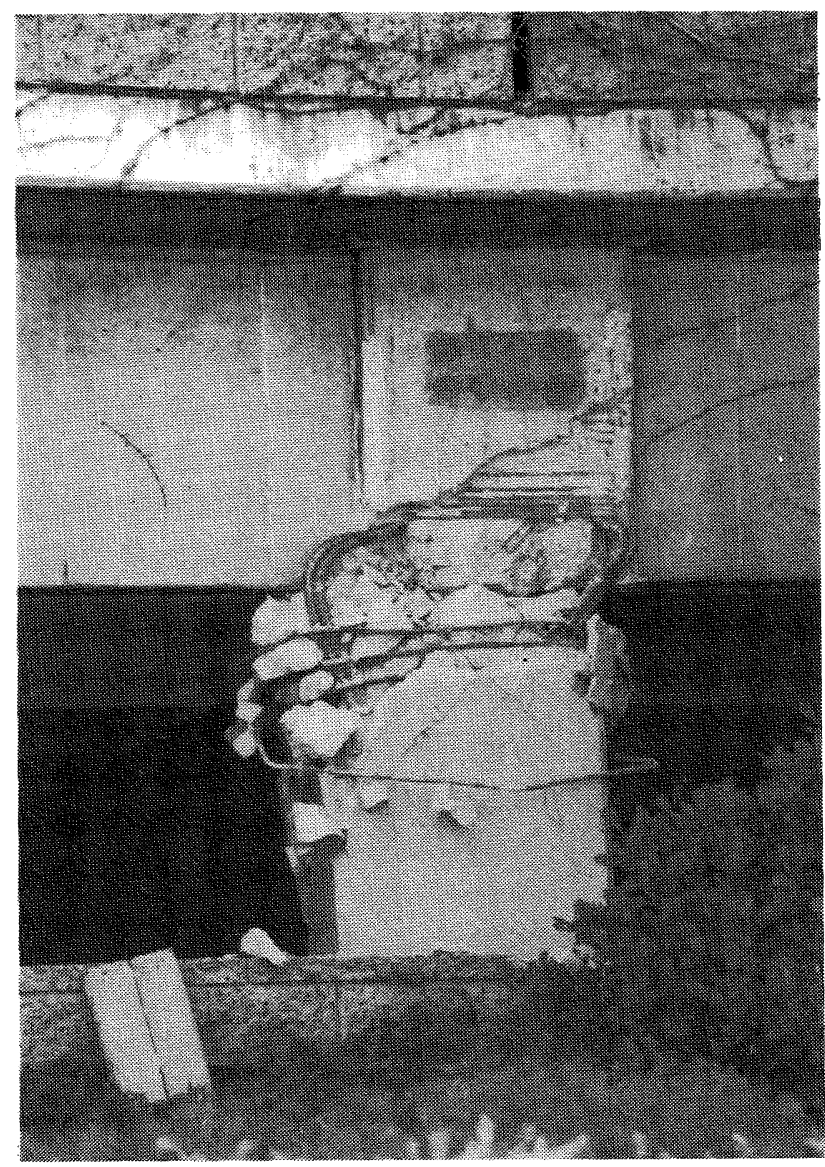

FIGURE 6.37. Sherman Oaks Galleria Car Park (south). Perimeter column at ground level.

\subsection{Steel}

\subsubsection{General}

At the time of the reconnaissance team's visit to Los Angeles, it appeared that structural steel had performed very well. Indeed it was difficult in the time to find steel buildings with damage. In the first technical meeting organised by AISC (American Institute for Steel Construction) [1994a], reports indicated that there were about 20 damaged steel buildings; this was later amended to 40 in April by AISC [1994b] and in the latest AISC [1994c] Technical Bulletin the figure has now been amended to more than 100 .

While this figure is high, there have been no collapses and most of the buildings have remained functional. The major concern with the damage to steel buildings was that problems were not readily apparent after the initial event. Indeed it was only when it was observed that damage resulting from aftershocks was greater than that caused by the initial shock that more exhaustive investigations were undertaken. It was then discovered that joint failure at beam column junctions was prevalent. The ability of structures to resist these additional loads and displacement has been greatly reduced.

If the magnitude and frequency of aftershock had not been at the recorded levels then it is doubtful that the extent of the problem would have been appreciated. 


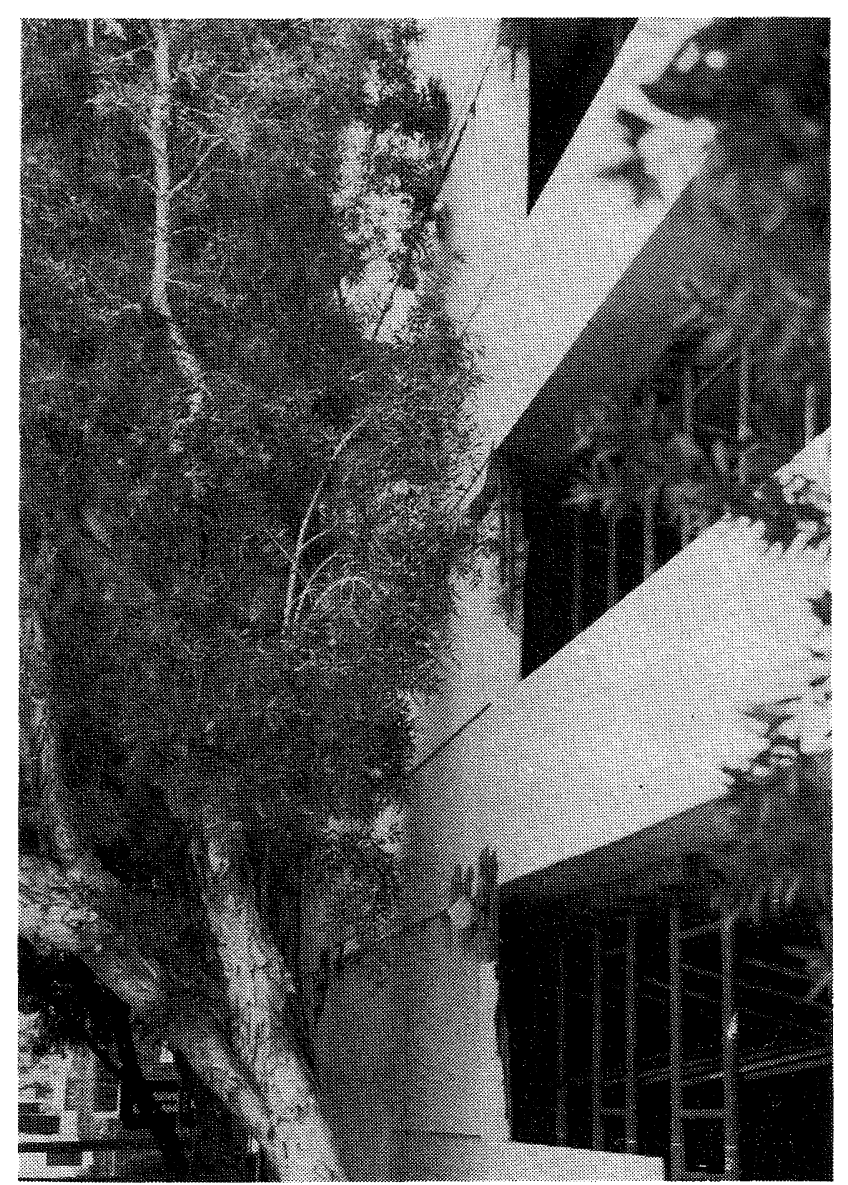

FIGURE 6.38. St Johns Hospital, Santa Monica. Car Park (west). View of the northern end. Note the damage to the shear walls (3 levels).
A common theme with nearly all buildings causing concern were beam column joints of moment resisting frames where the beam flanges had been site welded and shear was transferred to columns principally by bolting. This form of joint has rarely been used in New Zealand where the common practice has been to fully weld the beam web as well as the beam flanges to the column flange.

Additionally, as reported by HERA [Clifton, 1994], steels commonly used for construction in New Zealand are likely to exhibit greater ductility due to the use of steels having reducing yield strengths as thicknesses increase. In the USA the opposite applies where a uniform yield stress is sought regardless of plate thickness and is achieved principally by increasing carbon content with a resulting increasing in hardness.

With the problem now identified in the USA, a programme to reduce seismic hazard in structural steel has been put together by a SAC joint venture [1994]. This grouping will not only focus on design for future steel structures but will also address the development of guidelines for identification, evaluation and rehabilitation. Testing has already begun at the University of Texas by M.D. Engelhart [1994] with a progress report having been published, part of which is included in a latter section of this paper.

\subsubsection{Beam-Column Joints}

As noted above, the principal cause of failure in structural steel has been in beam-column joints where the flanges of the beams have been site welded and transference of shear is principally through bolting to the beam web. In more recent buildings, the SEAOC (Structural Engineers Association of California) [1994] code requires that where such a joint in a beam results in a ratio of flange-only plastic section modulus to original beam plastic section modulus of less than $70 \%$, then supplementary welds are required to the web cleat.

However, regardless of whether the supplementary welds were added or not a number of these joints also failed.

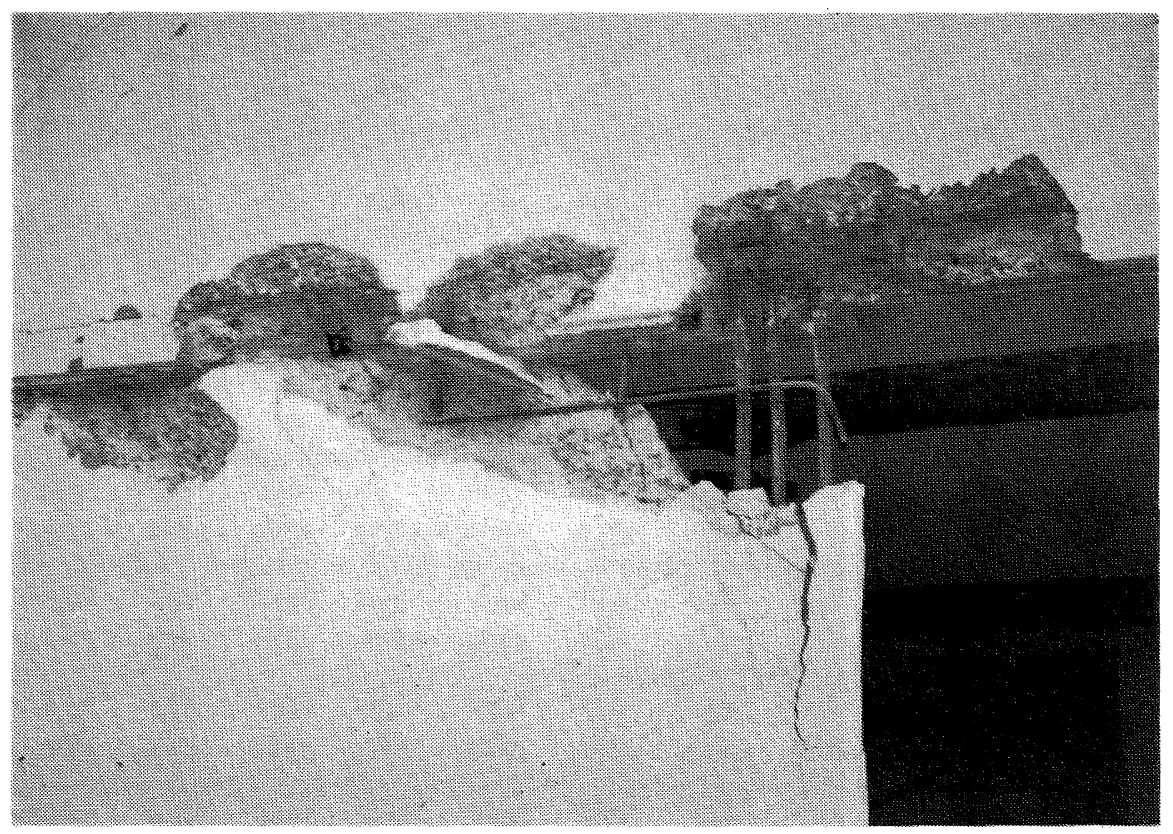

FIGURE 6.39. St Johns Hospital, Santa Monica. Car Park (west). Close up of the end region of the lowest wall. 
The failure in these joints has predominantly been by cracking in the bottom flange weld and in many cases these cracks have either propagated up through the beam web or through the column flange and into the column web. Figure 6.40 shows the various forms of cracking that have been reported. With the problems identified, the difficulty facing building owners and engineers was the form of repair to be undertaken so that the joint was restored to its original integrity.

In the only building observed, a four storey framed structure where the common joint failure was noted, repair was being made by cutting out the cracked original weld, grinding back to the crack in the column flange and re-welding the affected joint. Such a repair could only be considered doubtful at best.

A more appropriate repair would appear to be to cut out the defective weld and to weld flange plates to the top and bottom flanges of the original beam. Such a repair technique has the effect of reducing stresses in the original weld by $50 \%$. A paper by Sabol [1994] presented to the AISC March meeting on the Northridge Earthquake provided a suggested design procedure. Figure 6.41 shows the form of the detail.

More recently, Englehart [1994] has undertaken a series of tests beam/column varying from the welded flange, bolted web type which experienced all the problems to the augmented flange plate type suggested by Sabol [1994]. Figure 6.42 shows the load displacement and plastic rotation for the specimen and brief reporting on the joint. From the results to date, the joint suggested by Sabol is showing markedly improved ductilities and rotation characteristics compared to those of the welded flange and bolted web joint.

As well as providing a sound basis for repair of damaged joints, the work by Englehart will hopefully provide the necessary parameters for future designs.

The objectives and scope of the testing by Englehart [10] are to develop guidelines for steel moment joints and a repair form for where failures have occurred.

As noted earlier, the bolted web and welded flange joint has rarely been used in New Zealand and the intention of NZS 3404 [1992] Cl. 9.1.7 is to exclude such a joint. It is strongly recommended that the wording of $\mathrm{Cl}$. 9.1.7 is amended so that any doubt is removed.

\subsubsection{Braced Frames}

While the reported failures of braced frames have not been as extensive as moment resisting frames, this is probably because the actual numbers are considerably less. Where failures have been reported, this has been due to:

- large ratios of wall to thickness ratios of tube members, and

- weld fracture between the brace and gusset plate.

Bourneville [1994] reported on damage in a four storey concentrically braced building.

The extent of damage in the building was confined to brace failure in the second floor. The principle mode of failure in the brace was by local buckling with wall thickness ratios of 30 . The braces also had connection failures where no attempt had been made in the connection design to allow for the brace overstrength. It is understood that recent amendments to both the SEAOC and UBC codes will now require overstrengths to be taken into account when designing connections.

\subsubsection{Column Base Plates}

Evidence of base plate failure were noted at the Sylmar Converter Station and in reported findings of braced buildings. As with bracing connections in Section 6.4.3, no attempt had been made to match the overstrength of the brace with weld failure occurring in the column base plate connection and anchor bolt fractures. At the Sylmar Converter Station the base plate failures of equipment supports was principally by crushing of the grout between the base plate/foundation and by yielding of the holding down bolts.

\subsubsection{Welding/Material Concerns}

In nearly all the observed and reported failures, it is believed that the overall failure was through fracturing. However, there is lack of evidence at this time to identify the actual cause.

Areas of concern which would have contributed to the failure are as follows:

- A lack of fusion at the web for bottom flange welds;

- Failure to carry out testing of welds to ensure they complied with approved documents such as AWSD 1.185 [American Welding Society];

- Residual stresses in the joint due to the welding procedure;

- Inappropriate preparation of the joint either through pre-heat or inappropriate weld material;

- Failure to properly inspect joints after welding;

- The failure to remove bottom flange backing plates, and

- Poor acknowledgement of the variability of parent plate yield strengths. It has been reported that in one case actual yield strength to specified yield had a ratio of 1.75. As noted in the beginning, the New Zealand/Australian steel making process assures greater ductility in the parent material through a reducing yield strength as plate thickness increases. While obviously not the prime reason for the joint failures, it is essential that workmanship and testing of welds and material be appropriately controlled both before and after making welds.

\subsection{Timber}

\subsubsection{General}

Timber framed buildings were by far the most numerous within the epicentral zone, being used for nearly all houses and for most multi-dwelling apartments. Light timber framed buildings generally performed very well, particularly the more modern buildings (post 1980). Damage was typically limited to cracking in the external cladding ( $90 \%$ of which is stucco and very susceptible to damage) and to secondary elements such as chimneys, tiled roofs and concrete block garden fences.

Although there were examples of older construction, most of building stock was built since the 1950s. Individual single dwellings were very common $(90 \%+)$ on the slopes surrounding the San Fernando valley, and its perimeter suburbs. Over a wide extent of the valley floor however, rebuilding has been completed and there are numerous two and three storey multidwelling apartment units which are also primarily timber 

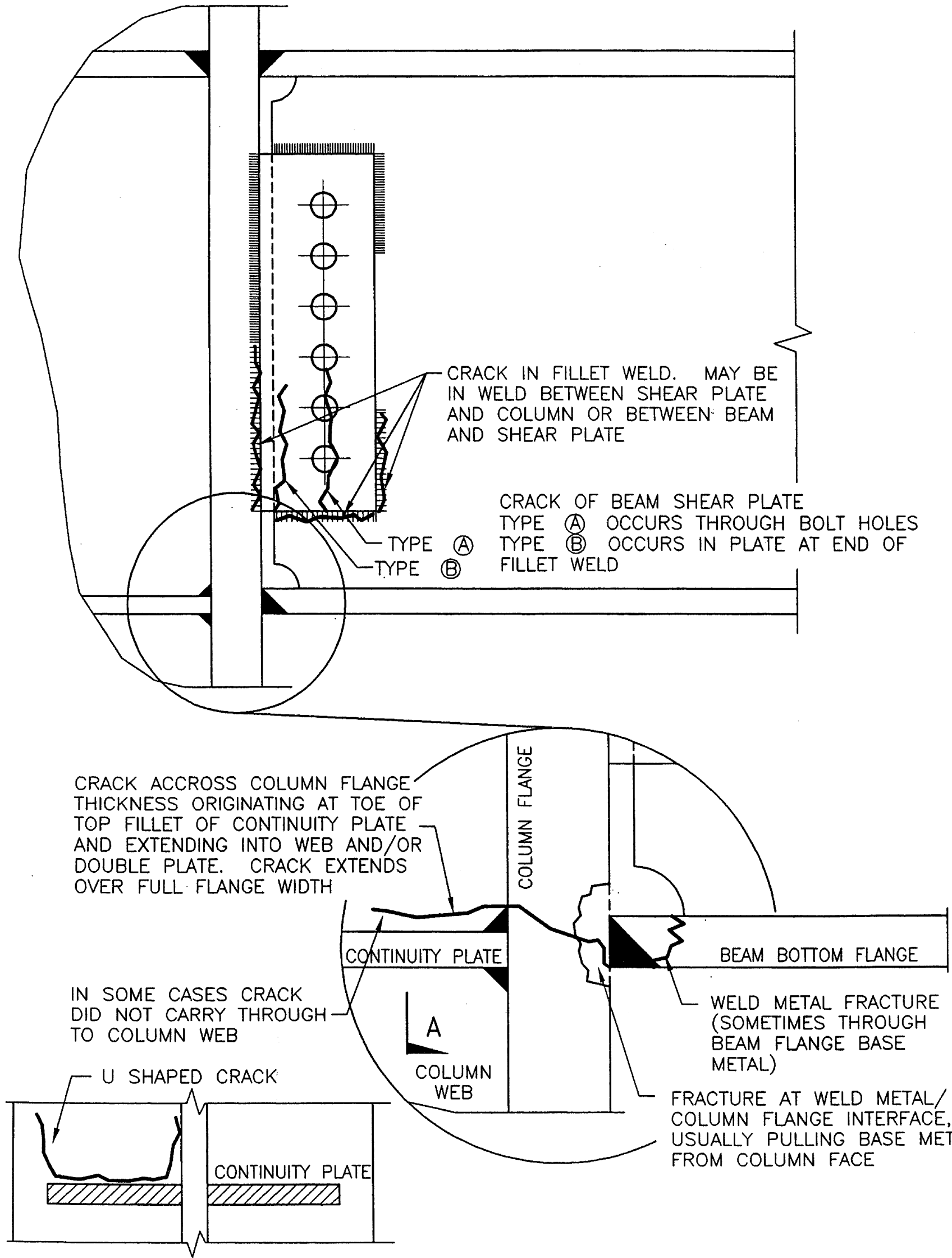

FRACTURE AT WELD METAL/ COLUMN FLANGE INTERFACE, USUALLY PULLING BASE METAL. FROM COLUMN FACE

(A)

FLANGE/WEB CONNECTION FAILURE NOT TO SCALE

FIGURE 6.40. Typical flange/web connection failure. 

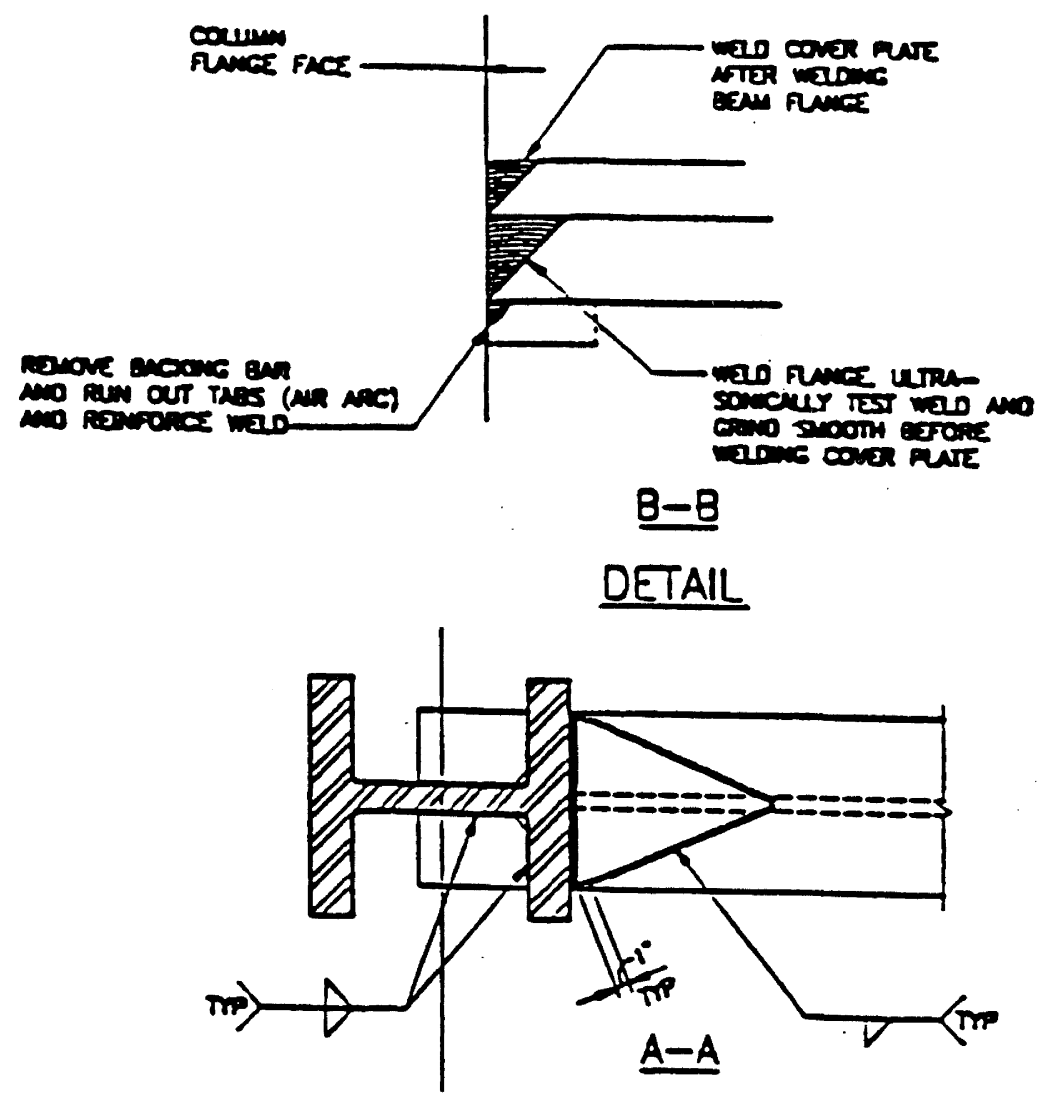

PLAN AT TOP FLANGE

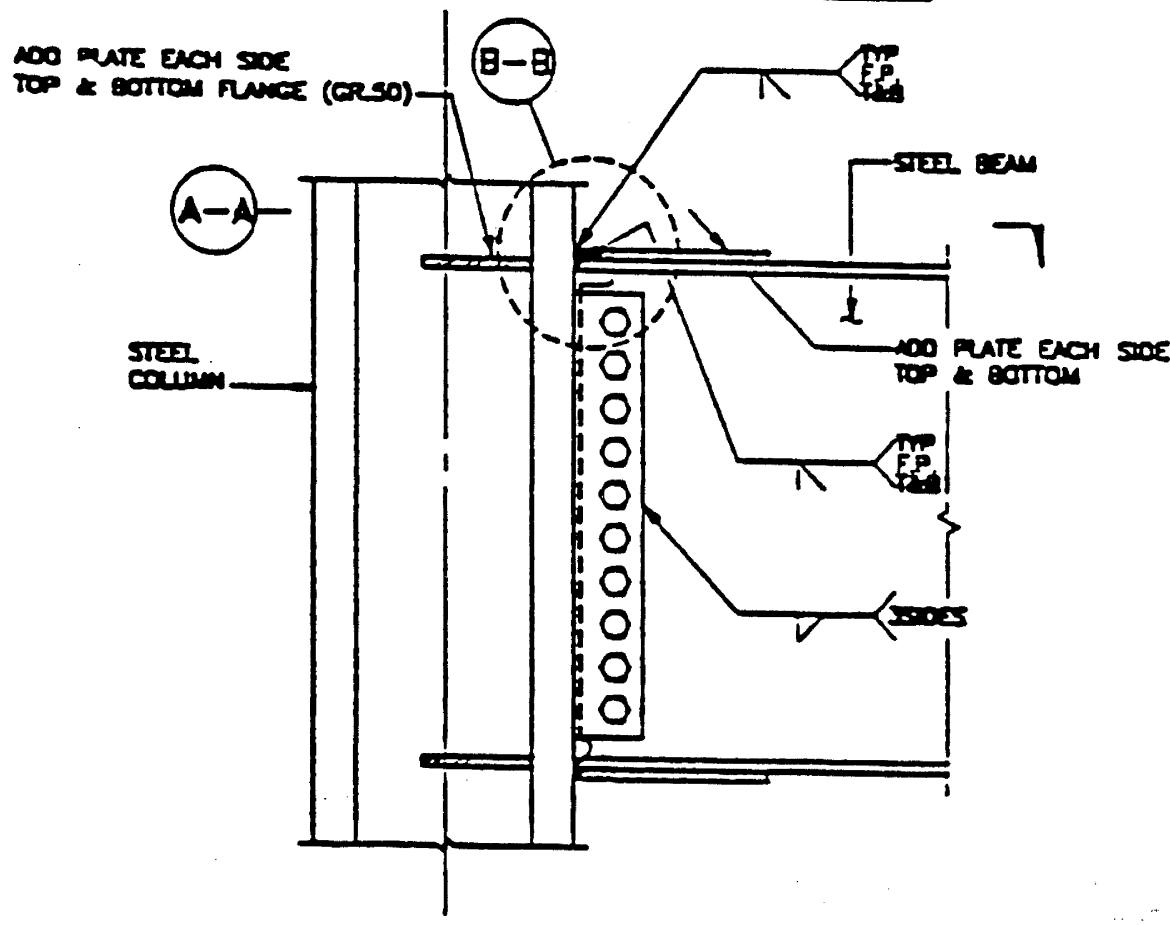

JOINT ELEVATION

FIGURE 6.41 Suggested repair detail. 
Specimen Number:

Specimen Description:

Test Date:

Description of Performance:

Beam Plastic Rotation:
3B

Cover-plated connection (tapered cover plate on top; rectangular cover plate on bottom); replicate of Specimen $3 \mathrm{~A}$

June 15,1994

The specimen sustained numerous cycles of inelastic loading (16 inelastic cycles). The strength of the specimen gradually deteriorated due to flange and web buckling in the region just beyond the cover plates. Final failure occurred by fracture of the bottom beam flange at the end of the bottom rectangular cover plate. The fracture initiated at the termination of the longitudinal fillet weld connecting the bottom cover plate to the bottom flange. Small cracks were also observed at the tip of the tapered top plate within the beam's top flange, and within the fillet welds connecting the tapered plate to the top flange.

3 cycles at $0.0035 \mathrm{rad}$.

3 cycles at $0.007 \mathrm{rad}$.

3 cycles at $0.010 \mathrm{rad}$.

3 cycles at $0.015 \mathrm{rad}$

3 cycles at $0.020 \mathrm{rad}$.

1 cycle at $0.025 \mathrm{rad}$.

Overall Assessment of Performance: Very good
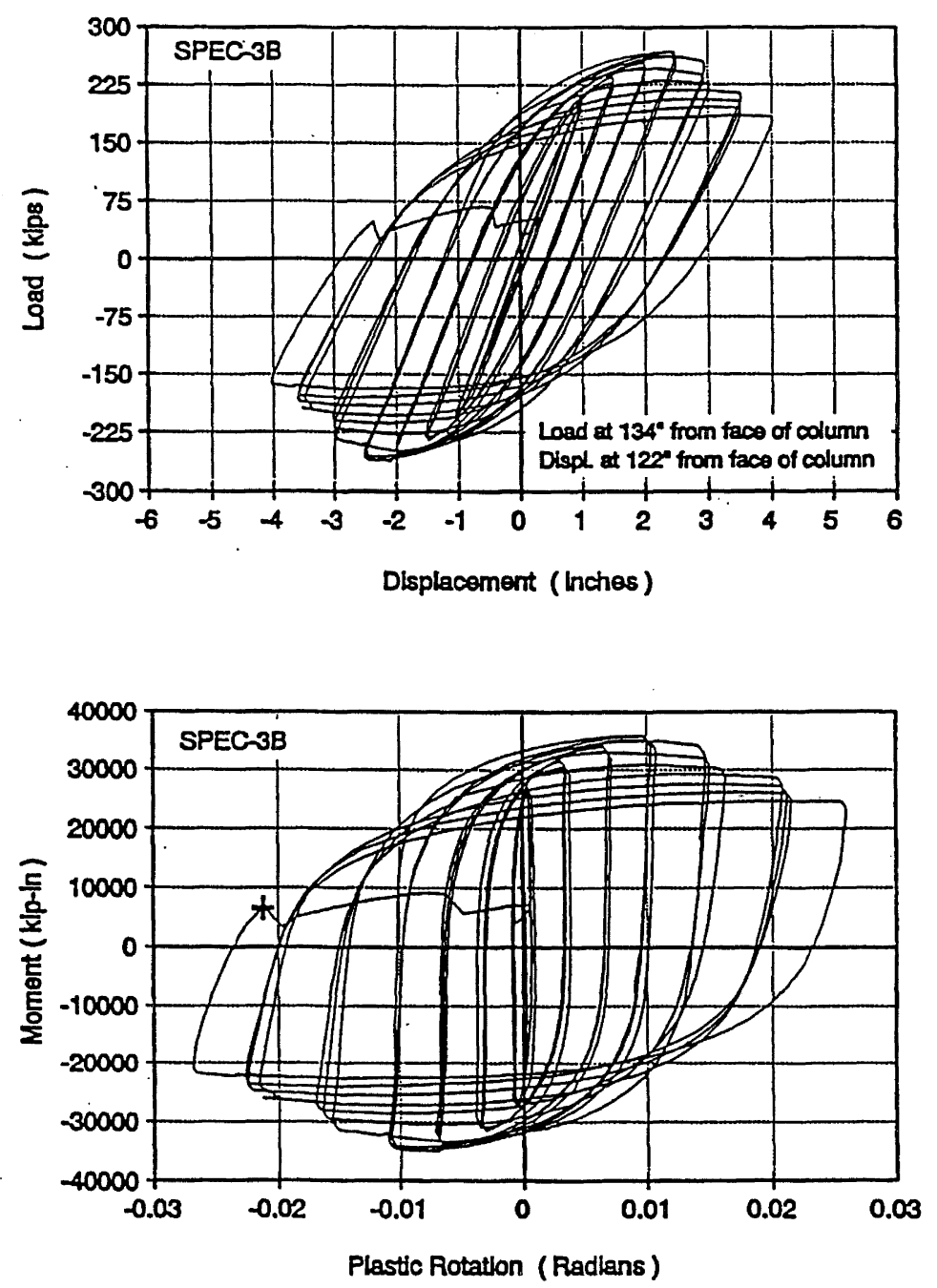

FIGURE 6.42 Typical load-deflection and moment-plastic rotation curves. 
framed. These units are required to provide on-site car parking which is most frequently provided either in the basement or at ground level, and although frequently of concrete or concrete masonry construction, timber or stucco over steel were also common in car park basements. Older style buildings were present both at Santa Monica and also in the more rural cities and districts to the north. Comments relating to older dwellings are drawn from observations of this type of construction in Fillmore (a township with a population of approx. 12000 people located some 30 miles north of Northridge beyond the Santa Susana Mountains) and from Santa Monica City.

\subsubsection{Single Dwelling Units (Houses)}

Modern homes were most commonly two storey, timber framed buildings built on a concrete slab foundation pad. Most (>90\%) have a stucco/cement cladding, aluminium window joinery, timber door joinery and either a light pressed metal roof or concrete or terracotta roof tiles (refer also to Section 7.2.3). Roof pitches were generally low $\left(<25^{\circ}\right)$ for single storey dwellings, but were steeper (up to $45^{\circ}$ ) in many of the more modern two storey dwellings with the upper storey commonly being built into the roof space. Many houses had masonry or precast concrete chimneys, most of which were (heavily) reinforced. These were generally against an exterior wall, and are required to extend at least two feet above the ridge line of the roof. Masonry boundary or garden walls were common. These were often up to $1.5 \mathrm{~m}$ high, founded on a simple strip footing without pilasters or other forms of buttressing.

Damage to the homes was generally non-structural, typically involving cracking of the stucco cladding (particularly adjacent to opening lintels and along the bottom plate) and of the interior gypsum plaster sheet lining. Cracking of the stucco cladding was generally superficial, mostly being confined to the ends of lintels and along the bottom plate. Such superficial cracking was easily repairable provided there is no structural damage behind the cladding. The hidden presence of structural damage behind such claddings is almost impossible to ascertain without removing the cladding itself. There was considerable reluctance of the home owner to undertake such investigations and the Building and Safety Department of LA City was concerned that much of the repair work was being undertaken before adequate inspection of the extent of the damage had been completed. Chimney damage was common, usually resulting in cracking of the chimney at or near the breast or at the foundation support (Figure 6.43). Complete overturning collapse of exterior chimneys was also observed. The collapse or damage to masonry boundary fences was also common within the epicentral area, with more distant areas experiencing horizontal crack development along lower mortar joints with their junction to masonry boundary walls. Such damage commonly resulted in either a permanent offset or partial collapse.

Internally damage experienced (in addition to the emptying of cupboard and shelf contents which was very wide-spread) also included joint popping of the internal paper faced plasterboard lining boards, along with joint damage at sheet junctions. Water cylinders and air conditioning chillers toppled when not adequately restrained. In addition to the loss of stored water to such houses, delays were experienced in the reconnection of both water and gas to affected dwellings as rupture to supply pipework commonly occurred following appliance movement.

Some of the older dwellings both at Santa Monica and at Fillmore, were supported on timber piles. These were unbraced and developed side-sway mechanisms and collapsed in several instances. The presence of lateral timber bracing within the subfloor framing system was not observed (Figures 6.44 and 6.45). Plywood sheet bracing systems were reported in some dwellings built on steeper sites and performed well.

Several unreinforced masonry dwellings were observed. These were primarily within Santa Monica and also at Fillmore. Damage to buildings of this form varied widely. In some instances no damage was apparent, whilst in other damage was quite severe. The most common damage involved the loss of gable end walls and other wall elements where inadequate support was provided at the building eaves. Cracking to door and window lintels was also noted. Few instances of corner cracking were observed.

Irregular (either in plan or elevation) dwellings experienced significantly greater damage than their regular counterparts. The irregularity may have been in plan, in elevation or may have been introduced though the irregular distribution of lateral load resisting walls. Some extreme cases of foundation irregularity were seen on the northern flank of the Santa Monica Mountains overlooking the valley where several dwellings were supported on very high $(15 \mathrm{~m}+)$ steel poles (Figure 6.46).

These timber-framed buildings used a building platform which was constructed from a rear concrete or concrete masonry retaining wall (typically at road level), and the elevated front poles. Reinforced concrete tie beams extended from the upper wall down the slope to avoid downhill spreading of the pole base. The connection between the floor diaphragm and the retaining wall was typically provided by a $100 \times 150$ Douglas fir

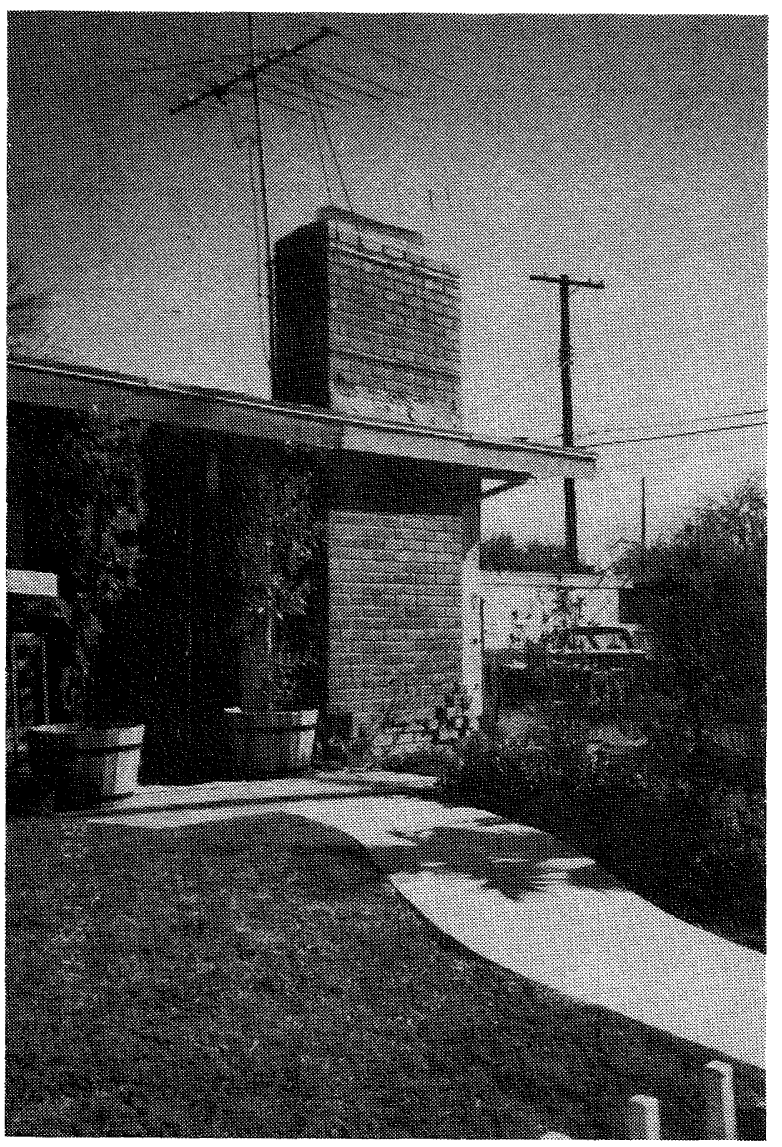

FIGURE 6.43 Masonry chimneys were commonly damaged either at their breast or foundation (13). 

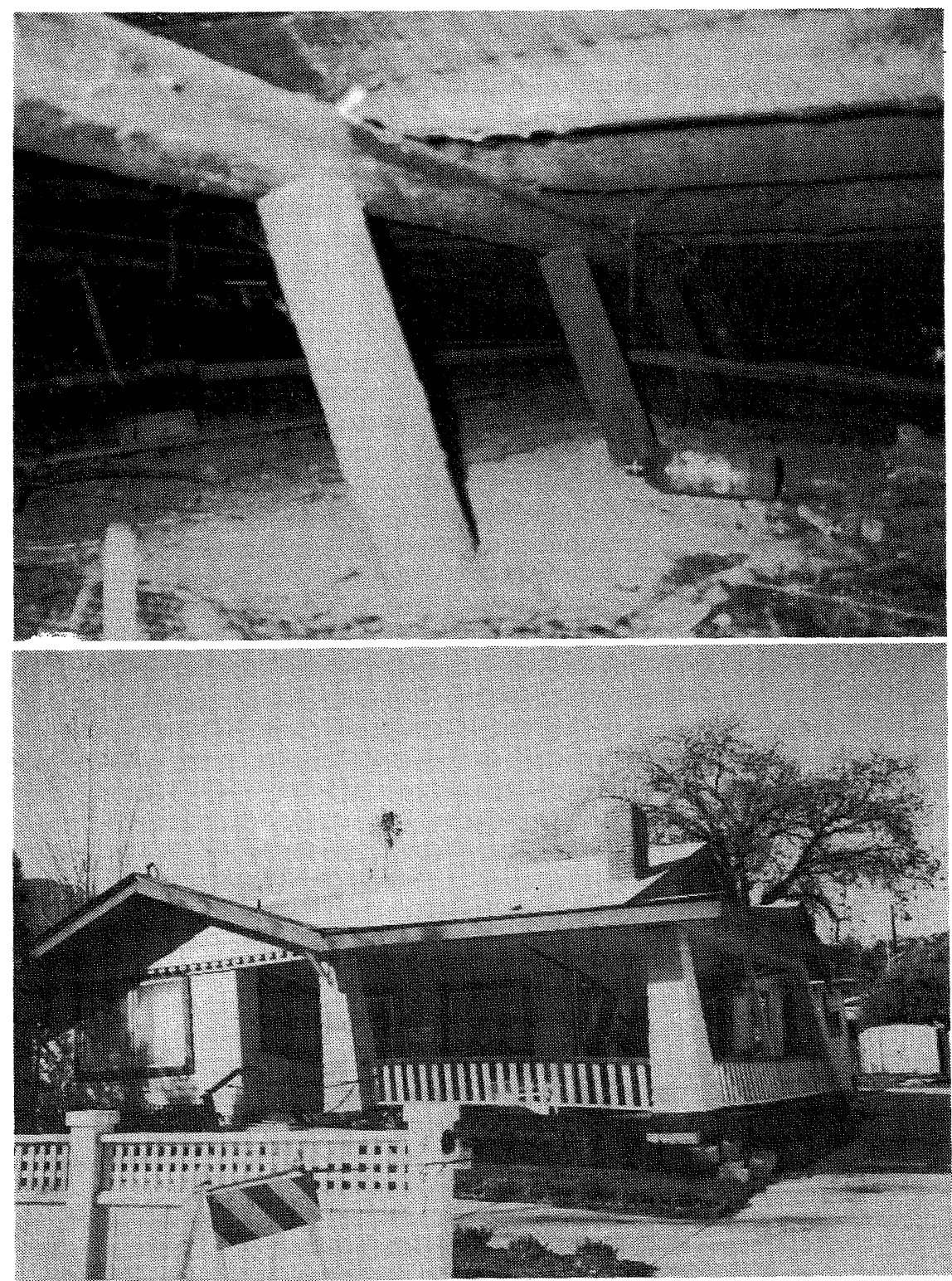

FIGURE 6.44. Unbraced pile collapse through sidesway.
FIGURE 6.45. Short piles without bracing were not common but performed poorly at Fillmore (25 miles north west of epicentre). ribbon plate bolted to the face of the retaining wall. The lateral load resisting mechanism depended totally on the structural adequacy of this connection as there was seldom any bracing present either within the plane of the supporting poles or down the slope fall line. Of the 40 or so buildings observed with these characteristics, two had failed by the ribbon plate disengaging from the retaining wall with the houses sliding down the hill (Figure 6.47).

Several others were showing signs of movement and were deemed unsafe. (Note: One such dwelling, which had experienced some footing damage on January 17 th, collapsed during the magnitude 5.3 aftershock of March 22nd). Buildings of this form were typically built in the early 1970's. Current code provisions require that there be a continuous contact area of not less than $75 \%$ of the floor area between the foundations and the floor slab. Whilst such buildings are similar to the typical New Zealand timber pole houses, the lack of lateral bracing within the pole system and the total reliance on the rear tie beam connection to provide combined lateral and torsional resistance are clearly different from both New Zealand and more modern LA practices. Thus the deficiencies of the past have been acknowledged and remedies are now in place.
The interior damage to split level dwellings tended to be concentrated at stairs and passages inter-connecting levels. A case study was made of a modern home which, although on a flat site, was structurally irregular. The north half of the house was two storey, while the living room extended the full width of the southern half of the house. The living room had a sloping $\left(45^{\circ}\right)$ full height cathedral ceiling. The upper (timber) floor system was therefore discontinuous from the southern wall. The east/west exterior walls were penetrated by two large door openings, one being the double leaf timber front door, and the other being an aluminium ranch slider. Both openings experienced spreading along their sills. The double leaf front door, whilst formerly tight, closed with a $25 \mathrm{~mm}$ gap at the bottom of the interlocking leaves. The sliding doors had been thrown from their runners. The two storey portion of the house had cracks within the stucco cladding along the bottom plate indicating approximately 20 to $25 \mathrm{~mm}$ displacement of the bottom plate from the foundation slab in a northerly direction. The UBC 91 code specification clearly prescribes bolted connections at $1.2 \mathrm{~m}$ spacings. While generally observed, these connections were periodically omitted with consequential sliding of the bottom plates over their concrete supports. The internal gypsum sheet lining had evidence of both joint tearing and sheet buckling being particularly obvious along the linings adjacent to the stairs. 


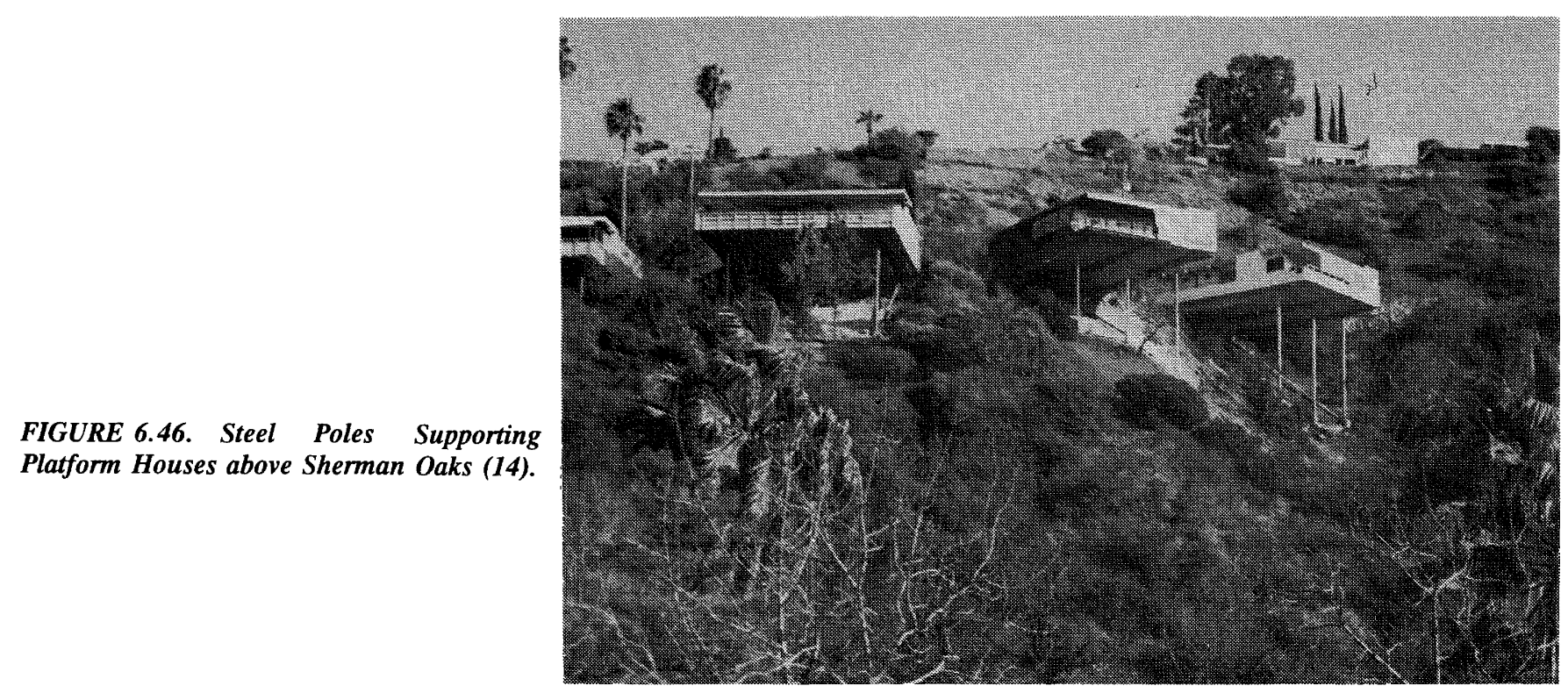

FIGURE 6.47. Sherman Oaks House separated from Ribbon Plate and collapsed down slope.

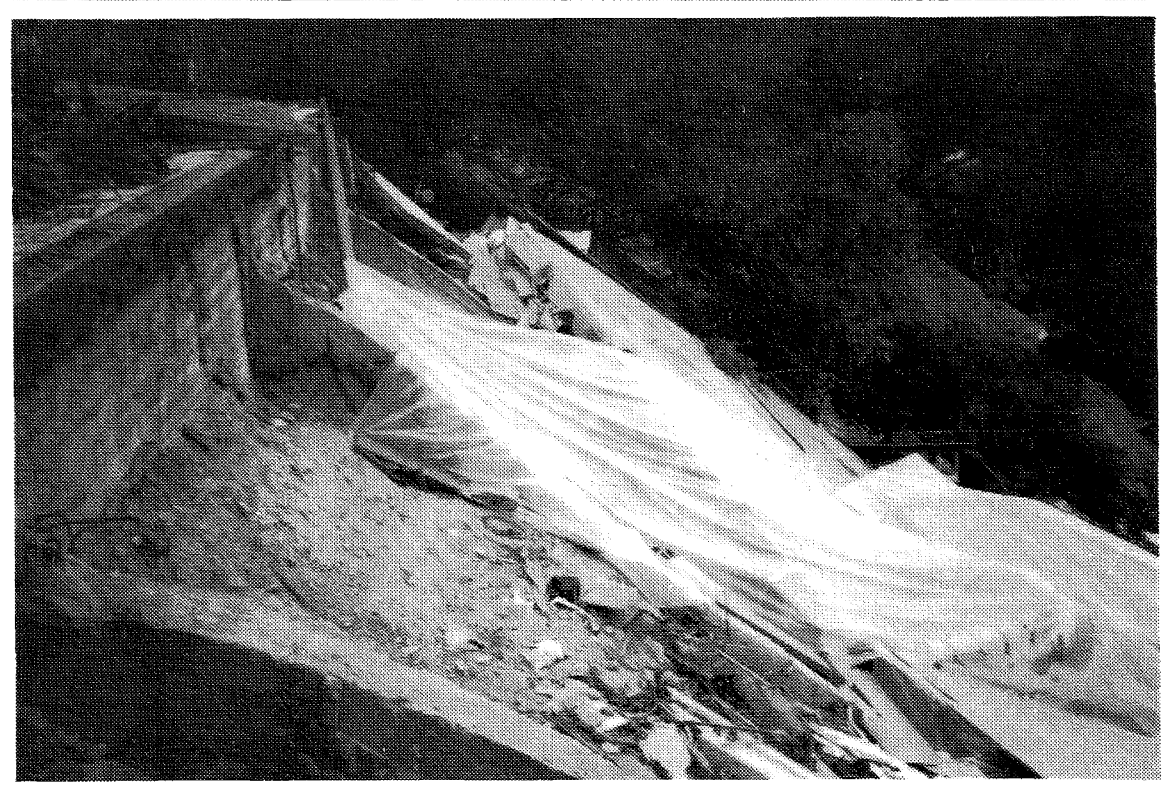

Dwellings of a style used in New Zealand (elevated piled subfloor, with sheet metal roofing and light claddings) were not common amongst the LA housing stock. Where present, however, they were noted to perform much better than their LA counterparts. The light weight more resilient claddings (eg weather boards or sheet claddings) appeared undamaged and remained fully functional. Some non-structural damage was noted with the displacement of roof tiles, particularly when these were comprised of terracotta half-rounds (replicating a Spanish roof forms). The method of fixing of these systems is understood to consist of nailing through the invert of the tile (into the ply substrate) and was found to provide inadequate restraint to the tiles. Some were observed to have fallen from the roofs and others to have become dislodged and, although still lying on the roof, were severely misaligned and provided an ineffective roofing system. The roof pitch of these roofs was generally less than $25^{\circ}$. The damage to precast chimneys discussed above are applicable to New Zealand and the need to ensure adequate connections to the structure were once again clearly demonstrated.

\subsubsection{Multi-Unit Apartment Buildings (Dingbats)}

The valley floor was well populated with multi-unit apartment blocks. This form of construction began in the late 1950s generally as simple low-cost buildings, but over time have become a building style in their own right with increasing complexity and popularity. They are generally timber framed buildings clad with stucco, with a low pitch roof with a light membrane finish. Light-weight concrete floor toppings were commonly used over light timber flooring system. Ground or basement level garages were commonplace. Many of these buildings performed poorly during the earthquake.

A soft-storey frequently developed in the garage system. This was particularly prevalent when the open face of the garage was formed by steel pipe (typically 4.5 inch diameter) columns with a steel or timber lintel beam. The steel-work was often encased in timber and rendered with a concrete stucco finish to blend with the remainder of the facade. The rear of such garages was commonly timber framing or a combination of timber and concrete masonry. Collapse of these buildings usually involved translation to the North with little rotation. The steel supports 
developed hinges at top and bottom with consequential rotation usually resulting in a $2.4 \mathrm{~m}$ offset developing as the building collapsed (Figure 6.48). In more dramatic instances, this resulted in the remaining structure being dragged with the collapse, and an internal rupture of the building occurring at some internal area of weakness (commonly around the entrance foyer) (Figure 6.49).

Garage frames formed using reinforced concrete or reinforced masonry frame support systems fared much better. Damage to such buildings was generally superficial being limited to shedding of concrete cover, cracking of the stucco cladding (severely in cases where this was at the same elevation as the garage) and crack damage to the internal paper-faced gypsum linings (Figures 6.50 and 6.51). Collapse of such buildings was not observed.

\subsubsection{Case Study}

\section{Northridge Meadows Apartments}

This large three storey apartment complex was built in the early '70's. The complex consisted of two blocks, one of which comprised five discrete rectangular buildings (Figure 6.52). This block contained 119 (one or two bedroom) dwelling units. A second block contained 139 dwelling units. The plan layout of each block was such that individual units opened outwards from a central passage on each floor. These passages were continuous from block to block and also opened onto the (external) stair landings. Car garaging facilities included some ground floor parking (accessed from the external perimeter away from the common courtyards) and to open two level parking buildings at the rear of the site. Various car garaging facilities were provided around the complex. Vehicular access was limited to the perimeter of the complex together with a central access driveway which extended east/west from the roadway. Garaging for the two front blocks was provided four parks at each end of those blocks.

Each building was timber framed (Ex 100x75 studs at ground floor level, without dwangs, but with cut in diagonal timber braces), stucco clad (approximate thickness $30 \mathrm{~mm}$ ), and with horizontally laid $12.5 \mathrm{~mm}$ paper faced plaster board internal linings fixed using $40 \mathrm{~mm}$ galvanised bugle head clouts at approximately 200 centres. The ceiling was similarly lined. Several areas, particularly links between blocks required fire rating and this was provided with $16 \mathrm{~mm}$ fire rated plaster board over the timber framing. The upper floor system comprised 150 x 35 timber boards, diagonally fixed over $250 \times 50$ joists. The joists were simply supported from pressed metal galvanised joist hangers. The joist to hanger connection for provided by two 10 $\mathrm{mm}$ claw teeth pressed from each side of the hanger, a connections which proved to be inadequate with significant movement being apparent even in the surviving hangers. A light-weight concrete topping (50 $\mathrm{mm}$ approximate thickness) was provided over the timber. The roof consisted of a chip seal membrane coating over a substrate (type unknown) (Figure $6.53)$.

The lateral load resisting system throughout was a combination of diagonal cut-in $150 \times 25$ timber struts, working in tandem with the sheet lining material. Although it is understand that buildings of this type (three storey multi-unit residential) would have required specific design, there was no evidence of any physical differentiation between bracing and non-bracing wall elements. Diagonal timber braces were installed in each lower floor transverse wall (such walls being generally spaced at approximately $3 \mathrm{~m}$ centres). Braces were noted to be at approximately $5 \mathrm{~m}$ centres along each of the longitudinal internal walls. The exterior longitudinal walls were penetrated by window and full-height sliding doors such that the aspect ratio of the remaining wall systems was less than unity.

Many of the blocks collapsed at ground floor level extending over approximately $60 \%$ of the complex (Figure 6.52 and 6.53). Upper floors remained largely intact (and undamaged) except where rigid ground floor elements protruded through the first floor fabric. There was very little overall horizontal rotation, with the collapse direction being predominantly directly to the north (Figure 6.54)

Collapse occurred following the overloading of the diagonal timber bracing elements. Load was shed from these braces as either their end fixings failed (tensile action), or they failed within their length (compression). Lateral shear was transferred to the lining material. These too became overloaded with the nails being drawn through the sheet. The sheet then appears to have fallen from the face of the lower floor studs and P- $\Delta$ effects provided the mechanism for ground floor collapse (Figures 6.55-58). Within the complex several blocks did not collapse, others experienced the 'ground floor' collapse mechanism described above over only part of their area, while some side-sway mechanisms developed over the complete block. Although there is no clear indication why these various degrees of collapse were experienced, it is noteworthy that buildings which were structurally separated from their neighbours appeared to have survived, while some form of structural interaction appears to be been present when collapse did occur. The proportion of the ground floor under building area assigned to car parking was another contributing factor for collapse.

Because collapse was avoided in some portions, it was possible to ascertain the system behaviour approaching collapse in some cases (Figures 6.59 and 6.60) The wall linings were found have become partially disconnected from the framing. The sheet lining fixing nails clearly exhibited evidence that they had been subjected to high loads and that some sheet rotation had occurred. The horizontal fixing method used for walls with a length to height ratio of 2 or more, together with the limited ability to provide nail edge support along the mid-height joint was seen as a common factor in placing greater demand for the nails to translate. This, combined with the high level of restraint provided against any rotation by the mass of the building, significantly increased the ductility demand on the sheet lining, which because of the nails used, degraded rapidly with a complete loss of lateral resistance once the diagonal cut-in braces had ruptured. Shear failures were noted within the body of some lining sheets, particularly when the lining is penetrated by switch boxes, ventilation panels and other protuberances which prevented sheet rotation and therefore initiated local bearing failure and shear rupture within the sheets. High local shear forces appeared to be present in these cases with internal sheet shear rupture resulting (Figure 6.61).

The rear car-park building was largely intact, except for the collapse of one section of precast, prestressed slab. The upper deck was formed by a hollow-core precast prestressed concrete slab (spanning $10 \mathrm{~m}$ ). Each deck panel was supported directly from the flange of an RSJ which were themselves supported by 112 (x $6 \mathrm{~mm}$ thick) tubular pipes. The failure appears to have been initiated by the upper slab structure being displaced to an extent that support was removed from one end of the precast concrete (Figure 6.62). The detail for connecting the slab to the beam was to weld a $1 / 2$ inch diameter deformed bar directly to 


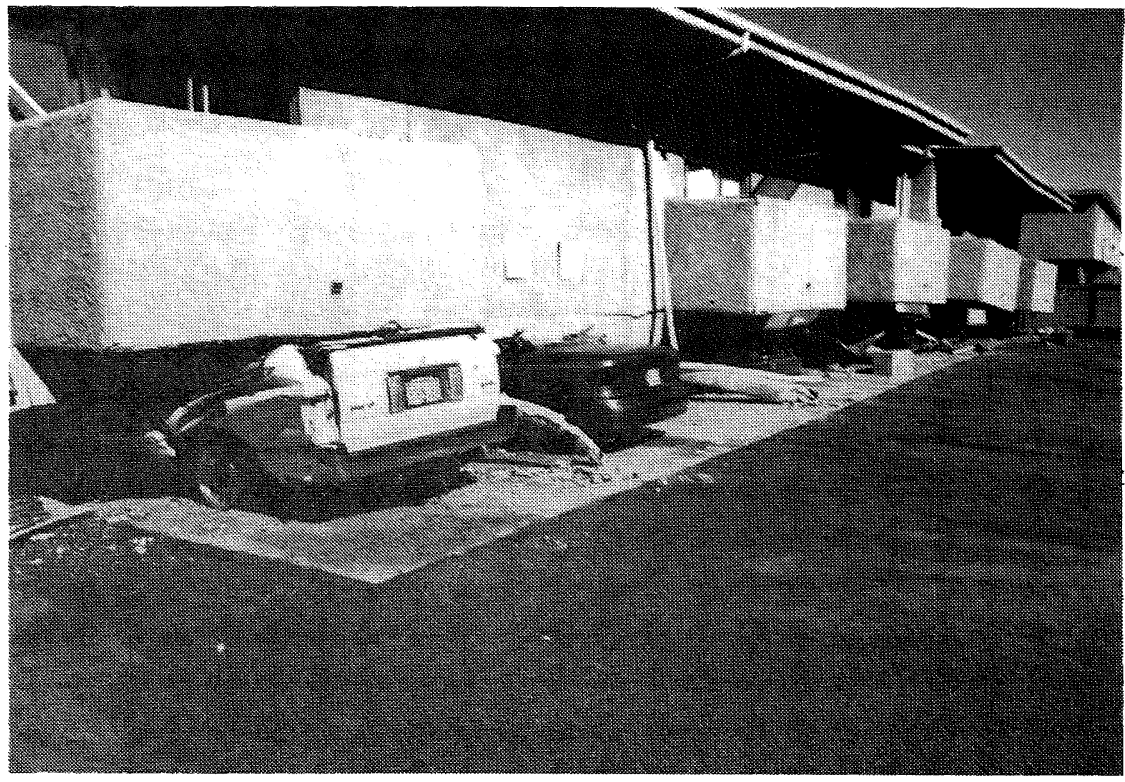

FIGURE 6.48. Dingbat collapse with stucco covered steel pipe columns (15).

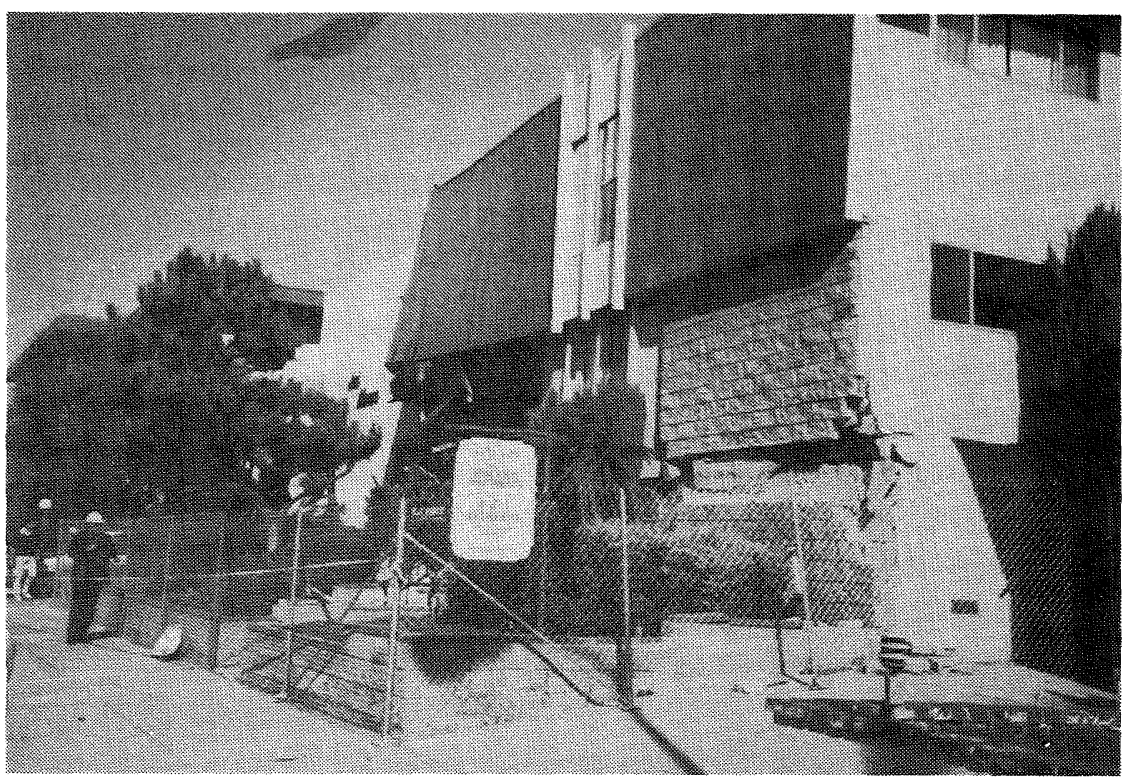

FIGURE 6.49. Apartment block partial collapse over garage while remaining section stands although stucco is severely damaged, being torn at the entrance-way (16).

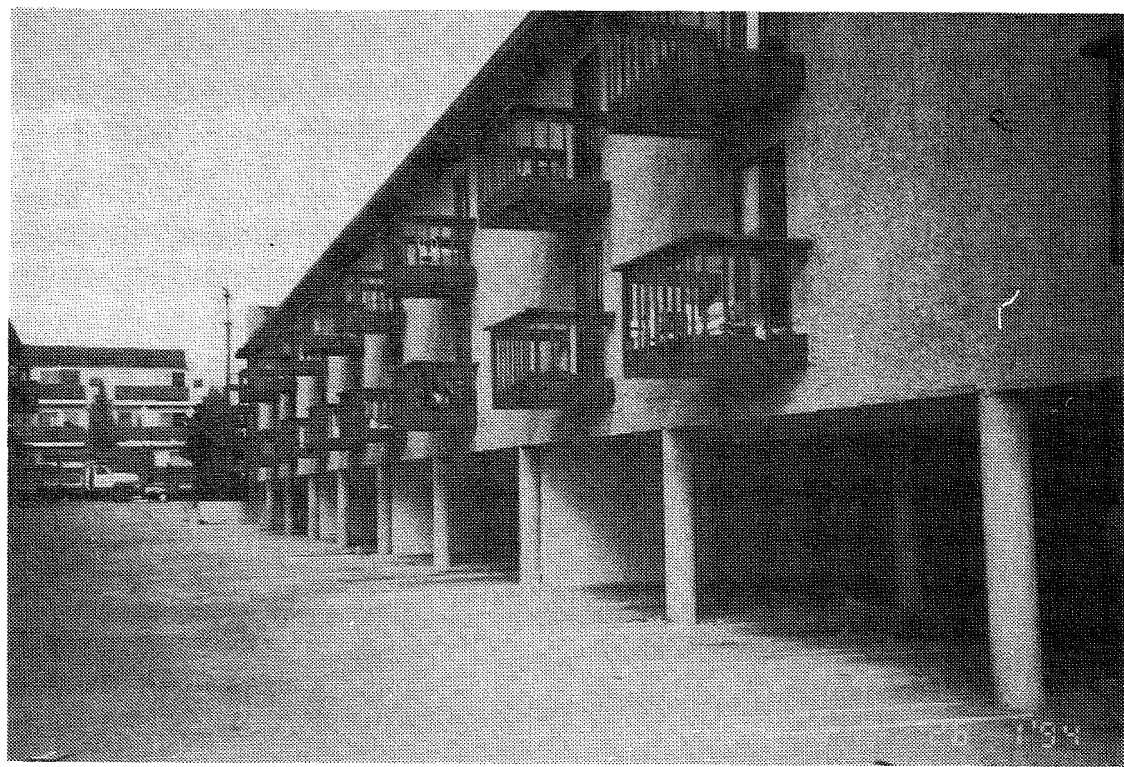

FIGURE 6.50. Concrete support columns damaged but survived (17). 


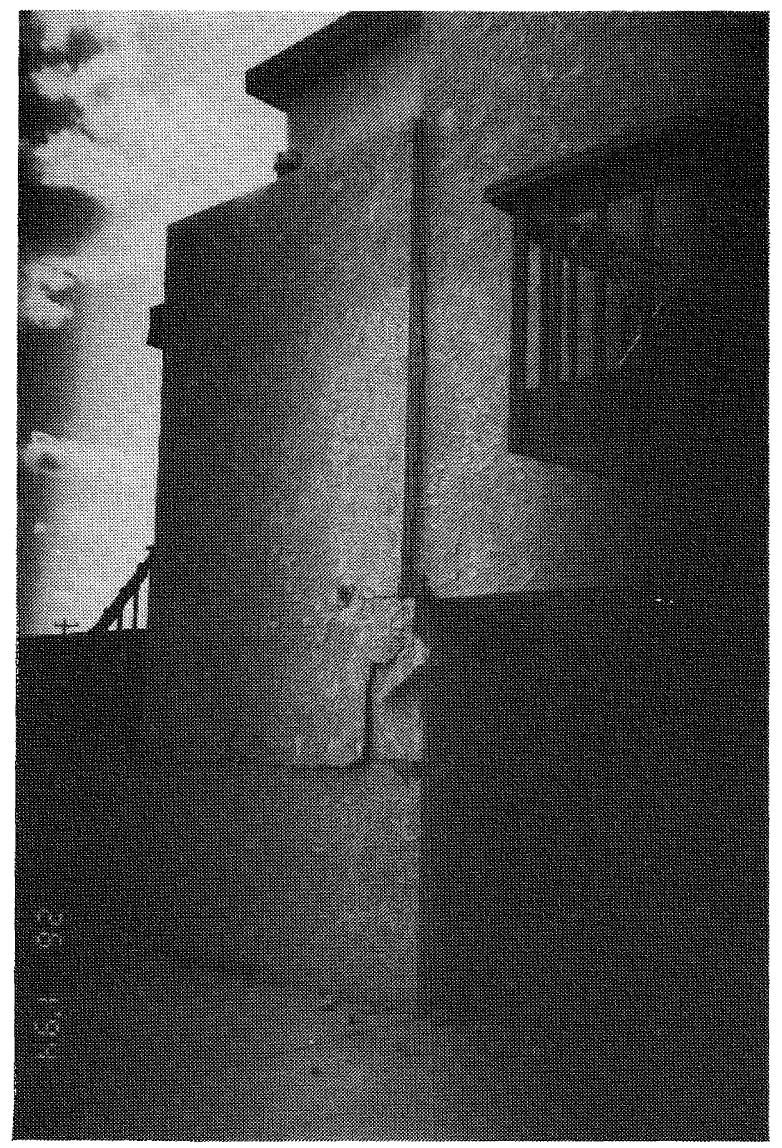

FIGURE 6.51. End wall of same apartment severely damaged stucco 'shear wall .

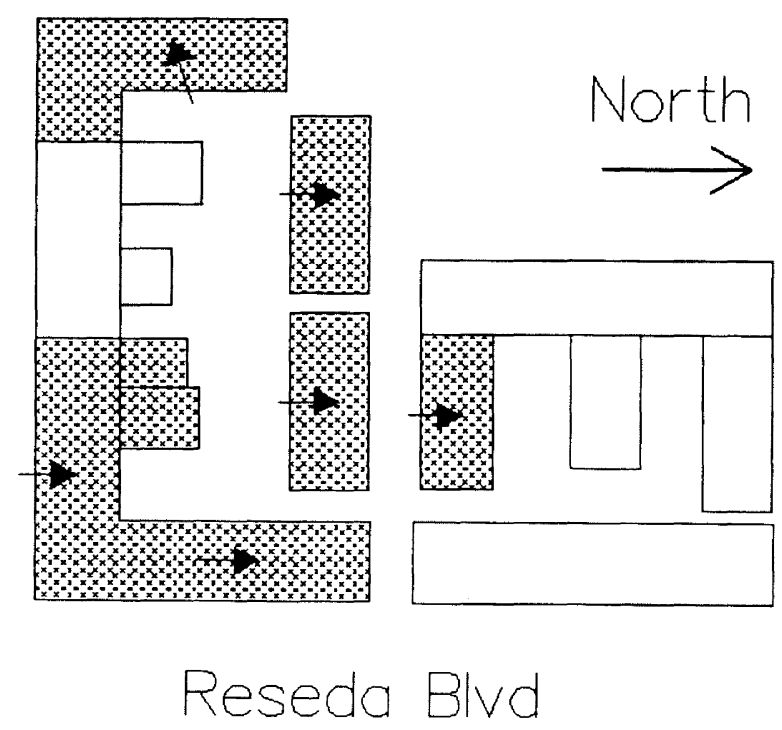

FIGURE 6.52. Meadows Apartment. Base Plan. Where the shaded buildings collapsed in the direction indicated by the arrows (18).

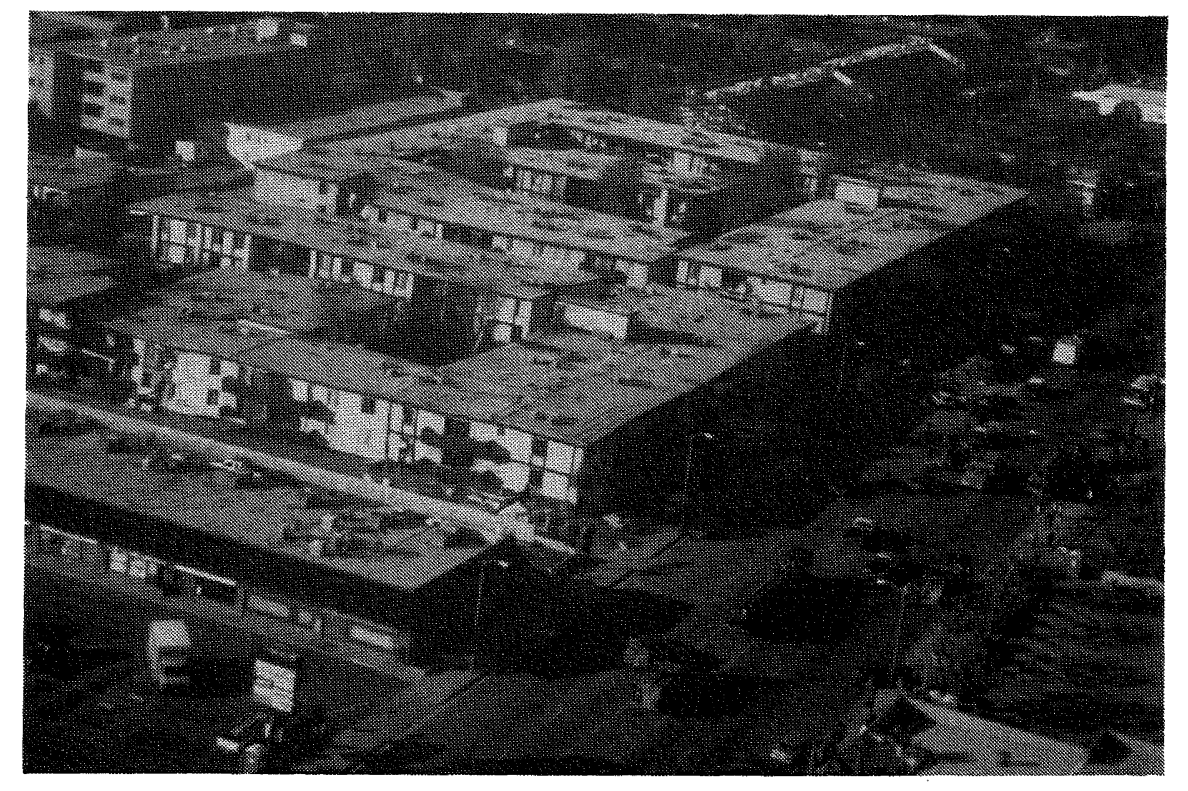

FIGURE 6.53. Meadows Apartments. Aerial view of front blocks.

Note the dislocation in the roofs at the junctions between collapsed and surviving units all were the same height. 


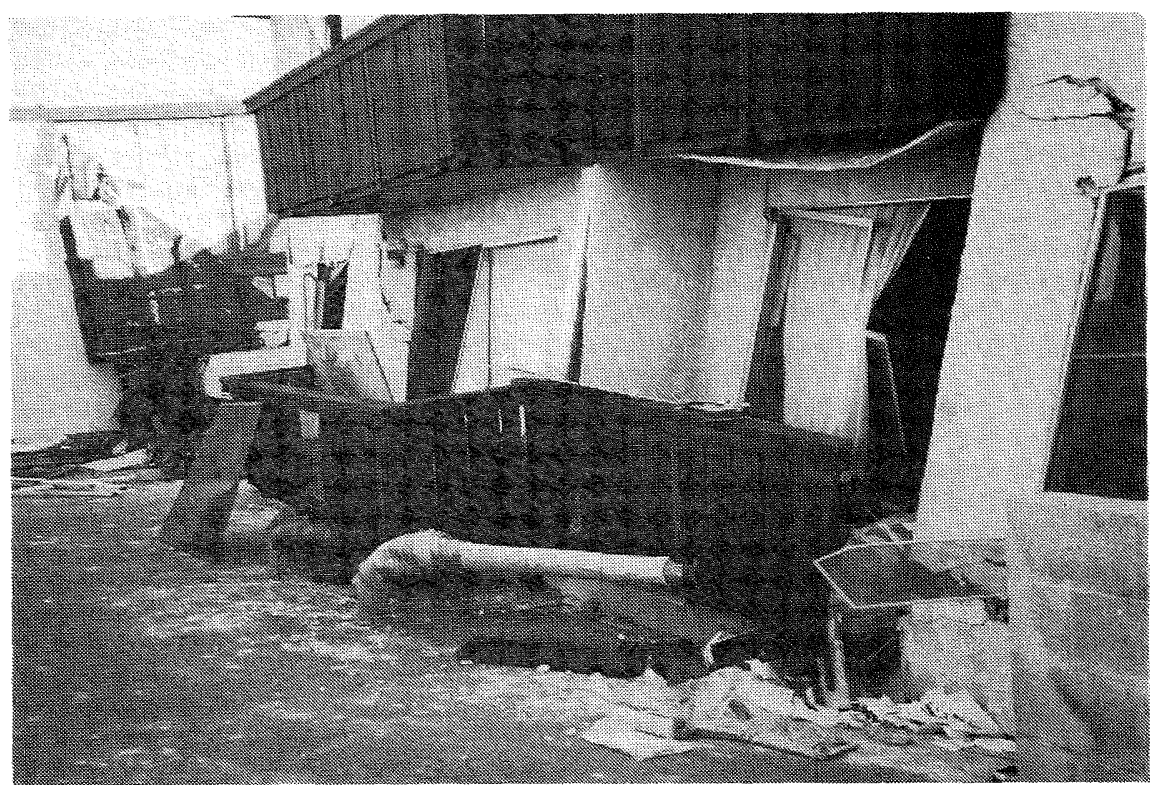

FIGURE 6.54. Meadows Apartments. Rear block collapses with $2.4 \mathrm{~m}$ offset

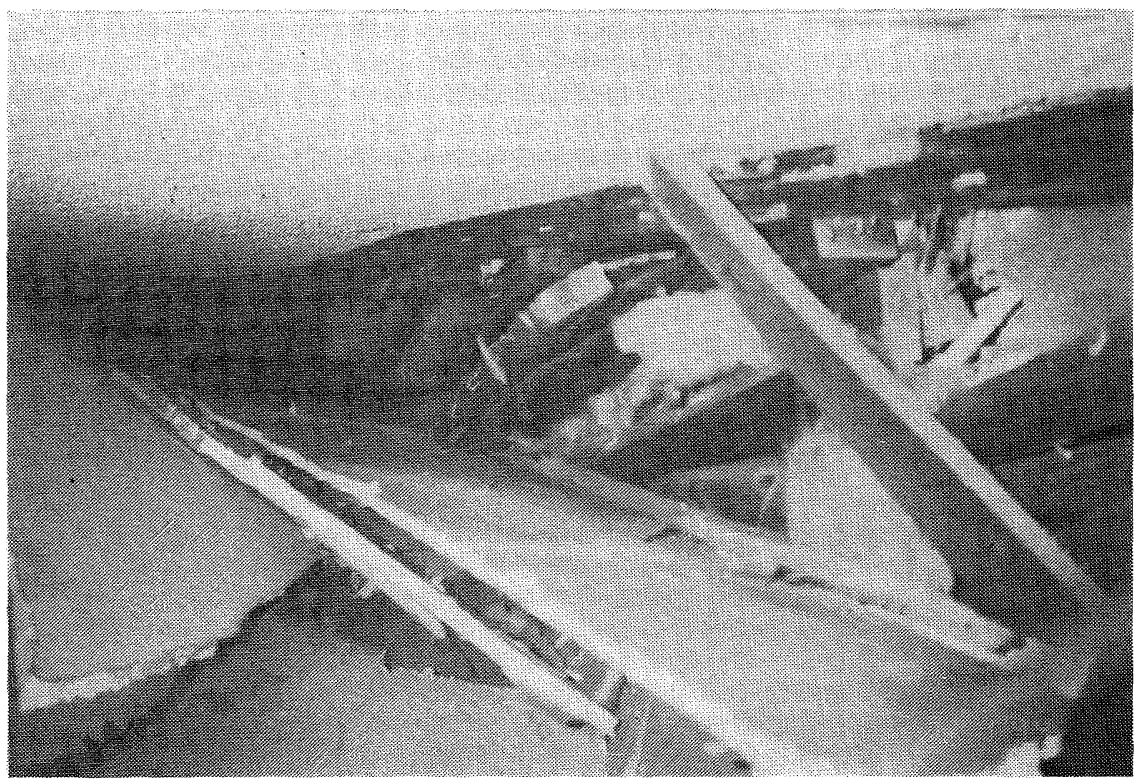

FIGURE 6.55. Meadows Apartments. The $600 \mathrm{~mm}$ crawl-space between ground floor and ceiling. Wall linings have become detached and diagonal timber bracing has fractured.

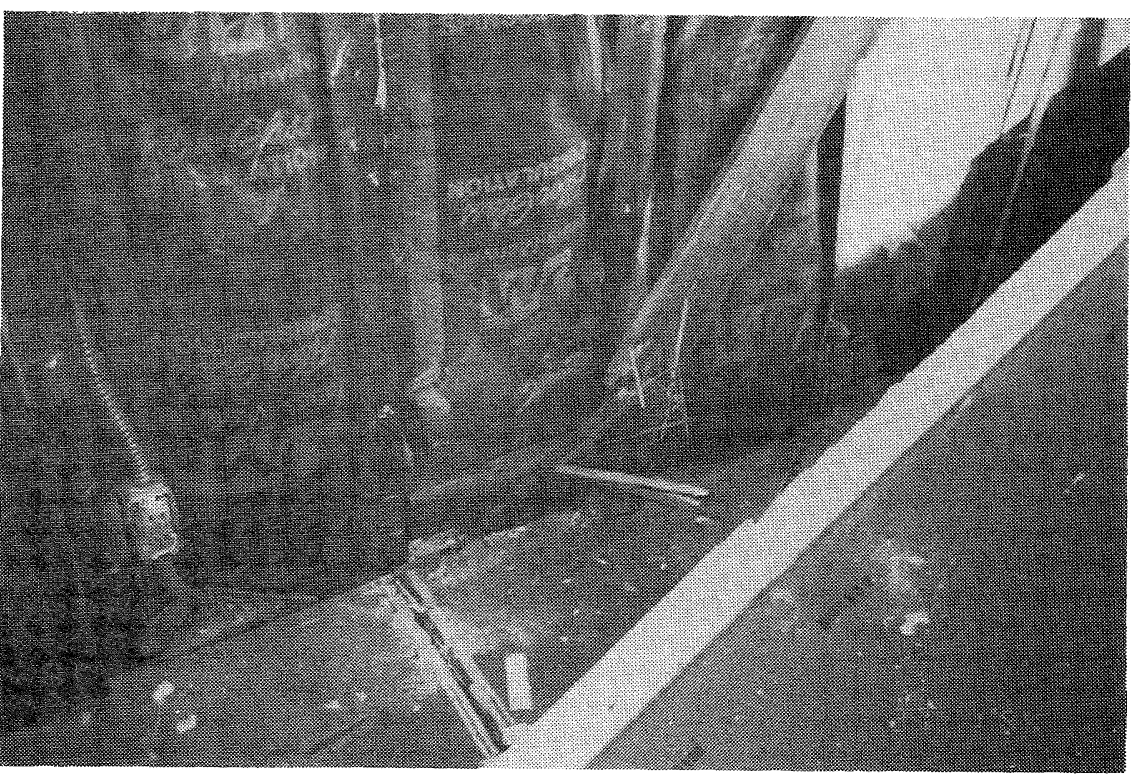

FIGURE 6.56. Meadows Apartments. Cut-in diagonal timber braces failed in compression. 


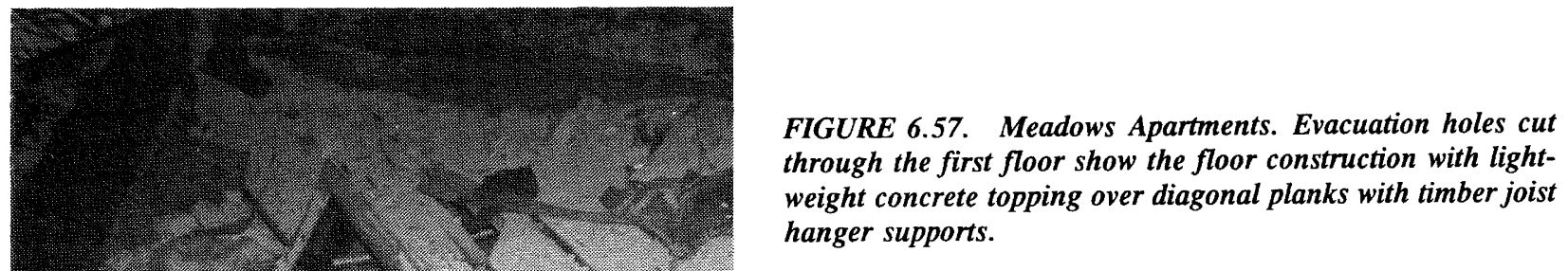

FIGURE 6.58. Meadows Apartments. Evacuation from upper floors was difficult with collapsed stairways (and total blackout).

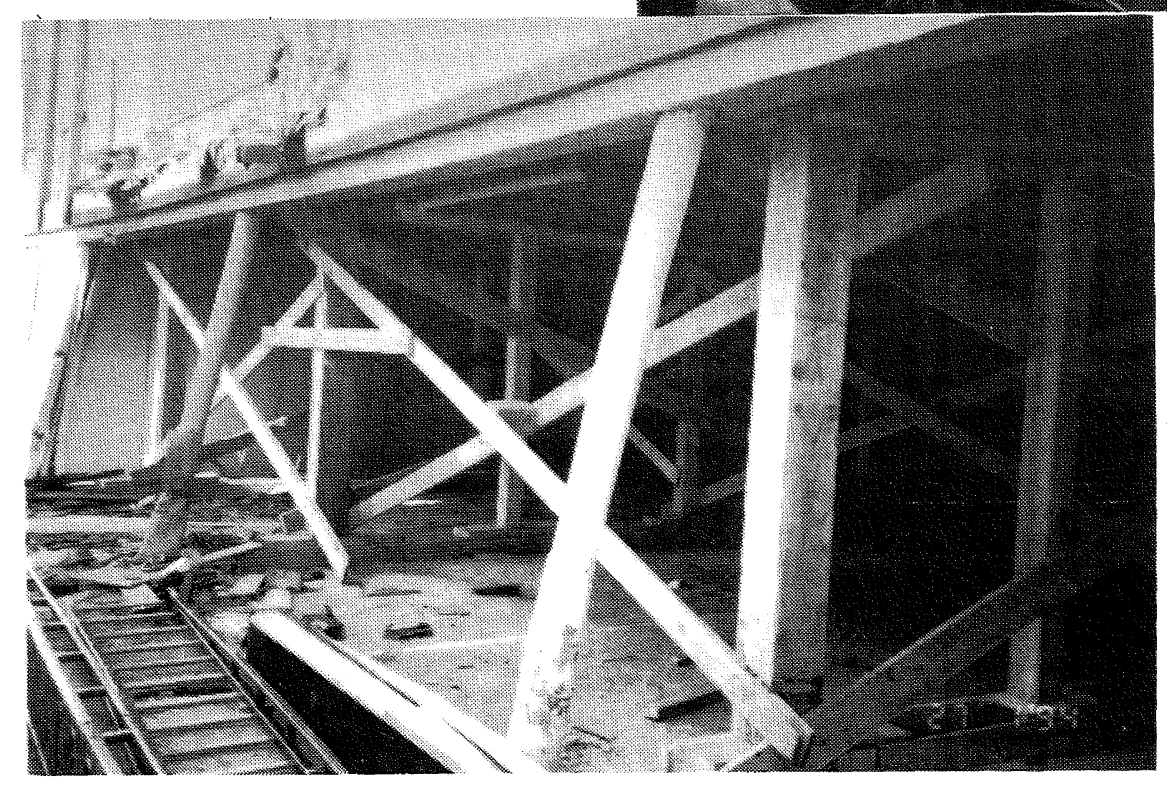

FIGURE 6.59. Meadows Apartments. Up to $500 \mathrm{~mm}$ offset was measured on some blocks which did not collapse - temporary propping has been installed. 


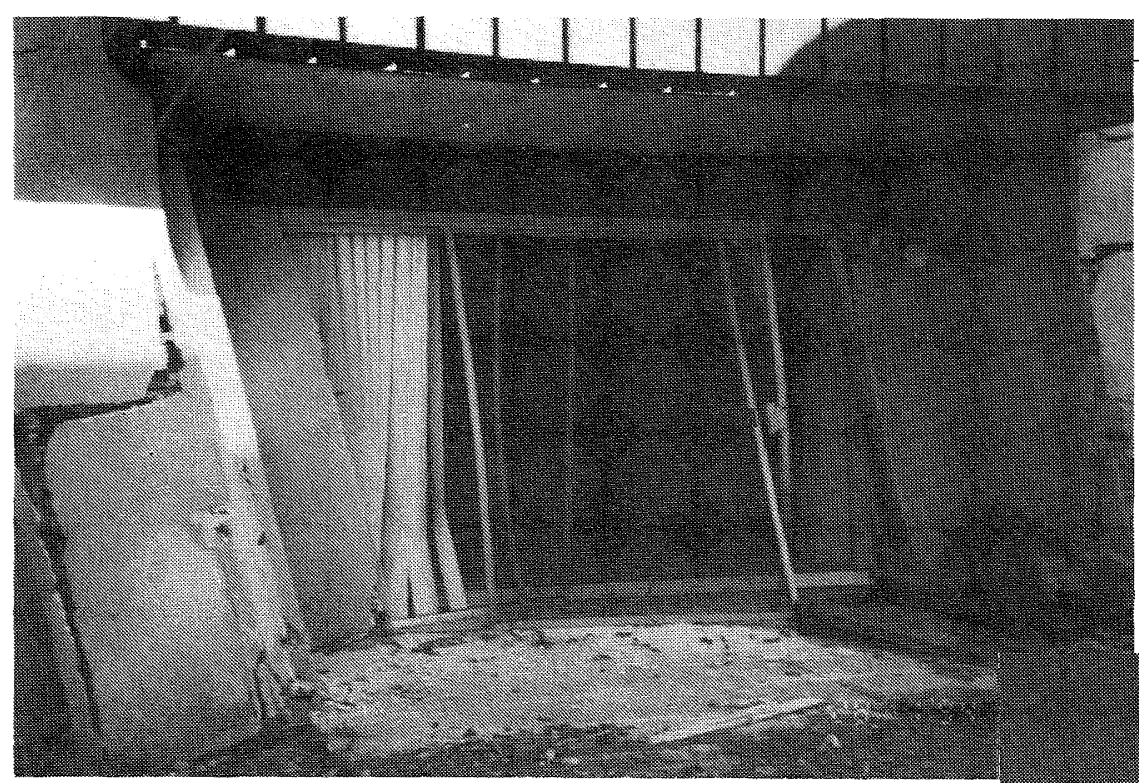

FIGURE 6.60. Meadows Apartments. Although the central passage walls were largely intact, outer longitudinal walls had wide penetrations through them.

FIGURE 6.61. Meadows Apartments. High shear was induced as the linings became wedged between protrusions with sheet shear ruptures resulting.

FIGURE 6.62. Meadows Apartments. Car-parking deck failure as the deck is dislodged from the support beams. (Note separation between the topping slab and the precast deck unit).

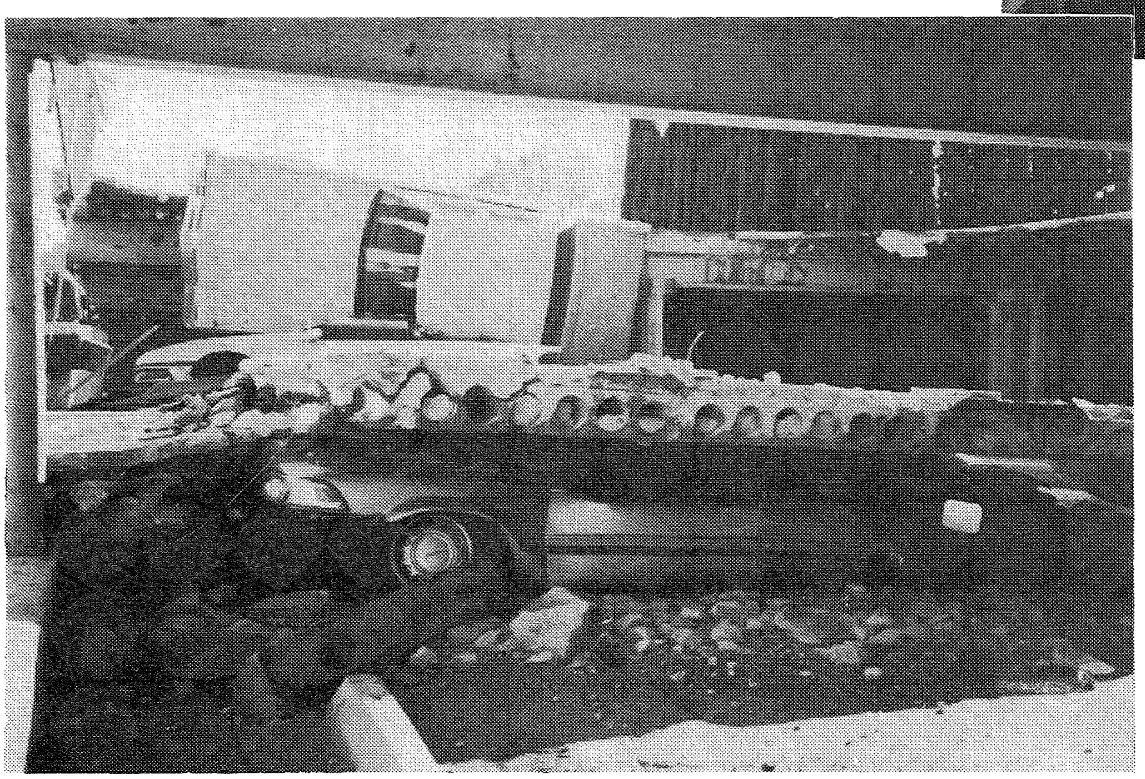


the top flange of the RSJ at approximately $600 \mathrm{ctrs}$, and to bend these bars alternate directions and cast them into the topping slab. The shift of the slab had fractured the splice bars at their weld to the top flange of the UB (Figure 6.63). At the line of failure, the topping reinforcing did not appear to extend far into the failed topping concrete (approx $100 \mathrm{~mm}$ ). At the rear, where the reinforcing extended further beyond the joint, an area (800 $\mathrm{mm}$ triangular) of the topping remained suspended. Elsewhere the prestressed panels separated from the topping and collapsed.

New Zealand Related Issues: These three storey timber framed buildings were clad in a brittle heavy cladding material with concrete floors separating inter-tenancy spaces. The lateral load resisting system was, however, provided predominantly by the interior paper faced gypsum wall lining material. This method of lateral load resistance is similar to that considered for New Zealand conditions. The nailing pattern used was also similar to New Zealand practices (Figure 6.64)

\subsection{Masonry}

\subsubsection{General}

The use of masonry for cladding and for carrying loads began before the turn of the century in the greater Los Angeles area. As codes have developed, sophisticated and well-performing structural masonry systems have been put in place. The extent of damage ranged across all masonry types of construction. It was evident that modern codes had brought the performance of structural masonry, in particular, to an acceptable level. However, there were, as expected, occasions when lack of detailing or lack of connection to load transferring diaphragms lead to poor performance, even in modern structures.

A comprehensive review of the performance of masonry structures during this seismic event can be found in the report of the Investigating Disasters Reconnaissance Team of The Masonry Society [1994].

\subsubsection{Shear walls}

Reinforced masonry shearwalls tended to perform as well as their counterparts - reinforced concrete walls. The only noticeable failures were where roof or floor diaphragms separating from these walls, resulting in collapse of the structure. Referring to Figure 6.65, this warehouse (in the Chatswood area) with roof carpark suffered extensive damage when the connections between the roof diaphragm and the reinforced concrete masonry walls lead to progressive collapse of the roof. The carpark in Figure 6.66 in the Santa Monica area exhibited no noticeable damage. The walls were reinforced concrete masonry. The general impression was that reinforced concrete block performed very well during this event.

The Berkeley East Convalescent Home is located immediately north of St Johns Hospital, Santa Monica. This two skinned grouted reinforced brick masonry shearwall structure, five storeys high is located $24 \mathrm{kms}$ from the epicentre. Deep spandrel units above windows suffered characteristic X-cracking through shear overload and the structural shearwalls that run parallel to the main axes of the building again failed in shear and there was an apparent lack of confinement of the end zones of walls, and no anti-buckling resistance for vertical reinforcement in a number of the walls (Figures 6.67 and 6.68).

\subsubsection{Infill walls}

There were few reports of the expected poor performance of infill masonry walls. One such instance was in the 3 storey administration block of John F Kennedy High School where the ground floor infill masonry panels completely filled the opening formed by the reinforced concrete frame. Damage occurred at the non-separated corners and the upper courses of the masonry (immediately below the first floor waffle slab) where it had proven impossible to adequately install the grout into the masonry blocks.

A hostel facility to the west of St Johns Hospital (Figure 6.69), exhibited classic diagonal cracking associated with the formation of struts bridging between the tops and opposite bottoms of the adjacent columns. Such poor performance was characterised by the lack of design to accommodate the infill type performance. Masonry infill panels have been reported as causing a number of short column effects referred to in earlier sections of this report. These short column effects lead to a number of shear failures in the columns resulting from the inflexibility of the partial height infill panels and architectural spandrels which were not adequately separated from the sides of the columns.

\subsubsection{Masonry Veneers}

Performance of masonry veneers varied greatly. Where the veneers were connected at corners and had adequate ties back to the supporting structure they appeared to generally perform quite well. On the other hand, veneers in at corners and lacking sufficient ties tended to be shed from buildings in the expected manner. The key to acceptable performance of masonry veneers appears to be ties that can withstand the movement, during the seismic event, of the supporting structures behind and the detailing to allow for relative movement between sections or panels of veneer, particularly at corners of buildings.

\subsubsection{Yard Walls, Chimneys and Road Sound Barriers}

As was evident around the greater San Feranando Valley area, masonry walls that were unreinforced, used along boundaries between houses and along major road ways to cut down noise from traffic, typically performed in a very poor manner. There were a number of sound barrier walls along the main highways which were reinforced and designed as cantilever walls on a broad base. These generally performed very well.

Chimneys became a major issue after this event. Typically chimneys had no reinforcing or were very lightly reinforced and tended to break off at the connection to the roof line. Numerous chimneys were damaged during this event. One of the local building regulations issued immediately after the event was that masonry chimneys being reinstated and new masonry chimneys required an engineer to specifically design these chimneys when they went above the roof line of a house.

\subsubsection{Unreinforced Masonry}

An active Un-Reinforced Masonry (URM) retrofitting programme has been underway in LA City since the mid-80s and within Santa Monica City since the late ' 80 s. Thus both retrofitted and unreinforced masonry structures were present within the epicentral region. While both experienced significant damage, no collapses were reported within retrofitted URMs, although several failures did occur in those which had not been strengthened, particularly in municipalities to the north of the city. Such collapses were dramatic and would have been highly 

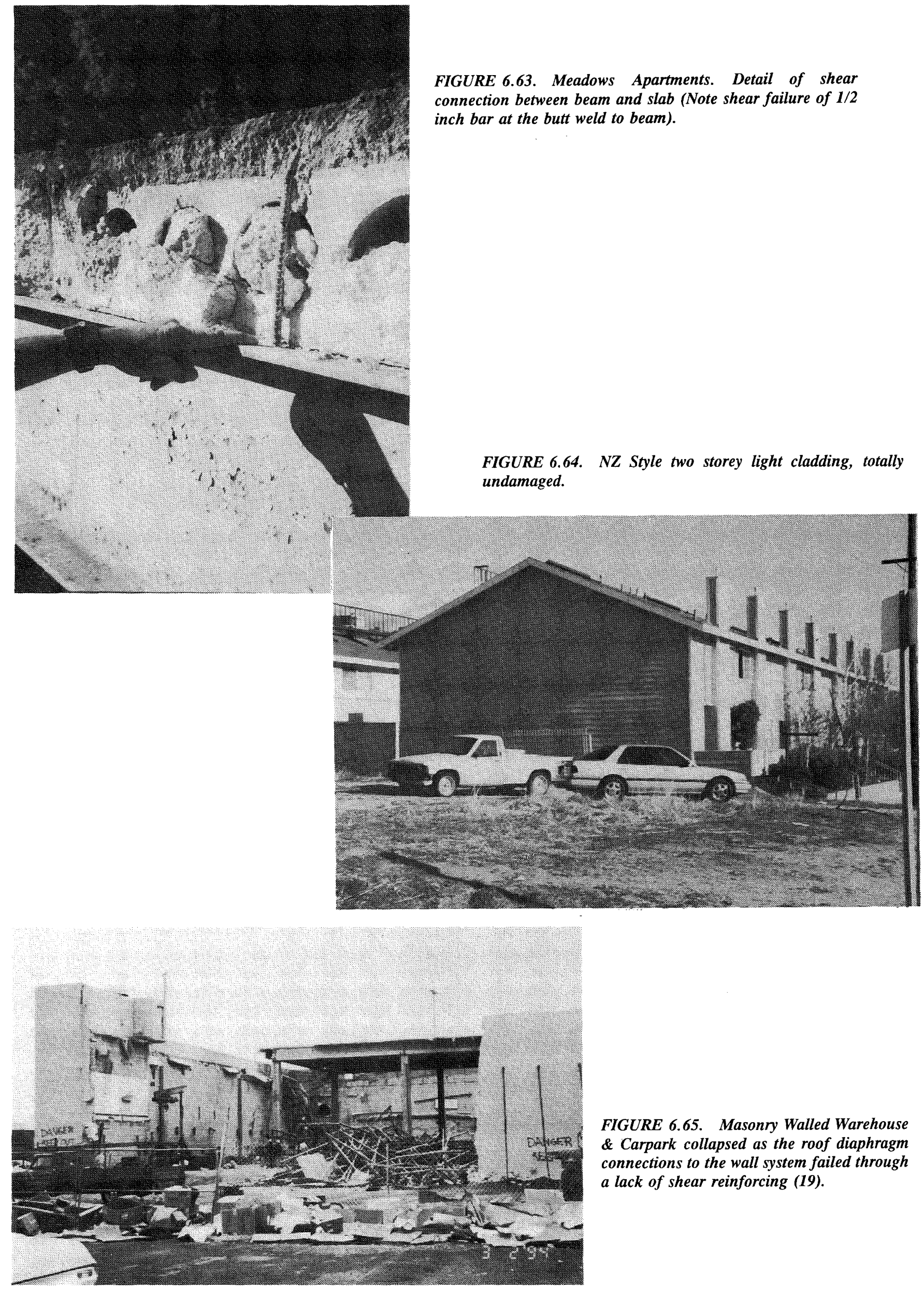

FIGURE 6.65. Masonry Walled Warehouse \& Carpark collapsed as the roof diaphragm connections to the wall system failed through a lack of shear reinforcing (19). 


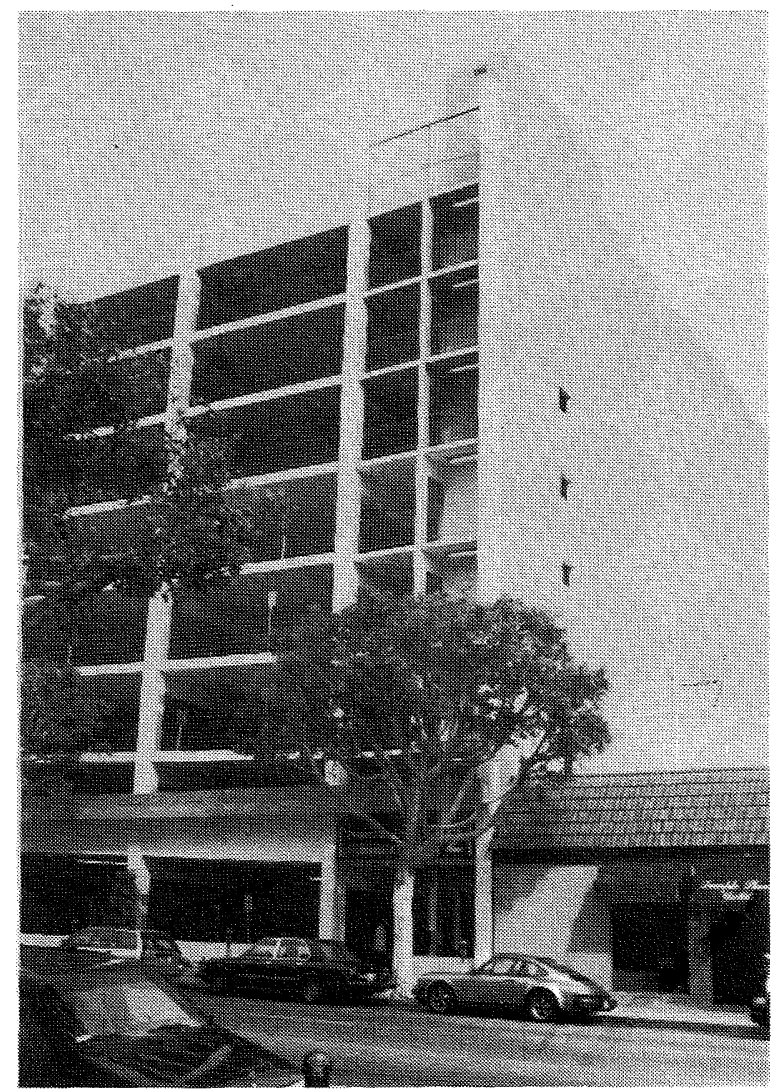

FIGURE 6.66. Carpark building, Santa Monica with little noticeable damage to reinforced concrete masonry walls (20).

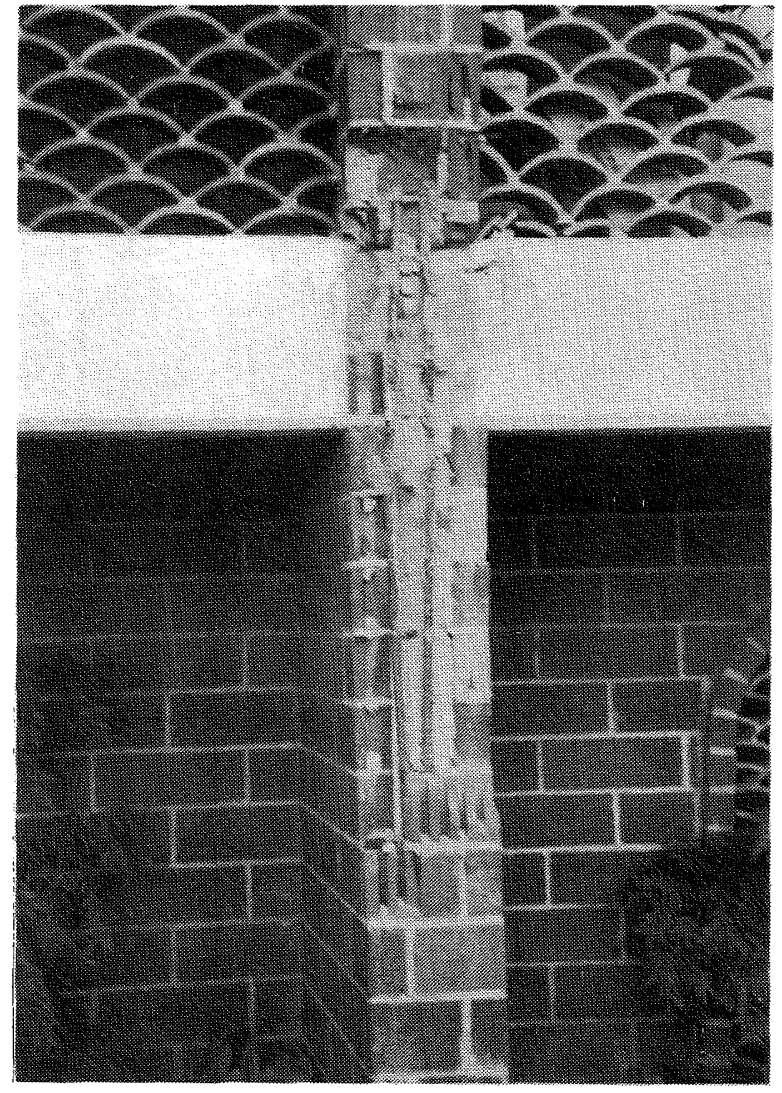

FIGURE 6.68. Berkeley East Convalescent Home. Brick Masonry end veneers shed from shear wall.

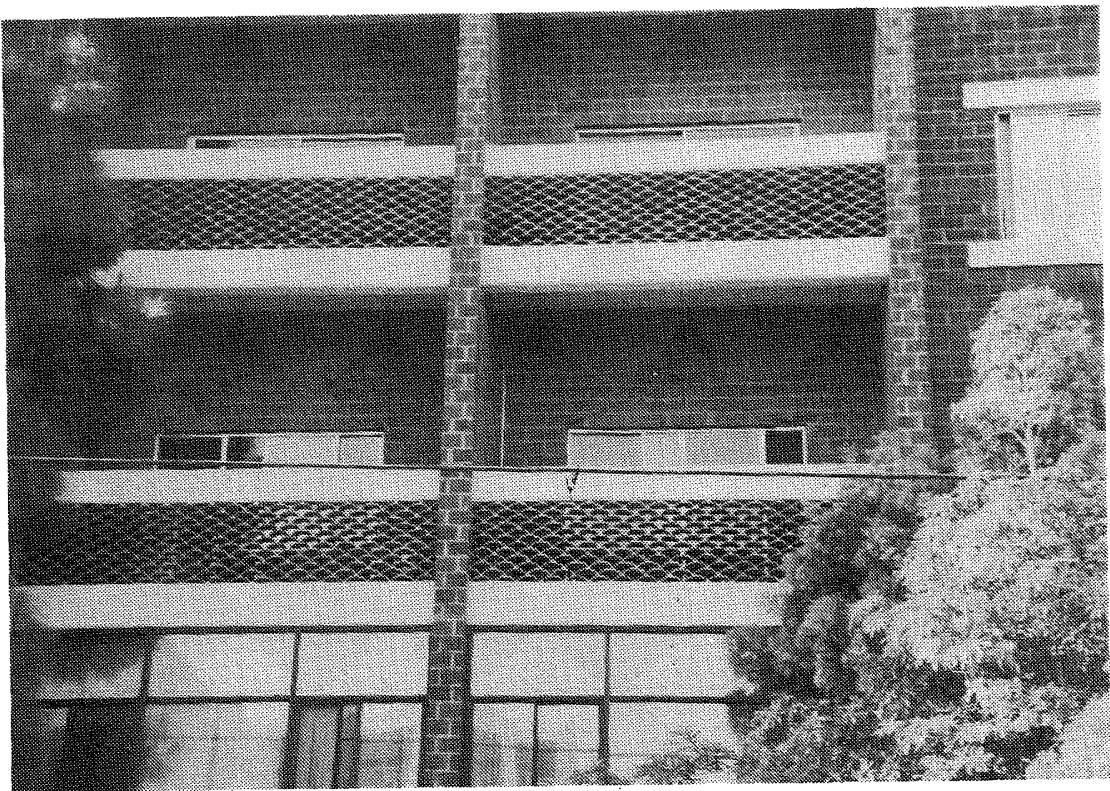

FIGURE 6.67. Berkeley East Convalescent Home, Santa Monica. 5 storey reinforced brick masonry building (21). 

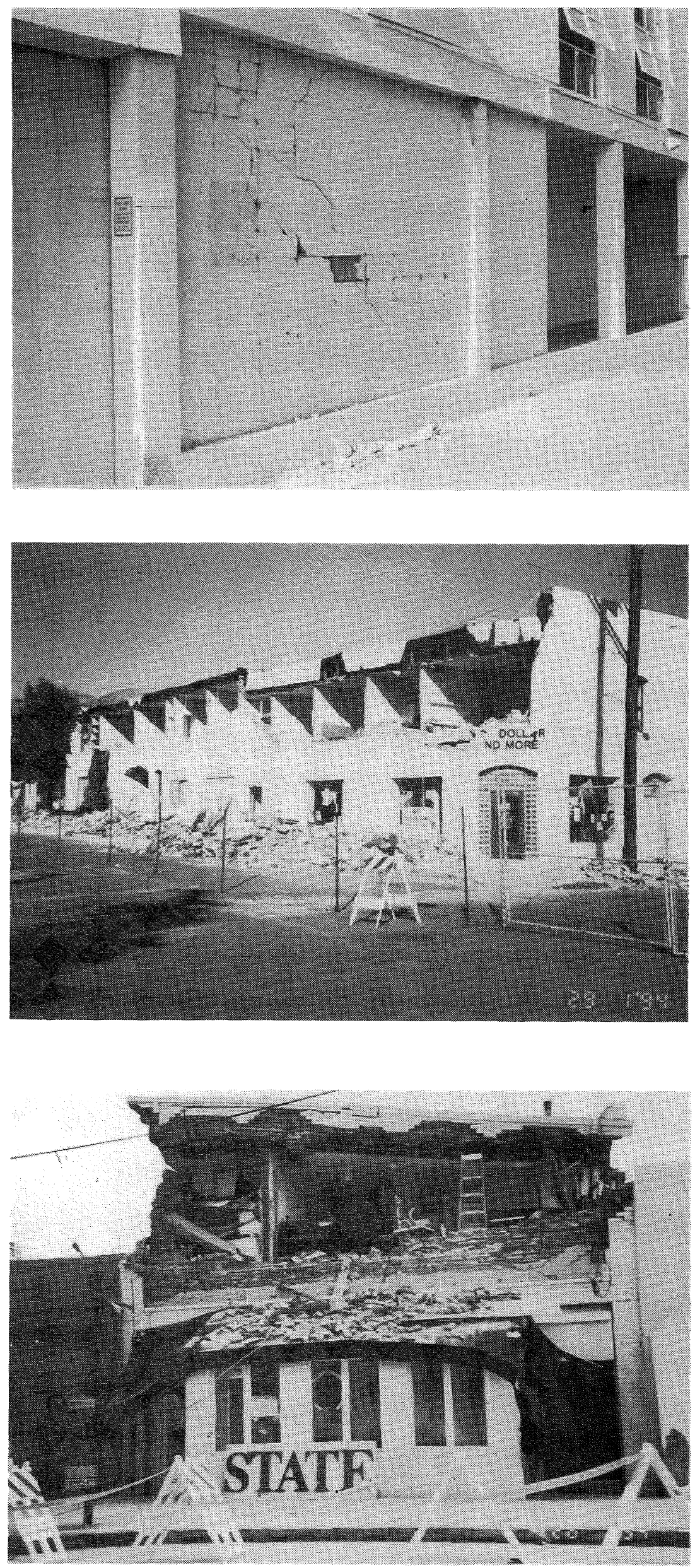

FIGURE 6.69. A hostel facility to the west of St Johns Hospital which exhibited classic diagonal cracking.

FIGURE 6.70. Unreinforced masonry structures at Fillmore, 25 miles north west of the epicentre.

FIGURE 6.71. Unreinforced masonry structures at Santa Monica, Several small retail outlets experienced similar damage (22). 
hazardous if the adjacent streets had been occupied (Figures 6.70 and 6.71).

The First Christian Church of Santa Monica (Figure 6.72) was $24 \mathrm{kms}$ from the epicentre. It had been retrofitted and was constructed of three-skin brick masonry. The building suffered damage on three sides, typically exhibiting that seen in the figure. It was reported that this building has subsequently been demolished. This building highlights the further issue that has arisen following the earthquake. Generally, retrofitted buildings performed satisfactorily in terms of protecting life. However, there was considerable damage to such buildings. What the building owner thought retrofit meant in terms of his investment and expectations of the state of the building (after a major event) and what actually resulted, have become issues which may only be resolved in court. Engineers apparently need to explain more clearly what the performance of a retrofit is likely to be in a range of possible seismic events. Retrofitting details are similar to those that are being used in New Zealand at the current time and generally, as mentioned above, have performed well in terms of life safety.

\section{NON-STRUCTURAL BUILDING COMPONENT BEHAVIOUR}

\subsection{General}

Damage to non-structural systems was, as expected, much more widespread than structural failures. The extent of this nonstructural damage was noticeably less within specifically engineered systems than within those that had not been so designed. For example, glazing damage was common within low-rise facades and shop fronts, whilst it was seldom observed within specifically designed systems. The economic impact of the non-structural damage is expected be much greater to the community because it was more widespread and there were significant delays in repairing and reinstating glazing, suspended ceilings, fire protection systems, mechanical and HVAC plant. Many small businesses had remained closed for several months following the event and it is feared that the economic impact of this disruption to trade would cause many businesses to close permanently.
This section of the report describes the performance of systems and elements which do not provide any structural support to the building, yet are essential for its functionality. Thus comments are made on the performance of curtain wall glazing systems, building facades, mechanical plant and equipment within the building, and building fit-out features such as ceiling systems and building contents. The location of buildings where nonstructural damage occurred, as described in the text, may be found in Figure 7.1.

As mentioned elsewhere, the building stock within the epicentral area was predominantly residential (single unit dwellings and multi-unit apartments). Commercial buildings tending the service needs of the local community, such as shopping centres, hospitals, community service centres, medical centres, schools and other educational facilities were therefore scattered throughout the area. Thus the predominantly high-rise Central Business District (CBD) of LA was largely untested during this event and informed comment on the performance under severe ground motion was not possible. The ground motion experienced within the CBD is assessed to be at about that of a 'serviceability earthquake' within the New Zealand environment (ie buildings responded elastically with little or no structural damage). Some damage to secondary elements was experienced as is discussed in this section.

While structural damage to commercial buildings was limited to less than $2 \%$ of buildings within the epicentral area, approximately $15 \%$ were classified as either unsafe or unsuitable for normal occupancy because of damage to non-structural components. Water damage, from damage to either fire sprinkler or HVAC systems, was the most common cause of commercial building outage. Damage to building facades, particularly shop-front glazing systems, was the second most common reason for closing commercial buildings. Collapses of suspended ceiling and lighting systems were also widespread and resulted in several low-rise commercial premised being declared unsuitable for normal occupancy. This damage was usually easily repaired, allowing key facilities such as hospitals, schools, telecommunication facilities, etc. to be rapidly repaired and resume full operation within days of the event. Normal businesses however were unable to acquire the necessary repair personnel and some were closed for several weeks (or in some

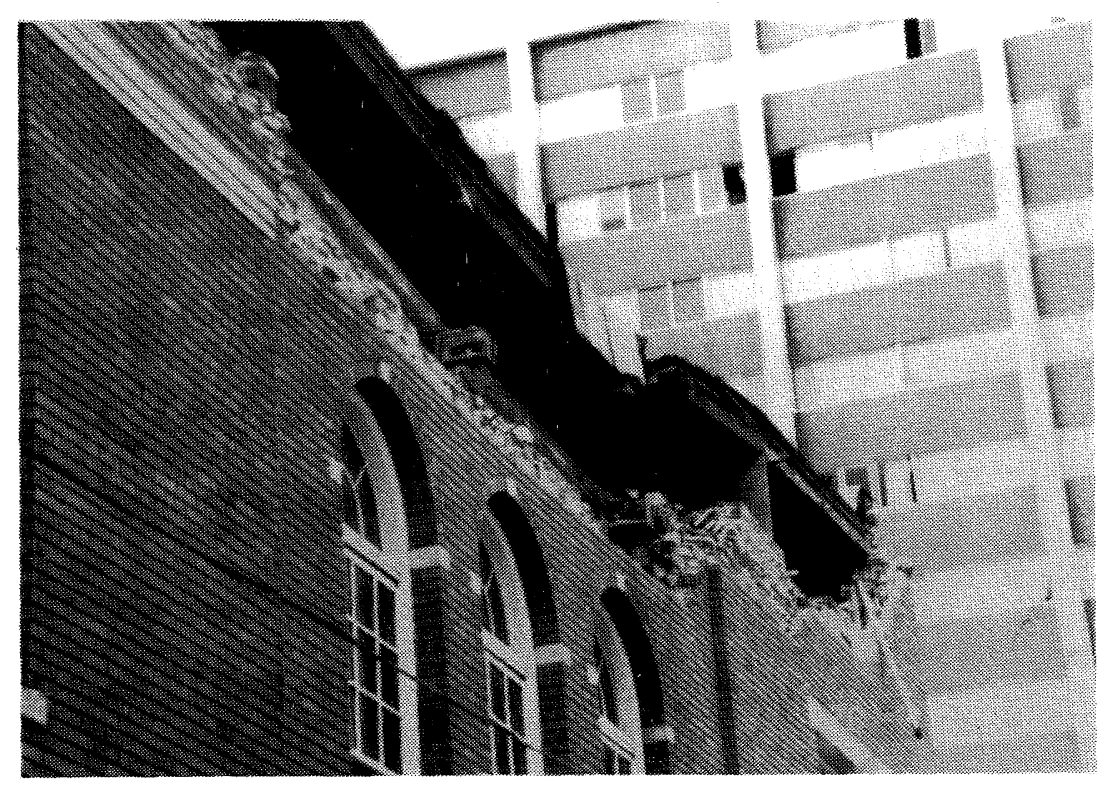

FIGURE 6.72. First Christian Church of Santa Monica (23). 


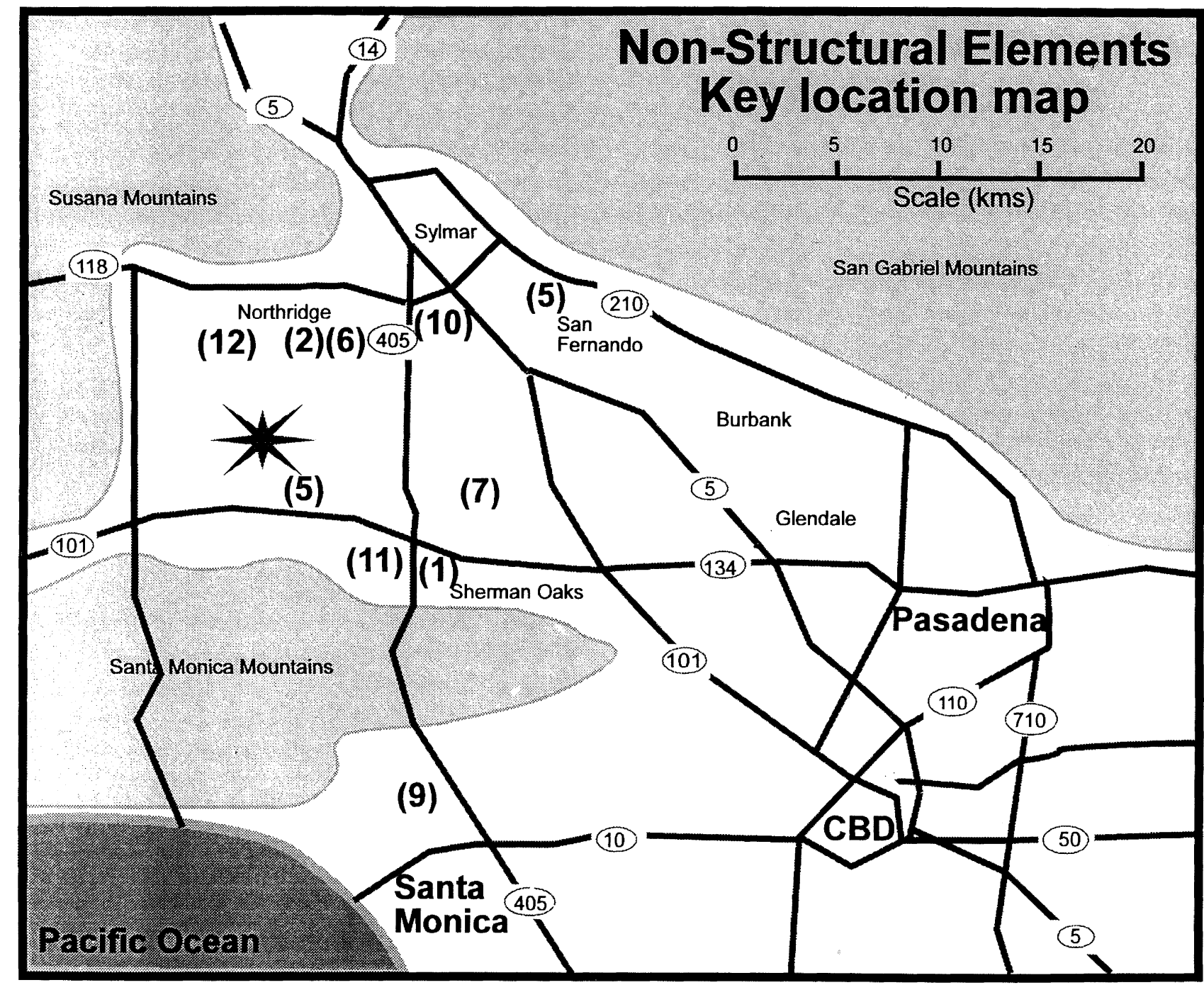

FIGURE 7.1 Key to the location of buildings where damage occurred to non-structural elements as described in the text.

cases months) while they awaited repair to damaged nonstructural systems.

Within residential buildings, non-structural damage was generally confined to cracking of the exterior stucco facades and the interior sheet lining materials. Chimney, roof tile and domestic hot-water and air-conditioning system failures were also common. Such damage was generally superficial, allowing the dwellings to be occupied but with reduced functionality. There were few broken windows in houses.

\subsection{Building Facades}

\subsubsection{Precast Concrete Panels}

Precast concrete building facades generally performed well except where inadequate clearance was provided between precast facade elements and the structural frame. In these instances the panels themselves experienced damage (falling from the frame in extreme cases) or the structural system was altered by the presence of the precast elements which damaged the frame itself (generally short column shear effects). Although the latter form of damage was more common in moment-resisting framed buildings, it was also observed in shear-wall structures. One such example is the 7 storey carpark building (2) shown in Figure 7.2 which experienced spalling of cover concrete from the structural frame elements. Damage to the frame occurred at both the upper and lower corners of the precast spandrel panels where inadequate clearances had been provided. Thus the assumed frame geometry was changed by the presence of the spandrel with damage most prevalent within the columns next to the shear-wall. One upper panel had fallen and cover concrete had spalled from several of the frame columns.

Precast concrete elements also experienced damage (or collapsed) through inadequate connection detailing. One example of this was the four storey Delmar T. Oviatt Library on the California State University Northridge campus (3) shown in Figure 7.3. Connections between the external precast concrete columns and facia panels appear to have been unable to accommodate the lateral drift induced in this structural-steel framed building. The central portion of the building had lateral support provided by concrete shear-walls (built 1973) and was extended with additions at both ends using cross-braced steel frames (additions 1991). Lateral stiffness incompatibility between the two systems has resulted in collapse of both and may have caused a large elongation within the facia parapet beam. A similar collapse had occurred at a second link span further along this face of the building. The problem appears to be related to enhanced movement at the tops of the precast columns, exacerbated by the different dynamic response of the original building and the addition. The resulting movement exceeded the seating provided for the cantilever eaves support beams and the associated parapet panel. Some sections of the eaves soffit also collapsed. Damage to the glass facade ( $>60 \%$ 


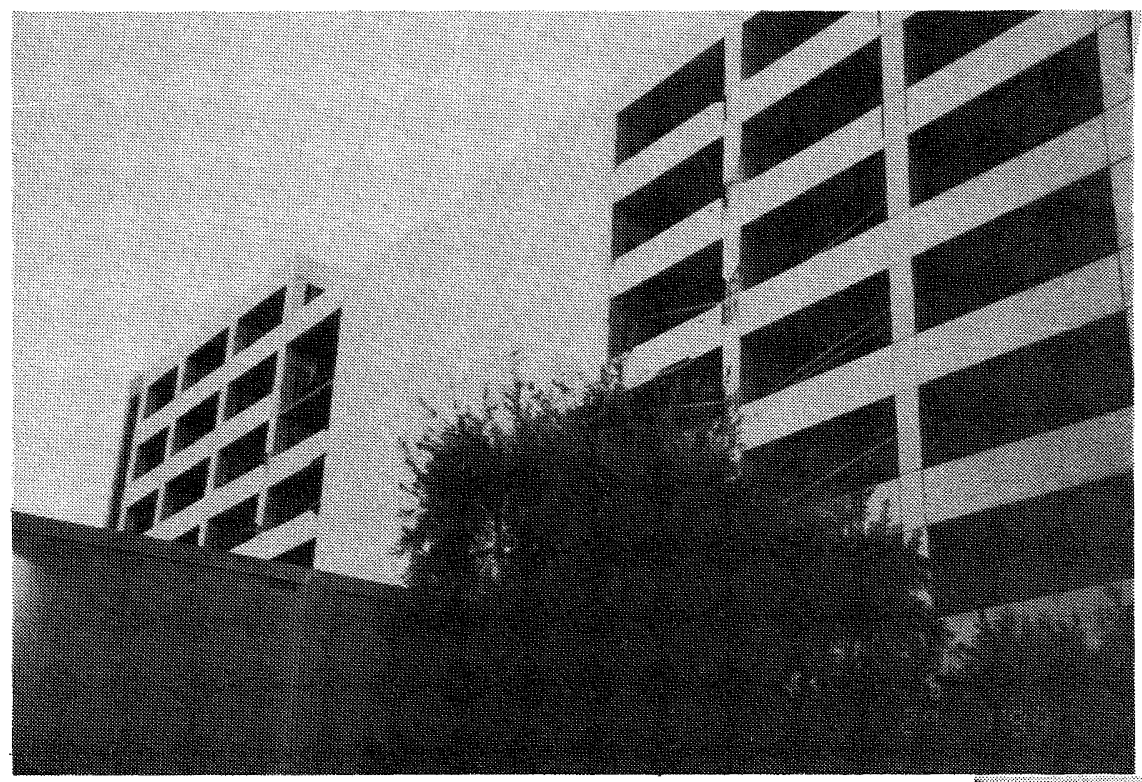

FIGURE 7.2 Precast panel damage (with one collapse) of carpark building (2) consequential to inadequate panel/column clearances.

\section{FIGURE 7.3 Oviatt Library (3). Precast concrete parapet panels collapsed consequential to inadequate fixings and high lateral stiffness irregularities.}

of the panes were broken) was observed within the west extension to the library where the internal floors hammered into curtain walling. It was reported that the library shelving performed well although the robotics book retrieval system used within the library is understood to have damaged.

\subsubsection{Glass Facades}

Glazing damage was quite dramatically distinct between facades which had been specifically engineered, where damage was minimal, and those which had not, where damaged within the epicentral area ranged from moderate to heavy. Although there were few examples of engineered facades within the epicentral zone (and conclusions cannot therefore be drawn as to their performance under severe attack), several were present around the peripheral of the zone where ground accelerations were approaching design level intensity. While some buildings experienced significant damage and were 'Red Tagged' (Unsafe) the facades generally performed well. The high-rise towers of the LA CBD experienced little or no glazing facade damage, as could be expected since ground acceleration intensities were only at or near 'serviceability design' levels. (NB some internal fit-out damage did occur in some of these buildings together with the displacement of contents particularly higher up the building). Glass stiffening fins were present as part of several engineered facades on tower blocks within the CBD. No damage to such systems was observed. No such examples were noted within the epicentral area and their performance in more severe shaking areas remains uncertain. Residential glazing systems generally survived well, with glass breakage being limited to buildings where shear distortions were severe.

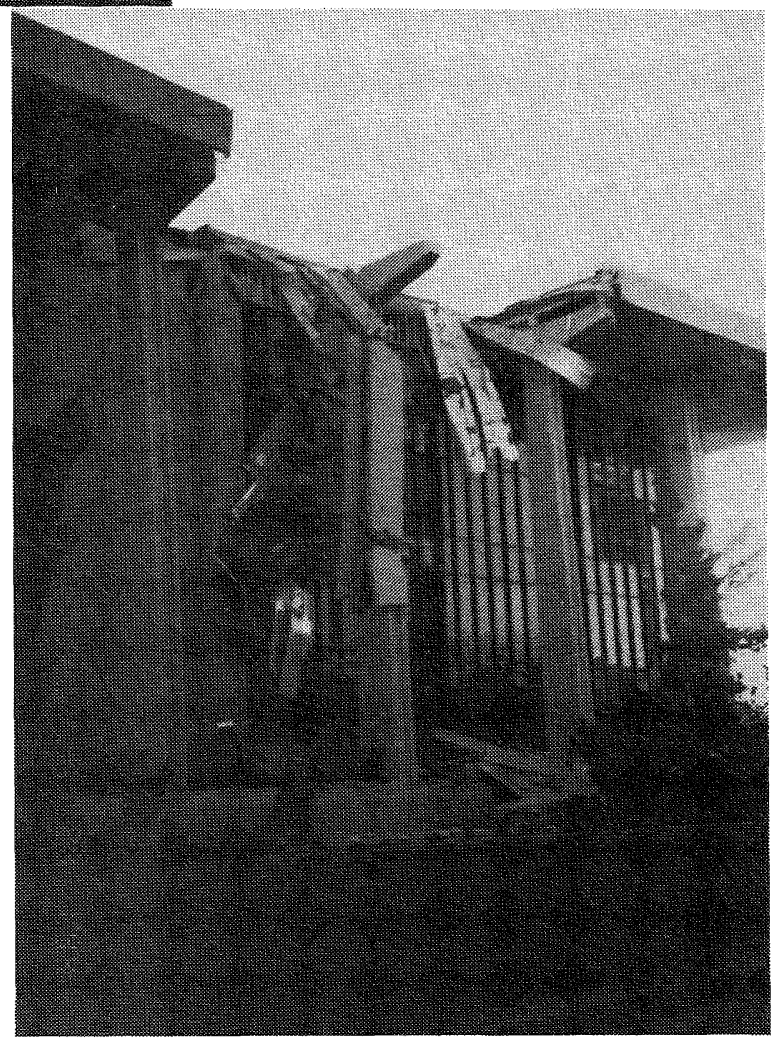

There was widespread damage to large shop front glazing with 30 to $50 \%$ of the glazed area damaged in several buildings used for low-rise commercial and retail purposes within the epicentral area. Glazing within these buildings was generally ordinary annealed glass installed in metal frames. (Post-1990 code provisions require toughened or laminated glass to be used where the panes are within $0.5 \mathrm{~m}$ of the ground but no examples of this were specifically identified and comment as to their performance is not possible). The use of mastic and putty was common in both metal and wood framed windows. Such materials become stiff with age and provided semi-rigid edge support for the glass. This inhibited the ability of the panes to slide within their frames and restricted or eliminated the ability of relief to shear distortion being possible by full-pane rotation. Breakages in these systems frequently resulted when shear distortions approached $\mathrm{H} / 150$ or where facade planes were disrupted (ie either right-angle or $45^{\circ}$ intersections (Figure 7.4). 


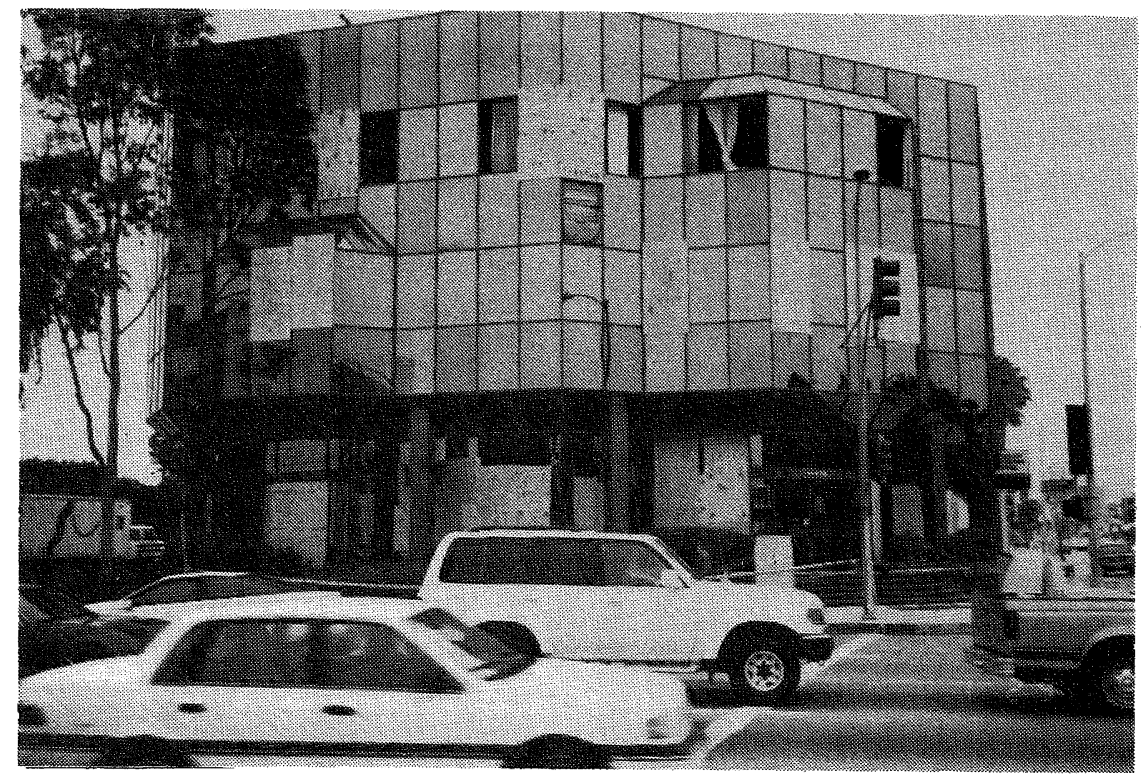

FIGURE 7.4 Medium rise office Block (4). Several glazing panels damaged particularly at changes facade plane.

More modern buildings, including several in the shopping malls, typically had neoprene gasket dry fixed glazing systems which were noticeably superior in their ability to withstand significant shear racking. Although the extent of pane rotation could not be accurately assessed, examination of the seals indicated its occurrence.

Where facade damage did occur, broken panes were usually at corners and where the windows abutted the structure symptomatic with out-of-plane and secondary distortion effects being present. Some instances of solar screen plastic film being applied to window panes were reported. Such film appeared to have beneficial influence on the behaviour of the glass.

The onset of secondary damage observed was that the breakage of shop-front windows generally preceded damage to suspended ceiling systems in commercial premises. In houses, damage to stucco preceded internal lining damage, both of which occurred before window breakage. It is of interest to note that very few of the large north-facing glass windows common in many schools, suffered damage, although many of these buildings did experience non-structural damage of other types. The strong directional nature of the ground motion (primarily north/south within the epicentral zone) may have influenced this apparently anomalous response.

\subsubsection{Stucco Facades}

Cement based stucco facade was by far the most common cladding for residential houses and apartment buildings and was commonly also used for commercial and retail facades for buildings up to 4 storeys in height. The render was typically between 30 and $45 \mathrm{~mm}$ thick, and applied over purpose supplied wire netting with paper tape infill over steel or timber framing. A variety of surface finishes were possible over the stucco, including terracotta tiles, brick slivers and cast-in dry-stone finishes. Failures of these systems were widespread and ranged from nearly all such cladding experiencing minor cracking to complete collapse of the facade, generally initiated by failure of the fasteners between the facade support framing (Figures 7.5$8)$.

The construction technique used for both commercial and domestic building facades was similar, except that where the facade was elevated and extended over several floors, support ledges (steel angles) were incorporated within the facade to provide self-weight support for the upper portions. Such devices provide very little support to the facade against either in-plane loads or face loads. The netting was typically fastened to the framing by either staples or turned over nails. As can be seen from figure 7.7 , the netting generally remained embedded into the reverse face of the stucco, with the fasteners to the framing exhibiting failure. The provision of more sturdy fasteners and reinforcing mesh embedded within the cladding is likely to have prevented the failures observed. The hazard created by the collapse of these systems, particularly when they are installed over publicly accessible areas, is quite unacceptable and should be addressed.

Stucco used in New Zealand cladding systems tends to be thinner is section (ie they contribute less to the seismic mass). Where supported on netting, care is essential to ensure (a) that the netting is fully embedded within the stucco, and (b) the netting is adequately fastened to the framing. Where a backer sheet is used behind stucco, an adequate bond between sheet and stucco is essential, and a positive connection between the body of the stucco and the framing as well as between the sheet and the framing is required. Where support is provided by metal lathe the nail or screw fasteners to the frame must be adequate to support the mass of the stucco against both self-weight and (up to $1 \mathrm{~g}$ ) face load. This continuous support of the cement plaster should be sufficient to inhibit the development collapse mechanisms observed in LA, but much of the crack development observed must be expected due to the brittle nature of the product.

\subsection{Building Services}

\subsubsection{General}

Water damage following the failure of building services systems was the most common cause for loss of building functionality and consequential closures. The minimum duration of such closures was four days, with several buildings remaining closed for several weeks (and in some cases months), due to this form of damage. Much of the comment in this section is reported by those who were in the field within the first week following the event any who were involved in the repair and reinstatement. Water damage is insidious in that failure of the reticulation 


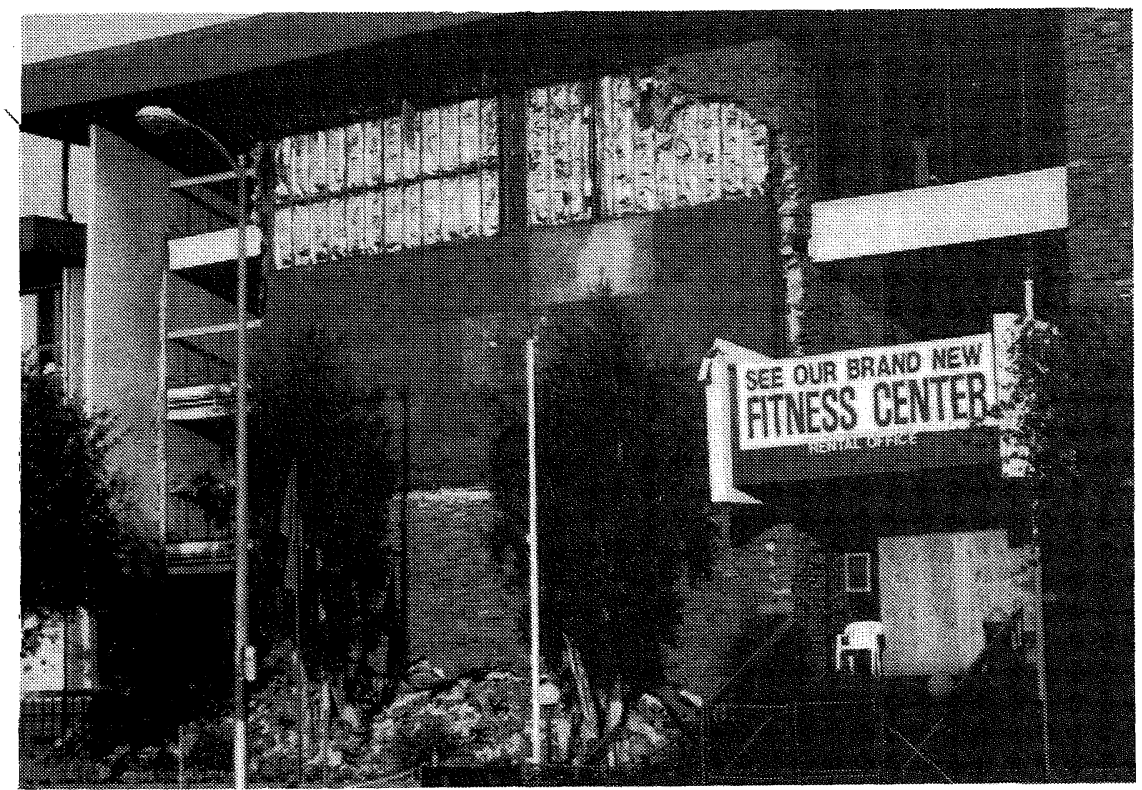

FIGURE 7.5 Woodman Ave Apartments (5). Three storey stucco facade with stone facing which separated from the support framing and ply bracing sheets

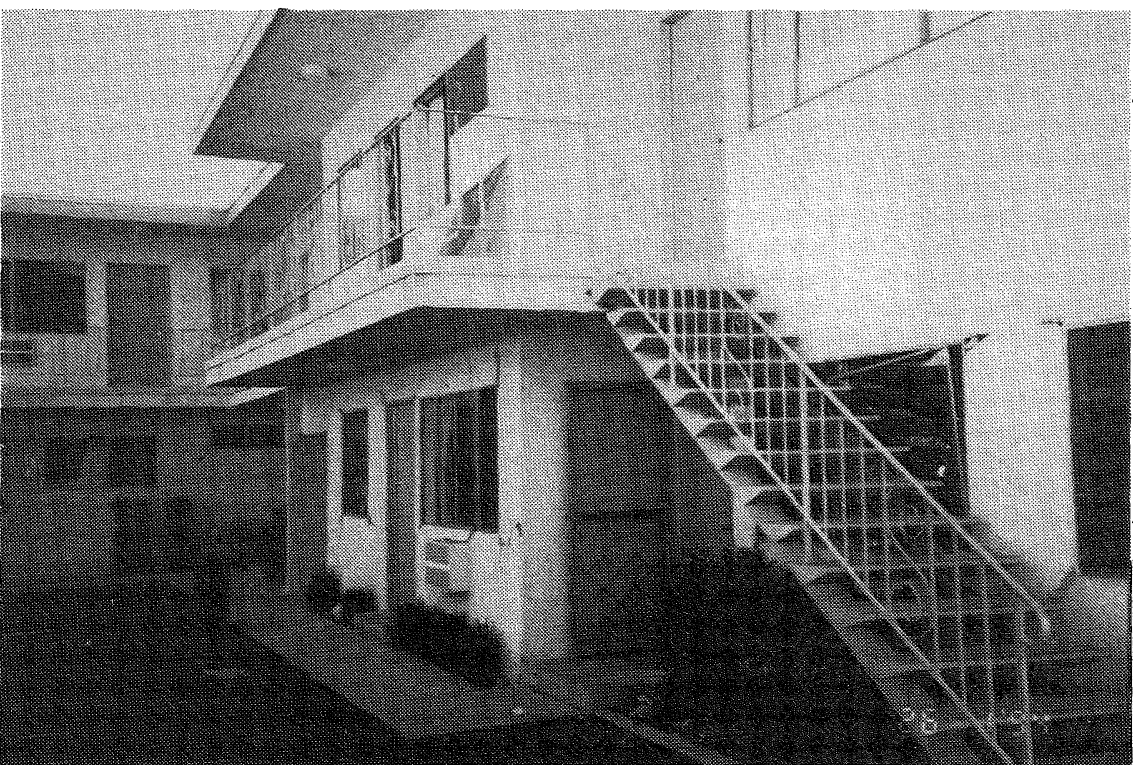

FIGURE 7.6 Olive View Apartments (6). Typical stucco damage to two storey residential units with cracking to lintels and parapets and periodic loss of windows and glass breakage.

FIGURE 7.7 Prairie St. Apartments (7). Stucco facade with impressed brick finish severely damaged and separated from support framing.

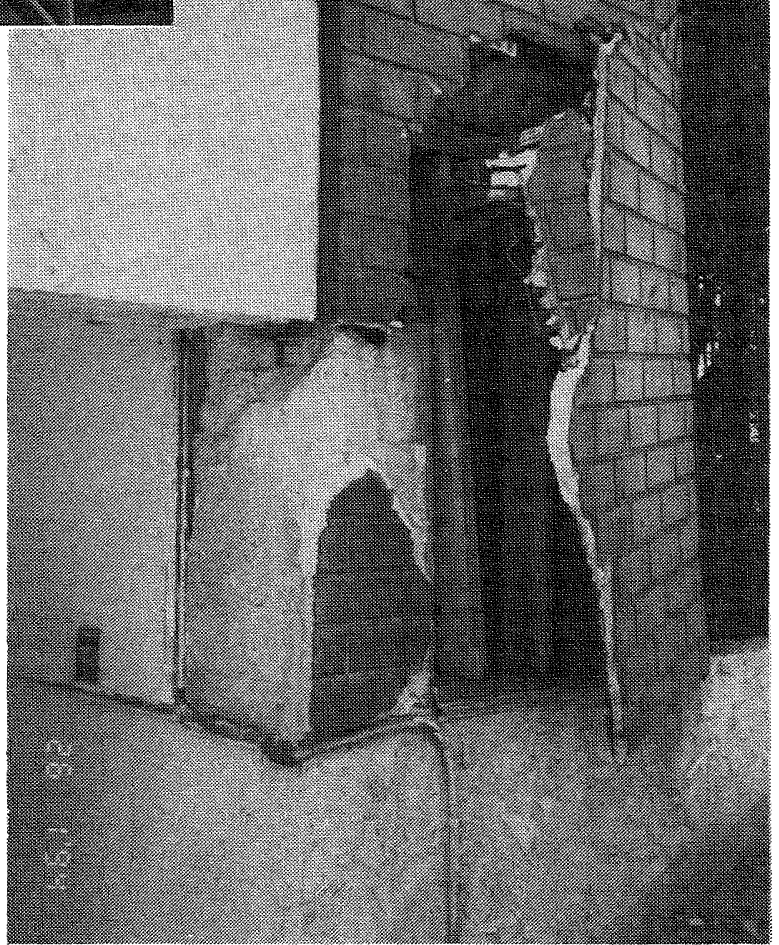




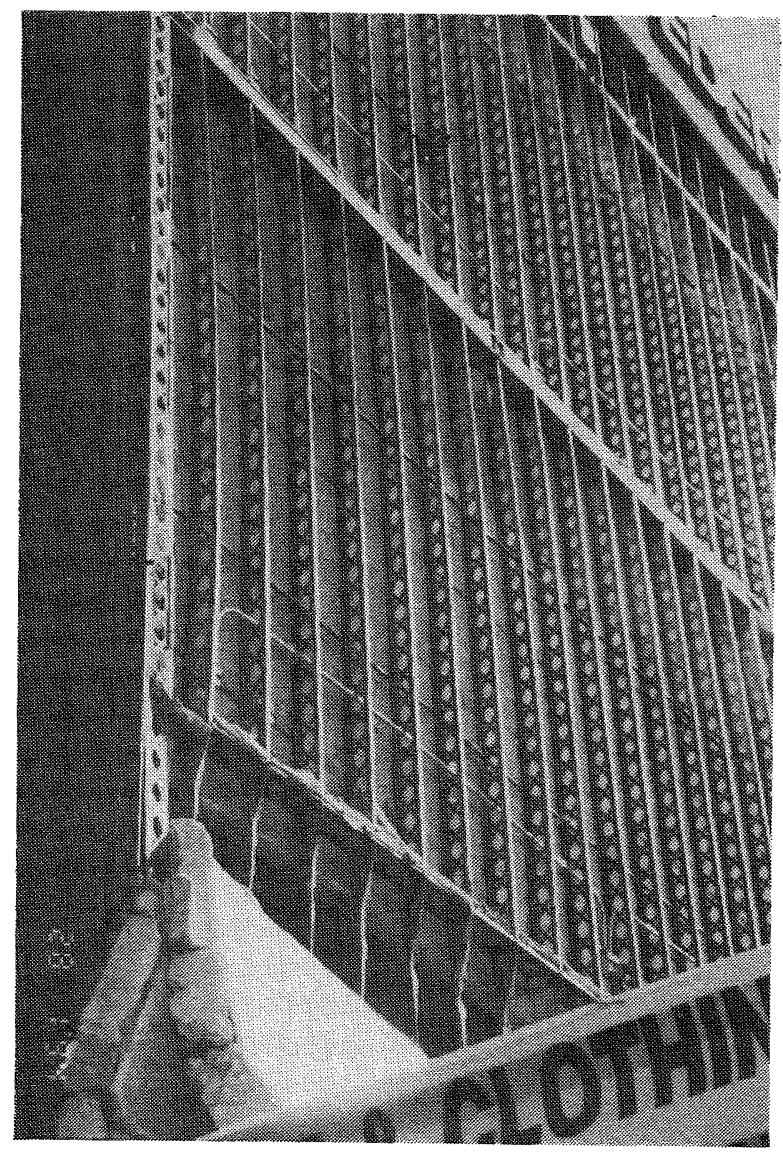

FIGURE 7.8 Glendale Federal Bank Building, Sherman Oaks (8). The upper two storey of stucco facade was shed from both ends of this building with significant consequential damage the roofs of neighbouring properties.

system may be quite localised but the water permeates from floor to floor before discharging from the building. Unfortunately, the buildings with more extensive mechanical plant demands (eg hospitals, educational facilities, etc.) are more prone to damage of this nature purely because of the amount of reticulation present.

\subsubsection{Fire Protection Systems}

Water damage was widespread in several multistorey service buildings within the epicentral zone. Many of these failures were directly attributed to rupture of pre-charged fire sprinkler systems, with failure of HVAC plant (particularly rupture of feeder pipes) being the second most common cause. Sprinkler heads were particularly vulnerable where they passed through the ceiling plane. Where the sprinkler head was exposed (ie mounted proud of the ceiling) the support pipes were commonly able to resist pounding between pipe and ceiling. Where the head was embedded within the ceiling, rupture was common with widespread consequential damage both to the area adjacent, and downstream of the discharge point. The actual number of such failures within given buildings was usually small (ie $<5 \%$ ) but the consequential damage and disruption was nevertheless widespread. Pipe ruptures also occurred within congested ceiling spaces where the dynamic response of different services resulted in pounding and damage in several cases. While lateral bracing was provided in some cases, the rigidity of such supports were commonly inadequate to prevent movement with damage resulting.

\subsubsection{Mechanical Plant and Equipment}

Mechanical plant general performed well particularly when plant restraints were designed and installed in accordance with modern code requirements. There were however some notable exceptions many of which were hospitals and medical facilities within the epicentral zone. There is little doubt that the extent of plant and services that were required by such facilities contributed to their above average failure rate. Mechanical plant was typically restrained against lateral movement with sprung support brackets and end-stops. Such devices generally performed their function as expected, although the clearance provided in some cases was insufficient and impact between plant and stop was observed. Feeder and distribution pipes were particularly vulnerable with rupture at or near the point of attachment to the plant being common. Damage of this type was more prevalent than other forms of plant failure and the extent of consequential damage often much more widespread. The rupture a high pressure air conditioning chiller feed pipe at Olive View Hospital resulted in the entire block becoming nonfunctional for four days as the water spread from the roof plant room through all six floors. Apart from this, the building survived the event without damage. The plant room of the Holy Cross Medical Centre was also extensively damaged when fans which hung from the plant room roof swung forward to hammer the outer facade. (This steel framed building was later found to have suffered significant beam/column weld failures which would have resulted in abnormally high lateral displacements with consequential high secondary damage expecting to be high). Similar damage was reported within one of the plant rooms at St Johns Hospital (9) in Santa Monica (a lightly reinforced clay masonry building, refer section 6.3.4.1(a)). Here air conditioning pvc pipework ruptured at junctions and changes of direction (Figure 7.9) and pipe support racks were seen to experience torsional failure because of inadequate longitudinal bracing of the pipes (Figure 7.10).

\subsubsection{Lifts}

Lift damage was generally minor with derailment of lift counterweights being the most common cause of outage. Damage of this type was reported both within the epicentral zone and the CBD. Such damage was readily repaired with most damaged lift systems returning within 4 days of the event. Exceptions were in some of the medical centres and hospitals within the epicentral zone. Damage to the lift shaft at Holy Cross Medical Centre (11) can be seen in Figure 7.11. In this case the counterweight became disengaged from its runners and pounded into the light gauged steel framed shaft to the extent that the outer lining was moderately damaged.

\subsection{Building Fitout}

\subsubsection{Ceiling Elements}

Suspended ceiling systems experienced considerable damage throughout the epicentral zone. Such systems were observed to collapse in commercial, retail and industrial buildings. The onset of damage was most commonly at the perimeter of the ceiling, consistent with pendulum action resulting from inadequate lateral bracing of the ceiling. UBC provisions of the 70 's and 80 's required quadrant wire ties $10 \mathrm{ft}$ spacings to the primary rails. There was no demand either for clipping tiles in place, nor for the provision of compression struts at connection points. The quad ties (ie a No 8 wire tie at $45^{\circ}$ in each orthogonal direction between the track and the soffit above) 


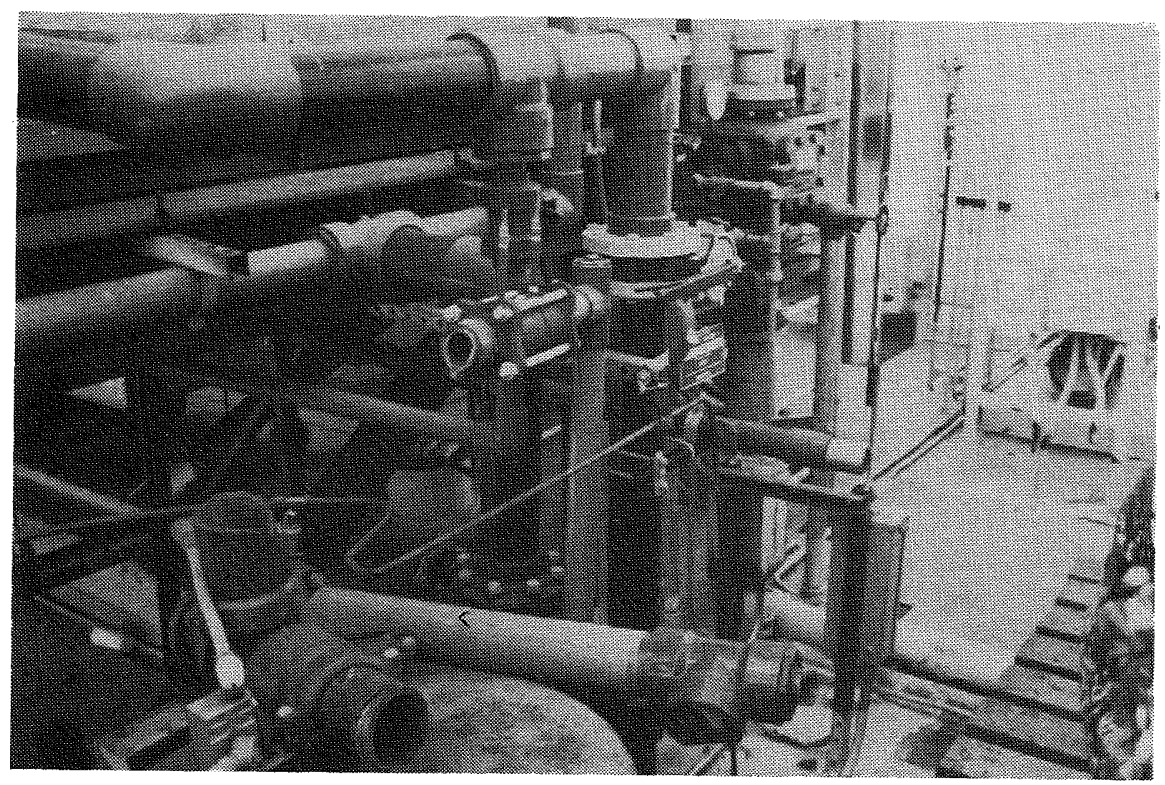

FIGURE 7.9 St Johns Hospital (9). Air conditioning plant pipework fractures at junctions and changes in direction.

FIGURE 7.10 St Johns Hospital (9). Pipe rack supports experienced torsional failure due to insufficient longitudinal bracing
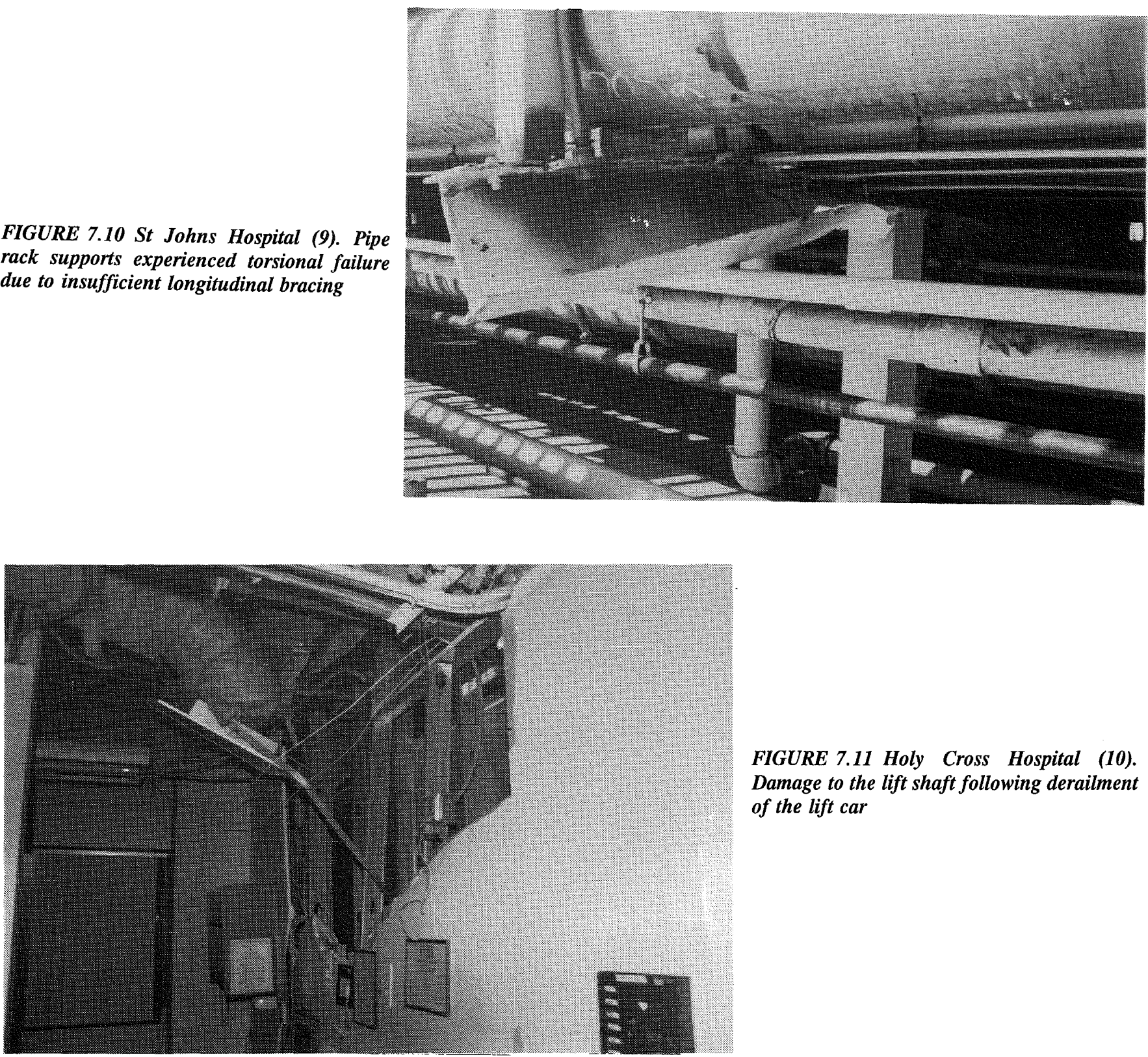

FIGURE 7.11 Holy Cross Hospital (10). Damage to the lift shaft following derailment of the lift car 
were thus unable to prevent side-sway of the complete ceiling grid. The perimeter tiles were crushed against the perimeter support bulkheads, and collapsed on the compression side while the rails spread away from the tension side, failing clips and initiating a domino collapse of the tiles and railings. Light fittings and air conditioning vents also lost support and commonly fell (Figure 7.12).

A common problem for schools, (as reported by Gary McGavin, Member of California Seismic Safety Commission [McGavin, 1994]) was the collapse of pendant light fittings within many schools with the epicentral zone. These fittings (often weighing up to 80 pounds) extend below rafters or ceiling on support rods. Secondary support chains are now required, but where these were not fitted, many failures of the pendants were observed. Approximately 100 classrooms had one or more such fittings collapse. Such failures would have created a significant hazard had the class-rooms been occupied. Most schools were operational one or two weeks after the event, although sometimes in temporary facilities.

\subsubsection{Plaster Ceilings}

Generally sheet plaster ceilings performed well with little or no damage. Such systems were typically supported directly from either timber or light gauge steel framing. A notable exception was an auditorium at UCLA where a ceiling segment of approximately 5 by $15 \mathrm{~m}$ collapsed, falling from a considerable height onto the (vacant) seating below. The collapse appeared to have been initiated by weld failure between the light gauge steel channel hanger, and hot rolled steel framing elements which extended down from above.

\subsubsection{Shelving and Racking}

High shelving and racking systems were common within many retail outlets within the epicentral zone. The performance of such elements varied widely, being dependent both on the type of shelving employed and on the intensity and character of the goods stored. Longitudinal lateral bracing was typically diagonal steel cross bracing which generally performed well although some anchor points failed, particularly when expansion bolts were employed to fasten these to floor slabs. Epoxygrouted systems appeared to be generally more reliable. Problems arose when anchorage points were either absent or inadequate even when the shelves were less than full laden. Several instances were observed where high elevation bracing of such systems were attempted, but with little appreciation of the strength demands which would be placed on the supporting members. Library shelving generally performed well, although most books were discharged from shelves and the time of reinstatement was considerable.

In the Levitz furniture warehouse (13), about half of the internal racking collapsed including all but two of the free-standing sections. The racking was of substantial construction, with the top shelf at approximately $7 \mathrm{~m}$ elevation, and the top connector beams connecting the rows of shelving (Figure 7.13) a meter higher. Cold-formed steel uprights were connected to footer beams, which extended the full width of the shelves (about 1.2 $\mathrm{m}$ each side of the upright) and were bolted to the floor slab. All the collapsed central racking fell longitudinally, as a result of shear failure of bolts which connected the bracing rods to the uprights. Some sections of the rack were fixed to internal columns. Connections were again severed with the racking being left standing but tilted. Others racks were connected to perimeter walls and those connected to the south face fell outward as the tilt-slab panels and associated end roof span collapsed. Likewise some racks were fixed to a masonry party wall and are likely to have contributed to its partial collapse. One section of wall-fixed racking broke its wall connections and fell outward. Thus, all the rack collapses were more directly attributable to failed connections, either to backing walls or bracing rods.

At the time of inspection, the furniture formerly stored on the racks had been removed. However, the owner's representative reported that large quantities of furniture fell from the racks, blocking the aisles. In addition, lights and sprinkler pipes were torn from the ceiling, and sections of the roof adjacent to the rear wall fell on top of the racks. Some sections of failed racks had been packed with heavy objects at the top, and light furniture below.

The nearby Sportsmart Sporting Goods supermarket (14) was fully accessible to the public, and had shelving of a different nature (Figure 7.14). Shelving was between 3 and $3.6 \mathrm{~m}$ in height and approximately $6 \mathrm{~m}$ wide each side of the verticals. The shelves had contained a wide variety of sporting equipment, often imposing markedly different loading on each side of the

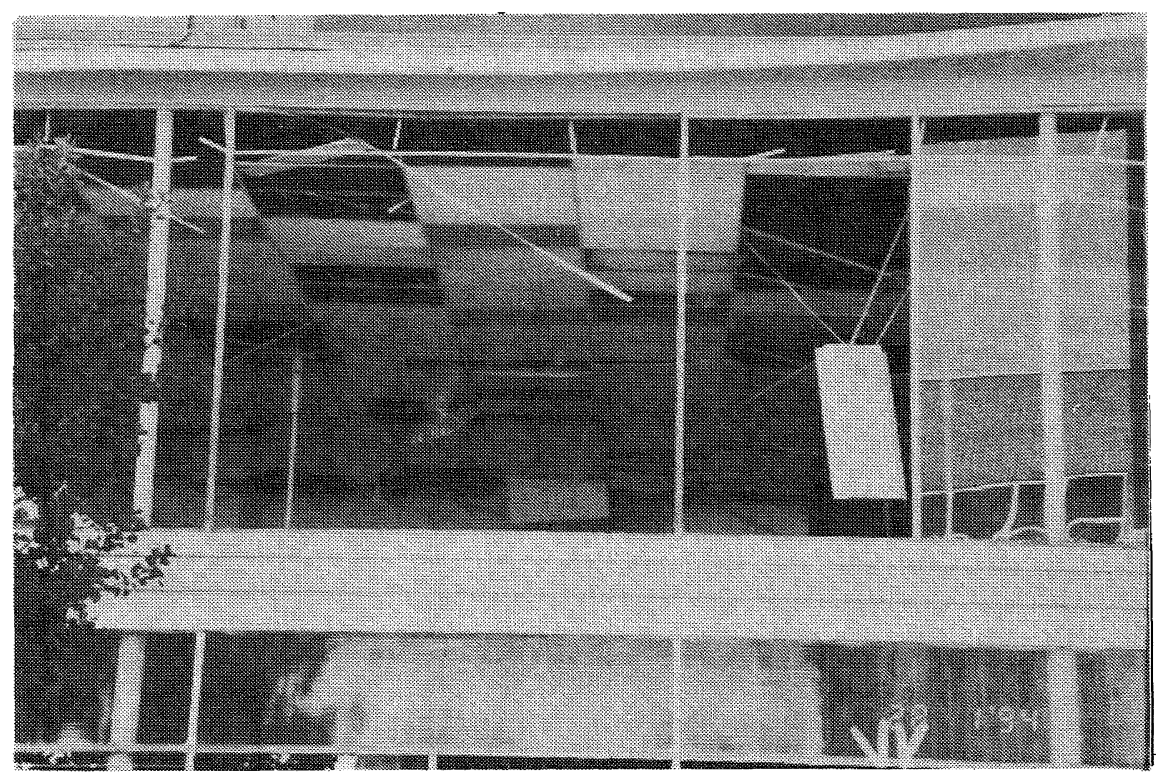

FIGURE 7.12 Retail outlet, Sherman Oaks (11). Suspended ceiling tiles and associated light and air-conditioning vents commonly fell from suspension grids. 


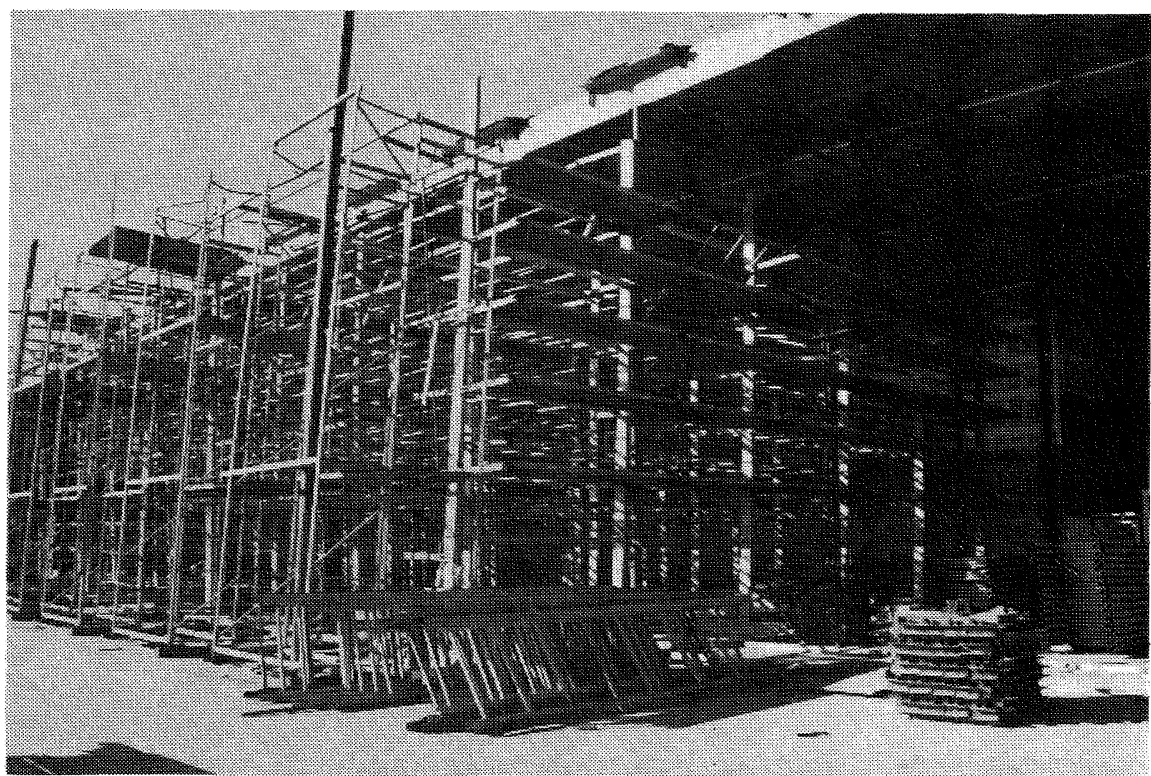

FIGURE 7.13 Levitz Furniture Warehouse (12). Many of these $7 \mathrm{~m}$ high furniture storage shelves failed as cross bracing connections failed and support walls collapsed

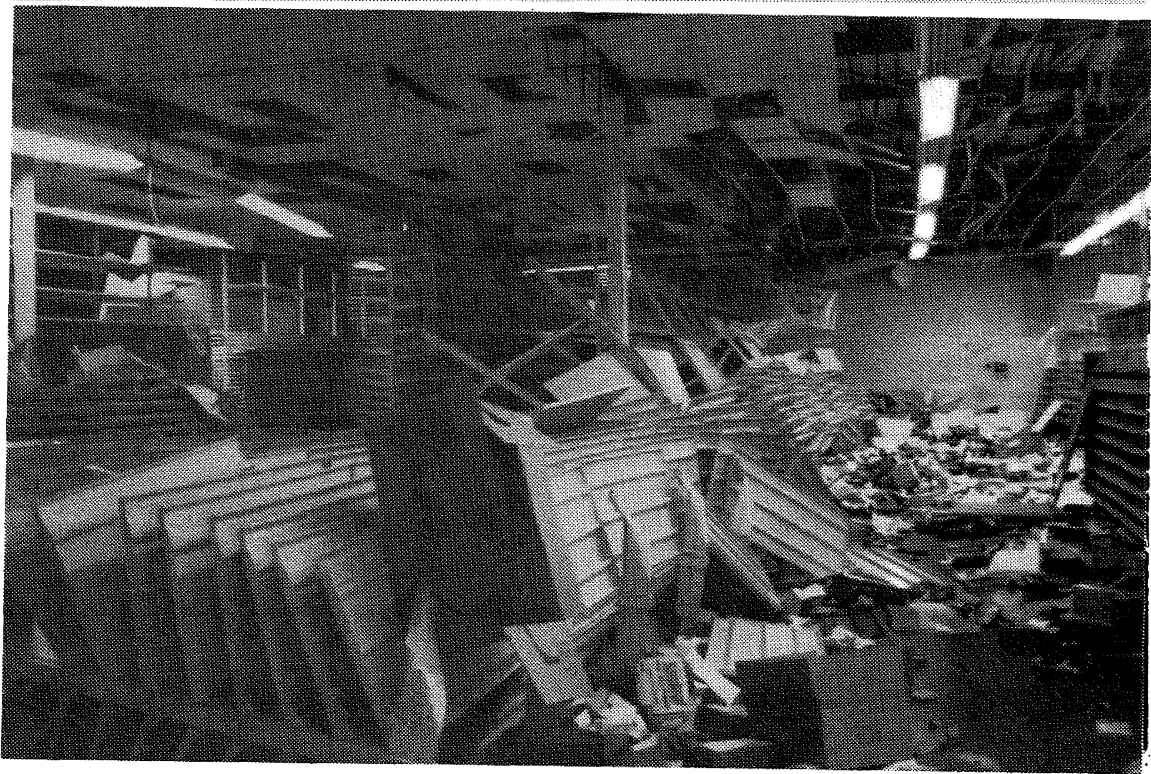

FIGURE 7.14 Sportsmart Sporting Goods Supermarket (12). Display shelves up to 3.6 $m$ high collapsed across their isles through upright to base connection failure.

shelving and at different heights. Most of the shelving had collapsed or overturned in the earthquake, scattering contents and covering aisles. The connection between base and upright had separated either initiating or consequential to the overturning. Ceiling tiles, light fittings and some ceiling rails had fallen over much of the store area, and part of the roof adjacent to the collapsed rear wall had also collapsed.

When photographed, the last of the building stock was being removed. Stock was first taken from the upper side of collapsed shelves, which were then lifted and collapsed in the opposite direction to remove the balance of goods. The direction of shelf collapse shown in Figure 7.14 is therefore generally opposite to that which the earthquake caused. However, the owner's representatives advised that the extent and nature of collapse shown is representative of that which had originally occurred.

In both the above examples, the distribution of load within the shelving or racking system emerges as a critical element in its performance. It is possible that the Health and Safety in Employment Act may offer a mechanism of increasing appropriate load distribution for such shelving in New Zealand.

\subsubsection{Building Contents}

By far the most widespread disruption to both residential and commercial premises was the wide-spread ejection of building contents. Shelves were frequently cleared of all items which commonly crashed to the ground, breaking in impact. Books were disgorged from shelves in most libraries, usually resulting in the shelving systems themselves remaining unaffected. Appliances also were thrown from benches and other shelves. Damage of this nature spread well beyond the epicentral zone with reports of damage of this nature over the northern sector of greater LA.

There were several examples were such damage was minimised. Schools where directives to fasten cupboards and tanks to walls and tabletops had been applied, resulted in greatly reduced damage being incurred. Similarly measures of protection applied to valuable artefacts were in the main effective. A study of some of the more advanced measures applied at the Paul Getty Museum were studied in some detail. Mitigation measures included two-directional horizontal bearing base isolation pads for two large statues, base counterweight systems to minimise overturning potential for several other elevated 
specimens and the widespread use of subtle tie-back systems for individual items of china and porcelain. Although the level of ground acceleration was well below that within the epicentral zone, (asséssed to be between serviceability and ultimate) the measures proved totally effective and were examples that New Zealand should consider applying directly.

\section{BRIDGING}

\subsection{Introduction}

Damage to bridging made immediate headlines in the media due to the disruption caused to the early recovery phase after the earthquake and, during the following weeks, to the everyday lives of Los Angelians. It is estimated [Caltrans, 1994] that approximately 1600 state and county bridges were in the area of significant shaking exceeding $0.25 \mathrm{~g}$ ground acceleration. At seven locations (Figure 8.1) bridges suffered collapses to a significant degree, while elsewhere a number were closed to traffic for structural reasons for three to four weeks after the event. None of the bridges that collapsed had been retrofitted with pier retrofits, but all but two at one site were high on the priority list for attention. Superstructure hinge restrainers had generally been fitted in the 1970's following the San Fernando earthquake of 1971. A number of crossings were closed to traffic until the approach embankments were regraded to rectify settlements caused by the shaking.

The party members were fortunate to have existing contacts with design staff from the State of California Department of Transportation (Caltrans). As a result, on arrival the latest earthquake damage report and the log of bridges on State highways in the Los Angeles district were made available, together with a permit to facilitate access to all Caltrans sites and the use of closed freeways. Also of great value was the generous donation of a day's time by $\mathrm{Mr}$ Gene Klein of Caltrans, who took three of the party rapidly around the most significantly damaged structures and let us gain a good knowledge of the area for subsequent more detailed inspection.

Various party members visited eleven sites where significant bridge damage had occurred, as indicated on Figure 8.1. A description of the structures inspected and the damage seen follows. Due to the speed of site clearance, some of the collapsed structures were not seen. Descriptions of the collapses are therefore included from other reports [Caltrans, 1994; Priestley et al, 1994], together with conclusions drawn from analytical work reported in Priestley et al [1994].

\subsection{Description of sites visited}

\section{Site 1 - Freeway 5 at Gavin Canyon undercrossing.}

This site is located approximately $3 \mathrm{~km}$ north of the intersection of Freeways 5 and 14 and was visited on 26 January. By this time the twin structures carrying four lanes in each direction had been demolished and removed, as collapse of large areas of the superstructures had occurred. The site had been cleared in preparation for reconstruction and a temporary bypass road was under construction to allow traffic to resume use of Freeway 5.

The structures were built in 1967 and retrofitted with hinge restrainers in 1974, and were each of five spans, with two intermediate hinges per bridge, with $200 \mathrm{~mm}$ long hinge seats. The maximum span lengths were 64 metres and the overall bridge lengths were 226 metres. The superstructures were reinforced concrete box girders between the abutments and the hinges, and prestressed box girders between the hinges. The piers were $1.9 \mathrm{~m} \mathrm{x} 3.05 \mathrm{~m}$ and up to 22 metres high, flared wider over the top 6.1 metres, and were founded on pilecaps and driven piles. The abutments were of integral diaphragm form.

The bridges were on a 66 degrees skew. Hinge restrainers had been fitted parallel with the bridge girders and hence at a very acute angle to the hinge lines. Transverse independent dynamic responses of the bridge sections had resulted in loss of support of the superstructure along much of three of the four lengths of hinge. Triangular pieces of the superstructure had consequently collapsed (Figure 8.2).

\section{Site 2 - Intersection of Freeways 5 and 14 (Figure 8.3)}

This intersection comprises a major interchange with a number of long and high overhead structures as well as numerous less spectacular structures. Two collapses had occurred at this site in both cases involving the end spans of long structures (Figure 8.3). In addition, a number of intermediate hinges in several structures had been cycled over large displacements, with the hinge restrainers working hard and limiting collapses. In these cases permanent extension of the restrainers had occurred (Figure 8.4) and it is thought likely that, had the approximately ten seconds of strong shaking been longer, several more collapses would have occurred at this site. The site was visited on 26 and 27 January, by which time the collapsed lengths of Structures 2 and 5 had been cleared away and preparations were advanced to demolish the remaining length of Structure 5 . Shoring of hinge 3 of Structure 4 (Figure 8.5) and insertion of additional high strength restrainers in hinge 2 of Structure 3 were also in hand to improve security against subsequent collapse.

\section{Structure 2}

This structure, built in 1974, and with a curve of 670 metres radius, connects southbound Route 14 with southbound Interstate 5. Its deck is a ten span insitu concrete box girder 2.1 metres deep and 480 metres long, with spans ranging from 33 to 63 metres and with four intermediate deck movement hinges. The structure comprises five frames with insitu prestressed and reinforced concrete superstructures alternately. Interestingly, the prestressed tendons were ungrouted. The flared single stem monolithic piers range in height from approximately 7 to 32 metres, are 3.7 wide $x 1.2$ to 1.8 metres in section (differing at various piers), and are founded by extending 11 to 18 metres into the ground as a 3.7 metre diameter pier shaft. The pier reinforcing ties are $13 \mathrm{~mm}$ diameter at $300 \mathrm{~mm}$ centres. Both abutments 1 and 11 are of the seat type, with $900 \mathrm{~mm}$ seating length and $50 \mathrm{~mm}$ thick elastomeric bearing pads supporting the box girder. The collapsed section at the southern end was 155 metres long, which was the whole length between the southern Abutment 1 and the first deck hinge. Piers 2 and 3 supported this section, with the hinge being 6 metres from Pier 4 . On the basis of others' photographs and calculations [Caltrans, 1994; Priestley et al, 1994] it has been concluded that the primary cause of collapse was the shear failure of Pier 2. This pier was of similar nominal height above ground to Pier 3 , but the ground level was approximately 1.5 metres higher than shown on the plans, and pier 2 had also been constructed in an area excavated 18 metres below the original ground level, while Pier 3 was not. Calculations [Priestley et al, 1994] indicate that Pier 2 was probably 2 to 3 times as stiff as Pier 3 , and that it could 


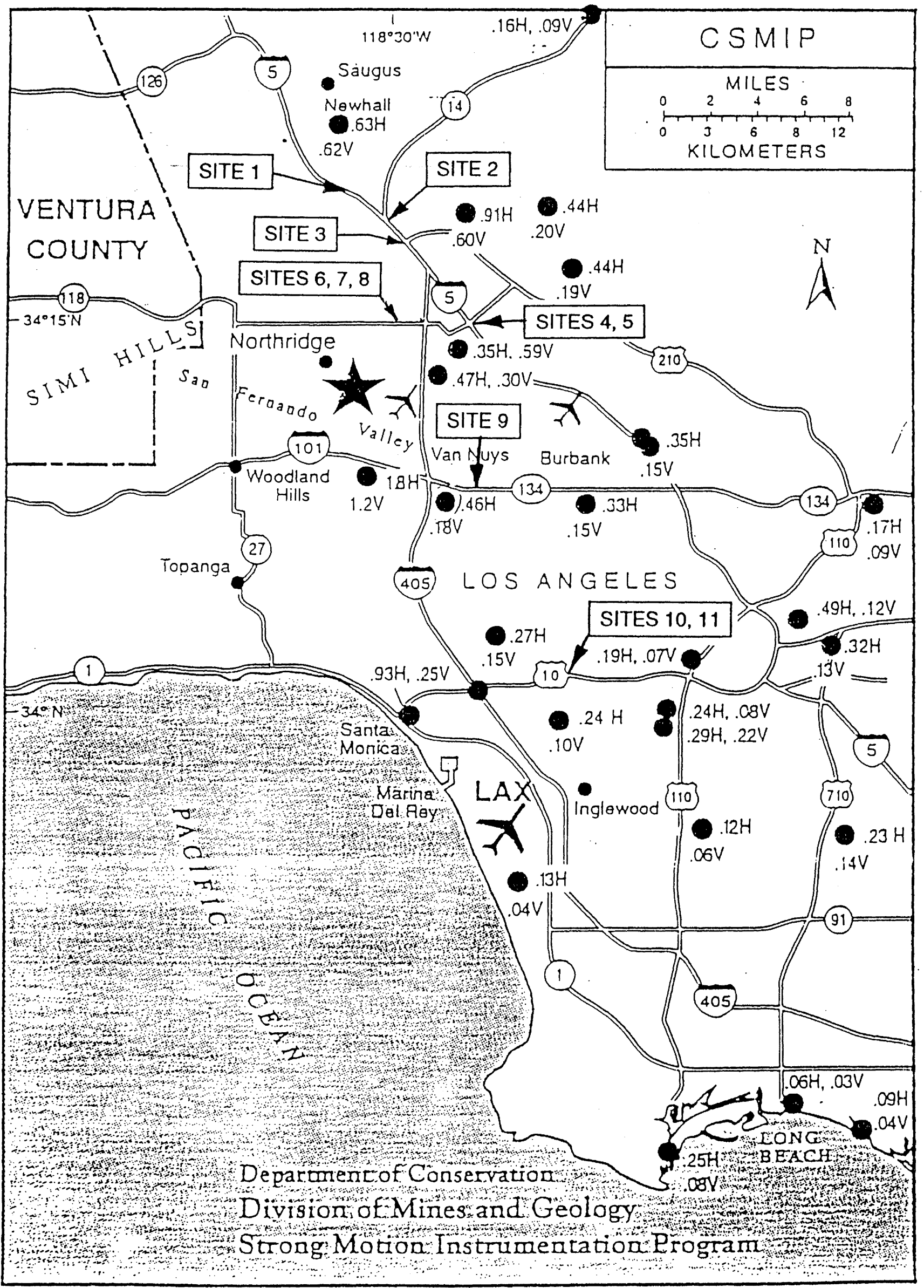

FIGURE 8.1. Selected CSMIP stations that recorded the Northridge earthquake of January 171994. Peak horizontal and vertical acceleration values are indicated. The earthquake epicentre is denoted by a star. The locations of the sites referred to in the text are also shown. [After Reference 6]. 


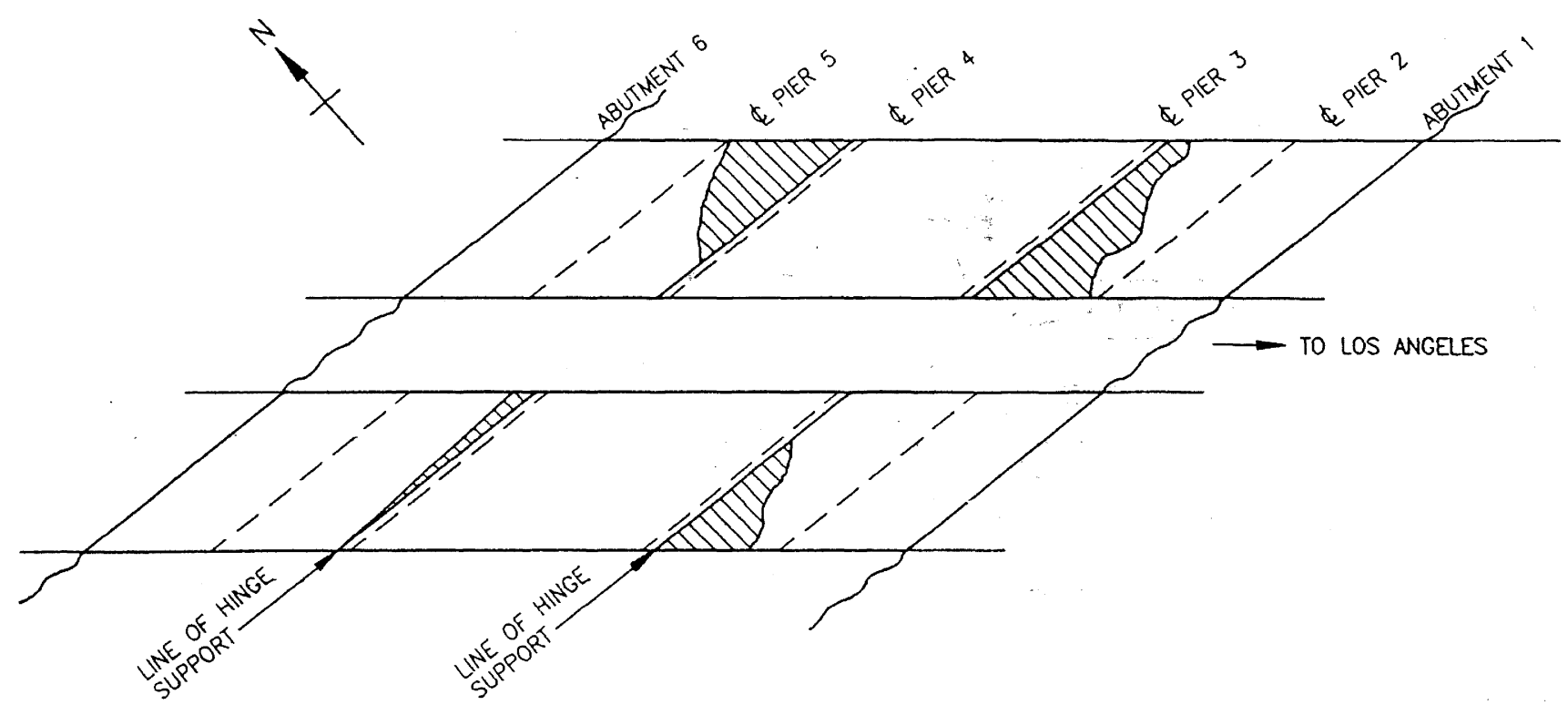

FIGURE 8.2. Plan showing areas of damage to the Gavin Canyon bridge.

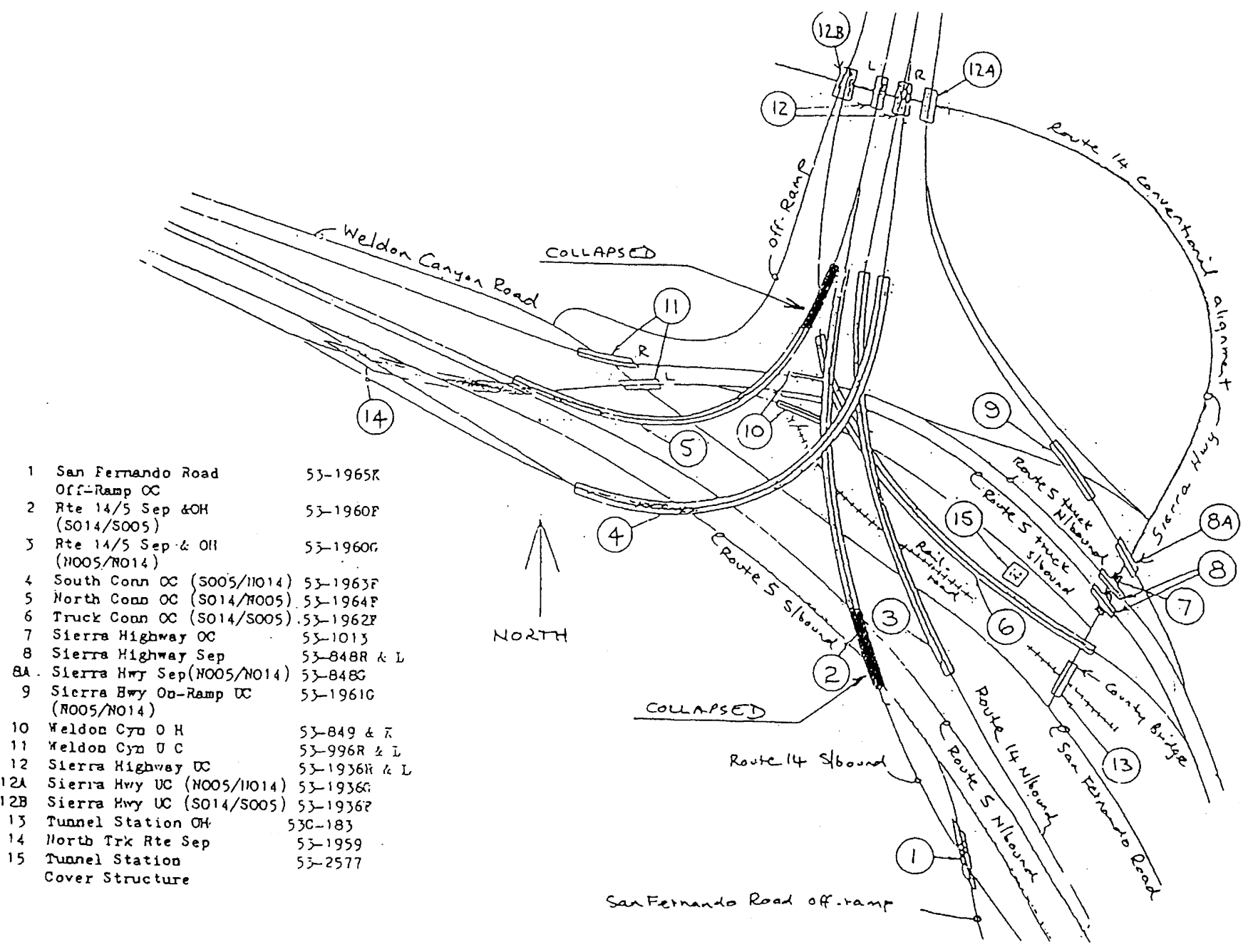

FIGURE 8.3. Sketch plan showing the layout of the interchange of Freeways 5 and 14. From Reference 1. 


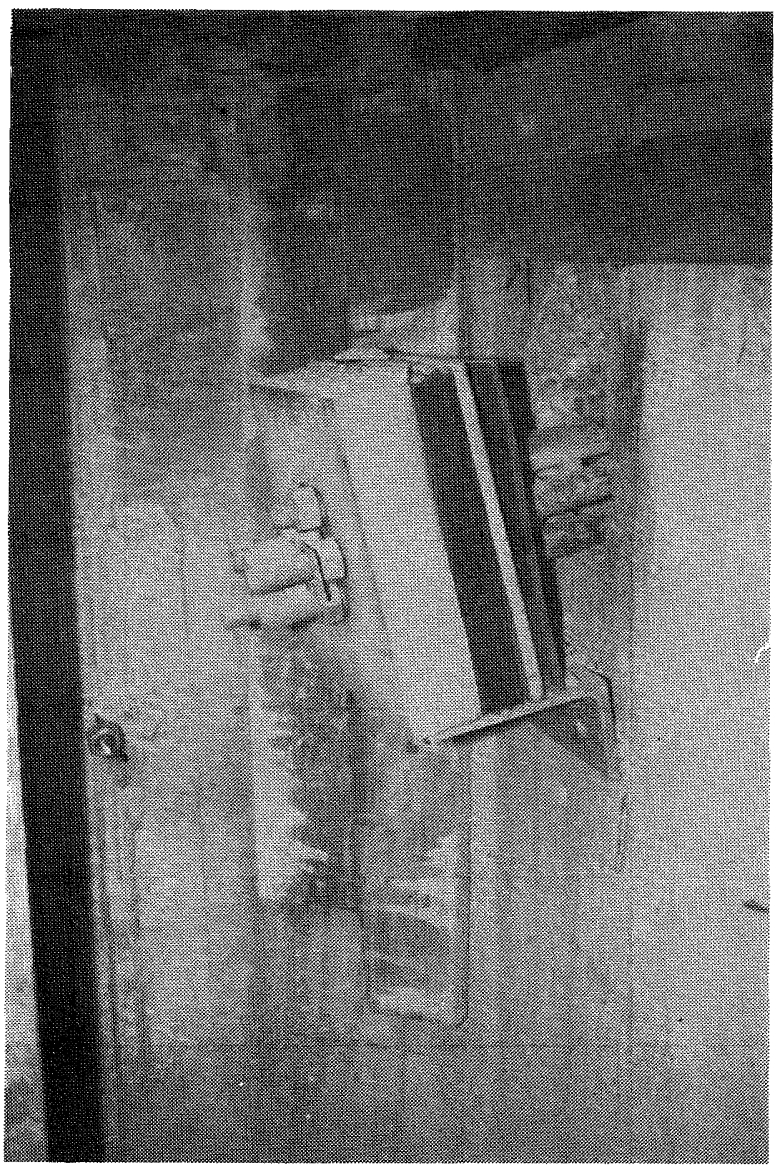

FIGURE 8.4. Interchange of Freeways 5 and 14, Structure 4, Hinge 3 - restrainer cables stretched $60 \mathrm{~mm}$. be expected to have failed in shear under longitudinal loading at ground accelerations $50 \%$ of those thought to have occurred at the site, causing the collapse of the whole of the length of structure to Pier 4 , as occurred.

Apart from the collapse of the southern end section, the rest of the structure did not show significant damage. Spalling due to pounding was evident at the intermediate hinges, and hinges 3 and 4 (by piers 7 and 9) showed residual openings of approximately $40 \mathrm{~mm}$. The box girder at the northern Abutment 11 showed a residual movement out of the abutment of approximately $40 \mathrm{~mm}$.

\section{Structure 5}

This tightly curved structure, built in 1975, connected southbound Route 14 with northbound Interstate 5. Its deck was a ten span insitu concrete box girder 2.4 metres deep and 467 metres long, with spans ranging from 30 to 61 metres and with four intermediate deck movement hinges. The structure comprised five frames with insitu prestressed girders in the first and third frames from the north, and reinforced concrete girders in the others. The straight monolithic piers ranged in height from approximately 7 to 23 metres, was 2.4 wide $x 1.2$ metres in section, and were founded on spread or piled footings. The pier reinforcing ties were $13 \mathrm{~mm}$ diameter at $300 \mathrm{~mm}$ centres. Abutment 1 (north end) was of the seat type, with a $350 \mathrm{~mm}$ seating length and internal shear keys (Figure 8.6). Abutment 11 was an integral abutment on piles. The collapsed section at the northern end was 95 metres long, which was the whole length between Abutment 2 and Pier 3, and included the first deck hinge. Piers 2 supported this section, with the hinge being 5 metres from the pier. On the basis of others' photographs and calculations [Caltrans, 1994; Priestley et al, 1994] the likely initiator of failure of this structure is considered to be the shear failure of Pier 2. This pier was very much shorter than those in the same frame - piers 3 and 4 - and was probably further restrained by a surrounding sealed area of paving. Calculations [Priestley et al, 1994] indicate that Pier 2 probably failed in shear under longitudinal, or a combination of longitudinal and transverse loading, at response accelerations of $0.3 \mathrm{~g}$, which would have been readily attained by the structure during the ground accelerations thought to have occurred.

Apart from the collapse of the northern end section, the rest of the structure did not show significant damage except that the

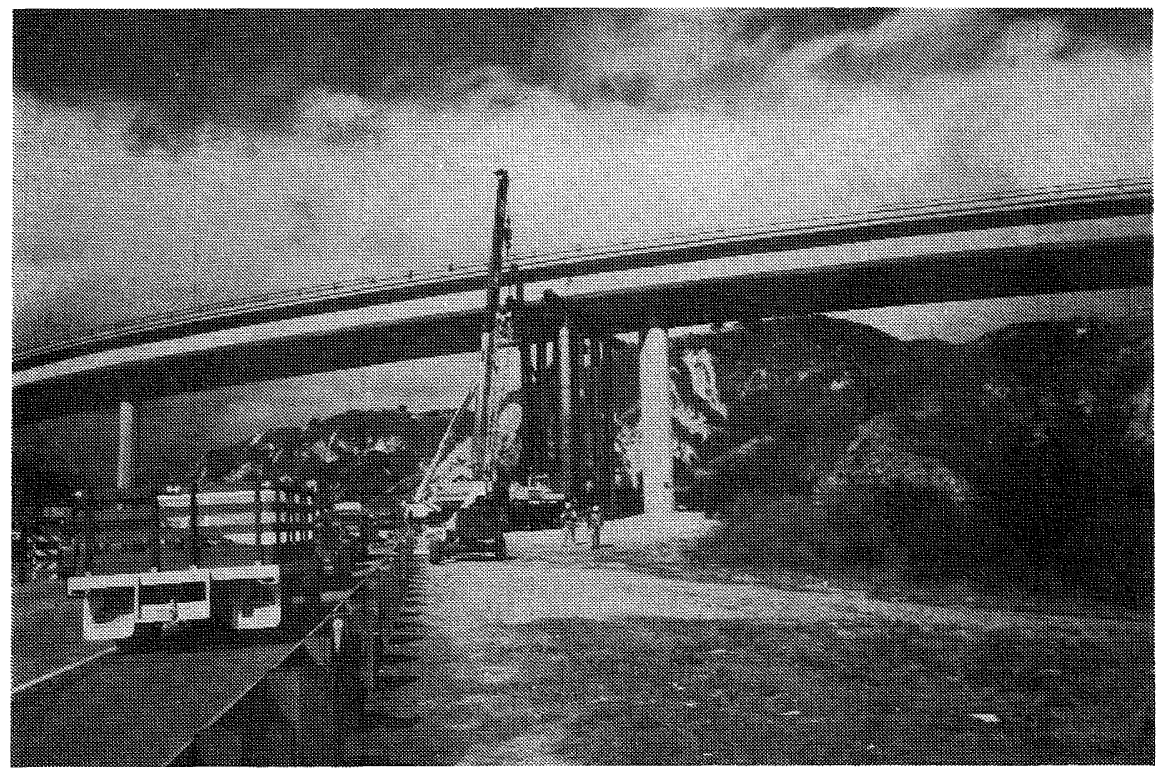

FIGURE 8.5. Interchange of Freeways 5 and 14, Structure 4, Hinge 3 - damaged hinge during shoring. 


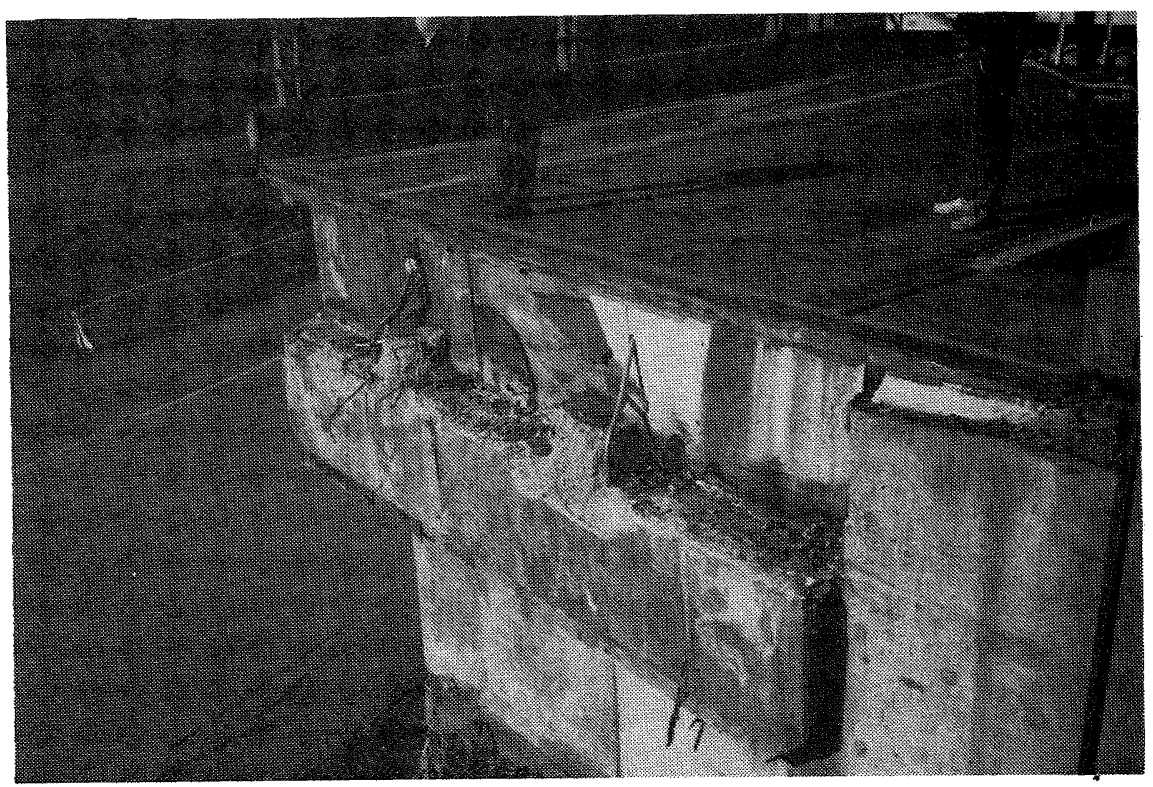

FIGURE 8.6. Interchange of Freeways 5 and 14, Structure 5, north abutment seat.

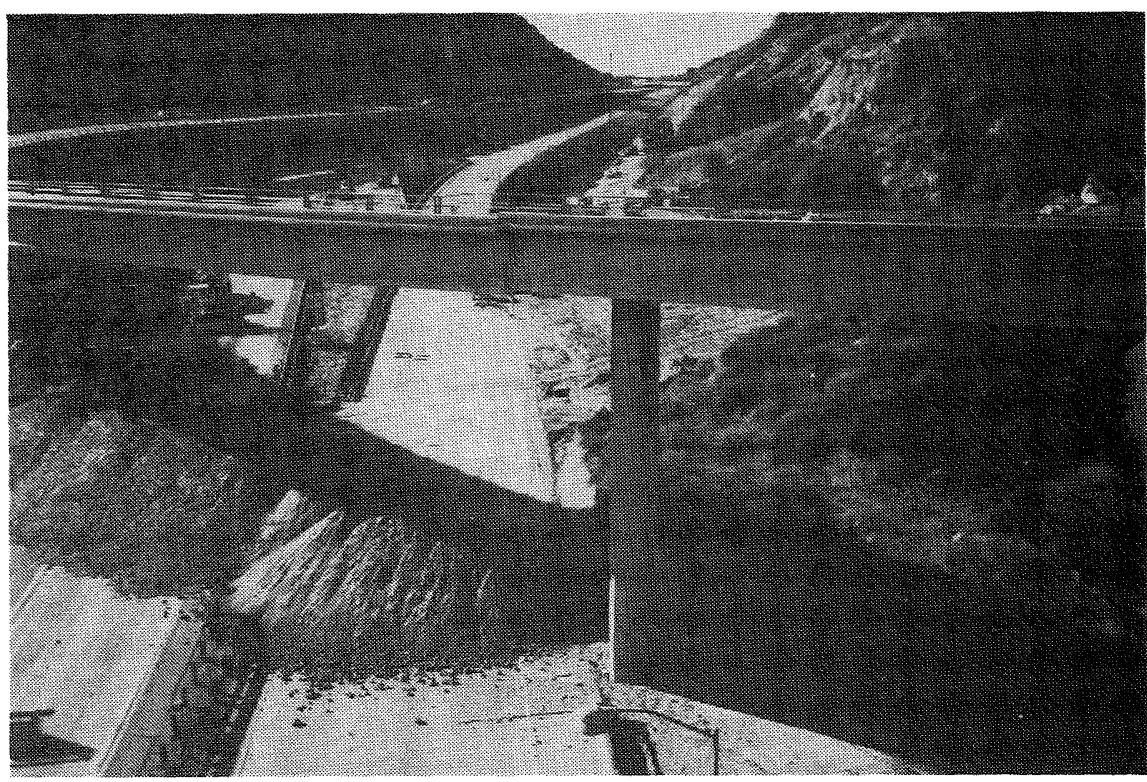

FIGURE 8.7. Interchange of Freeways 5 and 14, Structure 5, Hinge 2 showing large horizontal and vertical residual displacement at $350 \mathrm{~mm}$ hinge seat.

intermediate hinges showed spalling due to pounding, and the hinges showed residual openings of, in some cases, a large proportion of the $350 \mathrm{~mm}$ hinge seat width (Figure 8.7). It appeared that collapse of the northern length had allowed the joints to open more than they may otherwise have done. The insecurity of this structure was remedied by demolition in late January.

\section{Site 3 - Intersection of Freeways 5 and 210}

This intersection comprises a major interchange with two long overcrossing structures. The structure linking Freeways 210 westbound and 5 southbound was inspected at its eastern abutment on 27 January. The structure was built in 1975 with "post-San Fernando earthquake" details. It is a 239 metre long eight span box girder structure with spans ranging from 19 to 40 metres and no intermediate deck hinge joints. The single stem monolithic piers, 13 to 20 metres high, are rectangular and are founded on various types of piles. The pier reinforcement includes $13 \mathrm{~mm}$ diameter spiral at $90 \mathrm{~mm}$ pitch. The abutments are of the seat type, with the box girder supported on elastomeric bearings.
This structure showed only moderate damage and, considering the intensity of the shaking in the area, it performed very well. The main damage was to be seen at the eastern abutment where the side external shear keys had been fractured. The box girder had moved $150 \mathrm{~mm}$ longitudinally out of the abutment and had a vertical settlement of $100 \mathrm{~mm}$, presumably as a result of loss of bearing (Figure 8.8) and the end of the box girder had been shored with timber baulks. There was minor concrete spalling visible at the some of the pier/box soffit connections and some spalling in the box soffit near the abutment with some reinforcing bar buckling.

\section{Site 4 - Connector between Freeways 118 westbound and 5 southbound}

The intersection of Freeways 5 and 118 includes several high overcrossings, of which only the 118 westbound to 5 southbound was visited at its eastern abutment on January 29 . The structure is 510 metres long, with a 2.1 metre deep box girder superstructure of alternating RC and PSC insitu construction, with four intermediate deck hinges fitted with restrainers. The structure was built in 1976 with "post-San Fernando earthquake" 


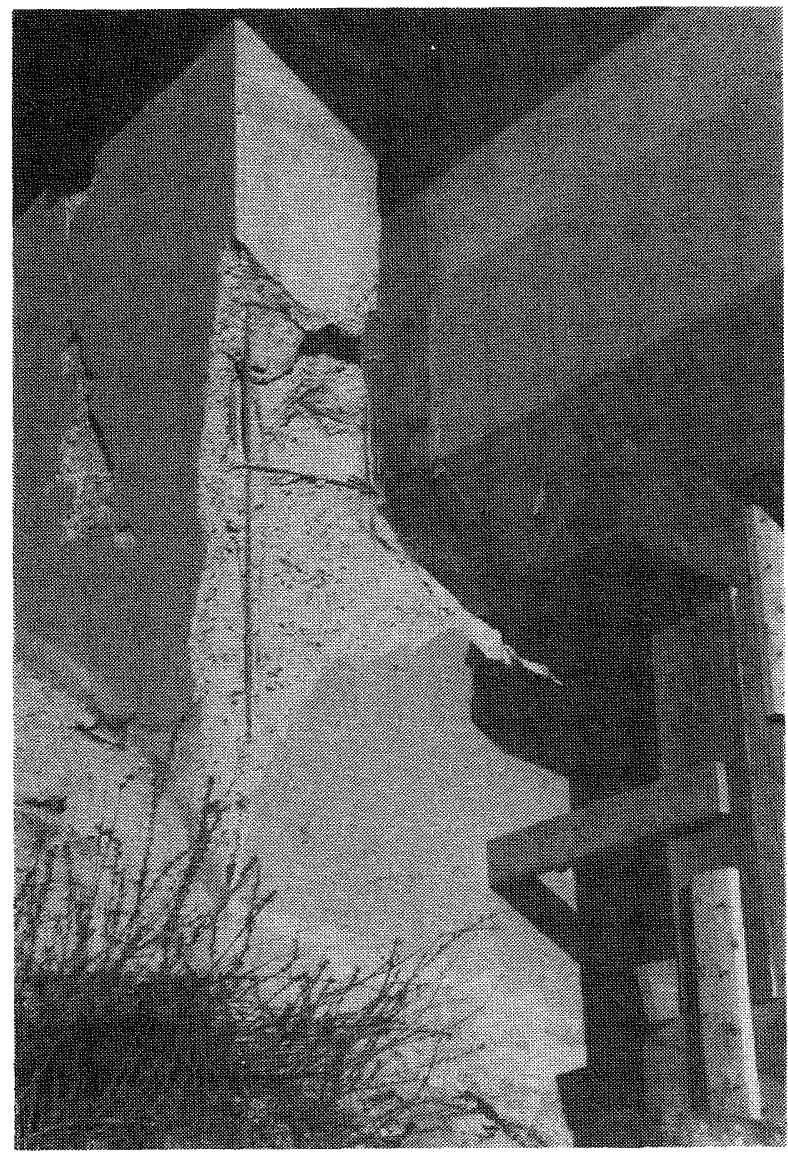

FIGURE 8.8. Interchange of Freeways 5 and 210, eastern abutment showing damaged shear keys and residual box girder displacements of $150 \mathrm{~mm}$ horizontal and $100 \mathrm{~mm}$ vertical. details. The piers are all single stem flared monolithic, variously founded on spread footings or drilled shaft foundations. The pier reinforcement includes spiral ties of 13 mm diameter at $90 \mathrm{~mm}$ pitch. The south abutment is of the seat type on spread footings with the box girder supported on elastomeric bearings and the eastern abutment is of the integral type on a piled foundation.

The main damage feature evident with this structure was the longitudinal movement of the abutment of $40 \mathrm{~mm}$ towards the span and a translation to the south of $30 \mathrm{~mm}$. Figure 8.9 shows a view of the structure from the east abutment, indicating the length of the overcrossing. Due to the intermediate deck joints, the length of deck effectively anchored by the abutment is indeterminate, but the structure performed well in the conditions of strong shaking which occurred in the area.

\section{Site 5 - San Fernando Road undercrossing of Freeway 118}

This structure, built in 1976, carries Freeway 118 over San Fernando Road and was visited on 29 January. It comprises twin two span bridges 78 metres long and an on-ramp for eastbound traffic. The centre pier comprises two flared octagonal columns per bridge, 1.2 metres across, monolithic with the RC box girder superstructures. The columns for the main bridges are "pinned" at the spread footing foundations and their reinforcement includes $13 \mathrm{~mm}$ spirals at $90 \mathrm{~mm}$ pitch. The abutments are of the integral type on spread footings.

The structure is a small one by Californian freeway standards. Its behaviour is of interest as the soffit of the box girder at the connection with the eastern integral abutment spalled to a depth of $100 \mathrm{~mm}$ as a result of flexural compression strains from moments developed by longitudinal forces on the integral abutment (Figure 8.10). Other evidence of the shaking applied to the structure was the presence of $8 \mathrm{~mm}$ gaps around the columns in the paving material. The structure performed well.

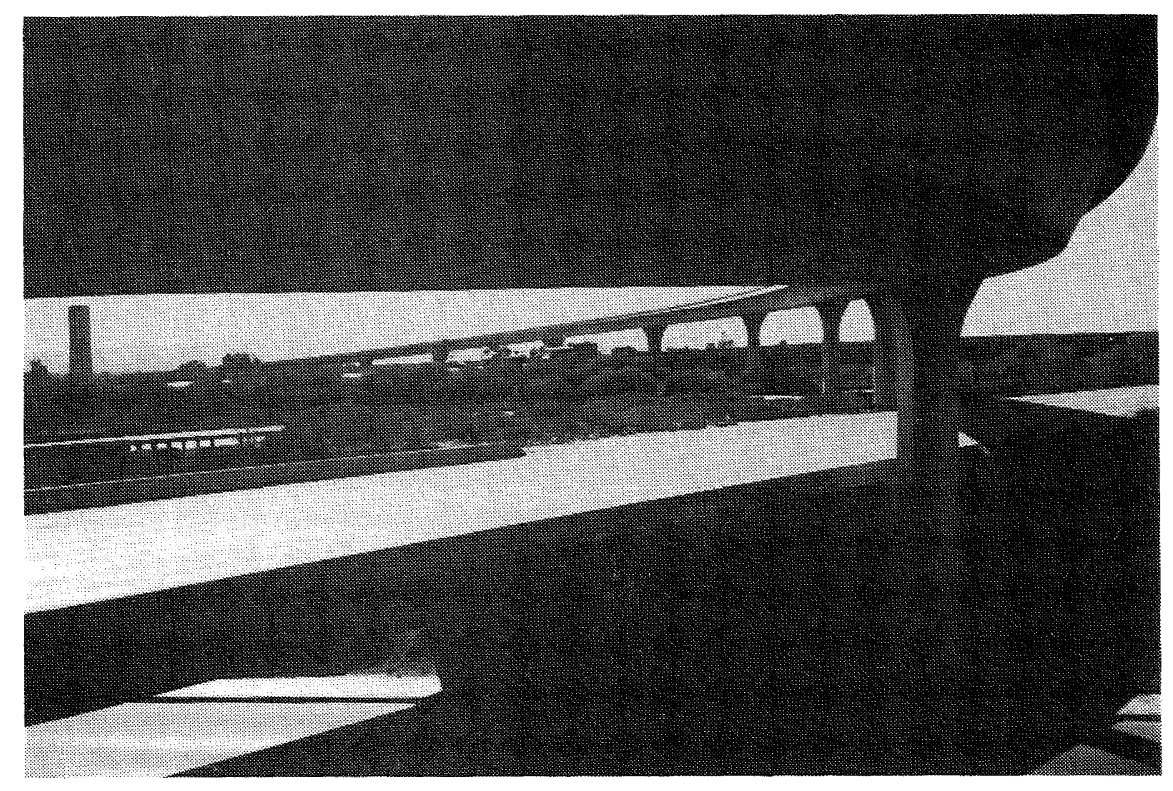

FIGURE 8.9. 510 metre long overcrossing linking Freeways 118 westbound and 5 southbound. 


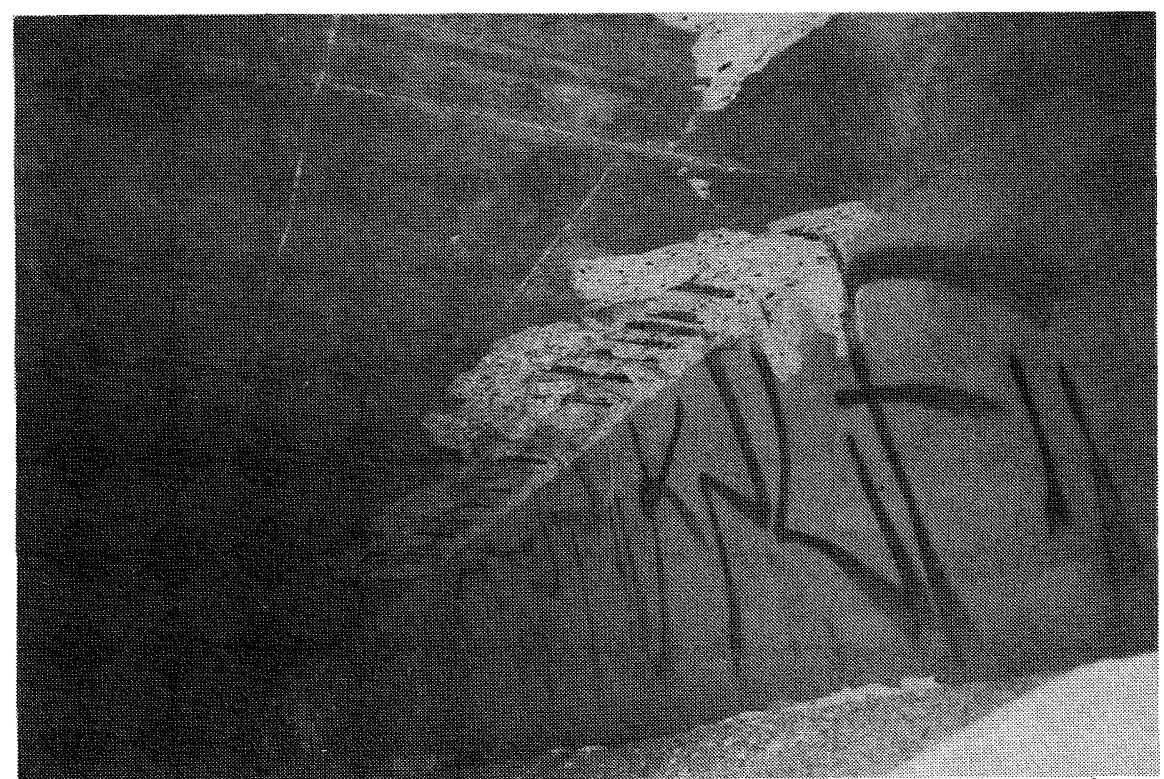

FIGURE 8.10. San Fernando Road undercrossing of Freeway 118, east abutment - spalled concrete at abutment/soffit interface.

\section{Site 6 - Balboa Boulevard overcrossing of Freeway 118}

This structure, built in 1976, carries Balboa Boulevard over Freeway 118 and was visited on 26 January. It is 86 metres long and comprises a two span single PSC box girder superstructure with spans of 45 and 35 metres, with an approach slab as part of the box abutment at the southern end. The abutments are seat type, with the box girder supported on elastomeric bearings. The centre pier, approximately 9 metres high, comprises three 1.5 metre octagonal flared columns monolithic with the superstructure and "pinned" at the spread footing foundations. The column reinforcement includes $16 \mathrm{~mm}$ diameter spiral with a $75 \mathrm{~mm}$ pitch.

The bridge is close to the epicentre and must have been subjected to strong shaking but was damaged only at the centre pier where there was minor cracking at the soffit/column connection. The pier was being shored with timber baulks - a very common technique seen at many of the structures in the area. In many cases the structures were being opened to traffic once the shoring had been placed. Of interest at this bridge was the fact that it was closed to traffic, not because of structural damage, but because of a broken water line. The line apparently ran along near the centreline of the box girder, and had been fractured at the south abutment. The fill material behind and around each side of the box abutment had been scoured out down to the freeway below, exposing the foundation piles for 3 to 4 metres and making the bridge impassable, even for emergency vehicles. This was a good example of the need for services using bridge crossings to be detailed to take account of the likely seismic movements of the bridge and its approach fills.

\section{Site 7 - Mission Boulevard - Gothic Avenue undercrossings of Freeway 118}

These comprised overhead twin straight bridges close to the right-angled intersection of the above two streets and were visited on 26 and 29 January. The longer, eastbound, structure, which collapsed, had been demolished by the time of the visit. Shoring of the westbound structure, which suffered severe pier damage and vertical settlement of its superstructure of up to 850 $\mathrm{mm}$, was in hand to allow its temporary reopening to traffic while the eastbound structure was being rebuilt.
The two abutments of each bridge are at skews of 45 degrees in opposite senses (Figure 8.11). The skewed piers are each of octagonal form, 1.8 metres across, are flared to 4.3 metres wide at their monolithic connection with the prestressed diaphragms and are approximately 7 metres high from the top of the foundation pilecaps. The pier reinforcement includes $16 \mathrm{~mm}$ diameter transverse spirals with $90 \mathrm{~mm}$ pitch. The multicell box girder is prestressed longitudinally and for this reason a clearance was left between the end diaphragms and the abutment backwalls, with the ends of the prestressed box girder supported on elastomeric bearings, and with a 1.2 metre overlap over the abutment. Concrete shear keys project down approximately 300 $\mathrm{mm}$ from the superstructure into recesses in the abutment cap, with provision for shortening and temperature movement of the superstructure made by leaving $150 \mathrm{~mm}$ clearance in the shear key (polystyrene filled). An interesting feature of the pier design is the provision of moment discontinuity at their bases by the containment of the bottoms of the piers within retaining collars on the pilecaps and no reinforcing steel through the pier/pilecap interface, thus increasing the flexibility of the piers and reducing moments induced in the foundations.

Analyses [Priestley et al, 1994] suggest that collapse of the eastbound structure, and settlement in the deck of the westbound structure, were initiated by flexural plastic hinge failure in bents $3 \mathrm{~L}$ and $4 \mathrm{R}$ at the base of the pier flares under loading in the transverse direction (Figure 8.12), across the strong axes of the columns. The closely spaced spiral confining steel had ruptured in this area, leading to collapse of the core concrete. In the westbound structure the damage to the eastern pier of bent 3 was less severe, but similar, to that of the western pier. The westbound bridge had displaced $180 \mathrm{~mm}$ transversely to the south at the eastern abutment. The substructure is very rigid and the differences in skew between the various pier bents may have contributed to disadvantageous sharing of the demand on the various piers. The form of the structure, with a large area of bridge supported on relatively few piers, some quite highly loaded, and with likely flexibility at the abutments, at least longitudinally, suggests a large demand would be placed on the piers under lateral load. The direction of major axes of the piers seems to have influenced the damage sustained, as piers $2 \mathrm{~L}$, at an angle of approximately 60 degrees to $3 \mathrm{~L}$, appeared to have been under flexure more across their weak axis (Figure 8.13 ), leading to cover concrete spalling over a large length of 


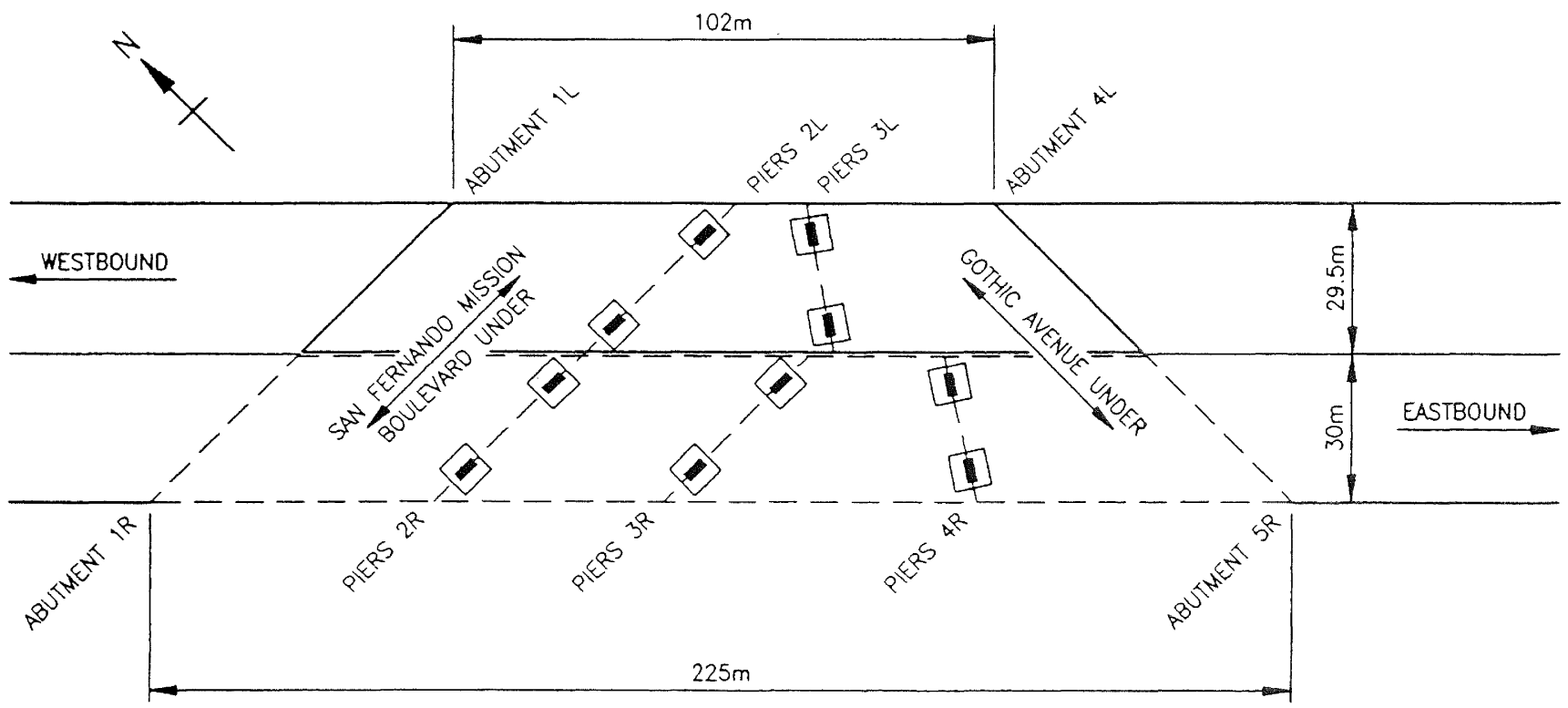

FIGURE 8.11. Sketch plan of the layout of the bridges across Mission Boulevard and Gothic Avenue.

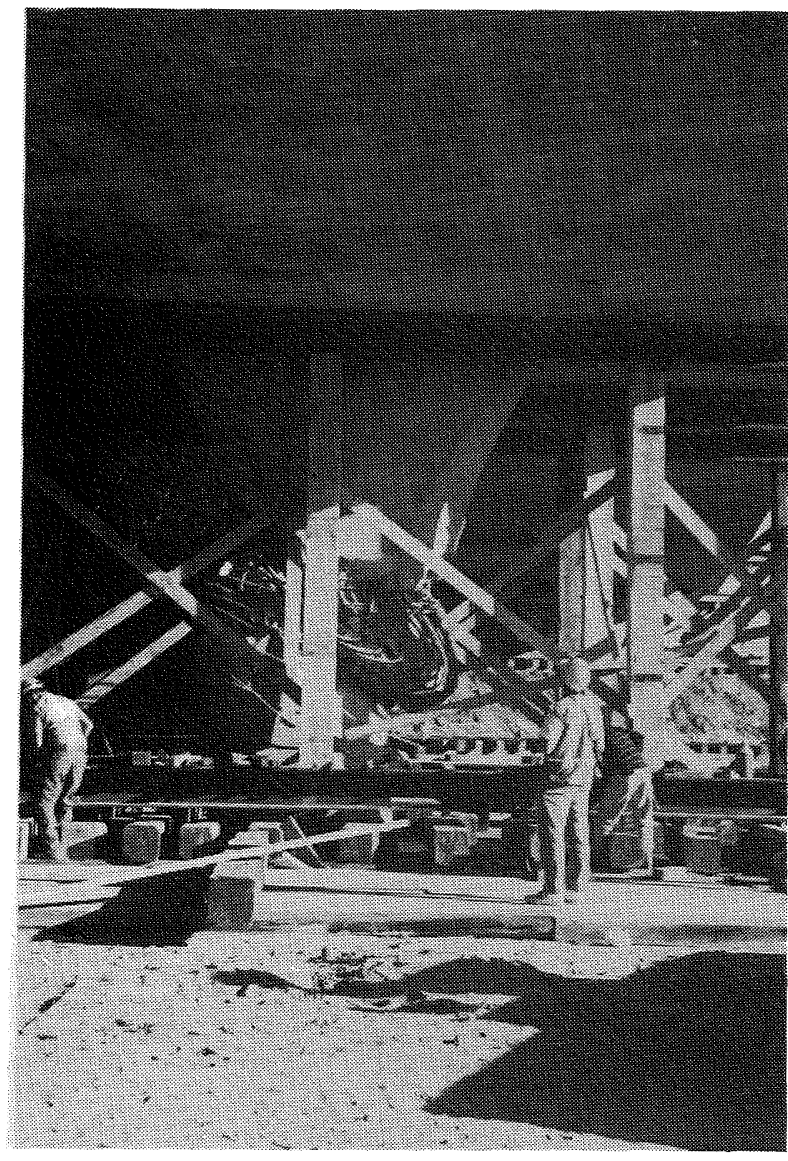

FIGURE 8.12. Mission Boulevard/Gothic Avenue undercrossing of westbound Freeway 118 structure, column $3 L R$ showing flexural plastic hinge failure.

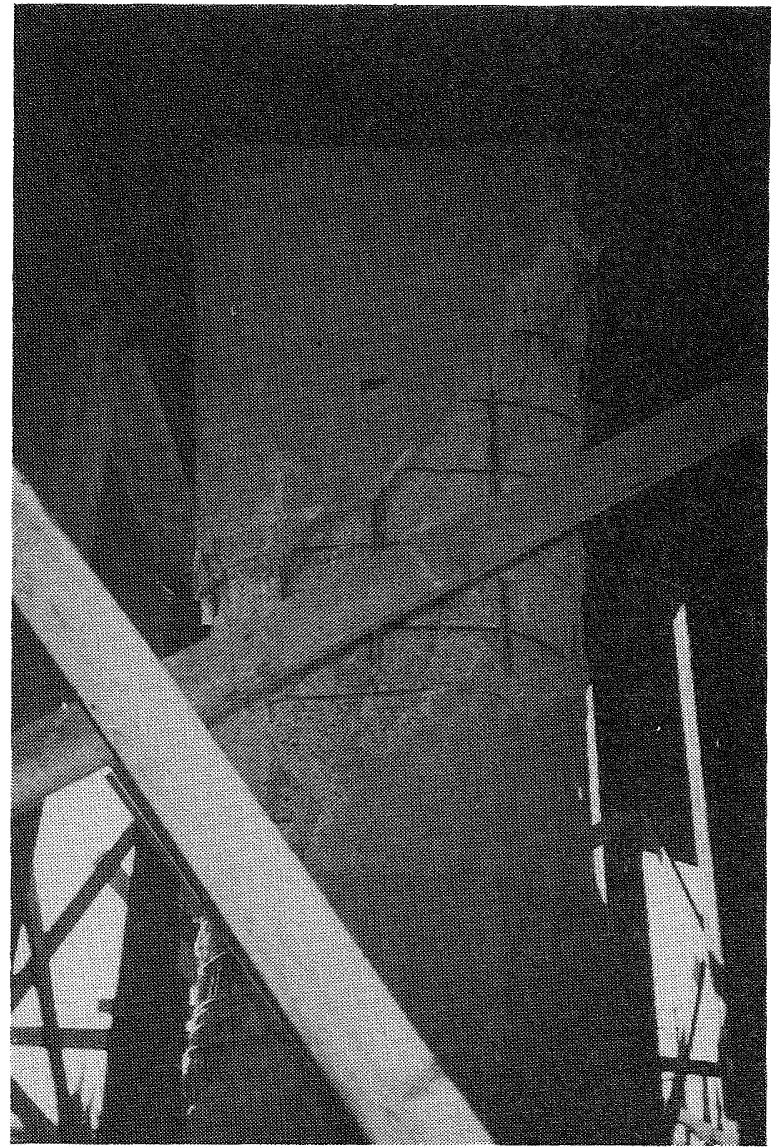

FIGURE 8.13. Mission Boulevard/Gothic Avenue undercrossing of westbound Freeway 118 structure, column $2 L R$ showing concrete spalled over length of column flare, and shear cracking. 
the flare and to shear cracking through the piers. It is suggested [Priestley et al, 1994] that the damage to piers in bent 2 could have been a consequence of the significant shortening of the piers in bent 3 .

\section{Site 8 - Bull Creek Canyon Channel bridges}

These twin straight three-span bridges carry Freeway 118 over the Bull Creek Canyon channel and were visited on 29 January. Spans are approximately 27,31 and 20 metres and the abutments and two lines of pier columns, are skewed at between 36 and 47 degrees in the same sense. The superstructure is a prestressed concrete box girder and the piers for each structure comprise a row of four or five octagonal columns 1.2 metres across on piled foundations. Pier free height between the superstructure soffit and the top of the pilecaps is approximately 7 metres. However at the eastern pier, adjacent to the channel, the pier columns are built integral with the channel wall which shortens their effective height to approximately 5.5 metres. Furthermore, while closely spaced confining reinforcement spirals (16 mm diameter at $75 \mathrm{~mm}$ pitch) were installed at each end of the columns over a length of one column diameter, no account was taken of the presence of the channel wall, which would cause plastic hinging to develop in the mid-height of the column where spiral pitch was $300 \mathrm{~mm}$. The abutments are integral diaphragm types, free to move longitudinally relative to their piled footings to accommodate prestress and temperature effects.

Analyses [Priestley et al, 1994] indicate that the shortened columns of the eastern pier of both bridges failed in a flexure/shear mode at low ductility due to their high stiffness and lack of confinement in the columns at the top of the channel wall (Figure 8.14). Two of the columns of the western pier in the eastbound bridge also failed, under the superstructure soffit, but in a more ductile manner. However, the closely spaced confining steel extended only one column diameter below the superstructure soffit, which was insufficient to prevent rupture of the spiral occurring at this location, leading to a flexure/shear failure (Figure 8.15). The eastern abutments of both east- and westbound bridges were measured to have moved transversely

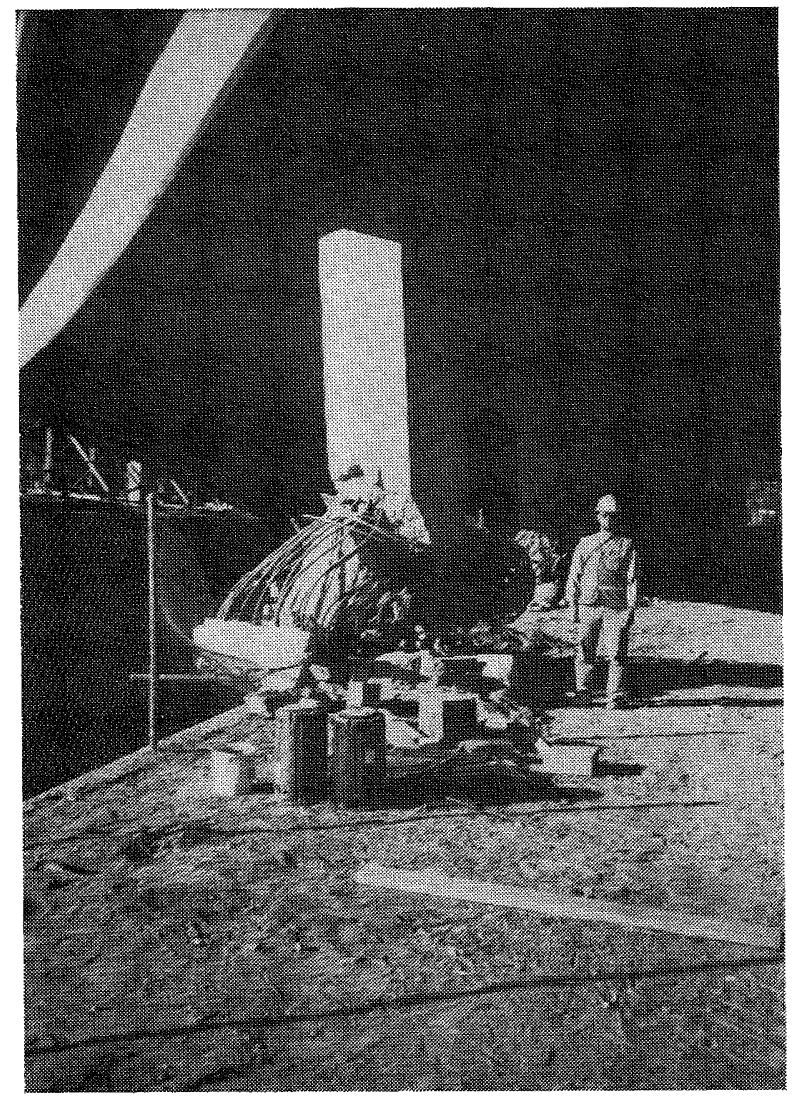

FIGURE 8.14. Bull Creek Canyon Channel Bridge on Freeway 118 - failure of columns at top of channel wall.

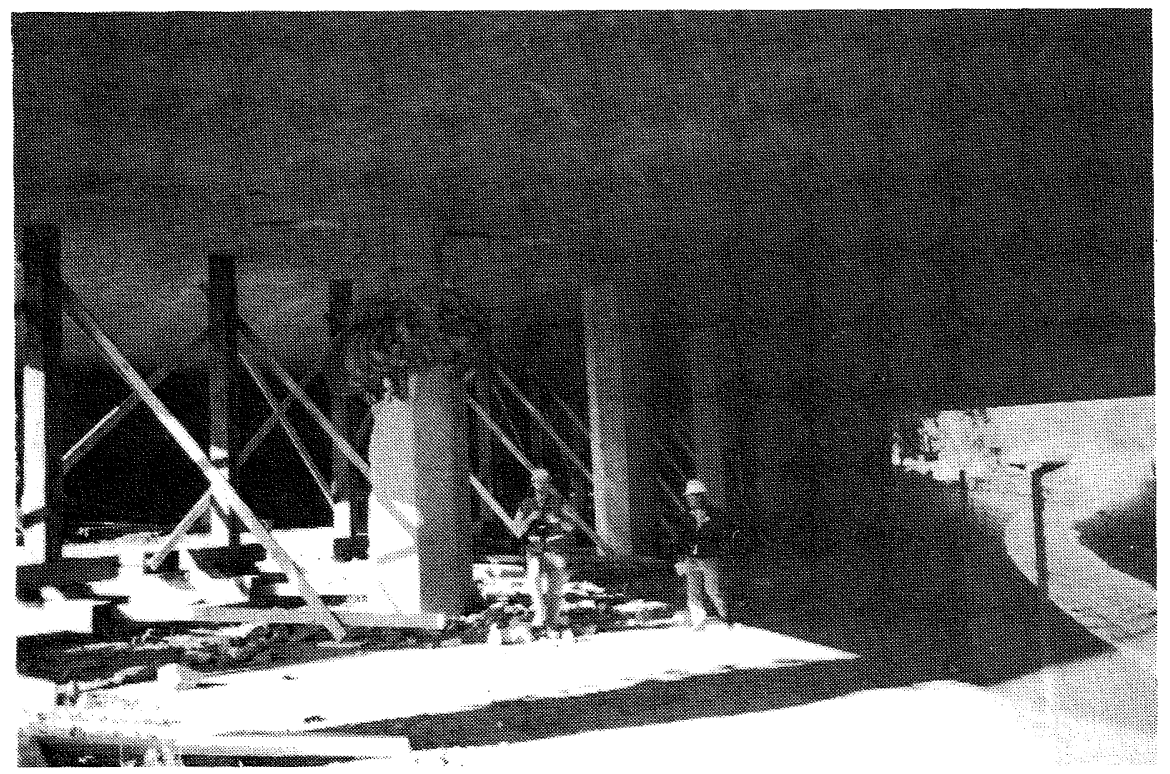

FIGURE 8.15. Bull Creek Canyon Channel Bridge on Freeway 118 - failure of columns below closely confined length below superstructure soffit. 
to the roadway by 95 and $45 \mathrm{~mm}$ respectively. It is interesting that the superstructure deflected vertically 1.7 metres over the failed (eastern) line of columns, in a very flexible manner (Figure 8.16). It should be noted that this site was only approximately $6 \mathrm{~km}$ from the epicentre and peak ground accelerations exceeding $0.5 \mathrm{~g}$, and possibly as high as $0.8 \mathrm{~g}$ [Priestley et al, 1994] probably occurred.

\section{Site 9 - Hazeltine Avenue undercrossing of Freeway 101}

This site was visited briefly on 31 January. The structures comprise six-span multi-column twin bridges carrying the freeway over a stream and surface street (Figure 8.17). No drawings of these bridges have been obtained for sizes, foundation details etc, but it appears the columns are founded as drilled cylinders continuing below ground to founding level.
The structures were built in 1959 and the columns had not been retrofitted before the earthquake. It is unlikely that the confining reinforcement was at closer spacing than the nominal $300 \mathrm{~mm}$ used at that time. Although the effect of the earthquake on these bridges was apparently minor, it was interesting to note that the tops of many of the columns showed the results of significant flexure, with minor spalling of cover concrete. Much more spalling, and possibly bar buckling, would probably have been evident, had the shaking continued for much longer. The other feature of the earthquake effects was the significant disturbance of the ground around the columns (Figure 8.18).

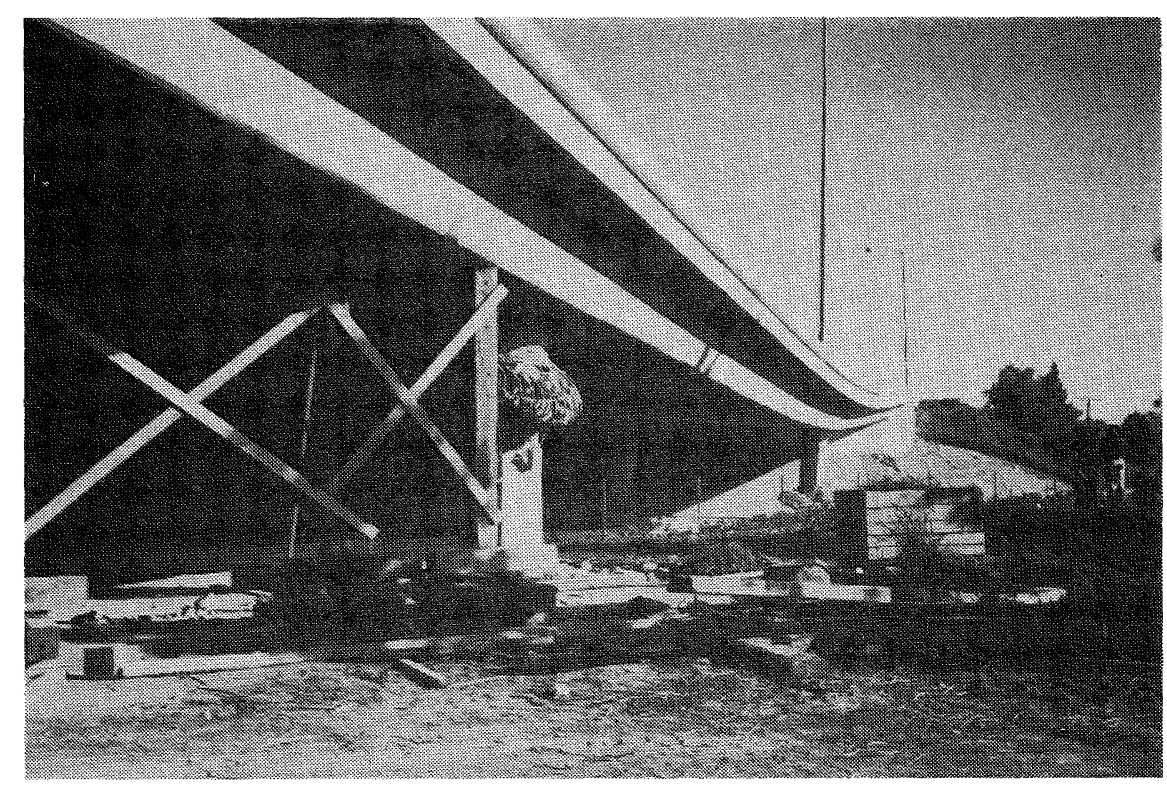

FIGURE 8.16. Bull Creek Canyon Channel Bridge on Freeway 118 - view along eastbound bridge showing 1.7 metre vertical displacement.

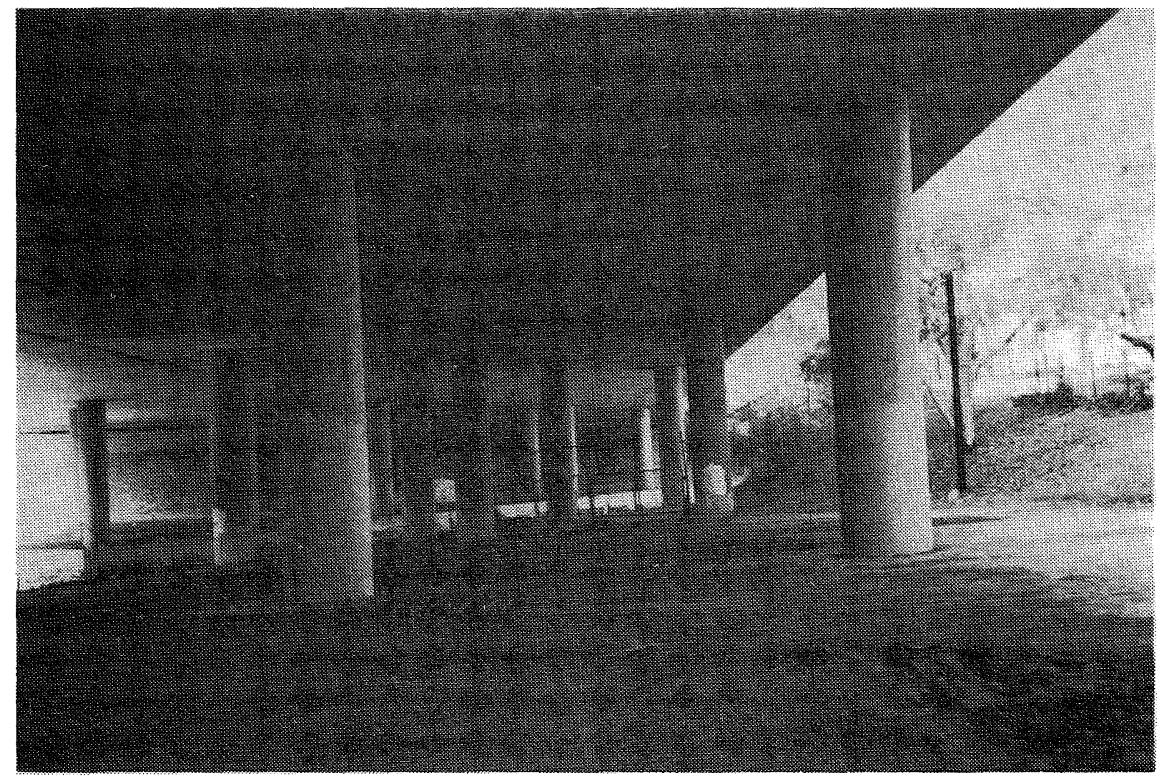

FIGURE 8.17. Hazeltine Avenue undercrossing of Freeway 101 - general view looking west. 


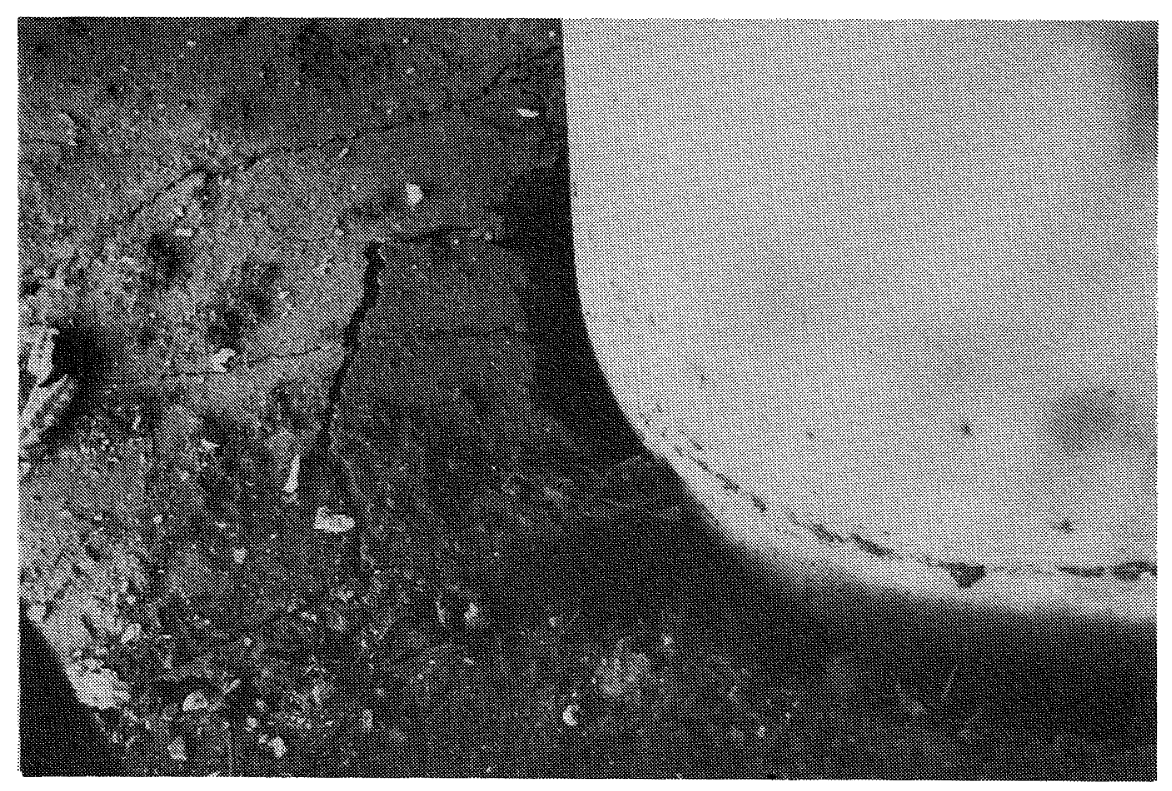

FIGURE 8.18. Hazeltine Avenue undercrossing of Freeway 101 - disturbance of ground due to column displacements.

\section{Sites 10 and 11 - Santa Monica Freeway I-10 at: La Cienega/Venice Boulevards and Fairfax Avenue/Washington Boulevard}

These two crossings of major city streets were designed in 1962 , built in 1964 and retrofitted with hinge restrainers in 1978 and 1974 respectively. They were visited on January 26 , by which time much of La Cienega/Venice crossing and all of the Fairfax/Washington crossing had been demolished, and the sites cleared. They are close to each other and were of similar form. Both comprised practically straight twin structures 265 and 175 metres long respectively, with some associated ramps in each case. The superstructures were of reinforced concrete box girder form with spans ranging from 14 to 34 metres, and their abutments vary in skew from 5 to 45 degrees. The piers for each structure each comprised 3 or 4 prismatic columns 1.2 metres in diameter, either pinned or fixed to the piled footings.
Pier heights were reasonably uniform at approximately 6 metres at the Cienega/Venice structure but ranged between 4.9 and 7.0 metres at Fairfax/Washington. Column main reinforcement quantities differed between columns, but a standard hoop steel arrangement of $12 \mathrm{~mm}$ diameter at $300 \mathrm{~mm}$ centres over the full column height was used for both structures.

The Cienega/Venice structures suffered extensive column damage (Figure 8.19) with total collapse of parts of both eastbound and westbound structures. The Fairfax/Washington structures suffered from primary failure of one line of columns across both east and westbound structures. Analyses [Priestley et al, 1994] have led to the conclusion that in all structures column shear failure at low ductility levels was the main cause, occurring at a peak ground acceleration of approximately $0.3 \mathrm{~g}$. Other evidence suggested that a peak ground acceleration of about $0.4 \mathrm{~g}$ was reached at the site.

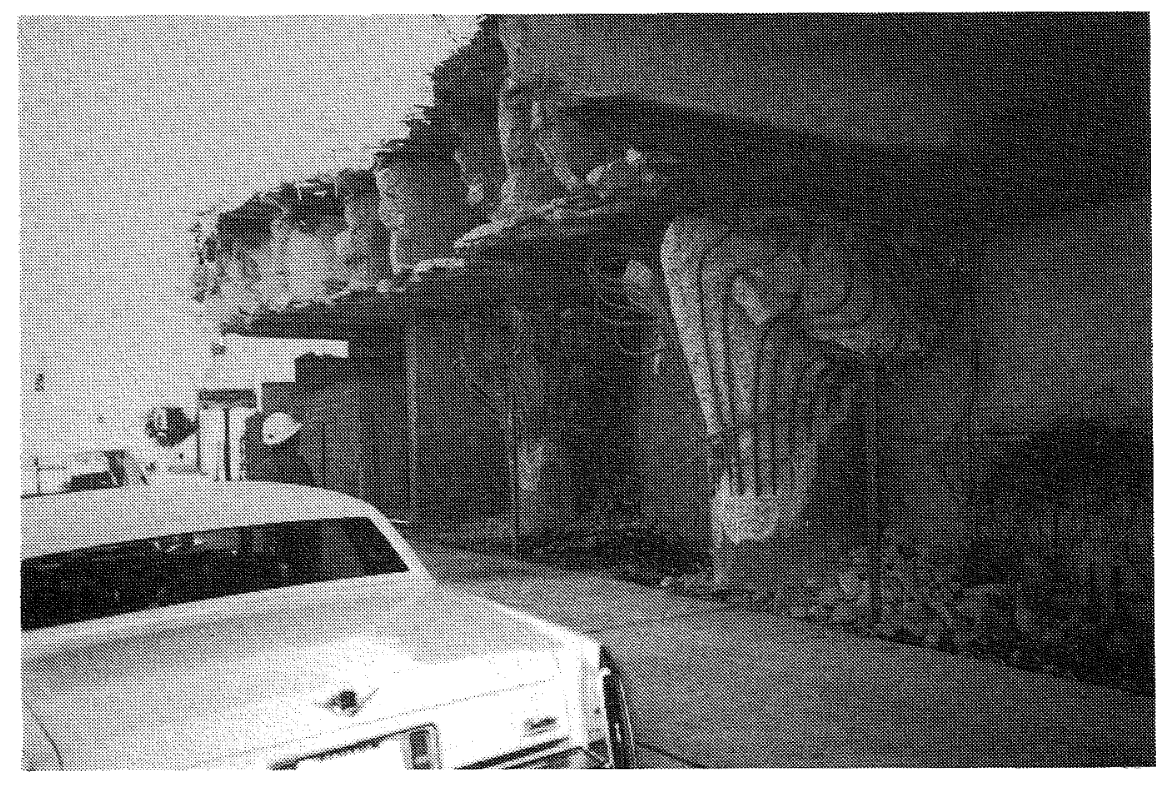

FIGURE 8.19. La Cienega/Venice Boulevards undercrossings of Freeway 10 damaged columns at La Cienega Boulevard. 


\subsection{Discussion}

On the basis of observations made during the visit, and from subsequent reports, it is concluded that the primary causes of failure which occurred fall into the categories of:

- Column shear failure at low ductility

- Loss of support at an intermediate hinge joint (one site), with other hinge joints in high, flexible structures close to losing support.

The opinion has been stated [Caltrans, 1994] that, had the current criteria for the design of new bridges been used in the designs for the collapsed bridges on Freeway 118 (sites 7 and 8), failure would not have occurred. This is probably also true for bridges at the other locations, particularly as far as design of the columns goes, for use of the capacity design procedures leads the designer to identifying the maximum shear forces which the members may be required to resist, and current column design methods provide members with significant ductility with which they may tolerate gross excessive loading without brittle failure. The column failures described demonstrated the shortcomings of design without use of capacity design methods and ductile detailing. It should, however, be recognised that in spite of the relatively moderate magnitude of the earthquake the ground motions to which some of the structures were subjected were particularly severe, although the duration of the strong shaking was not as long as might be expected from a greater magnitude event.

Of equal interest to the column performance is the performance of the hinge restrainers, some of which served their purpose successfully while others apparently failed in an undesirable mode - eg by either causing a punching shear failure of the span diaphragm, or stripping of their retaining nuts, or by failure at such locations as the swaged fitting in the cable. Caltrans design approach has been to design the strength of the restrainer to match a certain percentage of the weight of the restrained length of bridge, since it is extremely difficult to determine a required design force analytically. This approach is used also in New Zealand. However more emphasis is placed in New Zealand on detailing linkages to perform in a ductile manner after reaching yield, by protecting the threads from failure by machining as long a length of the main bar to a diameter sufficiently smaller to ensure yield may occur over a long length of the bar. While this approach is sufficient for most relatively stiff structures or for those with ample seat length, problems are still difficult to solve when very flexible structures, such as those at Gavin Canyon (site 1) or at the 5/14 interchange (site 2) must be retrofitted, and the end diaphragms impose capacity limits on the hinge restrainer strength which may be used. It is clear that great care is needed when designing the linkages for significant structures, and that consideration of the likely mode of behaviour is essential for successful detailing - as was illustrated by the inability of the linkages at Gavin Canyon to prevent the hinge from opening because of their orientation at a severe skew to the line of the hinge in that particular structure.

Observation of the forms of damage which occurred to the rigid low and the flexible high structures all indicate that designers must be constantly conscious of structure/member flexibility and displacements and their effects on structure performance - both in the distribution of shear forces throughout the structure and in the effect on displacements at support points. The concept of displacement based design procedures using displacement response spectra rather than acceleration response spectra [Kowalski et al, 1994] has the advantage of concentrating the designer's approach on this factor for design of primary members.

\subsection{Acknowledgments}

During the visit the New Zealand party received considerable help from colleagues in the State of California Department of Transportation (Caltrans). This help is gratefully acknowledged.

Since the visit a number of reports [Caltrans, 1994; Priestley et al, 1994; EERC, 1994; EERI, 1994] have been published which include detailed descriptions of the structures, and which have been drawn on in compiling this summary report. These sources of information are duly acknowledged.

Permission of the authors of the Fifth CSMIP Quick Report [1994] to use the map from that source is gratefully acknowledged.

\section{LIFELINES}

\subsection{Introduction}

This section addresses the lifeline utilities of electricity, telecommunications, gas, water and drainage. Each was assessed through discussions with the prime utility operators in the city to obtain information on outages, the extent and types of damage sustained and the nature of the utility response. In most cases this was supplemented with a site visit to particular areas of damage.

This information has been supplemented with information obtained from a follow up Lifelines Workshop held in Los Angeles in August attended by the Los Angeles utility companies and 11 New Zealanders from the Wellington and Christchurch lifelines engineering groups. That workshop will be the subject of a more detailed report by the 11 New Zealand participants to be published through the Centre for Advanced Engineering.

All the utility organisations visited in Los Angeles had undertaken substantial mitigation programmes in recent years and all credited these programmes with significantly controlling the extent of damage suffered. Nevertheless substantial damage was suffered as the earthquake sought out inevitable weaknesses in the network systems.

The following sections summarise the issues for each utility. Figure 9.1 provides a locality map for areas referred to.

\subsection{Electricity}

\subsubsection{Networks}

The bulk of electricity supply in the greater Los Angeles area is covered by two utility companies. These are the City of Los Angeles Dept. of Water and Power serving 1.36 million city customers and Southern California Edition serving 4.2 million customers in the surrounding cities.

Both utilities generate electricity and buy in large amounts from other regions. Distribution is controlled through major 


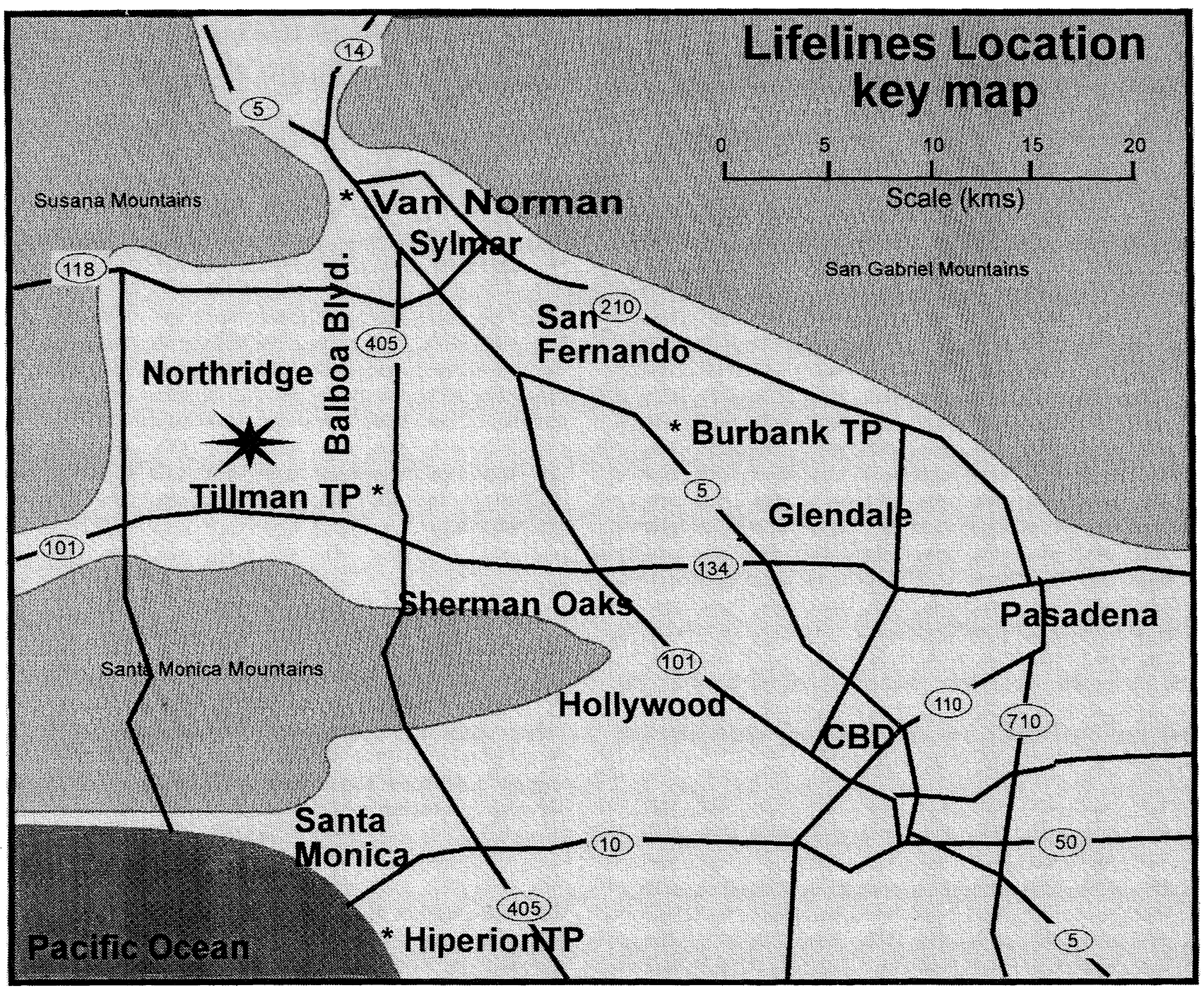

FIGURE 9.1 Location Map for Lifelines in the Los Angeles Area.

receiving stations stepping down to lower voltage distributing sub stations. Neither utility had generating plant in the area of major shaking but both sustained damage to receiving stations and distributing sub stations.

\subsubsection{Outage and Damage Assessment}

The Dept. of Water and Power sustained substantial damage to its major Sylmar converter station which was exporting power at a time of low demand. Load was lost causing a major imbalance in the city network which couldn't be controlled. Within 12 seconds and for the first time in its history the entire city network blacked out.

All bulk power facilities in the city were affected and the only local hydro generation plant, at Castaic to the north, which could have provided for a rapid restoration of service was isolated through the loss of transmission lines - the only significant transmission lines which DWP lost.

The Energy Control Centre located in the hills to the north-west was thus faced with a black-start. Aided by a robust network with considerable redundancy, a low power demand at the time $(1,860 \mathrm{MW}$ out of a capacity of 5,000 MW) and the experience of the operators a progressive re-energising of the grid commenced.

Within 30 minutes the first line was restored. Within 3 hours $15 \%$ of customers were restored, within 7 hours $51 \%$ were restored and within 24 hours $93 \%$ were restored.

In the damage area 63 facilities out of 221 in the Los Angeles area suffered damage. By the end of the third day these had all been bandaged or bypassed and $99 \%$ of customers were restored. After 7 days less than 100 customers who could take power remained out of service.

Damage was generally attributed to ceramic insulators breaking and falling with their conductors and bringing down adjacent equipment. Aluminium rigid bus connectors in electrical equipment experienced significant damage. Transformer bushings experienced problems in areas of ground disruption particularly higher voltage bushings which were harder to repair or replace. Holding down bolts stretched and nuts stripped threads.

On the positive side, recently installed equipment performed much better than older equipment. This was due to upgrades 
in standards since the 1971 San Fernando earthquake which caused catastrophic failures in the Sylmar Converter Station. From that time a programme had been undertaken to replace vulnerable live tank circuit breakers with qualification tested dead tank circuit breakers. It is significant that DWP had no circuit breakers fail in this earthquake. Nevertheless the Sylmar Converter Station suffered substantial damage and was expected to be out of commission for several months.

Southern California Edison lost power to 1.1 million of its 4.2 million customers. Within 60 seconds 250,000 of these were restored as automatic equipment re-energised facilities. Within 8 hours 600,000 were restored and within 24 hours all but 2,500 were restored. All services were running within 56 hours.

The transmission system to the north in the Santa Clarita area sustained damage with 3 major bulk substations being knocked out. All eight live tank circuit breakers at Pardee were destroyed through porcelain breakage. Several line dead end box section structures developed cracks in the welds. A section of $66 \mathrm{kV}$ transmission line on the ridgetops was lost as a tower footing failed due to a landslide and the resulting collapse caused 5 adjacent towers to also collapse. The line was returned to service in 11 days.

In summary the Edison system suffered US\$50 million in damage. Thirteen poles and 61 transformers required replacement. Over 200 spans of conductor required replacement and over 40 pad mounted transformers shifted on their pads and required resetting.

\subsubsection{Mitigation and Response}

Both companies have undertaken mitigation programmes over recent years and these were felt to have significantly reduced the damage. Response planning provided for a substantial response but the detail was not particularly adhered to. Plans need to be practically based and to be geared to individuals. The Dept. of Water and Power mobilised 70 teams to check 220 facilities. Damage was found in 63 of them. Recording of damage could be better organised.

\subsubsection{Lessons For New Zealand}

The following are key points to note:

- mitigation programmes pay off

- design standards need to be kept under review and design for realistic ground accelerations

- porcelain cantilevers dont work (still) and alternatives need to be found. There is interest in the NZ approach to base isolation and damping

- qualification testing of equipment should be demanded of manufacturers

- address the connections of conductors

- response plans need to address individuals and be site based. They need to be practical documents

- access into installations need to be addressed. Are there alternative routes and do staff know them?
- damage assessment following the earthquake is a response issue and procedures need to be defined

- provide better support for staff during the recovery process

- develop media responses

\subsection{Telecommunications}

\subsubsection{Networks}

The telecommunications network comprises two major Local Exchange Carriers (Pacific Bell and GTE) and three major toll (area code) or Inter Exchange Carriers (AT\&T, MCI and US Sprint). There are 250 major communications sites in Los Angeles including local exchanges, tandem exchanges and remote switching units. Communication between exchanges is provided by copper cable, fibre optics cable or radio links. Links to the Inter Exchange Carriers are through what is called the SS7 network.

Cellular, paging and mobile radio services are provided independently by various US companies including PacTel Cellular and McCaw Cellular Communications.

Information for this report has come from Pacific Bell who acknowledge the value of sharing information in order that better preparedness can be achieved for future events. Pacific Bell have 78 local exchanges and 9 tandem exchanges in Los Angeles. All their major sites (over 150) have emergency generator and battery power backup.

\subsubsection{Outage and Damage Assessment}

With the loss of power to the entire city the Pacific Bell network momentarily was without energy. Within seconds the emergency generators at all but three sites started. At these three sites batteries took over and the network stayed up. Overall this was a very impressive response given the difficulties with emergency generators elsewhere. At two of the sites the generators recovered before the batteries ran out. At one site backup batteries provided power for about 6 hours and the site was then without power for an hour until a mobile generator was connected - the connection took several hours to effect because an AC tap box was not available at the site.

Of the 78 local exchanges 3 went down and lost connections to other exchanges. These were the Northridge, North Hollywood and Culver City exchanges within or near the epicentral area and were caused by power and signalling equipment failures. This affected 190,000 lines from calling outside the exchange area for from 1 to 4.5 hours- calls were still possible within the exchange area.

In addition local exchange connections to the SS7 toll network were affected in 8 exchanges isolating 287,000 lines from the toll system for 1 to 8 hours.

Outages from damaged or broken cables was very limited. One fibre optic cable was burned by a gas fire near Fillmore affecting 1,500 lines. This was restored within 15 hours. Four inter-exchange fibre optic cables were damaged due to ground movements. These were isolated and by-passed.

There was the inevitable massive congestion on call lines with over double the normal demand of 70 million calls per day 
throughout the city. On local exchanges in the damage area demand was up to 100 times normal for a time with one exchange experiencing 250000 call attempts per hour compared to 2000 per hour normally. This resulted in local dial tone delays but if people held on dial tone would eventually be obtained. Network management controls were imposed by the toll carriers which denied access to area codes in the earthquake area.

The overload demand persisted for a day and a half through to noon on Tuesday and then fell rapidly. By Tuesday night demand was back to relatively normal. This was assisted by media messages keeping people informed about the earthquake and the status of systems.

The Los Angeles 911 emergency call service operated throughout with only one outage of less than an hour in Santa Cruz.

Damage to Pacific Bell facilities totalled US\$26 million. Damage occurred in 31 of the 78 exchange buildings and in 19 others. Nine buildings were significantly damaged with walls buckling, roof separations and ceiling tiles falling.

Equipment damage occurred with rooftop cooling fans, compressors and chillers toppling and damaging roofs and fracturing cooling water systems. Many of these items were not well detailed. In contrast equipment racks and cabinets within the buildings performed well. They had been covered in an aggressive mitigation programme to brace equipment and anchor bases.

\subsubsection{Mitigation and Response}

A major mitigation programme to brace equipment racks, anchor bases and strengthen at risk buildings has been undertaken by Pacific Bell over recent years. Emergency generators and battery backup in key facilities have been addressed with regular testing programmes instituted to minimise start-up failures. In addition response planning and preparedness exercises have been undertaken to ensure staff are familiar with their role in an emergency.

The effectiveness of this has been demonstrated in the response during the Northridge earthquake which, despite US\$26 million worth of damage, managed to maintain a largely uninterrupted service. Pacific Bell is planning a US $\$ 120$ million ongoing retrofitting programme to further upgrade their response capability. Amongst other things, rooftop cooling and ventilating installations are to be addressed.

\subsubsection{Lessons for New Zealand}

The following are key points to note:

- mitigation and preparedness planning reduced damage and provided for a largely uninterrupted service immediately after the earthquake

- regular full load testing of emergency generators is necessary to minimise start-up failures

- provision of 3 hour battery backup is insufficient for critical installations. The provision of AC tap boxes for portable generator hook up should be provided at critical sites as a final backup
- care needs to be taken with ancillary equipment to ensure it does not cause secondary damage or unexpected outages

- backup communications systems are vital to coordinate response efforts

- Network Management Centre technology is essential to reduce delays in dial tone delivery. Secure control lines are important for this to be effective

- exercises are felt to be the best preparation for actual emergencies

- industry Mutual Aid Agreements are vital

- coordination between utilities is critical to establishing response capability immediately after the event.

\subsection{Gas}

\subsubsection{Networks}

The gas network comprises $3,600 \mathrm{~km}$ of welded steel transmission lines of predominantly $300 \mathrm{~mm}$ and up to $900 \mathrm{~mm}$ diameter operating at greater than $1,000 \mathrm{kPa}$ pressure and $68,000 \mathrm{~km}$ of distribution lines of $50 \mathrm{~mm}$ to $300 \mathrm{~mm}$ diameter operating at pressures up to $400 \mathrm{kPa}$. The distribution lines are $66 \%$ steel and $34 \%$ medium density polyethylene plastic.

The network is supplied from external supply lines to the Eliso Canyon storage facility in the Santa Susana mountains about 5 $\mathrm{km}$ to the north of Northridge. The storage facility has over 100 wells, 2 gas dehydration plants, field separators, oil gathering and tankage facilities and water treatment facilities.

The Southern California Gas Company operates the network and supplies 4.9 million customers through 3.3 million service lines.

\subsubsection{Outage and Damage Assessment}

The Eliso Canyon storage facility suffered shaking damage to a number of the surface facilities and above ground pipe supports. There were also a number of landslides which displaced above ground pipes although none of these fractured. All the facilities were shut down and the wells shut off after the earthquake. There was no damage to the underground reservoir and no gas escaped from the reservoir. A basic supply was re-established quickly but disruptions continued for 5 days. There was a break in a $250 \mathrm{~mm}$ pipe leaving the field.

Gas supplies continued following the earthquake. In the Northridge area there were numerous line breaks caused directly by the severe ground shaking and by direct ground compression arising from the ground shaking causing tension and compression failures in pipes passing through that ground.

In transmission lines there were 35 pipe failures. These were generally circumferential tension cracking in pre-1942 acetylene welded pipes. The fractures occurred in the heat affected zone adjacent to the welds.

The most spectacular of these failures occurred in Balboa Boulevard which was the site of a sequence of buried pipe failures. The Boulevard runs north - south through Northridge about $3.5 \mathrm{~km}$ to the west of the epicentre. Five $\mathrm{km}$ to the north a section of Balboa Boulevard had several blocks of ground 
compressed by the north - south ground shaking pulse. This caused several $125 \mathrm{~mm}$ tension cracks to occur across the Boulevard at about $150 \mathrm{~m}$ centres. There were approximately 12 different utility lines in the road and a number suffered several breaks either by tension at the tension cracks or by compression buckling between the tension cracks.

It is noted a polyethylene fuel pipe in the road did not fracture demonstrating the ability of this material to withstand quite severe strains without fracturing.

A $150 \mathrm{~mm}$ gas distribution line and a major $1,350 \mathrm{~mm}$ water line both fractured at one of these tension cracks. Water flooded the road and for about 45 minutes gas escaped unnoticed. A passing utility truck stalled in the water and tried to re-start the engine. The ignition spark ignited the gas and a fireball exploded which burned down five houses. The main continued to burn at low pressure for a number of hours - this was preferable to closing off the supply and flooding the distribution system with water from the fractured water pipe.

Distribution mains suffered a total of 717 leaks in steel lines with 563 of them showing corrosion related defects which could have been leaking before the earthquake. Where fractures occurred they were at gas welded joints, at cast iron valves and at screwed mains joints. While $34 \%$ of the distribution system is polyethylene pipe only 27 failures occurred in this material and these were mainly at couplings and transition fittings.

In addition there were 1,400 service connection breaks in 12 $\mathrm{mm}$ to $50 \mathrm{~mm}$ lines between the mains and the meter connections.

Damage sustained to the network system was estimated at US\$35-40 million.

A total of 151,000 customers were cutoff from supply either by breakage or by customers turning off their gas valve as a precautionary measure. All but 15,000 of these were found to be unnecessary. There were 841 shutoffs from customer installed earthquake valves activating. The Gas Company undertook 123,000 restores and 61,000 leakage investigations of customers premises. The bulk of the restores were achieved in 10 days with 100,000 being completed after 5 days. For the remainder the customers restored themselves.

From the 61,000 leakage investigations 14,000 leaks were found on customer facilities after the meter. The majority occurred at appliance connections with nearly 9,000 on vent systems and 2,500 at unstrapped freestanding water heaters - only 211 strapped water heaters were damaged. The remainder of the leakages occurred in piping

Gas was involved in 51 of 58 structure fires reported. Toppling of unstrapped water heaters accounted for 20 of these. Gas was also a factor in fires in mobile home parks. Mobile homes on flimsy supports toppled and broke gas connections which were then inaccessible. Resulting fires destroyed 172 mobile homes. Nearly 5000 were damaged by ground shaking.

\subsubsection{Mitigation and Response}

The Gas Company has a comprehensive emergency response capability with a permanently set up emergency operation centre in the downtown Los Angeles head office. This was operational within an hour of the earthquake and provided communication control and workforce coordination. In accordance with the response plan facility managers did initial surveys and company structural engineers inspected buildings for occupation. This was completed within a few hours. One customer call centre facility was evacuated to other centres and calls were diverted.

A total of 3,400 people were placed in the field response with 500 of them coming from Mutual Aid Agreements with neighbouring gas companies from San Diego, Las Vegas and north California. Seventeen command centres were set up in the damage area to coordinate local callouts, materials and fittings supply and catering for work crews.

Within two weeks $3,700 \mathrm{~km}$ of gas line were checked for leaks with flame ionisation detectors and 150,000 service calls carried out. Over four and a half weeks 288,000 earthquake related orders were carried out.

In some instances restoration of electricity to an area would result in a fire from leaking gas. An attempt was made to coordinate with the electrical companies but this was not effective at the operations level. Also liaison with City Hall building inspectors on the status of damaged premises and homes presented problems. Both of these were the result of the scale of response involved and better procedures needed to be defined.

\subsubsection{Lessons For New Zealand}

The following are key points to note:

- preparedness and response planning provided for a very large scale response which was customer driven

- mutual aid agreements were important

- old gas welded pipe did not perform well. Polyethylene and ductile welded steel lines performed well

- the strapping or supporting of domestic gas appliances is fundamentally important

- the coordination with other utilities and emergency management organisations at the operations ievel is important and needs attention. For the gas industry this is particularly true with electricity restoration and buildings inspection

- the preparation for and use of the media for status information and instruction is important and needs prepreparation

- field and logistic support for staff in the recovery mode needs attention.

\subsection{Sewerage}

\subsubsection{Network}

The City of Los Angeles Bureau of Sanitation operates the wastewater treatment service for 4 million people in its service area. The main city system comprises $11,000 \mathrm{~km}$ of mainline sewer, 62 pumping stations for sewerage and stormwater, 2 landbased water reclamation plants and the major Hiperion sewerage treatment plant located near the Los Angeles Airport discharging $8 \mathrm{~km}$ into the sea.

The north of the city is served by the two water reclamation plants which treat the water and return the solids to the collector 
network for treating at Hiperion which has a design capacity of 2,000 million litres per day. The Northridge area is served by the Tillman water reclamation plant with a capacity of 300 million litres per day. This plant is located $8 \mathrm{~km}$ from the earthquake epicentre.

The large diameter collector network (up to $4 \mathrm{~m}$ diameter) has a variety of materials but is mainly brick and reinforced concrete with ring joints. The local distribution system is primarily $(90 \%)$ ceramic of 200 to $400 \mathrm{~mm}$ diameter. The average age of the sewer system is 50 years with some sewers over 100 years.

\subsubsection{Outage and Damage Assessment}

Damage to treatment plants was largely confined to the Tillman plant. Here damage was largely non structural and affected things such as sludge collection chains, broken flights in sedimentation tanks and unsecured cabinets falling. There was some broken glass and minor concrete cracking in the administration and shop buildings. In all damage was approximately US\$1.5 million. Despite this the plant was offline for only 7 hours.

The Hiperion plant located $35 \mathrm{~km}$ from the epicentre suffered only minor damage (US\$25,000) to miscellaneous items. Although the City lost power for 1.5 hours in that area the plants sludge burning generation plant continued without problems and their were no interruptions to the treatment processes.

All 62 pumping stations in the city suffered power loss from between 4 to 36 hours. Thirty of the critical stations have backup generators and all started up without incident. There were therefore no significant overflow problems arising from pumping station power loss. It should be noted that all backup generators are started weekly, checked bi-monthly and load tested bi-annually. This has been part of a mitigation programme running for the past 4 years.

In the Northridge area there are 4 sewerage and 4 stormwater pumping stations. Only one suffered damage with a broken cast iron entry pipe. Surprisingly there was no other damage to pumping stations located throughout the city.

There is a SCADA data and control system throughout the network which continued to operate apart from two leased telephone lines suffering short term outages.

The large diameter sewer collector system suffered very little damage with no significant incidents. These pipes were generally jointed and were at greater than $4.5 \mathrm{~m}$ depth. As such they would be expected to handle the heavy ground shaking reasonably well.

In contrast the $200-400 \mathrm{~mm}$ diameter ceramic local distribution sewers in the Northridge epicentral area suffered widespread cracking and collapse in areas where ground surface damage was evident. Damage was more widespread nearer the epicentre and in areas of high watertable. It has taken some months for damage to be found and the full assessment will not be complete until about 12 months after the earthquake.

Approximately $55 \mathrm{~km}$ of sewers have been identified as high risk - from an assessment of surface damage - and these are being progressively inspected by closed circuit TV. To date US $\$ 36$ million worth of damage has been identified and the expected total is expected to be around US\$50 million.

\subsubsection{Mitigation and Response}

It has been a feature of the sewerage system that there has been an almost complete absence of structural damage to pumping stations and treatment plants. Over recent years the Bureau has undertaken an extensive programme of mitigation to brace and support all equipment, pipes and fittings in these installations.

This is evident in all their plants and pumping stations and there is no doubt this contributed to their lack of damage. For their pumping stations which are below ground level the susceptibility to damage from ground shaking is lessened and that no doubt assisted.

The lack of damage to the large diameter collector sewers is almost certainly due to the nature of the earthquake and to the local ground conditions. The earthquake was a severe ground shaking event without significant ground settlements or liquefaction. These large jointed pipe systems can withstand ground shaking reasonably well (although it would be interesting to speculate what damage might have occurred with a few more cycles of shaking opening and closing joints) but would be much more susceptible to damage from ground settlements.

As part of the mitigation programme running since 1986 the Bureau has also put in place a substantial response planning and preparedness programme. This was accelerated by the Director in 1992 and addressed emergency plans, emergency generators and batteries etc., alternate work sites, logistical support and emergency training. This has been a major initiative and without doubt has played a major role in the ability of the system to continue operating through the earthquake.

Within six hours of the earthquake the Bureau was able to complete a status assessment of the network and incidents were handled without major difficulties.

The major damage to the local distribution network did not become apparent until the pipe network damage assessment programme had been running for some weeks. The problem was in identifying where to look because in a non pressurised system leaks and breakages are not readily apparent.

To identify likely areas of damage the damage assessment programme mapped surface damage incidents onto their GIS mapping network and looked for concentrations of damage of buildings and streetworks (road and curbing damage etc.) and water pipes as indicators of potential areas of pipe damage. This was an extensive exercise of plotting information from a range of different sources and looking for correlations from field closed circuit TV inspections.

The best correlation was found to be with surface damage to streetworks and that has become the basis of a 12 month TV inspection programme. Identified areas cover $55 \mathrm{~km}$ of sewers and inspections have revealed $16 \%$ of these needing emergency repair, $49 \%$ have sustained damage which may require repair and $35 \%$ which have not sustained damage.

\subsubsection{Lessons for $\mathrm{NZ}$}

The following are key points to note:

- large diameter jointed pipes perform reasonably well under severe ground shaking

- ceramic pipes are susceptible to severe ground shaking 
- structural and non structural mitigation measures substantially cut losses

- preparedness planning is hugely beneficial

- maintenance and testing of emergency generators is important. It should be carried out by those relying on them, not by an external agency

- means of assessing pipe network damage are necessary to focus inspections on likely areas. GIS mapping of surface feature damage has been useful for this.

\subsection{Water}

\subsubsection{Network}

The Los Angeles water system is largely supplied from treatment and reservoir facilities located in the Van Norman complex at Sylmar to the north of the city. Two filtration treatment facilities exist in the complex. One is the 480 million gallons per day Dept. of Water and Power (DWP) Los Angeles plant supplying 3.5 million people of the city through 660000 customer connections. The other is the 550 million gallon per day Metropolitan Water District (MWD) Jensen plant which is one of five supplying bulk water to $60 \%$ of the remainder of the Southern Californian municipalities. The Van Norman site is 10 $\mathrm{km}$ from the earthquake epicentre.

The two plants are fed by three major aqueduct pipes from the north which are supplied from North California and the Colorado river.

Seven major trunk lines feed out from the Van Norman complex into the city. The DWP reticulates the city through $11,400 \mathrm{~km}$ of mains of which $2,600 \mathrm{~km}$ are in the Western Valley sector containing Northridge. This sector contains 44,500 valves and 14,000 hydrants.

\subsubsection{Outage and Damage Assessment}

Both aqueducts supplying to the Los Angeles Filtration Plant suffered damage with pipe breaks and channel disruption which put them out of service. The First Aqueduct was returned to limited service on the 6th day and the Second Aqueduct on the 8 th day after the earthquake. The Filtration Plant was inoperable with damage to the ozone generators, filtration beds and backwash ponds with joint movements causing seals to fail. Progressively the plant was restored to service and was back at $90 \%$ capacity after 9 days with chlorine disinfection instead of ozone.

During this time supply to the city was maintained in the undamaged areas from storage reservoirs. A "boil water" notice was issued on the morning of the earthquake as a result of loss of disinfection and possible contamination from broken water and sewer lines. The last notices were lifted after 12 days.

The $2.1 \mathrm{~m}$ diameter aqueduct feeder pipe to the Jensen Filtration Plant was ruptured and the plant itself was damaged and out of commission for 3 days. The system was back in full operation within a week. Damage to the plant was US $\$ 4.8$ million and further mitigation work is to be undertaken with the total cost of repairs and mitigation expected to be US\$11 million.
The Los Angeles distribution and reticulation system suffered extensive damage in the western San Fernando valley around Northridge and Sherman Oaks and local regions of damage in the West Los Angeles area and through the eastern San Fernando valley. Seven major trunk lines of $1400 \mathrm{~mm}$ to 2100 mm diameter were ruptured including the L.A. City Trunk line. Supply to the major parts of the city was maintained through redundancies in the network.

Supply to the western San Fernando valley was disrupted with breakages to the Granada and Rinaldi Trunk lines in a number of places. These lines had no redundancy and supply was lost to 100,000 customers in the area. This was out of 660,000 customers throughout the city. In addition four 10 million litre capacity steel reservoirs failed in the Santa Monica hills and emptied their contents into the valley. This was out of 26 reservoirs in that broad area. Failure was by shifting of the reservoir by about $50 \mathrm{~mm}$ on its foundation and shearing off the inlet and outlet pipe connections. A number of other tanks suffered lesser damage.

Distribution lines and service connections between them suffered more than 1,500 breaks. Most breaks in distribution lines occurred in cast iron bell and spigot pipes with tension and compression failures occurring at the bell. Where they existed, ductile iron pipes performed reasonably well. PVC pipe had not been hugely successful. Self tapping service connections did not perform well and many sheared off damaging the pipe. In comparison collar type connections performed much better.

Most mains repairs were completed within 20 days and supply to the western San Fernando valley was progressively restored from day 4 through to day 11 . A local network of water supply points was established supplied by water tankers. On day 1 seven water tankers were operating. On day 2 seventy five tankers were operating with 30 employees coordinated the activity.

Damage to the Dept. of Water and Power system is estimated at US\$30 - 40 million.

\subsubsection{Mitigation and Response}

Substantial mitigation work has been undertaken in treatment plants and pumping stations over the past 20 years and this without doubt reduced the extent of damage. Some reservoirs have been fitted with flexible couplings at the pipe connections. Those that failed were not so fitted. Old steel riveted trunk mains have been the subject of a large replacement programme but many remain and are at risk. Non ductile pipe reticulation networks remain at risk. Policies to use ductile iron for pipe replacement programmes will gradually upgrade the network.

A major response was put in place with mutual aid agreements with nine external water utility companies being activated. This took a lot of coordinating and a liaison person was attached to each external crew and these were generally worked during the day while local DWP crews worked at night. There were problems with communications with the external crews because radio telephone frequencies were not compatible. This was resolved with the use of cellular phones which in this instance proved satisfactory.

While a response plan was in place the DWP found it broadly useful but lacking in flexibility. The first day was largely spent identifying damage. A particular issue which had not been adequately addressed was the support required for staff and 
mutual aid teams in the field in terms of logistics and accommodation.

\subsubsection{Lessons for New Zealand}

The following are key points to note:

- mitigation measures reduce damage

- non ductile pipes are at risk from severe ground shaking

- flexible pipe couplings at reservoirs are necessary

- consideration should be given to automatic shut-off valves on water reservoirs to avoid loss through broken reticulation. Flow sensing devices are more reliable than seismic shaking sensing devices

- communication with field crews is an important issue. Backup systems are necessary

- response plans need to be covering all aspects of activity but to provide for flexibility

- logistic support for staff is very important

- co-ordination between Divisions of the organisation is crucial as is co-ordination with other city agencies and utilities

- media responses need to be managed

\subsection{Acknowledgements}

The assistance provided by the following organisations during the reconnaissance visit and their willingness to freely share their experiences and information is very gratefully acknowledged:

Los Angeles Department of Water and Power - Power and Water Divisions, Southern California Edition Electricity Company, Pacific Bell Telecommunications Company, Southern California Gas Company, Department of Public Works Bureau of Sanitation, Metropolitan Water District of Southern California.

The contribution of the participants to the Joint New ZealandLos Angeles Lifelines Workshop held at the Gas Company Offices in Los Angeles on 1516 August 1994 is acknowledged. This Workshop will be the subject of a detailed report to be published by the Centre for Advanced Engineering of the University of Canterbury.

\section{FIRE}

\subsection{General}

Although several hundred fires which occurred in LA on the 17 th January were attributed to earthquake damage, there was no loss of life due to fire and few instances of building-tobuilding fire spread. Overall the fire damage, when the intensity of the population is considered, was lower than expected due to a combination of fortuitous circumstances and sound planning.

Leaking gas was by far the most common cause of building fires.
Fifty outbreaks of fires were reported to the LA City Fire Department alone (figures not available for other municipalities) during the first hour following the Northridge Earthquake. A total of 466 fire incidents were reported during the 24 hours following the event (compared with the normal 30 to 40 reports per day). The severity of these incidents varied widely from minor outbreaks to multi-building events. Widespread fire conflagration still remains the main concern following an earthquake as it has since the 1906 San Fransisco earthquake The LA City Fire Department (LAFD) were greatly relieved when all fires were under control and there were no major fires still burning within 6 hours of the earthquake. The total number of fire, paramedic/ambulance, and rescue incidents attended by the LAFD was in excess of 2200 compared with approximately 900 during a normal days operation.

The fortunate circumstances which combined to assist in reducing the damage and material loss caused by fire were:

- the very light winds during the 12 hours following the earthquake reduced the spread of fire potential,

- the early morning occurrence of the earthquake, on the dawn of a public holiday, enabled

(a) rapid identification of fire locations using helicopter surveillance (LAFD have 6 helicopters able to be diverted for such work),

(b) direct access to the fire incidents since traffic congestion was non-existent and the surface roads were largely undamaged, and

(c) the Fire Department to dedicate nearly all its resources to fire suppression operations (since there were very few vehicle accidents - which normally consume the Fire Department resources)

- there was little structural damage to fire stations houses themselves.

Effective planning by the various Fire Departments within the County minimised the extent of post-earthquake fire damage. Such planning recognises that fire damage follows earthquakes (as distinct from building collapse which occurs during the period of ground shaking) and that fire suppression measures can be effective provided they are initiated immediately. These measures, combined with the effective mutual aid programmes which operates between the various municipalities, proved effective in minimising fire damage.

\subsection{Causes of Fires}

Leaking gas, both inside and outside buildings, was by far the most common combustion source within buildings. Gas, although not an ignition source itself, it is easily ignited when confined or when there is a large volume present. The incidence of gas related fires was significantly reduced by complete failure of electricity supply to the city following the earthquake, which removed the most common ignition source. Many home-owners manually shut down their domestic gas supply. Only a few of these were subsequently found to have developed leaks but in these instances, had the power supply not been interrupted, additional outbreaks of fire would have occurred. As it was, several fires were reported when power was restored (Figure 10.1). These were generally brought under control rapidly using a combination of fire tankers and cross-linked boosters between un-broken water mains. (Note: the manual closure of over 150,000 domestic gas supply lines 


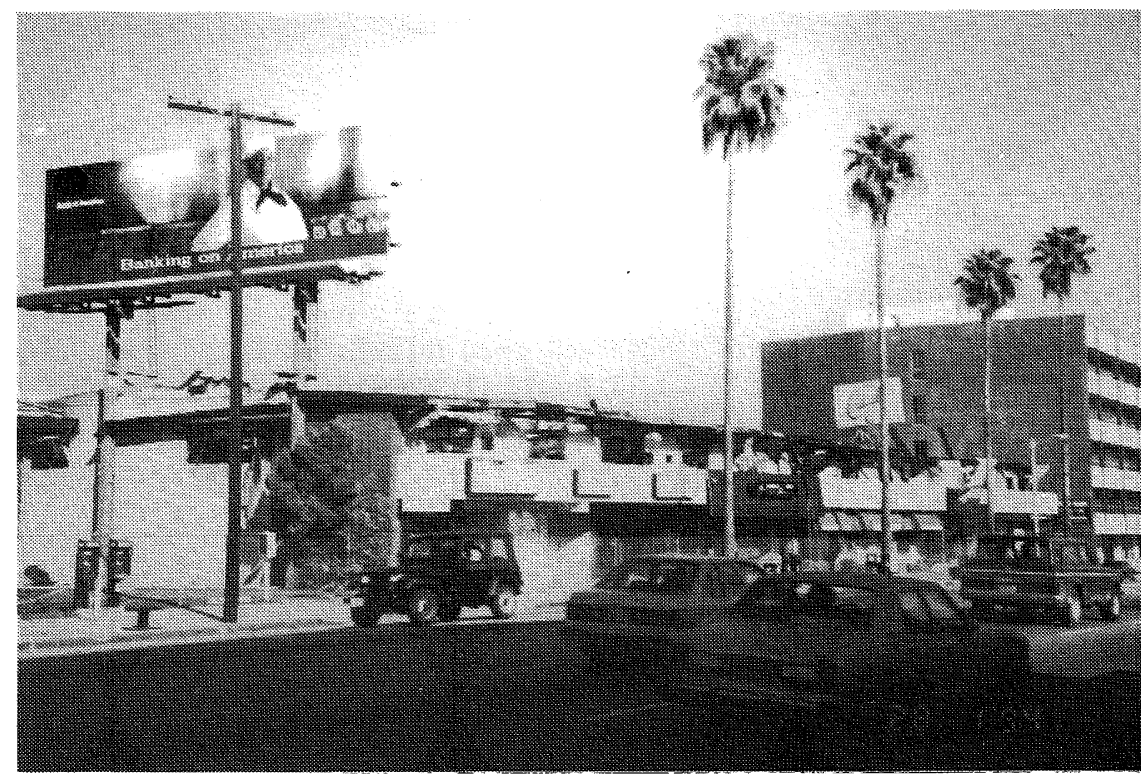

FIGURE 10.1. Several tenancies were burnt out as fire spread along the upper floor of this retailing complex. The fire outbreak coincided with restoration of power to the area several hours after the quake.

created a problem for the Gas Companies who were severely stretched to provide the resources needed to completely check each system before gas supplies were reinstated.)

Several fires within homes were traced to overturning of gas fired hot water cylinders and water tanks associated with heating and ventilating units. (Such tanks are themselves being moderately heavy and prone to overturning.) When this happened the gas supply line usually ruptured enabling gas to escape. Where an ignition source was or became present, fire outbreak resulted

Chemical ignition is thought to have occurred in one instance namely in the three storey science block at CalState Northridge University. Here it is understood that chemical interaction initiated the outbreak in the upper level. The fire developed to an extent that it migrated down to the second floor before it was extinguished by fire fighting intervention (using water pumped from a nearby swimming pool).

Isolated cases of wildland fire were reported which were thought to have been ignited by arcing between transmission lines. These incidents were few and, with the cool night temperatures and damp vegetation during winter, were readily controlled. This suppression may have been much more difficult during hotter or drier climatic conditions. There were no reported incidents of petrol storage or pumping facilities igniting, nor of domestic fires being involved as ignition sources. Likewise, with this event occurring in early morning, cooking and most lighting sources were extinguished and there are no known instances of these as ignition sources.

\subsection{Fire Spread}

Few instances were noted where the fire moved beyond the building where ignition occurred. There were several instances where complete fire compartments burnt, but building to building fire spread was rare. The team was unable to assess sufficient data to comment on the effectiveness of the various passive (i.e., fire walls, separation distances etc) or active fire prevention measures.

There were some isolated cases of fire spread between buildings, usually where the fire occurred immediately following the earthquake and, when combined with a complete loss of water pressure, the fire was left to burn out. In figure 10.2, fire is understood to have broken out at a rupture to the gas heater and consumed the dwelling within 20 minutes. The adjacent property was enveloped after approximately 10 minutes and the fire nearly spread to an adjacent third property. Fire appliances were committed elsewhere during this period and all water pressure was lost.

Manufactured (or mobile) home estates also experienced fire spread between buildings. There are three such estates around the northern perimeter of the San Fernando. Valley. These homes, typically less than $100 \mathrm{~m}^{2}$ in area, are in most ways permanent, being built of permanent materials and having permanent surroundings such as gardens, sheds, fences, etc.. The control of such estates rests with state rather than city officials so they fall outside city ordinances. Thus building separation distances are markedly reduced from those permitted elsewhere (to 3 to 5 metres between buildings), and subfloor lateral load resisting systems were non-existent. The combination of these conditions resulted in widespread fire related damage being inflicted within these estates. The lack of lateral load resisting restraint within the foundations resulted in several of the units rolling from their support stools and collapsing, in several cases onto their gas supply mains. The close inter-building spacing, combined with multiple ignition points and low water pressure resulted in 67 homes in one such estate $(20+$ and 23 in the other two) being destroyed by fire. Fire was observed to spread between buildings through direct radiation. Generally control was only possible at the wider fire breaks created by roads or access paths (Figure 10.4).

There was very little wind during the morning of the 17 th of January in a region where a steady wind (the Santa Anna winds) are common. These sweep over the epicentral region from the north, sometimes for days on end. The fortunate lack of such conditions considerably assisted in fire containment.

Water pressure was severely affected by mains breaks and reservoir failures in several places and fire fighters commonly used water shuttle or relay operations in order to combat outbreaks of fire. 


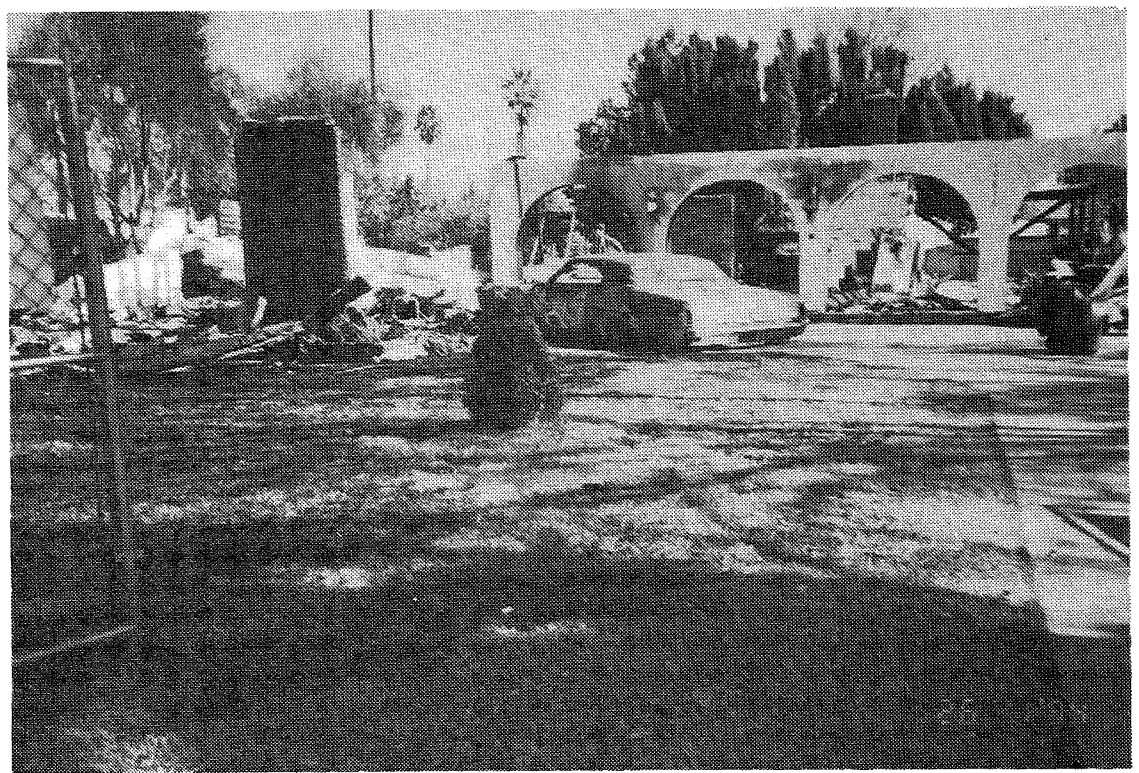

FIGURE 10.2. Gas leak initiated fire consumed this house within 20 minutes of the earthquake. It spread to and consumed an adjacent home before burning itself out (see also Figure 10.3)

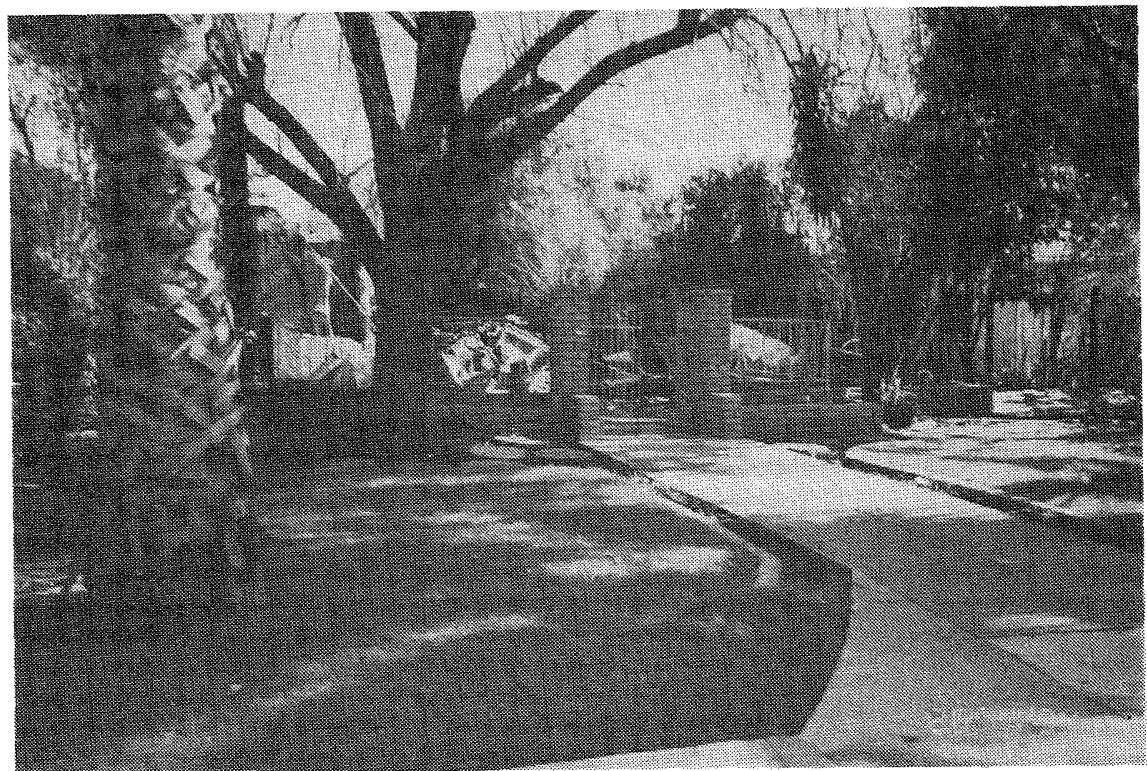

FIGURE 10.3. This house burned as fire spread from its neighbour. All water pressure was low to this area.

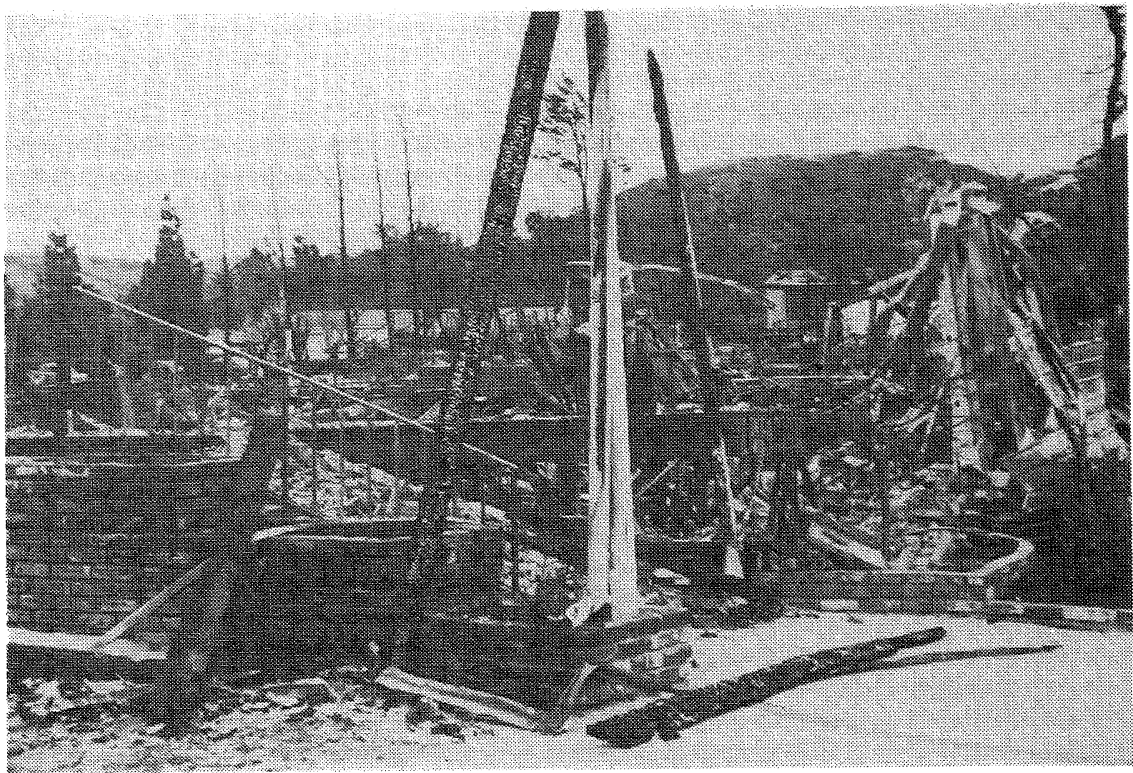

FIGURE 10.4. Widespread fire related damage occurred within manufactured home estates. 


\subsection{LA City Fire Department Response}

In the USA, fire and police responsibilities lie with individual municipalities. The Fire Department is responsible, in addition to the traditional fire suppression role, for paramedic (ambulance), motor accident rescue operations and urban search and rescue (USAR). The LA City Fire Department moved into earthquake response mode immediately after the earthquake. This involved several operational changes which include dispatching emergency response vehicles to area patrol and retaining reserves by dispatching fewer appliances to respond to an incident than normal. A state of emergency, declared by the LA City Mayor at 5:45 am on the 17th, remained in effect until February 6th. Throughout this period the primary control of buildings and personnel lies with the Fire Department with other city departments (eg Police, Health \& Safety (Buildings)) providing support to the Fire Department. In any such emergency, the Emergency Operations Centre (EOC) in the fourth level basement of City Hall undertakes an inter-services coordination role. The EOC was continuously manned by City, State and Federal agency representatives. While each agency undertook its specific recovery tasks, the EOC provided direct access for inter-agency support as needed (Figure 10.5).

The important role of urban search and rescue was clearly evident in the few instances where people were trapped within collapsed buildings. Fortunately, with the earthquake happening in the early morning, there were few calls for this service. However the need remained for all buildings to be checked for trapped people and the USAR team performed this task admirably. Had the event occurred during the day, Bullocks Department store alone would have seen several hundred, if not thousands, of people trapped and in need of rescue. It is with considerable concern therefore to look at New Zealand's state of readiness in this regard. The need to formulate, train and equip a rapid dispatch team of specialists is long overdue and should be taken up with all possible haste. Either the NZ Fire Service or the military would be best placed to undertake such a role.

LAFD has a total compliment of 3500 personnel who are responsible for the 3.5 million people who live in the City of Los Angeles which extends over an area of 1200 square kilometres. Fire suppression is provided from 103 fire stations distributed around the city. The LA City Fire Department has 47 task forces (each comprising one ladder truck and two fire engines), 51 single engine companies, 5 fire boats, 6 helicopters and 4 hazardous material squads. In addition to this huge resource, mutual aid agreements have been developed between the various municipal fire departments within LA County and neighbouring Ventura County and Orange County. Under this agreement, support is (usually) available from neighbouring districts when called upon. Intercity training programmes and equipment capabilities are in place and were available upon during the emergency. While Santa Monica called for assistance shortly after the Northridge earthquake, LA city found they had sufficient resources without outside help in most areas. New Zealand needs to plan for support on a more modest basis, making use of our more compact size and small population to ensure our more limited resources are effective in combating similar emergencies here.

This was the first time an earthquake reconnaissance team has included someone from the NZ Fire Service. Assistant Commander Bruce Jones, Executive Officer, National Headquarters, was with the team for the first 10 days of the visit and provided a very valuable contribution both by adding his specialist expertise and perspective to the party and providing a liaison directly with the LA Fire Department. Through the cooperation of Captain John Howell from the LAFD, the team was able to gain assess to many areas closed to ALL OTHERS. The importance of this contact and access cannot be overstated, and the team is grateful to both Commander Jones and Captain Howell for their assistance and support.

\section{ACKNOWLEDGEMENTS}

The team would like to acknowledge the help and assistance offered them by

- Mr Jim Bihr and the International Conference of Building Officials (ICBO) under whose commission Jim provided both technical advice and practical guidance throughout our period in LA and whose ongoing support in providing clippings and other information after our return was truely appreciated.

- Lam Pham of the Division of Building Construction and Engineering, CSIRO, Australia.

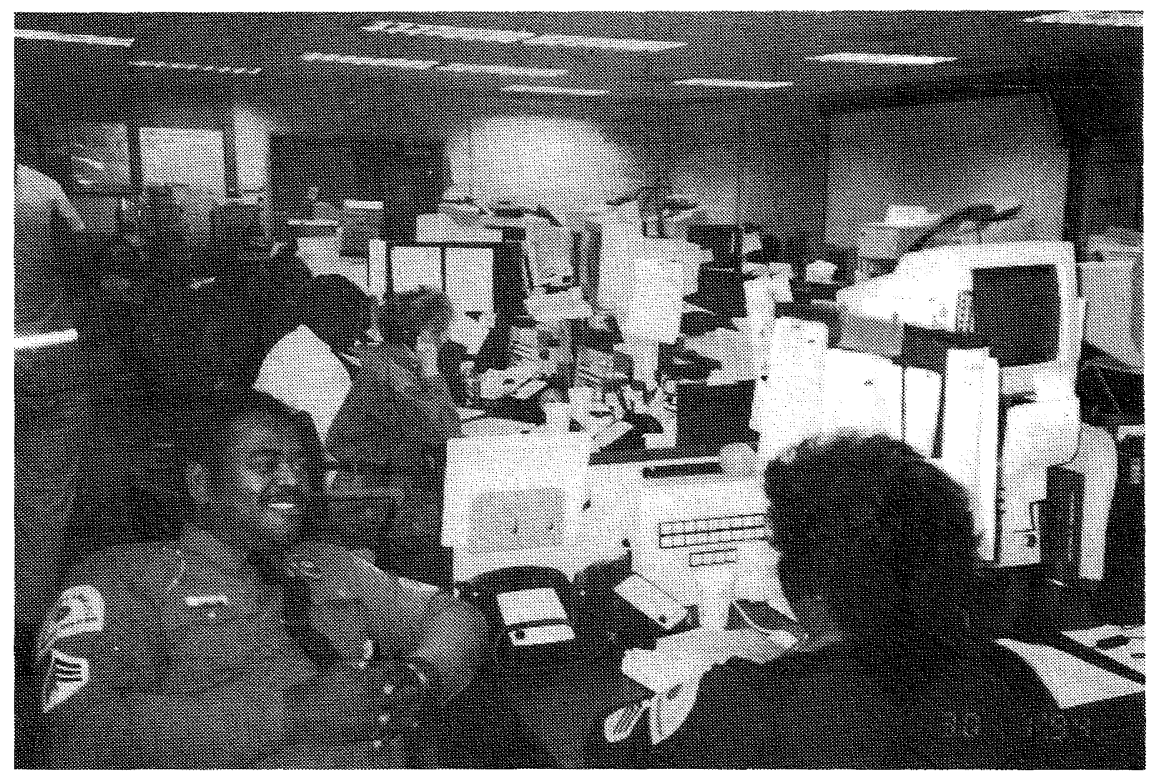

FIGURE 10.5. The LA City Emergency Operations Centre. 
- Captain John Nowell of LA Fire Department and Assistant Commander Bruce Jones from the NZ Fire Service who combined to provide the team access to many area otherwise closed.

- The Architectural Reconnaissance team of Mr Warwick Massey, Mr Alan Perry and Mr Gary Tonks who visited LA soon after our return and provided valuable follow-up and supplementary photographs and information into aspects of the building behaviour.

- EQC and BRANZ for contributed financial support to the NZNSEE reconnaissance team fund.

- Our respective employers who have made time and resources available while away from the office undertaking the reconnaissance, and that required to fulfil our obligations through participation in the speaking engagements following our return and the preparation of this report.

\section{REFERENCES}

American Concrete Institute. 1989. Building Code Requirements for Reinforced Concrete and Commentary. Detroit, USA.

American Institute of Steel Construction (AISC) Committee on Specification TC113. 1994. Seismic Design Meeting on 14, 15 March.

American Institute of Steel Construction (AISC) Special Task Committee on the Northridge Earthquake. 1994. Executive Summary. Interim Observations and Recommendations, 7 April.

American Institute of Steel Construction (AISC). 1994 Northridge Technical Bulletin \#1, July.

American Welding Society. AWSD 1.185. Structural Welding Code.

Anderson, T.L. 1990. Seismic Isolation Design and Construction Practice. Proceedings of Fourth U.S. National Conference on Earthquake Engineering. Palm Springs, California, 3:519-528.

Archuleta, R.J. 1982. Analysis of Near-Source Static and Dynamic Measurements from the 1979 Imperial Valley Earthquake. Bulletin of the Seismological Society of America 72A:1927-56.

Asher, J.W., Van Volkinburg, D.R., Mayes, R.L., Kelly, T., Sveinsson, B.I. and Hussain, S. 1990. Seismic Isolation Design of the USC University Hospital. Proceedings of Fourth U.S. National Conference on Earthquake Engineering, Palm Springs, California, 3:529-538.

Bachman, R.E. 1994. Base Isolation Performance Northridge Earthquake January 17, 1994, in Northridge Earthquake Seminar, March 26, 1994. Structural Engineers Association of Southern California.

Bachman, R.E., Gomez, M.J. and Chang, K.C. 1990. Verification Analysis of the Base Isolated Los Angeles County Fire Command and Control Facility. Proceedings of Fourth U.S. National Conference on Earthquake Engineering. Palm Springs, California, 3:539-548.
Bertero, V.V., Mahin, S.A. and Herrerra, R.A. 1978. Aseismic Design Implications of Near-Fault San Fernando Earthquake Records. Earthquake Engineering and Structural Dynamics 6:31-42.

Blume, J.A. and Associates, 1973. Holiday Inn, 8244 Orion Avenue, Van Nuys, in San Fernando, California, Earthquake of February 9, 1971, ed. Murphy, L.M., National Oceanic and Atmospheric Administration, U.S. Department of Commerce, 1A:359-393.

Boore, D.M., Joyner, W.B. and Fumal, T.E. 1993. Estimation of Response Spectra and Peak Accelerations from Western North American Earthquakes: An Interim Report. U.S. Geological Survey Open-File Report 93-509. Menlo Park, California.

Bourneville, D.R. 1994. Northridge Earthquake Damage to a Modern Steel Braced Frame Office Building. Proceedings of American Institute of Steel Construction (AISC) Special Task Committee on the Northridge Earthquake Meeting, 14-15 March 1994.

Caltrans. 1994. The Northridge Earthquake, Post Earthquake Investigation Report, California Department of Transportation, Division of Structures, 276pp.

Campbell, K.W. 1981. Near-Source Attenuation of Peak Horizontal Acceleration. Bulletin of the Seismological Society of America 71:2039-2070.

Campbell, K.W. 1988. Preliminary Analysis of Peak Horizontal Acceleration, in The Whittier Narrows Earthquake of October 1, 1987. Earthquake Spectra 4:115-137.

Clifton, C. 1994. Personal communication. BRANZ/HERA Technical Note, 5 August.

Crouse, C.B. and Jennings, P.C. 1975. Soil-Structure Interaction during the San Fernando Earthquake. Bulletin of the Seismological Society of America 65:13-36.

CSMIP. 1994a. First Quick Report on CSMIP Strong-Motion Data from the San Fernando Valley Earthquake of January 17, 1994. Report OSMS 94-01, California Strong Motion Instrumentation Program (CSMIP), California Division of Mines and Geology, Sacramento, California.

CSMIP. 1994b. Second Quick Report on CSMIP Strong-Motion Data from the San Fernando Valley Earthquake of January 17, 1994. Report OSMS 94-02, California Strong Motion Instrumentation Program (CSMIP), California Division of Mines and Geology, Sacramento, California.

CSMIP. 1994c. Third Quick Report on CSMIP Strong-Motion Data from the Northridge/San Fernando Valley Earthquake of January 17, 1994. Report OSMS 94-03, California Strong Motion Instrumentation Program (CSMIP), California Division of Mines and Geology, Sacramento, California.

CSMIP. 1994d. Fourth Quick Report on CSMIP Strong-Motion Data from the Northridge/San Fernando Valley Earthquake of January 17, 1994. Report OSMS 94-04, California Strong Motion Instrumentation Program (CSMIP), California Division of Mines and Geology, Sacramento, California. 
CSMIP. 1994e. Fifth Quick Report on CSMIP Strong-Motion Data from the Northridge/San Fernando Valley Earthquake of January 17, 1994. Report OSMS 94-05, California Strong Motion Instrumentation Program (CSMIP), California Division of Mines and Geology, Sacramento, California.

CSMIP. 1994f. Processed Data for Burbank 6-story Commercial Building from the Northridge Earthquake of 17 January 1994. Report OSMS 94-11A. California Strong Motion Instrumentation Program (CSMIP), California Division of Mines and Geology, Sacramento, California.

CSMIP. 1994g. Processed Data for Sherman Oaks 13-story Commercial Building from the Northridge Earthquake of 17 January 1994. Report OSMS 94-11B. California Strong Motion Instrumentation Program (CSMIP), California Division of Mines and Geology, Sacramento, California.

CSMIP. 1994h. Processed Data for Sylmar 6-story County Hospital from the Northridge Earthquake of 17 January 1994. Report OSMS 94-11C. California Strong Motion Instrumentation Program (CSMIP), California Division of Mines and Geology, Sacramento, California.

CSMIP. 1994i. Processed Data for Van Nuys 7-story Hotel from the Northridge Earthquake of 17 January 1994. Report OSMS 94-11D. California Strong Motion Instrumentation Program (CSMIP), California Division of Mines and Geology, Sacramento, California.

Darragh, R., Cao, T., Cramer, C., Huang, M. and Shakal, A. 1994a. Processed CSMIP Strong-Motion Records from the Northridge, California Earthquake of January 17 1994: Release No. 1. Report No. OSMS 94-06B. California Strong Motion Instrumentation Program, California Division of Mines and Geology, Sacramento, California.

Darragh, R., Cao, T., Huang, M. and Shakal, A. 1994b. Processed CSMIP Strong-Motion Records from the Northridge, California Earthquake of January 17 1994: Release No. 2. Report No. OSMS 94-08. California Strong Motion Instrumentation Program, California Division of Mines and Geology, Sacramento, California.

Darragh, R., Cao, T., Cramer, C., Graizer, V., Huang, M. and Shakal, A. 1994c. Processed CSMIP Strong-Motion Records from the Northridge, California Earthquake of January 17 1994: Release No. 3. Report No. OSMS 94-09. California Strong Motion Instrumentation Program, California Division of Mines and Geology, Sacramento, California.

Darragh, R., Cao, T., Cramer, C., Graizer, V., Huang, M. and Shakal, A. 1994d. Processed CSMIP Strong-Motion Records from the Northridge, California Earthquake of January 17 1994: Release No. 4. Report No. OSMS 94-10. California Strong Motion Instrumentation Program, California Division of Mines and Geology, Sacramento, California.

Darragh, R., Cao, T., Huang, M. and Shakal, A. 1994e. Processed Data for Pacoima Upper Left Abutment from the Northridge Earthquake of 17 January 1994. Report OSMS 9412A. California Strong Motion Instrumentation Program (CSMIP), California Division of Mines and Geology, Sacramento, California.

Davis, T.L., Namson, J.S. and Yerkes, R.F. 1989. A Cross Section of the Los Angeles Area: Seismically Active Fold and Thrust Belt, the Whittier Narrows Earthquake, and Earthquake Hazard. Journal of Geophysical Research, 94:9644-9664.

Earthquake Engineering Research Center. 1994. Preliminary Report on the Seismological and Engineering Aspects of the January 17, 1994 Northridge Earthquake, Report no. UCB/EERC-94/01, EERC, College of Engineering, University of California at Berkeley, $77 \mathrm{pp}$.

Earthquake Engineering Research Institute. 1994. Northridge Earthquake January 17, 1994, Preliminary Reconnaissance Report, EERI Publication no. 94-01., ISBN no. 0-943198-453, $111 \mathrm{pp}$.

Earthquake Engineering Research Laboratory. 1971. Engineering Features of the San Fernando Earthquake, February 9, 1971, EERL 71-02, California Institute of Technology, pp 512.

Englehart, M.D. 1994. Testing of Full Scale Steel Moment Connections, Progress Report, The University of Texas, Austin.

Fenves, G.L. and Serino, G. 1990. Soil-Structure Interaction in Buildings from Earthquake Records. Earthquake Spectra, 6:641-655

Gates, W.E., Hart, G.C. and Crouse, C.B. 1990. Vibration Studies of an Existing Building for Base Isolation Retrofit. Proceedings of Fourth U.S. National Conference on Earthquake Engineering. Palm Springs, California, 3:559568.

Hauksson, E. 1990. Earthquakes, Faulting and Stress in the Los Angeles Basin, Journal of Geophysical Research 95:1536515394.

Hauksson, E. et al. 1988. The 1987 Whittier Narrows Earthquake in the Los Angeles Metropolitan Area, California. Science 239:1409-1412.

Hauksson, E. and Jones, L.M. 1989. The 1987 Whittier Narrows Earthquake Sequence in Los Angeles, Southern California: Seismological and Tectonic Analysis. Journal of Geophysical Research 94:9569-9589.

Housner, G.W. 1957. Interaction of Building and Ground during an Earthquake. Bulletin of the Seismological Society of America 47:179-186.

Jones, L. and Hauksson, E. 1988. The Whittier Narrows, California Earthquake of October 1, 1987 - Seismology. Earthquake Spectra 4:43-53.

Joyner, W.B. and Boore, D. M. 1988. Measurement, Characterisation, and Prediction of Strong Ground Motion, in Earthquake Engineering and Soil Dynamics II - Recent Advances in Ground-Motion Evaluation, ed. Von Thun, J.L. . Geotechnical Special Publication No. 20, American Society of Civil Engineers, New York, pp 43-102.

Kowalski MJ, Priestley MJN and MacRae GA. 1994. Displacement Based Design of RC Bridge Columns, Proceedings of the Second International Workshop on Seismic Design of Bridges, Queenstown, New Zealand, August 1994. 
Krawinkler, H. 1994. Chapter 4 in Hall, J.F., Preliminary Reconnaissance Report, Northridge Earthquake, January 17, 1994, Earthquake Engineering Research Institute, Oakland, California.

Marachi, N.D. 1973. Dynamic Soil Problems at the Joseph Jensen Filtration Plant, in San Fernando, California, Earthquake of February 9, 1971, ed. Murphy, L.M., National Oceanic and Atmospheric Administration, U.S. Department of Commerce, IB:815-820.

McGavin, G. 1994. Observations of Public Educational Facilities within the Epicentral Area of the January 17th, 1994, Northridge, California, Earthquake, HMC Group.

McVerry, G.H. 1979. Frequency Domain Identification of Structural Models from Earthquake Records, Report No. 7902, Earthquake Engineering Research Laboratory, California Institute of Technology, Pasadena, California.

Midorikawa, S., Kobayashi, H. and Le Doare, J.-Y. 1984. Characteristics of the Near-Field Ground Motions during the Imperial Valley Earthquake of 1979. 8th World Conference on Earthquake Engineering. San Francisco, 2:265-272.

Moehle, J.P. (ed.) 1994. Preliminary Report on the Seismological and Engineering Aspects of the January 17, 1994 Northridge Earthquake. Report No. UCB/EERC-94/01, Earthquake Engineering Research Center, University of California at Berkeley.

Papageorgiou, A.S. and Lin, B.-C. 1990. Analysis of Recorded Earthquake Response and Identification of a Multi-Story Structure Accounting for Foundation Interaction Effects. Soil Dynamics and Earthquake Engineering 10:55-64.

Papageorgiou, A.S. and Lin, B.-C. 1991. Earthquake Response of Two Repaired Buildings Damaged in Past Seismic Shaking, Soil Dynamics and Earthquake Engineering 10:236248.

Porcella, R.L., Etheredge, E.C., Maley, R.P. and Acosta, A.V. 1994. Accelerograms Recorded at USGS National StrongMotion Network Stations During the $\mathrm{M}_{\mathrm{S}}=6.6$ Northridge, California Earthquake of January 17, 1994. Open File Report 94-141, U.S. Geological Survey, Department of the Interior.

Priestley MJN, Seible F and Uang CM. 1994. The Northridge Earthquake of January 17 1994, Damage Analysis of Selected Freeway Bridges, University of California, San Diego, Department of Applied Mechanics and Engineering Sciences, Report no. SSRP-94/06, 264pp.

Sabol, T.A. 1994. Damage to Ductile Steel Frames in The Northridge Earthquake, Proceedings of the Northridge Earthquake Seminar 26 March.

Scott, R.F. 1973. The Calculation of Horizontal Accelerations from Seismoscope Records. Bulletin of the Seismological Society of America 63:1637-1661.

Shakal, A., Huang, M.J. and Cao, T.Q. 1988. CSMIP Strong Motion Data, in The Whittier Narrows Earthquake of October 1, 1987. Earthquake Spectra 4:75-100.
Shakal, A., Huang, M., Darragh, R., Cao, T., Sherburne, R., Malhotra, P., Cramer, C., Sydnor, R., Graizer, V., Maldonado, G., Petersen, C. and Wampole, J. 1994a. CSMIP Strong-Motion Records from the Northridge, California Earthquake of 17 January 1994. Report No. OSMS 94-07. California Strong Motion Instrumentation Program (CSMIP), California Division of Mines and Geology, Sacramento, California.

Shakal, A., Cao, T. and Darragh R. 1994b. Processing of the Upper Left Abutment Record from Pacoima Dam for the Northridge Earthquake. Report OSMS 94-13. California Strong Motion Instrumentation Program (CSMIP), California Division of Mines and Geology, Sacramento, California.

Singh, J.P. 1985. Earthquake Ground Motions: Implications for Designing Structures and reconciling Structural Damage. Earthquake Spectra 1:239-270.

Standards Association of New Zealand. 1982. NZS 3101, Part 1, Code of Practice for the Design of Concrete Structures and Part 2, Commentary on the design of Concrete Structures. Wellington, New Zealand.

Standards Association of New Zealand. 1992. NZS 3404, Part 1, Steel Structures Standard. Wellington, New Zealand.

Stein, R.S. and Yeats, R.S. 1989. Hidden Earthquakes. Scientific American (June):30-39.

Structural Engineers Assoc. of California, Applied Technology Council, California Universities for Research in Earthquake Engineering (SAC) Joint Venture Partnership. 1994. Programme to Reduce Earthquake Hazards in Steel Moment Frame Structures, July.

Structural Engineers Association of California (SEAOC). 1992. Recommended Lateral Force Requirements and Commentary.

Sveinsson, B.I., Ewing, R., Mayes, R.L., Hart, G.C. and Elhassan, R. 1990. Seismic Isolation Analysis of an Existing Eight-Story Building. Proceedings of Fourth U.S. National Conference on Earthquake Engineering. Palm Springs, California, 3:589-597.

The Masonry Society (TMS). 1994. Performance of Masonry Structures in the Northridge, California, Earthquake of January 17, 1994.

Todorovska, M.I., Trifunac, M.D. and Ivanovic, S.S. 1994. Second Preliminary Report on Distribution of peak Ground Accelerations During the Northridge, California, Earthquake of January 17, 1994 (Data from the Los Angeles Strong Motion Network). Department of Civil Engineering, School of Engineering, University of Southern California, Los Angeles, California.

Uniform Building Code. 1973. International Conference of Building Officials, $\$ 973$ edition, Whittier, California, USA.

Uniform Building Code. 1976. International Conference of Building Officials, 1976 edition, Whittier, California, USA.

Yerkes, R.F. 1985. Geologic and Seismologic Setting, in Evaluating Earthquake Hazards in the Los Angeles RegionAn Earth-Science Perspective, ed. Ziony, J.I., U.S. Geological Survey Professional Paper 1360, pp 25-42. 